This item was submitted to Loughborough's Research Repository by the author.

Items in Figshare are protected by copyright, with all rights reserved, unless otherwise indicated.

\title{
The influence of pitch quality on anode carbon gasification
}

\section{PLEASE CITE THE PUBLISHED VERSION}

PUBLISHER

(C) Khadam Hussain

\section{PUBLISHER STATEMENT}

This work is made available according to the conditions of the Creative Commons Attribution-NonCommercialNoDerivatives 2.5 Generic (CC BY-NC-ND 2.5) licence. Full details of this licence are available at: http://creativecommons.org/licenses/by-nc-nd/2.5/

\section{LICENCE}

CC BY-NC-ND 2.5

\section{REPOSITORY RECORD}

Hussain, Khadam. 2018. "The Influence of Pitch Quality on Anode Carbon Gasification”. figshare. https://hdl.handle.net/2134/27950. 


\section{Loughborough University}

This item was submitted to Loughborough University as a PhD thesis by the author and is made available in the Institutional Repository

(https://dspace.lboro.ac.uk/) under the following Creative Commons Licence conditions.

\section{cc) creative}

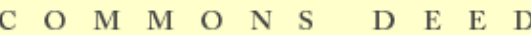

Attribution-NonCommercial-NoDerivs 2.5

You are free:

- to copy, distribute, display, and perform the work

Under the following conditions:

Attribution. You must attribute the work in the manner specified by the author or licensor.

Noncommercial. You may not use this work for commercial purposes.

No Derivative Works. You may not alter, transform, or build upon this work.

- For any reuse or distribution, you must make clear to others the license terms of this work.

- Any of these conditions can be waived if you get permission from the copyright holder.

Your fair use and other rights are in no way affected by the above.

This is a human-readable summary of the Leqal Code (the full license).

Disclaimer 민

For the full text of this licence, please go to: http://creativecommons.org/licenses/by-nc-nd/2.5/ 


\section{BLDSC no:- DX188180}

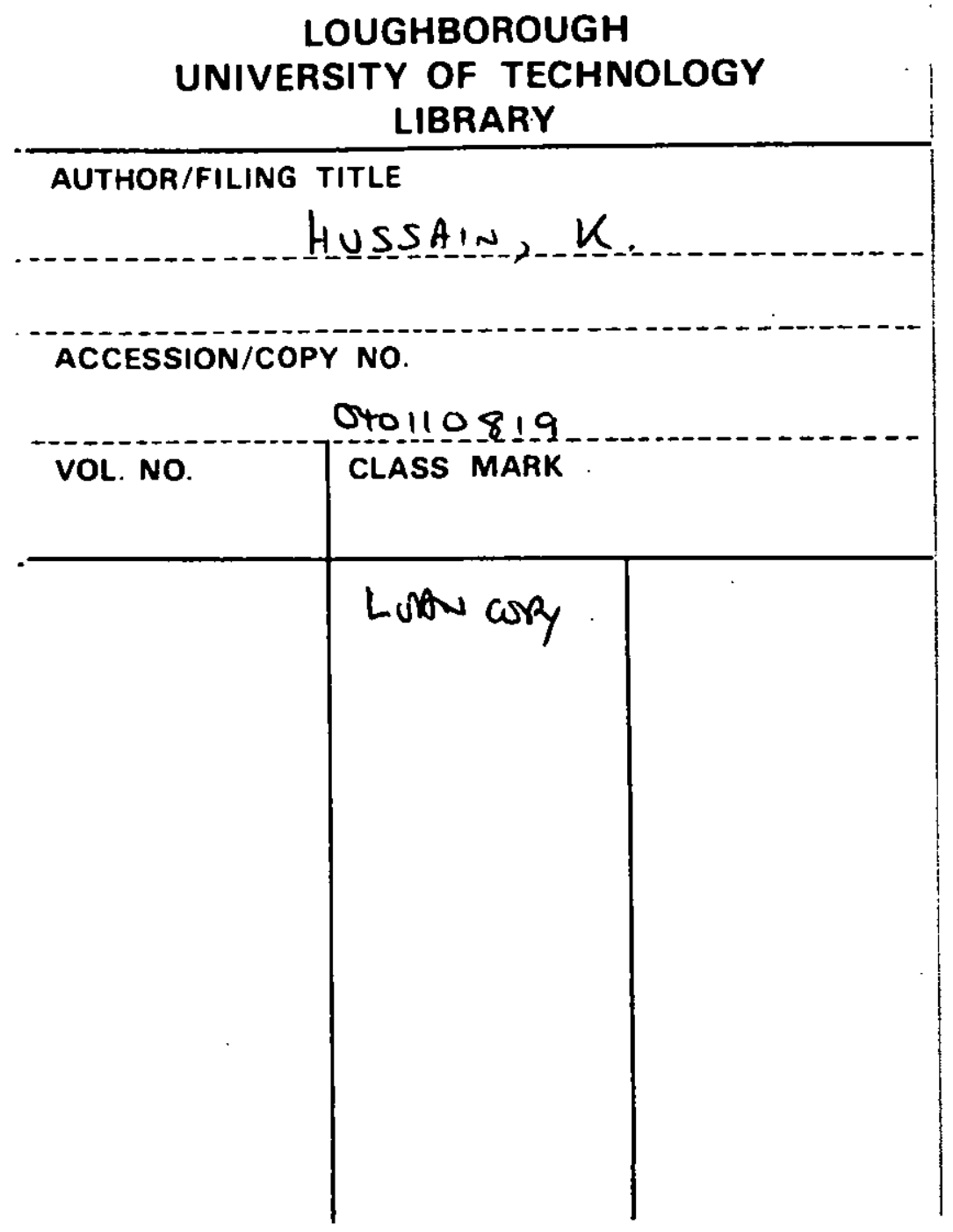





\section{THE SITUATION}

Humanity is asleep, concerned only with what is useless, living in a wrong world.

Believing that one can excel this is only habit and usage, not religion. This "religion" is inept....

Do not prattle before the People of the Path, rather consume yourself. You have an inverted knowledge and religion if you are upside down in relation to Reality.

Man is wrapping his net around himself. A lion (the man of the Way) bursts his cage asunder.

(The Sufi master Sanai of Afghanistan, teacher of Rumi, in The Walled Garden of Truth, written in 1131 A.D.) 


\title{
THE INFLUENCE OF PITCH QUALITY ON ANODE CARBON GASIFICATION
}

\author{
BY \\ KHADAM HUSSAIN
}

\begin{abstract}
A Ductoral Thesis
Submitted in partial fulfilment of the requirements

for the award of

Doctor of Philosophy

of the Loughborough University of Technology
\end{abstract}

December 1994

(C) by Khadam Hussain 1994 


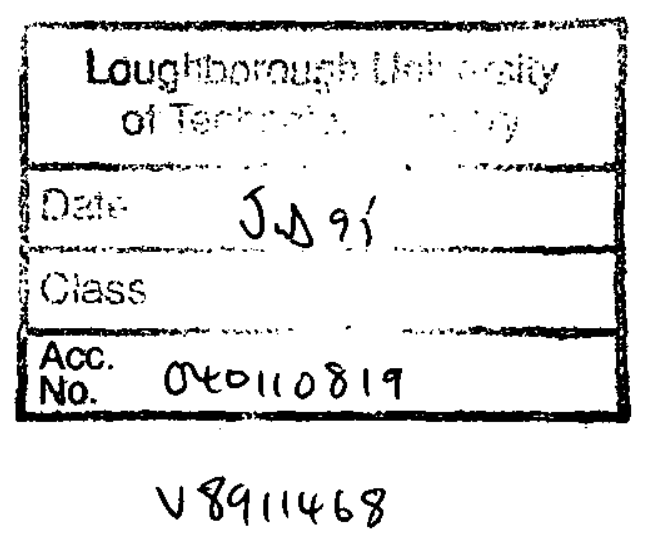




\title{
THE INFLUENCE OF PITCH QUALITY ON ANODE CARBON GASIFICATION
}

BY

KHADAM HUSSAIN

\begin{abstract}
The objective of this research is to investigate the gasification, in air and carbon dioxide, of anode carbons used in the aluminium industry, to identify any differences in the behaviour of filler coke and the coke from the coal-tar binder pitch, and to study the effect of pitch quality, especially the type and proportion of quinoline insolubles (QI) and the sodium content, on those processes which contribute to excess anode consumption.
\end{abstract}

Carbon anodes used in aluminium production are consumed by the electrolysis reaction and from gasification by oxidising gases i.e. carbon dioxide and oxygen in the air. Catalytic impurities in the binder coke of the anode promote excess carbon consumption. Because sodium is a known catalyst of these gasification reactions, anode manufacturers demand low sodium contents of binder pitch, i.e. $<500 \mathrm{ppm}\left(<500 \mathrm{mg} \mathrm{kg}{ }^{-1}\right)$. Currently, in the literature, there is no evidence of the extent of catalysis by different sodium contents in binder pitch and so this has been investigated. Pilot-scale anode carbons have been exposed to air and carbon dioxide at elevated temperatures to determine their rates of gasification. Oxidised specimens have been examined by polarised light microscopy (PLM) and scanning electron microscopy (SEM) to seek sites of preferential attack. Attempts have been made, using mechanical means (friability test) and optical microscopy/ image analysis to quantify the structural damage, caused by oxidation, which leads to dusting loss (loss of particulate carbon from the surface) during anode use.

The results of the studies have shown that the reactivity of anode carbons towards air is influenced by the sodium- and the Ql content of the binder pitch used in their production. In both cases, the increasing reactivity was accompanied by a corresponding increase in the friability of the oxidised surface. The sodium effect was shown to be associated with the increased porosity of the outer layers, as measured by image analysis. SEM indicated 
preferential attack by the oxidant on the binder phase in the outer layers of the anode carbon. The Ql effect operated in conjunction with the sodium effect but to a less significant degree, ie. the presence of pitch QI enhanced the catalytic activity during anode oxidation. Results from a study of the effect of temperature on the variation of gasification rates in air of the two series of carbons have shown that, in accord with diffusion theory, the high temperature portion of the Arrhenius curve has an activation energy which is close to onehalf that for the low-temperature regime. 


\section{ACKNOWLEDGMENTS}

I would like to express my most sincere thanks and gratitude to my supervisor, Dr. A. Walker, and Professor J.W. Patrick, Director of the Carbon Research Group, for their constant encouragement and generosity with their time in reading, discussing and constructively criticizing my work. Indeed their encouragement and guidance has done much to carry me through difficult moments.

I am grateful to Mr. D. Hays for the experimental assistance that he provided.

The financial support for this work by the European Coal and Steel Community is gratefully acknowledged.

I owe a special debt to my family for their support throughout this study and especially for their forbearance during the latter months.

Finally, to our MASTER... 


\section{Published Papers}

The following paper, based on the work described in this thesis, has been published for publication.

Hussain, K., Patrick, J.W. and Walker, A.

'The influence of pitch quality on anode carbon gasification.'

Carbon 1994, Extended Abstracts and Programme, 3-8 July, 1994, Granada/Spain, p434 


\section{CONTENTS}

Page No.

1. LITERATURE REVIEW ' 1

1.1 Introduction 1

1.2 Aluminium production by the Hall-Heroult electrolytic cell 2

1.3 Necessary and excess anode consumption 4

1.4 Dusting 8

1.5 The anode equation 9

1.6 Required properties of anodes 11

TABLE

FIGURES

2. ANODE PRODUCTION

2.1 Coal-lar pitch manufacture $\quad 14$

$\begin{array}{ll}2.2 \text { Coal-tar pitch properties } & 18\end{array}$

$\begin{array}{ll}2.3 \text { Petroleum coke properties } & 20\end{array}$

2.4 Petroleum coke manufacture 21

2.5 Anode manufacture 25

2.6 Cathode manufacture 28

TABLES

FIGURES

3. STRUCTURE OF CARBONS 32

3.1 Graphite 32

3.2 Graphitizing carbons 34

3.3 Intercalation of sodium and potassium in carbons 36

3.4 Polarized-light microscopy of carbons 38

3.5 Electron microscopy (SEM and TEM) $\quad 40$

3.6 Image analysis 42

TABLE

FIGURES

4. THE FORMATION OF GRAPHITIZING CARBONS 43

4.1 Early studies of coke texture $\quad 43$

4.2 Formation of graphitizing carbons 43

4.3 Mesophase development 44

4.4 Structure of mesophases 46

4.5 The role of quinoline insolubles in pitch carbonisation 47

4.6 Mesophase development during petroleum coke formation 48 FIGURES 
5. KINETICS AND CATALYSIS OF CARBON GASIFICATION 50

5.1 Introduction 50

5.2 Reactivity of carbons 51

5.3 Kinetics and mechanisms of gasification 53

5.3.1 Transport of reactants/products $\quad 55$

5.3.2 Importance of active surface area (ASA) to reactivity 57

5.3.3 Adsorption and desorption $\quad 59$

$\begin{array}{ll}\text { 5.3.4 Basic thermodynamics } & 61\end{array}$

$\begin{array}{ll}5.4 & \text { The carbon-carbon dioxide reaction }\end{array}$

5.5 The carbon-oxygen reaction 64

$\begin{array}{ll}5.6 \text { Catalysis of carbon gasification reactions } & 67\end{array}$

$\begin{array}{lll}5.7 \text { Mechanisms of catalysis } & 67\end{array}$

5.7.1 Oxygen-transfer mechanism 68

$\begin{array}{ll}5.7 .2 \text { Electron-transfer mechanism } & 69\end{array}$

$\begin{array}{ll}5.8 \text { Catalysis of the Boudouard reaction } & 69\end{array}$

5.9 Catalysis of the carbon-oxygen reaction 73

$\begin{array}{ll}5.10 \text { Topography of catalytic gasification } & 76\end{array}$

FIGURES

6. PROGRAMME OF RESEARCH 80

7. EXPERIMENTAL PROCEDURES 82

7.1 Introduction $\quad 82$

7.2 Materials used $\quad 82$

$\begin{array}{ll}7.3 \text { Sodium doping of pitch } & 83\end{array}$

7.4 Sodium analysis of pitch by atomic absorption spectroscopy (AAS) 83

7.5 Test anode production $\quad 84$

7.6 Gasification test methods $\quad 86$

7.6.1 Test 1: Air oxidation / Friability test 86

7.6.2 Test 2: Oxidation of specimens for examination using image analysis $\quad 87$

7.6.3 Air oxidation using a magnetic balance $\quad 88$

$\begin{array}{lr}\text { 7.6.3.1 Principles of operation of Cahn balance } & 89\end{array}$

$\begin{array}{ll}\text { 7.6.4 Specimen preparation for SEM examination } & 90\end{array}$

TABLES

FIGURES

8. RESULTS 91

$\begin{array}{lll}8.1 & \text { Air reactivity / Friability studies } & 91\end{array}$

$\begin{array}{ll}\text { 8.1.1 Preliminary experiments } & 91\end{array}$

8.1.2 Studies of anodes using sodium-doped pitch 93

8.1.3 Studies of anodes using pitches varying in quinoline insolubles content 96 
8.2 Alomic absorption spectroscopy results 98

8.3SEM studies of oxidised $15 \mathrm{~mm}$ diameter specimens 99

8.4 Image analysis studies of carbons oxidised in air and carbon dioxide 104

$\begin{array}{ll}\text { 8.5 Variation of air oxidation rates with temperature } & 106\end{array}$

TABLES

FIGURES

$\begin{array}{ll}\text { 9. DISCUSSION } & 110\end{array}$

9.1 The influence of mass transport on gaseous oxidation rates $\quad 110$

$\begin{array}{ll}\text { 9.1.1 } \mathrm{CO}_{2} \text { oxidation } & 113\end{array}$

9.1.2 The relation between mass transport properties and porous texture $\quad 113$

$\begin{array}{ll}9.2 \text { General discussion } & 115\end{array}$

$\begin{array}{lll}9.3 \text { Recommendations for future work } & 120\end{array}$

FIGURES

10. CONCLUSIONS 122

$\begin{array}{ll}\text { REFERENCES } & 128\end{array}$ 


\section{LITERATURE REVIEW}

\subsection{Introduction}

Aluminium is the most plentiful metal in the earth's crust, of which it forms eight per cent. The aluminium industry consumes much more carbon, as baked anode composites, than the total of all other industrial uses for baked and graphitised carbon products. The world total production of primary aluminium in 1987 was $16,200,000$ tonnes of which $2,330,590$ tonnes were provided by EC countries (1). Worid aluminium production involves the consumption (oxidation) of about 8 million tonnes of anode carbon. In the European Community consumption of coal-tar pitch amounts to approximately $2 \times 10^{5}$ t/annum (2). The bulk of this pitch is used to make anodes for aluminium reduction cells; hence the consideration given to this use in this study.

Although unchanged in principle, the electrolytic reduction (smelting) process of today differs in detail and in scale from the original process discovered and patented simultaneously, but independently, in 1886 by Hall in America and Heroult in France. Modern technology has effected substantial improvements in equipment, materials, and control of the process and has lowered the energy and labour requirements and the final cost of primary metal. Aluminium is produced, in a Hall-Heroult cell, by the electrolysis of alumina between carbon anodes and cathodes. Both are produced by slowly carbonising a compacted mixture of a filler and a coal-tar pitch binder. Either pre-baked or Soderburg anodes are used. Soderburg anodes are carbonised at the cell but pre-baked anodes are produced in a carbon plant on the smelter site. For pre-baked anode production, calcined petroleum coke is used as the filler while calcined anthracite and/or graphite are used in Soderburg anode and in cathode production. The anodes are consumed during the process and herice their quality has a marked bearing on process economics.

The aluminium industry consumes about $0.45 \mathrm{~kg}$ of anode carbon for each kilogram of aluminium produced. The ideal carbon should have a moderatelyisotropic structure with minimum oxidant-accessible surface of low, uniform reactivity, and a maximum ash content, excluding bath salts, of a few tenths of one percent. Industrial anode carbon is a baked composite usually made of calcined petroleum coke filler with a binder of coal-tar pitch coke. While there 
is no shortage of calcined petroleum coke, the quality can be variable and likely to deteriorate. Also, coke binders are subject to variability in both quality and supply. In this context, Chapter 1 reviews the important factors which affect anode carbon usage in the aluminium industry, while Chapter 2 surveys the complex chain of events affecting anode performance, ranging from the properties of precursors for filler cokes and binder pitches, through production of these raw materials and their fabrication into anode and cathode carbon.

\subsection{Aluminium Production by the Hall-Heroult Electrolytic Cell}

Aluminium is produced by the electrolytic reduction of molten alumina $\left(\mathrm{Al}_{2} \mathrm{O}_{3}\right)$ in the Hall-Heroult cell, Figures 1.1 and 1.2 . At $1000^{\circ} \mathrm{C}$ a molten mixture of synthetic cryolite $\left(\mathrm{Na}_{3} \mathrm{AlF}_{3}, \mathrm{AlF}_{3}\right.$ and $\mathrm{CaF}_{2}$, approx. ratio $\left.87: 5: 8\right)$ will dissolve up to $15 \%$ alumina by weight. This is electrolysed at a potential of $4-7 \mathrm{~V}$, depending on size and condition of cell, between a consumable carbon anode and a carbon cathode which constitutes the cell lining.

The industrial electrolytic cell (pot) consists of a rectangular steel shell lined with carbon about $3 \mathrm{~m}$ wide by $8 \mathrm{~m}$ long for a $140 \mathrm{kA}$ cell, and which must be deep enough to hold the bath of molten electrolyte 10 to $25 \mathrm{~cm}$ deep (density 2.1 $\mathrm{g} / \mathrm{cm}^{3}$ ) and beneath it a pool of molten aluminium $20-40 \mathrm{~cm}$ deep (density 2.3 $\mathrm{g} / \mathrm{cm}^{3}$ ). Carbon anodes are suspended in the electrolyte and spaced about $5 \mathrm{~cm}$ from the liquid metal surface, and lowered into the cell at the rate of about $2.5 \mathrm{~cm} /$ day as the carbon is oxidised. The heat required to keep the bath molten is supplied by the electrical resistance of the bath as current passes through it. The amount of heat developed with a given current depends on the length of the current path through the electrolyte, i.e. anode-cathode distance, which is adjusted to maintain the desired operating temperature. A crust of frozen bath, about $2.5 \mathrm{~cm}$ thickness, forms on the top surface of the bath and cell sidewalls. Alumina is added to the bath or on the crust, where its sorbed moisture is driven off by cell heat. While preheating on the crust, the alumina charge serves as thermal insulation. Periodically, the crust is broken and the alumina is stirred into the bath to maintain proper concentration. The passage of direct current through the electrolyte decomposes the dissolved alumina. Metal is deposited on the cathode, and oxygen at the gradually consumed anode. The smelting process is continuous. Alumina is added, anodes replaced, and molten 
aluminium is periodically siphoned off without interrupting current to the cell.

Current efficiencies are about $85-92 \%$, and the energy efficiency is about $40 \%$. Voltage is required to force the current through the entire cell, and the corresponding power (voltage $x$ amperage) is largely converted into heat in the bath. The amount of power required to maintain the temperature is a smaller proportion of the total power input in large cells than in small ones because of the lower ratio of surface to volume. Thus, power consumed $/ \mathrm{kg}$ of metal is somewhat less in large than in small cells. Consumption of $13.18 \mathrm{kWh} / \mathrm{kg}$ of aluminium produced includes bus-bar, transformer, and rectifier losses. A potline may consist of $50-200$ cells with a total line voltage of up to $1000 \mathrm{~V}$ at current loads of $50-225 \mathrm{kA}$ (2-9 amp/in² current density). Electric power is one of the most costly raw materials in aluminium production. Aluminium producers have continualiy searched for sources of cheap hydroelectric power, but have also had to construct facilities that produce power from fossil fuels. In the past half century, technological advances have significantly reduced the amount of electrical energy necessary to produce a tonne of aluminium.

Current is led out of the cell to the anode bus bar by a number of carbon block anodes suspended in parallel rows on vertical conducting rods of copper or aluminium. Because impurities in the anodes dissolve in the bath as they are consumed, pure carbon (calcined petroleum coke or pitch coke) is used as raw material. The ground coke is mixed hot with enough coal-tar or petroleum pitch to bond it into a block when pressed in a mould to form the 'green' or raw anode. This is then baked slowly at temperatures up to $1100-1200^{\circ} \mathrm{C}$. In a cavity moulded in the top of each block, a steel stub is embedded by casting molten iron around it or by using a carbonaceous paste; the conducting bar is bolted to this stub. Such an electrode is termed a prebaked anode to distinguish it from the Soderberg anode, in which the electrode (single large anode to a cell) is formed in situ from a carbonaceous paste which is baked by heat from the pot as it gradually descends into the electrolyte.

The steel shell of the pot is thermally insulated and lined with carbon. The carbon bottom, covered with molten aluminium, serves as the cell cathode. Electrical connection is made to the carbon cathode by steel bars running. through the cell base and embedded in the carbon lining. 
For the production of one tonne of aluminium metal raw material requirements are estimated as: 4.5 tonnes of bauxite, $160 \mathrm{~kg}$ of caustic soda and one tonne of fuel oil are needed to produce 1.9 tonnes of alumina by the Bayer process (3). In the electrolysis of the 1.9 tonnes of alumina by the Hall-Heroult process, 0.5 tonne of carbon electrode, 0.023 tonne of cryolite and 0.029 tonne of aluminium fluoride are required to produce the one tonne/day of aluminium metal. Molten aluminium is siphoned from the smelting cells into large crucibles. From there the metal may be poured directly into moulds to produce foundry ingot, or transferred to holding furnaces for further refining or alloying with other metals to form fabricating ingot. The aluminium produced is over $99 \%$ pure.

\subsection{Necessary and Excess Anode Consumption}

A carbon electrode consists of two solid phases: the large particles which make up the bulk of the electrode are known as the filler, while the component of the electrode which is used to cement the filler particles together, and which also makes its own contribution to the mechanical and electrical properties of the electrode, is known as the binder. The filler in electrodes used in aluminium extraction may be petroleum coke (the most common) or a calcined anthracite; the binder is usually coal-tar pitch.

Anode consumption depends on many factors. These include the raw materials, the manufacturing process, the smelter's cell design, current efficiency and cell operation. Traditionally, calcined petroleum cokes are purchased upon specified properties. These nominal specifications don't ensure minimum anode consumption.

For industrial aluminium production by the Hall-Heroult process, the major reaction is:
$\mathrm{Al}_{2} \mathrm{O}_{3}$
(s) $+3 / 2 \mathrm{C}$
(s)
$2 \mathrm{Al}$
(l) $+3 / 2 \mathrm{CO}_{2}(\mathrm{~g})$

with a reversible decomposition potential of $1.18 \mathrm{~V}$ at $1250 \mathrm{~K}$. The theoretical carbon consumption according to Eqn.(1) is $0.37 \mathrm{~kg}$ of carbon for each $\mathrm{kg}$ of aluminium produced, at $90 \%$ current efficiency. 
During electrolysis complicated reactions, not fully understood, occur but the net effect is that aluminium accumulates on the cell floor and oxygen, which is given off at the anode, reacts with the carbon anode to give $\mathrm{CO}(70 \%)$ and $\mathrm{CO}_{2}$ $(30 \%)$. The cryolite remains essentially unchanged but small quantities are needed from time to time to replenish losses. The loss of some cryolite in the form of fluorides causes a pollution problem in the neighbourhood of the works. The following basic electrolysis reactions occur:

Cathode: $\quad 2 \mathrm{Al}^{3+}+6 \mathrm{e}^{-} \longrightarrow 2 \mathrm{Al}(\mathrm{I})$

Anode: $\quad 3 \mathrm{O}^{2-}-6 \mathrm{e}^{-} \longrightarrow 3 / 2 \mathrm{O}_{2}(\mathrm{~g})$

In spite of the large number of investigations, however, the problem of the structure of alumina in molten cryolite is not resolved. It's generally agreed that aluminium-oxygen-fluorine complexes are formed (Equation (4)).

Anodes in aluminium reduction pots are consumed by electrochemical, chemical and mechanical processes (4), but, most carbon is consumed by the basic electrolytic reactions by which aluminium is deposited at the cathode while aggressive nascent oxygen attacks the anode. For example, about $79 \%$ of the carbon is removed electrolytically when atomic oxygen, as $0^{-2}$, is deposited with the primary formation of $\mathrm{CO}_{2}$ at the normal current density for industrial cells. This oxidation is very aggressive and unselective in attacking the carbon surface microstructure wherever atomic oxygen is deposited. However, reaction overvoltage is lower for more reactive surfaces, and this factor determines where the oxygen will be deposited at low current densities. Overvoltage selectivity decreases with increasing current density used for industrial cells. While the details about various steps in this process remain controversial, probable steps in the process that have been agreed upon are as follows:

i. Dissociation of oxygen-carrying complexes: $\operatorname{AlOF}_{x}{ }^{1-x}=\operatorname{AlF}_{x}^{4-x}+O^{-2}$

ii. Discharge and chemisorption of oxygen: $\mathrm{O}^{-2}+x \mathrm{C}=\mathrm{C}_{\mathrm{x}} \mathrm{O}+2 \mathrm{e}$

iii. Conversion of $\mathrm{C}_{\mathrm{x}} \mathrm{O}: 2 \mathrm{C}_{\mathrm{x}} \mathrm{O}=\mathrm{CO}_{2}$ (ads) $+(2 \mathrm{x}-1) \mathrm{C}$

iv. Desorption of $\mathrm{CO}_{2}: \mathrm{CO}_{2}$ (ads) $=\mathrm{CO}_{2}(\mathrm{~g})$ 
Anode carbon is consumed by four substantially different mechanisms (4):

(i) $79 \%$ of carbon consumed is by the above mechanism, i.e. the electrolytic process through the equations:

$2 \mathrm{Al}_{2} \mathrm{O}_{3}+3 \mathrm{C} \longrightarrow 4 \mathrm{Al}+3 \mathrm{CO}_{2}$

$\mathrm{Al}_{2} \mathrm{O}_{3}+3 \mathrm{C} \longrightarrow 2 \mathrm{Al}+3 \mathrm{CO}$

If carbon dioxide is the primary gas product by the electrolysis, i.e., the process is described by Eqn.(8) only, the theoretical carbon consumption is $334 \mathrm{kgC} / \mathrm{tAl}$ at $100 \%$ current efficiency. Present-day cells have current efficiencies in the $85-95 \%$ range, with actual carbon consumption ranging from 420 to $550 \mathrm{kgC} / \mathrm{tAl}$. Current inefficiency reactions involve backreactions of electrolytic $\mathrm{CO}_{2}$ with reduced metal species from the cathode. The anode consumption decreases with increasing current density (5) due to a reduced reactive surface area.

(ii) About $12 \%$ represents excess carbon consumed due to these current inefficiency effects, typically:

$2 \mathrm{Al}$ (dis) $+3 \mathrm{CO}_{2} \longrightarrow \mathrm{Al}_{2} \mathrm{O}_{3}+3 \mathrm{CO}$ then,

$2 \mathrm{Al}_{2} \mathrm{O}_{3}+3 \mathrm{C} \longrightarrow 4 \mathrm{Al}+3 \mathrm{CO}_{2}$

(iii) About $17 \%$ of total prebake carbon consumption is due to airburn of anode tops, but can vary (for different cell designs) from less than $10 \%$ to about $40 \%$ during severe airburn problems:

$\mathrm{C}+\mathrm{O}_{2} \longrightarrow \mathrm{CO}_{2}$
$2 \mathrm{C}+\mathrm{O}_{2} \longrightarrow 2 \mathrm{CO}$

These reactions occur at the air-exposed parts (sides and top) of a prebaked anode. Small concentrations of alkali or transition metal impurities in the carbon material catalyse the anode oxidation and contribute to an increased anode consumption (6), depending on the chemical form and distribution of the catalytic elements. 
(iv) About $4 \%$ of total carbon consumed is due to the reduction of primary $\mathrm{CO}_{2}$ by carbon in the pores just above the electrolytic anode face, and by free carbon in the bath, according to the following carboxy reaction, Figs. 1.3 and 1.4:

$\mathrm{CO}_{2}+\mathrm{C} \longrightarrow 2 \mathrm{CO}$

The rate of reaction (13) increases exponentialiy with temperature, and is approximately doubled by a temperature rise of $15^{\circ} \mathrm{C}$ in the temperature range $900-1000^{\circ} \mathrm{C}$. Formation of $\mathrm{CO}$ inhibits the reaction between $\mathrm{C}$ and $\mathrm{CO}_{2}$. In fact, the reaction rate of any carbon at a given temperature varies a great deal (Fig.1.5) with the $\mathrm{CO} / \mathrm{CO}_{2}$ ratio (7). Under these conditions, it can be understood why this rate is greater as the current density rises and vice versa.

Studies have shown that the surface area accessible for reaction (13) to a large extent is determined by the pitch coke properties (8). Since a gas/solid heterogeneous reaction is concerned here, the area to be taken into consideration is one affected by the $\mathrm{CO} / \mathrm{CO}_{2}$ mixture at 900 to $1000^{\circ} \mathrm{C}$. This area is difficult to determine and generally a representative area i.e. the area measured by gas adsorption -either at ambient temperature (with methanol for instance) or at low temperature (with nitrogen or krypton) -is adopted. The study of this actual area shows that it comes essentially from the carbonbinding agent $(8)$ and that it also varies a great deal, for prebaked anodes, with the anode baking temperature (9). To illustrate this, Fig.1.6 shows the variation curve of the BET area measured on ordinary anode specimens, according to the baking temperature of a prebaked anode, for a given binding agent. The rapid decrease of this area can be observed, and consequently that of the corresponding reaction rate at about 800 to $900^{\circ} \mathrm{C}$.

In contrast to the aggressive, unselective attack of the first, and principal carbon removal mechanism, reaction (13) is quite selective. Factors affecting this selectivity are anode gas permeability, temperature, and the presence of impurity oxidation catalysts.

The relative contribution of each mechanism to the total consumption can vary considerably depending on many factors of cell design and operation. 


\subsection{Dusting}

In addition to oxidation losses by the above four mechanisms, mechanical carbon loss (dusting) also occurs due to uneven oxidation of the anode surface, Figs.1.3 and 1.4. Dusting in aluminium reduction pots is one of the visual signs of unwanted anode consumption. The balance between the carbon dioxide and air reactivity of the different carbon phases present in the anode is the key to the dusting phenomenon. Pitch coke is considered to be the most reactive phase of the carbon composite, whereby selective oxidation erodes the material and causes carbon particles to loosen from the matrix and to accumulate in the bath. The transfer of carbon particles to the bath is facilitated by convection in the electrolyte (mechanical abrasion). Convection is caused by the continuous release of anodic gas products, thermal gradients and the movement of metallic pad in the magnetic field. Convection also contributes to vertical transport of carbon particles in the cell and may cause local enrichment of carbon particles under the anodes, which results in uneven wear of the electrolytic surface and thereby operational irregularities.

In the cell electric field the carbon particle surfaces are polarized and the dust particles therefore act as electrical insulators, causing higher bath resistance. The effect of the increased cell resistance is to raise the electrolyte temperature of the anode. The anode consumption then increases due to the higher carbon dioxide - and oxygen reactivities of the anode $(6,10)$ and more carbon dust is formed. Thus, a vicious circle with increasing operational problems is entered, which stresses the importance of using anodes with homogeneous reactivity with respect both to the $\mathrm{CO}_{2}$ and the air oxidation.

It has been argued (10) that if less than $10 \%$ of the anodes of a cell have inferior dusting characteristics, the total amount of dust in the cell will be smalt and not cause operational problems. However, with $15-20 \%$ anodes of high dusting ability the operational situation quickly deteriorates and increases the anode consumption.

The dust concentration represents the balance between the dust formation and dust consumption rates. Thus, the accumulated level may be significantly influenced by the cell design, operation and practice including crust breaking and ore/bath covering procedures. In a limited number of bench scale experiments air was injected into melts containing 0.1 wt\% carbon, and 
approximately $40 \%$ of the carbon was removed within $15 \mathrm{~min}$, indicating a way to control the dust level in aluminium reduction pots. Besides representing an excessive specific carbon consumption, dusting may cause losses in current efficiency through direct current leaks as well as through side reactions with dissolved aluminium. The major basic exercise to avoid carbon dusting is to balance the reactivities of the various anode phases towards $\mathrm{O}_{2}$ and $\mathrm{CO}_{2}$.

Whereas cause (i) above (see Section 1.3, Equations (8) and (9)) is perhaps outside the immediate control of anode manufacturers, these groups are interested in the removal of causes (ii) to (iv) including dusting (Equations $(10),(11),(12)$, and (13)).

There is no easily available panacea to the problems of excess carbon consumption of anodes. The existing specifications of chemical analysis, softening temperature, quinoline and toluene insoluble contents ( $Q I$ and $T I$ ), coking value and coke reactivity apparently select the most suitable pitches. The role of the reactivity of binder coke still remains an enigma.

A variety of other factors, related to anode fabrication and use, can affect carbon consumption. The most important of these factors are (1) raw material quality, (2) aggregate sizing and control, (3) pitching level and control, (4) adequate paste mixing, (5) paste compaction, (6) proper baking, (7) rodding procedures, (8) oxidation coatings, and (9) cell operating variables (anode exposure, anode heat balance, bath temperature, gas exhaust rate, housekeeping).

\subsection{The Anode Equation}

The factors contributing to anode consumption are as given in Fig.1.7. Gross consumption of the anode is composed of net consumption and the butts. The difference between net consumption and the so-called electrolytic consumption, of $334 \mathrm{~kg} /$ tonne divided by current efficiency, is the excess consumption. Excess consumption is due to the side reactions of airburn and carbon dioxideburn. It can be as low as $20 \mathrm{~kg} /$ tonne, but in some plants, very bad figures are reported, as high as $100-200 \mathrm{~kg} /$ tonne. The propensity for excess carbon consumption is determined by the $\mathrm{CO}_{2}$ and air reactivity tests. The full formula for forecasting net carbon consumption from laboratory data is: 
where the quantities above are as defined in Table 1.1.

Behind the formula there has been more than one million tonnes of aluminium production. That's about 12 years of research and quality control. This formula doesn't cover everything, but it gives the sensitivity of each parameter of anode consumption, and represents carbon consumption as a function of current efficiency, bath temperature, $\mathrm{CO}_{2}$ reactivity, air permeability (AP), thermal conductivity and air reactivity. AP influences both $\mathrm{CO}_{2}$-burn and airburn of the anode. Air reactivity and anode temperature influence airburn. The cell factor, $\mathrm{C}$, inherently includes airburn carbon losses.

Manufacturers have used this formula for some time. There are many things that are measured on anodes, so they do quite a lot with the formula in just supplying to their customers not only the traditional lab figures, but also quality figures. These quality figures relate to the parameters in the formula. For instance, for quality they report $\mathrm{CO}_{2}$ residue and air permeability. To report the variability of anode quality within a shipment, they have developed "quality figures" for airburn, $\mathrm{CO}_{2}$-burn and the thermal shock of the anodes. For example, $\mathrm{CO}_{2}$-burn is based on the air permeability, the $\mathrm{CO}_{2}$ reactivity residue and the double standard deviation of the $\mathrm{CO}_{2}$ residue values. As well, when someone buys anodes they give them air and $\mathrm{CO}_{2}$ reactivity figures from the actual shipment, and the average of the last 12 months. So as it can be seen, manufacturers work quite heavily with this formula.

Keller and Fischer (11) have established the above relation between anode performance, air permeability and reactivity to oxidising gases, and have discussed the development of anode quality criteria by statistical evaluation of operational results of the electrolysis cell.

Low values of permeability are associated with a minimum of open porosity, in turn having a crude but definite dependence upon apparent density and associated with the detail of the shape and frequency, et alia, of the binder coke bridges. Keller and Fischer (11) state that "reactivity and permeability" should be taken as independent anode properties which together determine to a major extent the excess consumption of the anodes in the reduction cell. This 
statement is essentially correct except that permeability and reactivity are not independent parameters for the following reasons.

With an anode operating with, for example $25 \mathrm{wt} \%$ of the anode being lost as excess consumption, from all causes, over a 21 day period, the rate of carbon loss is below $1.0 \times 10^{-6} \mathrm{~s}^{-1}\left(\mathrm{gg}^{-1} \mathrm{~s}^{-1}\right)$. This is indeed a low value if compared with gasification rates of carbon by carbon dioxide obtained from the literature. Marsh et al. (12) have indicated that an extremely pure coke, prepared from a model system (polyvinyl acetate), will gasify, comparably, at rates of $10 \times 10^{-6} \mathrm{~s}^{-1}$ and a typical coal-tar pitch coke at $70 \times 10^{-6} \mathrm{~s}^{-1}$. This wide difference between rates of gasification is indicative that rates of anode gasification (being only about $1 \%$ of what could be expected) are controlled by the accessibility of the carbon of the anode to carbon dioxide, i.e. by the permeability of the anode. Marsh and Latham (13) using an image analysis technique to examine porosity in anodes have established that most of the porosity of anodes is indeed open or interconnected. This interconnected porosity will limit the rates of diffusion of the carbon dioxide to the reacting surfaces of the anode. Further, the reaction product, carbon monoxide, will be retained in the porosity where it can act as a reaction inhibitor by removal of the intermediate surface oxygen complexes:-

$$
\begin{aligned}
& \mathrm{C}+\mathrm{CO}_{2} \longrightarrow \mathrm{C}(\mathrm{O})+\mathrm{CO} \\
& \mathrm{CO}+\mathrm{C}(\mathrm{O}) \longrightarrow \mathrm{CO}_{2}
\end{aligned}
$$

The gasification of carbon by e.g. carbon dioxide does not occur homogeneously over surfaces but can be selective so introducing pitting and fissures (14). Accordingly, aspects of permeability of reactivity and dusting are all interdependent.

\subsection{Required Properties of Anodes}

As presently perceived, the specific criteria which an anode must satisfy are (a) high electrical conductance, (b) low reactivity with oxygen or bath, i.e, maximum-performing anode carbon has minimum oxidant-accessible surface of low, uniform sensitivity to air $\left(\mathrm{O}_{2}\right)$ and $\mathrm{CO}_{2}$, (c) relatively low cost and ready availability, (d) ability to produce commercial purity aluminium, (e) ability to be fabricated in large shapes, (f) stable electrical connections and adequate mechanical strength. 
Anode carbon consists of three elements: (1) graphite crystallites in various sizes, shapes, and orientations, associated with different quantities and arrangements of (2) impurities, and (3) voids. Graphite crystallites are the basic building blocks of anode carbon. They are very anisotropic, with property values for strength, electrical and thermal conductivity, and oxidation resistance which differ markedly in the basal planes of the crystal from those at right angles to the basal planes. For this reason, the properties of bulk anode carbon will reflect the graphite microstructure of which it is composed. The property values of this structure are further affected by its association with impurities and voids. Impurities affect carbon performance by (1) acting as oxidation catalysts, (2) contributing to aluminium impurities, and for sulphur, (3) increasing carbon consumption while contributing to environmental concerns $\left(\mathrm{SO}_{2}\right)$. Voids affect carbon performance by determining the extent of oxidant-accessible surface.

The optimum anode carbon has been found to consist of graphite crystallites in a condition of intermediate disorder, and sized to reflect heat treatment in the $1100-1400{ }^{\circ} \mathrm{C}$ range. Impurities are present to a maximum of a few tenths of one percent ash content, excluding cell bath salt contributions. Voids are structured to reduce total porosity (usually about $30 \%$ ) and to produce small closed and blind pores, rather than open connected pores, to reduce oxidantaccessible surfaces. This is usually accomplished by maximizing baked carbon density.

Anode carbon quality is specified by a property value range for certain important physical and chemical properties. The most important single property is baked apparent density (BAD). Satisfactory full-size anode performance has been obtained with $B A D$ values in the $1400-1650 \mathrm{~kg} / \mathrm{m}^{3}$ range $(15,16)$. However, the most common $B A D$ range is $1500-1600 \mathrm{~kg} / \mathrm{m}^{3}$. Electrical resistivity should be in the $0.0050-0.0075 \mathrm{ohm}-\mathrm{cm}$ range. The compressive strength should be $34325-49035 \mathrm{kPa}$. Regarding other anode carbon mechanical and thermal properties (17), a bending strength (BS) of $5884-7846 \mathrm{kPa}$ is considered adequate. Young's modulus (YM) should be 800 1000 times BS to provide acceptable elastic properties. Thermal conductivity (TC) should be in the $3.5-5.5 \mathrm{~W} / \mathrm{m}{ }^{\circ} \mathrm{C}$ range, and the coefficient of thermal expansion (CTE) should be $3.5-5.0 \times 10^{-6 / 0} \mathrm{C}$. Thermal stress resistance (TSR) is determined by the ratio, BS $\times$ TC/YM $\times$ CTE, and Alcan reports (17) 
that acceptable TSR values should be $\geq 1.50$. Total carbon porosity should be $<30 \%$, with a pore spectrum which minimizes gas permeability and oxidantaccessible surfaces. Even though there is much surface area in the submicron porosity range, it is usually so diffusion-limited that there is essentially no oxidant-accessible surface (18). Laboratory tests are used to determine oxidation resistance of cylindrical carbon samples to air and $\mathrm{CO}_{2}$ under conditions which indicate relative chemical reactivity $(20-40 \%$ weight loss) without oxidant diffusion limitation (19). Airburn values, at $550^{\circ} \mathrm{C}$ range from $\leq 20(38)$, excellent, to $\geq 80 \mathrm{mg} / \mathrm{cm}^{2} / \mathrm{h}(153 \mathrm{mg} / \mathrm{g} / \mathrm{h})$, poor. $\mathrm{CO}_{2}$ oxidation values, at $970^{\circ} \mathrm{C}$, vary from $\leq 10$ (excellent) to $\geq 50$ (poor) $\mathrm{mg} / \mathrm{cm}^{2} / \mathrm{h}$.

Finally, for prebaked cells, anode height varies within the $40-65 \mathrm{~cm}$ range, and has a marked influence on the temperature profile and performance. The additional oxidation exposure of tall anodes causes greater sensitivity to oxidation catalyst (e.g.Na) impurity levels. Another factor affecting anode temperature and performance is the location and manner of crust-breaking for feeding alumina to the cell. In particular, large centre break openings which do not close between breaks (possibly due to alumina crusting behaviour) can adversely affect anode performance. Any condition, e.g. poor current distribution, or dusting) which produces a "sick" (hot) cell will put added thermal and oxidation stresses on the anodes, which can reduce performance. 
TABLE 1.1. Factors influencing the net consumption of anodes.

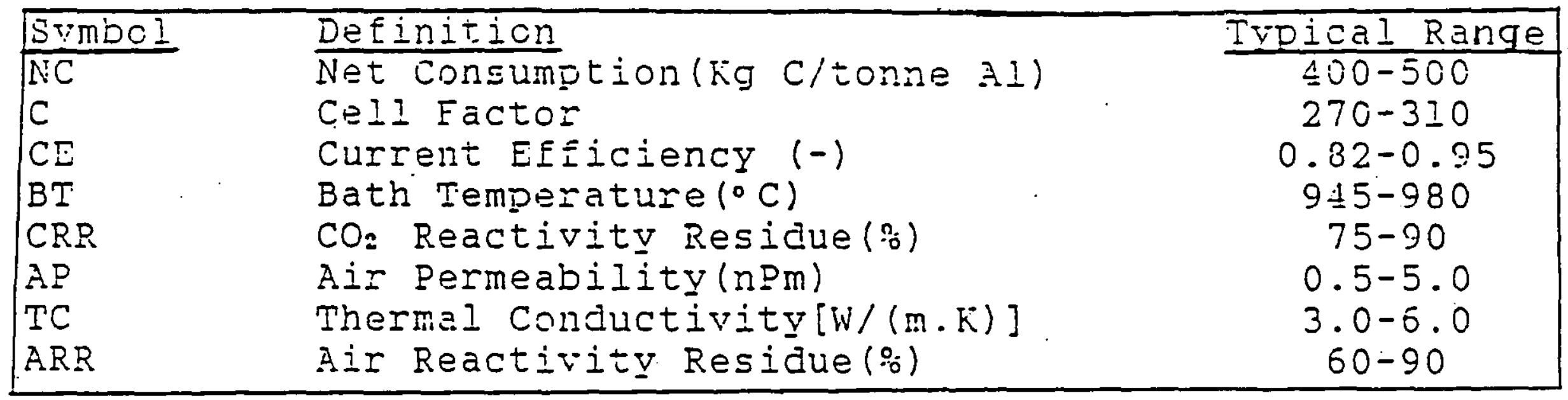




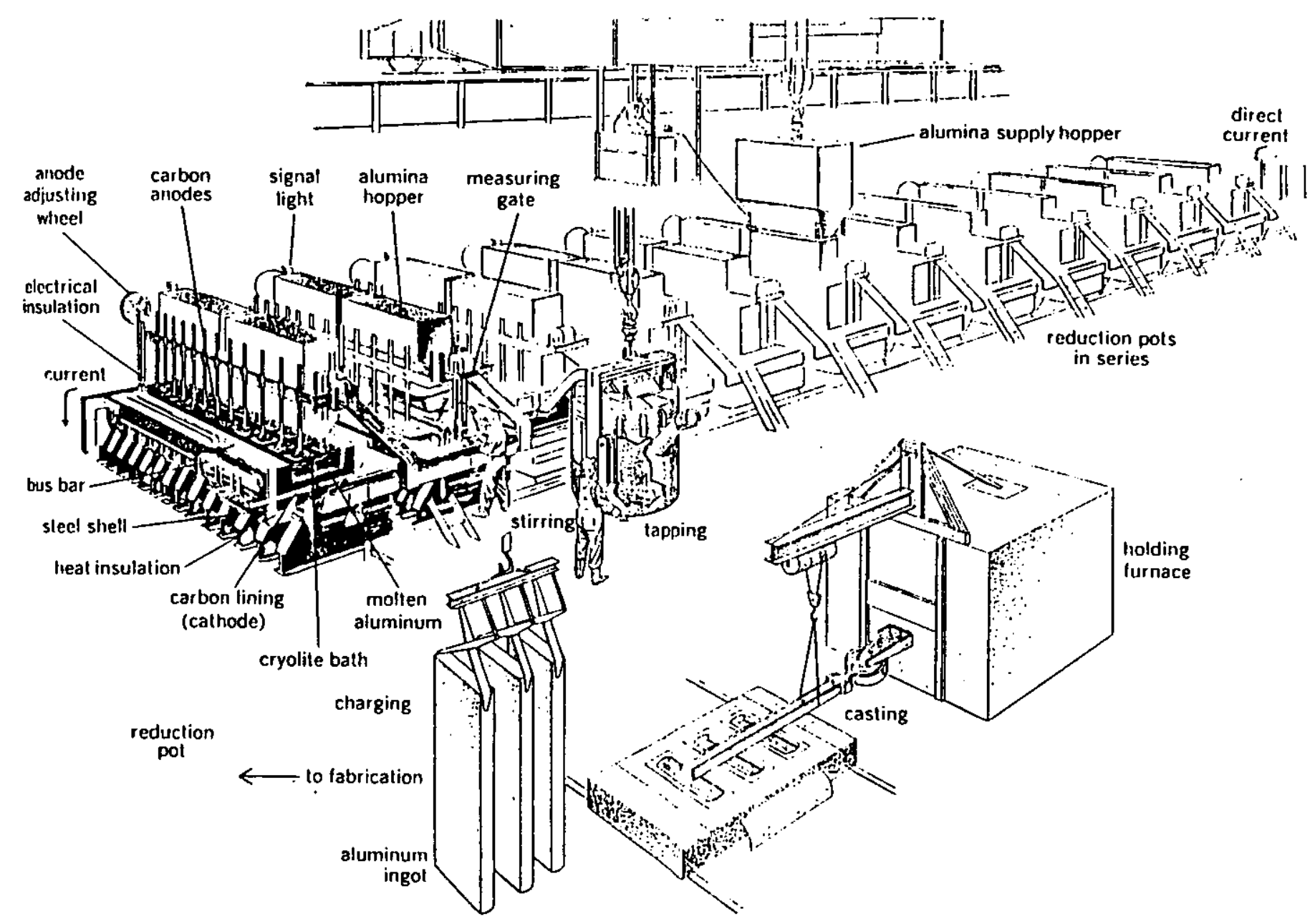

FIG.1.1. Production of aluminium metal. 


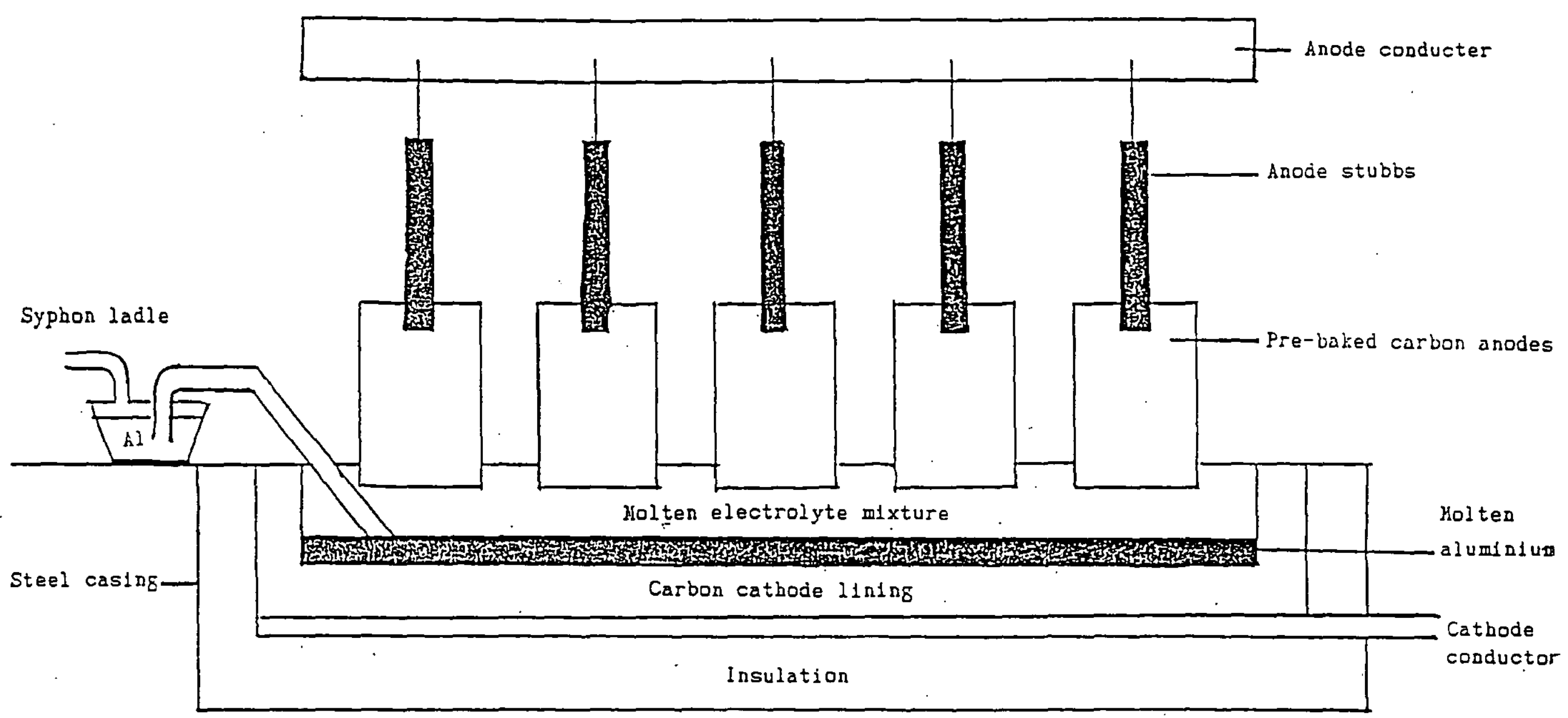

FIG.1.2. Diagram of aluminium reduction cell. 


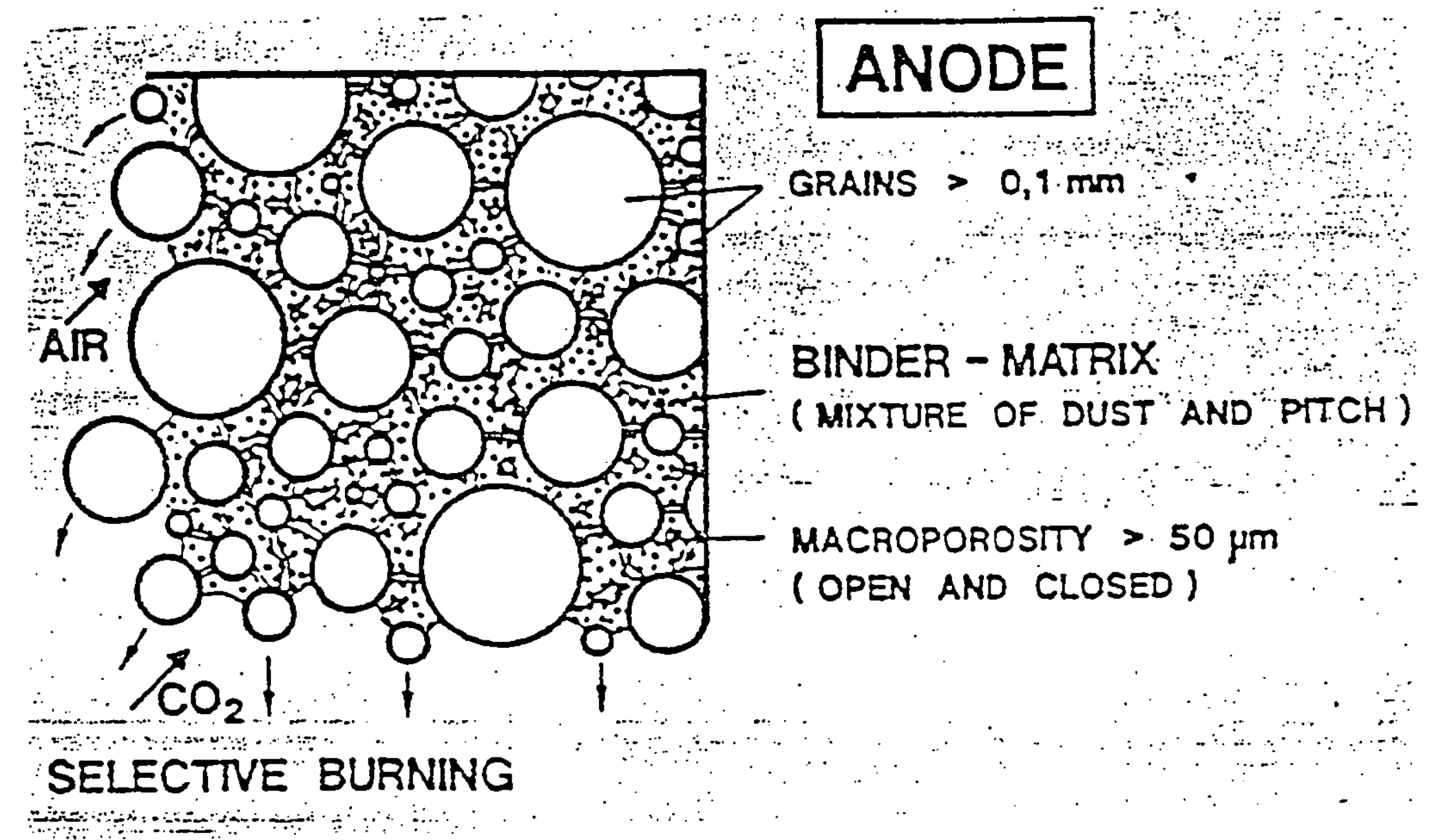

FIG.1.3. Composition of a baked anode. 


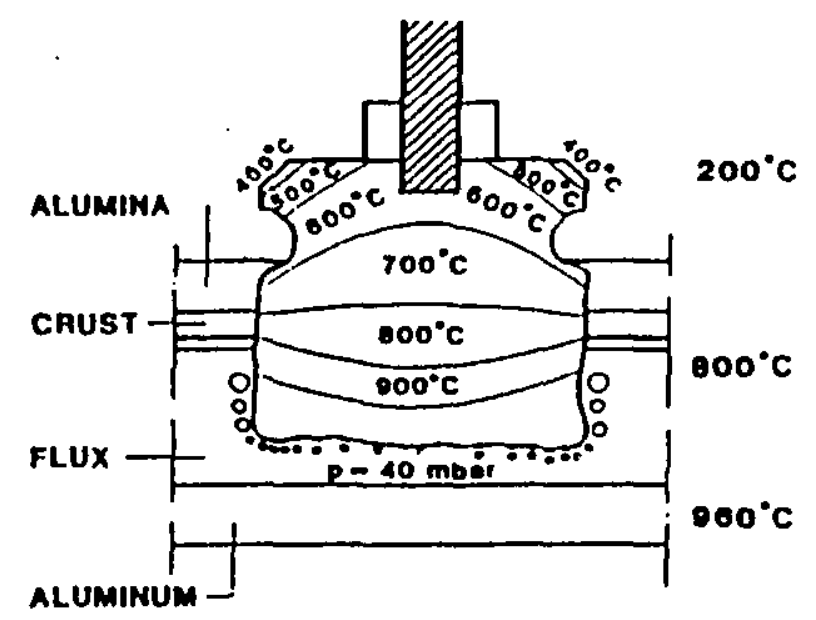

FIG.1.4. Anode behaviour in a reduction cell.

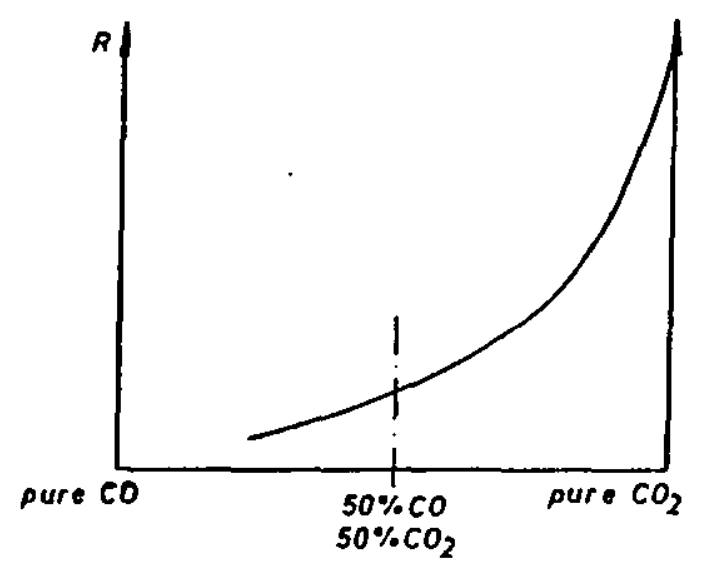

FIG.1.5. The reaction rate of carbon consumption in the function of the $\mathrm{CO} / \mathrm{CO}_{2}$ ratio. 


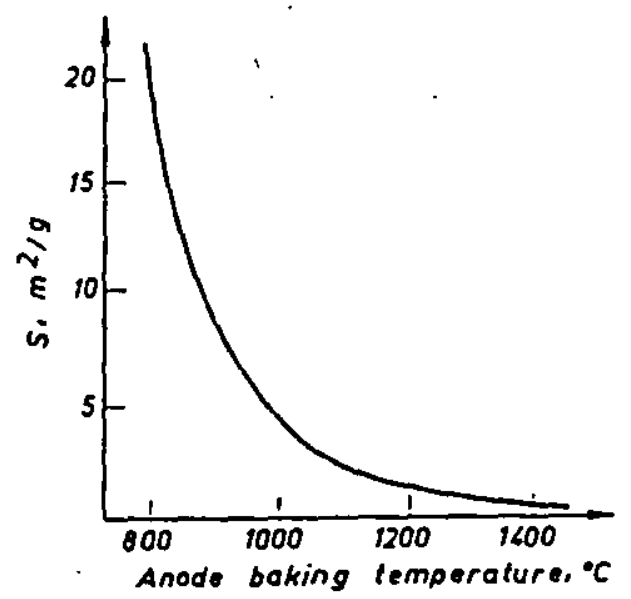

FIG.1.6. BET measured area of ordinary anode specimens vs. the baking temperature of the pre-baked anode.

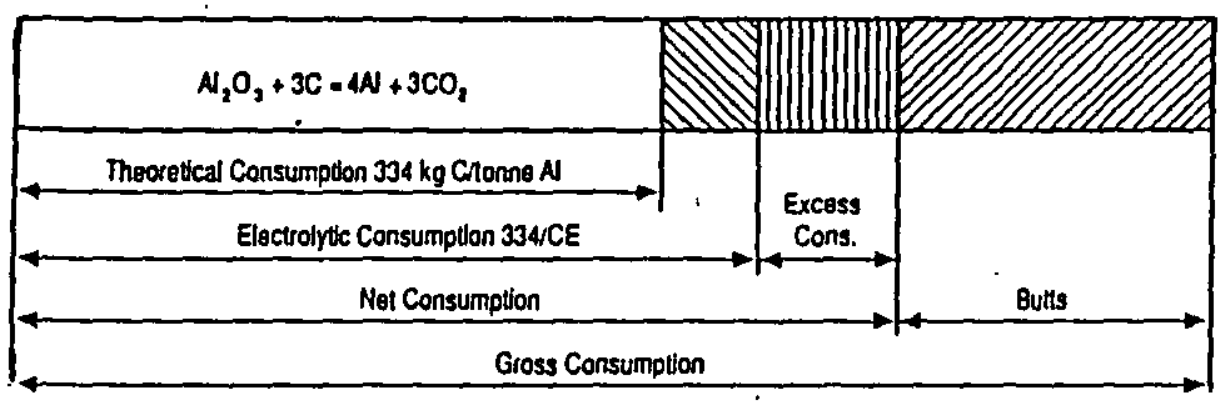

FIG.1.7. The factors contributing to anode consumption. 


\section{ANODE PRODUCTION}

In this chapter, consideration is given to the chain of events affecting carbon consumption, from the properties of the precursors for filler cokes and binder pitches, through production of these raw materials and their fabrication into anode and cathode carbon.

\subsection{Coal-Tar Pitch Manufacture}

Anode binder pitches are complex mixtures of highly-aromatic hydrocarbons derived from high-temperature coal-tar and petroleum residues after various distiliation, thermal, and sometimes oxidation treatments. Coal-tar is a byproduct from the carbonisation of bituminous coal to make coke. Coal-tar pitch is the residue remaining after vacuum distillation removal of about half of the more volatile constituents. This pitch has been the binder most frequently used by the aluminium industry for anode fabrication. In principle, it is possible to make a similar binder from various petroleum residues (e.g. vacuum resids, decant oil from fluid catalytic crackers, ethylene steam cracker tar). However, with rare exceptions, most of the petroleum pitches produced have not received enough severe thermal cracking treatment to produce a product with the binding quality of coal-tar pitch.

The nature of the tar is dependent on many factors including the type of coal carbonised, but mainly on the high carbonisation temperatures used to make coke. Thermal decomposition of tar compounds produced at lower temperatures increasingly controls the ultimate nature of the tar product as the carbonisation temperature increases.

The major effects of carbonising temperature on the yields of primary products and on tar composition are:-

a) The yield of tar, based on coal throughput, decreases as the carbonisation temperature is increased above $600^{\circ} \mathrm{C}$.

b) The pitch yield from the tar increases with carbonising temperature.

c) The yield of paraffins decreases with increasing carbonisation temperature.

d) The aromaticity of the pitch product, as measured by such parameters as density and atomic $\mathrm{C} / \mathrm{H}$ ratio, increases with increasing carbonisation temperature. 
Tars used to make electrode binder pitches are those from metallurgical coke production and contain negligible quantities of paraffinic species, phenolic compounds and basic compounds. The tars used in coal-tar pitch binder production are highly aromatic materials.

The nature of the pitch produced from the tar distillation process is also dependent on the proportion of the tar removed as oil and, to a much lesser extent, the amount of heat treatment the tar receives during the distillation process.

Tar pre-treatment also has an effect on pitch quality. in general more highly aromatic tars and pitches contain higher percentages of material insoluble in powerful solvents such as quinoline. Such material is desirable in pitches to be used for electrode making but is undesirable in pitches to be used for impregnating or in paint systems. It may be removed by a number of methods including tar filtration and centrifuging. Details of the manufacture of pitch have been given elsewhere $(20,21)$.

Pitches are made for a number of purposes, including: binder pitch for the aluminium industry, binder pitch for the graphite industry, impregnation pitches for graphite, pitch fibre pipes and refractories, binder for refractories and what is termed general purpose pitch which is used to make road tar and coal-tar fuels.

Pitch for each of these purposes must meet tight specification requirements and in order to achieve this, the first stage in the production process is the segregation of crude tars which are usually segregated according to either density or insolubles content. The high density/high insolubles tars are used for producing electrode and graphite binders. The low insolubles tars are used for making impregnation and special pitches. Tars of intermediate density/insolubles contents are used to produce general purpose pitch or for blending.

The low insolubles tars may have their insolubles contents further reduced by centrifuging. This also produces a tar fraction with a higher insoluble content which is used in electrode and graphite binder production. The tar is then distilled to produce pitch and a series of coal-tar oil fractions. Almost all tar is 
now distilled in continuous units which are either of the straight-through type such as the ProAbd (Fig.2.1) and Koppers, or of the recirculating type such as the Wilton (Fig.2.2). In all types of unit, the tar would be heated to a temperature of around $360^{\circ} \mathrm{C}$ to $370^{\circ} \mathrm{C}$ and leave the heat exchanger typically at around $220^{\circ} \mathrm{C}$. The main difference between the two types of unit is the residence time of the pitch at high temperatures in the heating coils. This is considerably longer in the recirculatory type and this can have the effect of increasing slightly the contents of insolubles. Other variations exist in different tar plants which allow a greater quantity of steam to be used to achieve the desired softening point.

It has been found advantageous in the case of aluminium binder to subject the pitch from the distillation plant to an after-treatment. This consists usually of maintaining the pitch at a temperature in the region of $375^{\circ} \mathrm{C}$ for a period of around 7 hours. The effect is to increase the softening point and the insolubles contents, particularly the B-resin fraction, to the desired levels.

If a high softening point pitch such as electrode binder is required in a liquid state, it is stored in large tanks, up to 1000 tonne capacity, at a temperature between 170 and $250^{\circ} \mathrm{C}$. It is then transported at these temperatures in insulated tankers, often equipped with some form of re-heating if necessary.

If solid pitch is required it is usually prepared in one of two forms, (a) pencil pitch or (b) plate pitch. A schematic layout of a pencilling plant is shown in Fig.2.3. Conditioned or plate pitch is prepared on another plant, a schematic layout of which is shown in Fig.2.4. These types of solid pitch have the advantages of ease of handling, lowered dust content, freedom from extraneous impurities and a lower water content.

A number of sets of specifications for aluminium electrode binder pitches are given in Table 2.1. A cursory examination suggests there is a wide divergence in the levels of properties required in different sets of specifications and also the methods by which the levels are to be determined.

Certain properties are common to all sets of specifications, namely: softening point, material insoluble in a powerful solvent such as quinoline or anthracene oil, material insoluble in a less powerful solvent such as toluene or benzene, a 
residual carbon level, widely described as a coking value, a residual ash content and pitch density.

The equivalent levels given in Table 2.1 for ring and ball softening point laid down by STPTC (22) and Alcan coking value (22) were obtained using empirical conversion factors. It cannot be stressed too highly that these factors are only approximate and can vary from company to company because a particular test may be carried out by a slightly different procedure. Examples of the factors used for the inter-relation of softening points and other pitch specifications are given below:

(A) Ring and Ball = Cube in air minus 4

(B) Ring and Ball = K. \& S. (1 deg. C./min.) +18

(C) Coking Value (Alcan) $=0,751 \times$ Coking Value (SERS) $+16,209$ (This is taken from the Pechiney publication Electrodes pour Aluminium, 1-Matieres Premier Brais.)

(D) Coking Value Alcan $=$ C.V. Conradson +2

(E) Coking Value Aican $=$ C.V. Barrett +10

The latter two relationships have been found by experience in a British Steel Chemicals Laboratory.

Examination of the equivalents given in Table 2.1 shows that specifications fall roughly into the following bands:

\section{Pre-baked}

S.pt. R \& $B^{\circ} \mathrm{C}$

Quinoline insols. \%

Toluene-insols. \%

B-resins \%

Coking value $\%$

Density $\mathrm{g} / \mathrm{cc}$

Ash \%
98-115

8.15

28-37

$20-25$

$55-58$

1.3-1.32

$0.15-0.25$

Other properties which are often quoted are: sulphur content 0.5 to $1.0 \%$, water content 0.2 to $0.6 \%$ and distillation 4 to $5 \%$ at $360^{\circ} \mathrm{C}$.

All the specifications mean that a binder must be made from highly aromatic coke oven tars. This is demonstrated by the high pitch density and coking value requirements. Aromaticity is a property which is very difficult to increase by any 'mild' type of treatment. Similarly, ash and sulphur contents may be 
regarded as inherent properties of any particular tar. This means that research work into 'mild' forms of treatment is limited to those which bring about changes in softening point, QI contents, TI contents and B-resins contents. Nonspecification properties such as paste flow characteristics are measured and controlled to some extent but other properties can only be monitored.

An aluminium company which was supplied with a straight run binder pitch encountered a high incidence of pre-baked anodes sticking together in the baking furnaces, coke filler adhering to the anodes and slumping of the conductor stud holes of the electrodes. Plant process variables were carefully examined and the problem was tenuously ascribed to the pitch used. When sticking anodes were separated they performed well in the pot-line. The pitch supplied was accepted within specification requirements, but the problem illustrates that pitch specification requirements are only a guide to the production and usage of successful pitches, the ultimate success of a pitch may only be ascertained when it is used in electrode production.

\subsection{Coal-Tar Pitch Properties}

Pitch binders consist of thousands of different molecular structures with molecular weights in the 100-5000 range. Average binder elemental composition consists of at least $90 \%$ carbon, 3-7\% hydrogen, and up to several percent each of oxygen, sulphur, and nitrogen. Coal-tar pitches are usually more aromatic and more highly condensed than petroleum pitches. One method which is widely used for binder characterisation is the solubility of the pitch in selected solvents, particularly benzene, toluene, or xylene, and quinoline. The more condensed pitches have lower solubility, and a typical coal-tar pitch is $\sim 70 \%$ toluene-soluble and $\sim 90 \%$ quinoline-soluble. The toluene-soluble (TS) fraction is referred to as oil and acts as a plasticiser, or softener, which affects binder softening point (SP). The fraction which is toluene-insoluble (TI) and quinoline-soluble (QS) is referred to as B resin, and consists of intermediate-size molecules which contribute much to coking value (CV) and bond formation between filler particles. The quinoline-insoluble (QI) fraction contains the largest binder molecules, and has the form of a coarse (micronsize) carbon black with $3-5 \%$ volatiles. The QI fraction increases bond-coke quality when present at the $10-25 \%$ level (23). When combined to form a pitch binder, oil, B resin, and QI fractions interact so that whole pitch properties are improved over the properties of the separate fractions. 
When pitch binder is pyrolysed during the carbon bake operation, it is converted from an isotropic liquid, with no structural order, to a liquidcrystal (called mesophase) having a layered structure which is finaliy converted to layers of carbon atoms in a hexagonal lattice of graphite crystallites. These crystallites of binder coke become more disordered and crosslinked into a more-isotropic coke as the pitch QI content increases. Such moderately-isotropic coke, in contrast to highly-anisotropic microstructure (24), is preferred for binder coke because it forms both physical and chemical bonds between filler coke particles which are stronger and more oxidationresistant (23).

Regarding pitch property values, it is desirable to use pitch with the highest softening point(SP) (e.g. $110-120^{\circ} \mathrm{C}$ ) that plant facilities will permit, since this means fewer volatiles (reducing the carcinogen hazard) and more binder carbon (and probably better performance) in the baked anode. QI in coal-tar pitches (e.g. 10-20\%) is beneficial, and gives a better (denser, stronger, more conductive) carbon at levels up to at least $20 \%$ (23). The Conradson value (CV) should be high as possible (e.g. 55-60\%), and anode properties tend to become marginal as $\mathrm{CV}$ drops below $50 \%$, which can occur with some petroleum pitches (15). The lower the distillation fraction at $360^{\circ} \mathrm{C}$ and one atmosphere pressure (e.g. $<5 \%$ ), the fewer light hydrocarbons (and carcinogens) are lost during coking, resulting in a higher CV. Specific gravity (SG) is an indicator of degree of condensation, and should be as high as possible $(>1.25$ ) since this means more bond coke and better performance for the anode carbon. The $\mathrm{C} / \mathrm{H}$ atomic ratio also indicates condensation level, and should be less than about 1.5 (1.7 is common for coal-tar pitches). Finally, binders and particularly petroleum pitches may have somewhat lower ash levels (e.g. $<0.25 \%$ ) than available filler cokes. This helps make the binder coke more oxidation-resistant and adds less impurity to the metal product. Regarding sulphur content, coal-tar pitches typically have <1\%S (e.g. 0.5-0.7\%S), while petroleum pitches may contain much more (e.g. $3-5 \% \mathrm{~S}$ ), which might result in excessive plant $\mathrm{SO}_{2}$ emission under some circumstances. 


\subsection{Petroleum Coke Properties}

Carbon, in the form of coke may be produced when organic matter is heated to $400-600^{\circ} \mathrm{C}$, essentially in the absence of air. The organic matter used for anode binder coke has come primarily from coal-tar, with minor amounts from petroleum residues. In contrast, filler coke is produced almost entirely from petroleum, with minor amounts from coal-tar pitch, although in recent years, solvent-refined coal (SRC) filler coke has been found to produce high quality anode carbon.

Coke has an elemental composition of over $80 \%$ carbon, with varying amounts of hydrogen, nitrogen, sulphur, oxygen, and a few tenths of one percent other impurities. The specific composition depends on coke heat treatment, with the carbon content increasing with temperature. Coke is available in (1) the green or raw state corresponding to a temperature of $\sim 450^{\circ} \mathrm{C}$, and (2) the calcined state corresponding to a temperature of $1300-1400^{\circ} \mathrm{C}$. Green coke is $\sim 85-$ $95 \%$ carbon, $3-4.5 \%$ hydrogen, $0.5-2.5 \%$ nitrogen, $0.5-6.0 \%$ sulphur, and $1.0-8.0 \%$ oxygen, with $6-15 \%$ volatile matter (VCM), exclusive of moisture, released when heated to $950^{\circ} \mathrm{C}$. Calcined coke is $\sim 95-98 \%$ carbon, $0.03-$ $0.06 \%$ hydrogen, $0.5-1 \%$ nitrogen, $0.5-5 \%$ sulphur, and $0.1-1 \%$ oxygen, with $<0.5 \%$ volatile matter. Calcined coke is thus rather pure carbon (except for sulphur content) as graphite crystallites, associated with voids, and a few tenths of one percent metallic impurities.

Filler coke is formed by the same general mechanism as that already described for binder coke. However, the feedstocks used are various petroleum residual fractions, instead of coal-tar. Temperatures of $400-500^{\circ} \mathrm{C}$ convert these resids into green coke within a day. A complex series of endothermic pyrolysis reactions produce liquid-crystal mesophase which is transformed to a carbon polymer of generally graphitic structure. However, there are varying amounts of structural disorder caused by exothermic crosslinking reactions. The result is coke with a more or less isotropic structure (25), and related property values, depending on the degree of order of the graphite crystallites of which it is composed. If the coke is very isotropic (disordered), it will tend to be more dense, less pure, and less porous (more blind and closed pores), with a high CTE. It will also tend to have the same property values in all directions (i.e. isotropic), reflecting properties of a random array of graphite crystallites. If the coke is very anisotropic (ordered), it will tend to have less impurities, to 
be more porous (more open, connected pores), with a low CTE. In the extreme case, the product is called needle coke, and has different property values perpendicular and parallel to the graphite basal planes. This coke is sold to the graphite industry at a premium price, where its low CTE is important for producing thermal shock-resistant electrodes for electric steel furnaces. However, such coke is not desired for aluminium industry anodes, but rather a coke with intermediate disorder between the two extreme cases. The important considerations are to obtain (1) high bulk density, (2) low oxidant-accessible surface, (3) moderate thermal shock resistance, and (4) adequate purity, at a reasonable price. Coke impurities tend to increase as the coke becomes more isotropic because one of the principal crosslinking agents in coker feedstocks is asphaltenes, which contain many of the crude oil impurities.

\subsection{Petroleum Coke Manufacture}

About $90 \%$ of all coke is produced by a batch process in which the coker feedstock is heated to about $450^{\circ} \mathrm{C}$ and then held or "delayed" in large tanks, or drums, for periods up to one day $(26,27,28)$. The product is called delayed coke (DC), and each coke drum produces 500-1000 tonnes of coke per day. This delayed coking process is the principal method of petroleum coke manufacture. World production by this method was recorded as 19 million tons/annum in 1987 (29). A wide variety of feedstocks is used, principally thermal tar, decant oil, catalytic cracker slurry, coal-tar pitch and ethylene cracker tar. This ability to use a range of feedstocks is one of the reasons why the delayed coking process is so popular.

The delayed coker feed is fed hot to the heater of the coker and heated to about $450^{\circ} \mathrm{C}$. The feedstock then flows into one of two coke drums where it thermally cracks to gas, petrol, gas oil and coke, at pressure of $0.5-1 \mathrm{MPa}$. Over a period of hours, the coke accumulates in the drum, while the light products pass back to the combination tower. When the first drum is full, the feed is switched to the second drum and quenching of the first drum commences, first by steam and then by water. After the water has been removed, the now cool coke is drilled from the drum using high-pressure water jets, see Figure 2.5.

In the drum, coke formation takes place by polymerisation and homogeneous nucleation of the feedstock molecules, to produce lamellar nematic liquid crystals. At first, the system is highly fluid, and spheres may coalesce to form 
larger spheres, but eventually, a fully-coalesced structure known as bulk mesophase is formed, because increasing temperature or time leads to further polymerisation of the constituent molecules. The bulk mesophase still shows plastic properties, and will undergo further polymerisation before becoming a rigid semi-coke (with a heat-treatment temperature of $<500^{\circ} \mathrm{C}$ ) or a green coke (with a HTT of $>500^{\circ} \mathrm{C}$ ).

The remaining $10 \%$ of petroleum coke is produced by a continuous fluid-bed process $(26,28)$. The product, called fluid coke (FC), is produced by coking of liquid feedstock coating tiny coke seeds as they are agitated on a fluid bed, where the temperature is $100-150^{\circ} \mathrm{C}$ above that for delayed cokers. Relatively little fluid coke is used in the aluminium industry because it's often high in impurities (sulphur and metals), and available only as submillimetre particles which are harder to grind and bind into the anode.

The quality of coker feedstock and control of coker operation have an important influence on green coke quality. The purity and density of the feed strongly affects coke purity and yield. Also, the presence of crosslinking agents (e.g. asphaltenes) affects both carbon yield and coke structure. Coke yield and structure are both affected by recycle ratio. As coking severity (time, temperature) increases, coke volatile matter (VCM) decreases. Green coke VCM affects the ease of coke removal from the drum, the sizing of the coke removed, and the bulk density of the calcined coke $(30)$. Experience indicates the following VCM ranges for good calcined coke property values: (1) ordinary semi-isotropic delayed, $10-12 \%$, (2) moderately-anisotropic delayed, 8$10 \%$, (3) highly-anisotropic needle delayed, $6-8 \%$, (4) fluid, $5-7 \%$.

Coke for the aluminium industry must be calcined before use to produce quality anode carbon. The desired range of property values is as given in Table 2.2. Rates given in Table 2.2 for coke aggregate are measured under conditions which indicate relative reactivity, not limited by oxidant diffusion rates. It is necessary to calcine green coke to prevent intolerable shrinkage cracks in the baked carbon. The normal calcination process involves exposure of green coke to temperatures up to $1400^{\circ} \mathrm{C}$, without using heatup rates high enough to puff the coke and so reduce bulk density. At maximum temperature, calcination continues until specifications for real density and/or resistivity have been met. Most commercial coke calcination is carried out using rotary kiln calciners (31). These units consist of a heated steel pipe, $2.5-3 \mathrm{~m}$ in diameter 
and $61-76 \mathrm{~m}$ long, lined with refractory, and tilted at a small angle to the horizontal which rotates at a few rpm. Green coke enters the upper end and tumbles in a thin cylindrical section through the pipe. Some commercial calcination is done using rotary hearth calciners. In this case, green coke is deposited at the outer edge of a slowly-rotating circular refractory table about $12-24 \mathrm{~m}$ in diameter. The coke is guided by rabbles toward the centre of the table where it falls into a soaking pit before removal from the calciner. Both rotary kiln and rotary hearth calciners have been developed in to more energyefficient and environmentally-acceptable equipment.

Much of the energy required for coke calcination is now supplied by burning volatiles from the green coke. Originally, rotary kiln calciners were end-fitted with natural gas (32). Then, kiln-mounted air blowers were attached in the central region of the kiln (31), and the energy produced has greatly reduced the amount of natural gas required. The use of lifters for mixing the coke charge is another recent improvement for rotary kiln calciners (33), which appears to have substantially improved the uniformity of coke calcination, and increased coke bulk density by reducing the heatup rate.

During typical rotary kiln calciner operation, coke feed rates are in the range of 20-50 tons $/ \mathrm{h}$. as the green coke enters the low-temperature end of the calciner, residual moisture is flashed to steam and the coke is heated to temperatures last experienced in the coker. At this stage the coke is in a sticky, plastic state, and the chord section of the coke charge has a relatively high angle of repose on the wall of the rotating calciner. As calciner temperature increases further, maximum coker temperature is exceeded and the coke begins to emit large quantities of hydrogen and light hydrocarbons. In this zone, near the calciner centre, vigorous combustion occurs using air supplied by the kiln-mounted blowers. Coke heatup rate appears greatest at the interface between these zones. Since almost of the energy for kiln operation is generated in the second zone, heatup rates can easily exceed $100^{\circ} \mathrm{C} / \mathrm{min}$., particularly if the calciner is operating at maximum temperature and the coke charge is not kept well mixed $(30,32,34)$. Such high heatup rates are known to seriously reduce coke bulk density (34). Another characteristic of this stage is reduction of repose angle of the coke charge. This occurs because the coke loses its sticky, plastic character and becomes fluidised from volatiles emission. After coke volatiles emission is complete, the charge is no longer fluidised. The coke then arrives at the back section of the calciner, where the repose angle of the 
unfluidised charge is greater than previously. Heat treatment is completed, and the coke then leaves the calciner after a residence time of about one hour. The coke is finally water-cooled and is usually given a coating of some petroleum fraction to reduce the dust level in later coke processing for anode fabrication.

The calcining operation can have an important influence on coke quality. In principle, cokes with significantly different volatiles contents (quality and quantity), microstructures, and/or impurity levels should be calcined differently. For example, high-volatile matter cokes require lower heatup rates. Also anisotropic (ordered) cokes require less calcination than isotropic (disordered) cokes (35). In practice, custom calcination is rarely done. Instead, green cokes with substantially different property values are often mixed so as to produce a calcined product with acceptable average property values. It is important that the calcined coke has the property values previously specified, particularly as they apply to bulk density, real density, resistivity, and purity. To produce high-quality calcined coke, it is necessary to minimise coke puffing from volatiles release, with controlled heatup rate, and to offset actual puffing and shrinkage occurring above $700^{\circ} \mathrm{C}(35,36)$. With optimum counterbalance of these opposing factors, higher bulk density (and lower oxidant-accessible surface) is achieved. Coke real density and resistivity values are achieved mostly by calcination time near maximum temperature. However, normal calcination has essentially no beneficial influence on coke purity. In fact, calcined coke ash levels tend to be somewhat greater than those for green coke due to volatiles removal. Sulphur is the only important impurity which can be reduced by calcination, if severity is increased by using a maximum temperature near $1500^{\circ} \mathrm{C}$ (16). Such thermally-desulphurised coke has substantially greater submicron porosity and reduced bulk density, but the oxidant-accessible surface is not increased. It has been determined that thermally-desulphurised coke will produce satisfactory anodes (37). However, the practicality of this method for improving coke quality has not yet been reported. 


\subsection{Anode Manufacture}

The objective of making good anode carbon, which has the property values already specified, involves four important operations, which are (1) filler aggregate sizing, (2) paste pitching level determination, (3) paste compaction, and (4) compacted composite baking.

The most important objective for anode filler aggregate sizing is to obtain a high vibrated aggregate bulk density (38). For prebaked anodes, maximum aggregate bulk density is required to achieve maximum baked carbon density. For most cokes, bulk density increases as particle size is reduced because the large void fraction due to coarse pores is progressively reduced with decreasing particle size. In general, coarse particles act as support pins to hold the composite together, and reduce bake shrinkage while requiring less binder pitch and having less oxidant-accessible surface. However, it is important that these particles be dense as the coarse fraction increases, to prevent reduction in composite compressive strength. Fine coke particles, on the other hand, exhibit more surface, require more binder pitch, and increase composite bake shrinkage. However, in a properly pitched composite, they will increase carbon conductivity and strength. Thus, what is needed is an aggregate balance which emphasizes overall particle sizing skewed toward coarse particles and high vibrated aggregate bulk density to achieve good baked carbon property values and maximum anode performance $(39,40)$.

Filler aggregate selection in prebake plants use four aggregate fractions: (1) coarse butts, and (2) coarse, (3) intermediate, and (4) fine coke particles. The butt fraction results from the need to recycle about $25 \%$ of the anode carbon near the supporting steel stubs. Butt particles are usually more dense than coke particles due to cell bath impregnation, and tend to increase anode carbon density and conductivity. Maximum butt particle size is about $2.5 \mathrm{~cm}$, with finer particle sizing extending through the three coke size fractions (41). The sizing ranges for the coke fractions are approximately as follows: coarse $(6-0.6 \mathrm{~mm})$, intermediate $(0.6-0.15 \mathrm{~mm})$, and tine $(<0.15 \mathrm{~mm})$. High vibrated aggregate bulk density is achieved by a series of statistically-designed experiments to obtain the desired result most efficiently. 
Once aggregate sizing is determined, the prebake aggregate requires about $15 \%$ pitch to produce maximum baked carbon density, strength, and electrical conductivity. This value relates rather directly to the surface area of the aggregate particles coated. The optimum value can be determined by measuring the properties of baked carbon produced from paste batches which are incrementally-pitched about this value. Some plants use a formula based on particle surface area to determine a specific amount of binder. However, since this method does not consider coke particle porosity or the void volume between particles, it's often desirable to do an iteration based on coke and aggregate property values to optimize the level of pitch (42).

After the optimum level of pitch has been determined, anode paste is usually mixed for periods up to an hour, while the paste is at least $60^{\circ} \mathrm{C}$ above the binder SP. During this operation, the pitch must coat the filler particles uniformly, to produce well-mixed paste. As a properly mixed condition is approached, compacted paste green density will increase to a constant maximum value. The paste is then ready for compaction into green anode composites, which is either pressure-moulded or vibratory-compacted into blocks which must be baked before use in an operating cell. Pressure-moulding techniques usually involve the single (high pressure) or multiple (low-pressure) application of pressures in the $3.4-48 \mathrm{MPa}$ range, to paste which has been cooled to $5 \cdot 10^{\circ} \mathrm{C}$ above the binder softening point. Specifically developed compaction methods also include control of loading rate, holding time, and release rate to produce composites with acceptable property values. Vibratory compaction techniques employ much lower pressures ( 0.7MPa), but produce good carbon quality. This method also has the advantage of requiring a smaller plant capital investment than that for pressure-mould compaction. There is some evidence that the two methods give similar results for high-modulus (elastic) cokes, with some advantage for pressure-moulding for low-modulus cokes.

The final step in anode fabrication is baking the compacted composite. For prebaked anodes, the heatup rates can be as high as about $10^{\circ} \mathrm{C} / \mathrm{h}$, because there are enough void spaces to accommodate pitch expansion and gas evolution. Above $600^{\circ} \mathrm{C}$, the heatup rate can be increased to $50-100^{\circ} \mathrm{C} / \mathrm{h}$, without damage to the baking carbon. Prebaked anodes should finish the bake operation with about ten hours near a maximum temperature of $1000-1200^{\circ} \mathrm{C}$, preferably $1150+.50^{\circ} \mathrm{C}$. It has been found that increasing bake finishing temperature 
from 1000 to $1200^{\circ} \mathrm{C}$ reduces net carbon consumption by about $0.2 \mathrm{~kg} \mathrm{C} / \mathrm{kg} \mathrm{Al}$ per $100^{\circ} \mathrm{C}(43)$. In the $900-1000^{\circ} \mathrm{C}$ range, the rate is three times greater, and is essentially zero in the $1200-1400^{\circ} \mathrm{C}$ range. Thus, temperatures above $1200^{\circ} \mathrm{C}$ don't improve carbon quality, and accelerate furnace deterioration from fluoride attack on the refractory. During this bake operation, normal linear shrinkage for good prebake anodes is $0.2-0.5 \%$.

Anodes must be baked to a given temperature following a given temperature profile in order to end up with the required mechanical and electrical properties. Baking is done in huge furnaces made of pits inside which "green" (unbaked) anodes are placed in layers, surrounded by packing coke. The pits are lined with refractory bricks, and alternate with flues in which the hot combustion gas flows. Figure 2.6 shows part of such a furnace, called a ring furnace, corresponding to what is commonly referred to as a baking group. A baking group is made of a cooling zone and a heating zone. In the case illustrated, there are 5 sections in each zone. A ring furnace is so called because it is composed of 4 to 6 such baking groups built in a ring shape so that the burners can move around as baking proceeds.

Air is blown into the cooling end of the flue (right hand side of Fig.2.6) where it picks up heat while cooling the baked anodes. The air then reaches the heating zone where it receives heat from one or more burners. The hot gas then gives up part of its heat to the solids before leaving the flue through the exhaust fan. The burner ramps together with the fans are moved (leftward in the case of Fig.2.6) by one pit length (range $3-5 \mathrm{~m}$ ) after each regular time interval called fire cycle (range 25-45h) while the anodes remain stationary in their pits. For an imaginary observer sitting on the burner ramp, this amounts to moving the anodes rightward by one pit length after each fire cycle while the gas flows leftward inside the flues. The whole process corresponds to a counterflow semi-continuous heat exchanger.

Due to the cooling fan blowing air into the cooling end of the flue and the exhaust fan sucking air out of the other end, a slight depression $(\Delta P<0$, i.e. pressure is below atmospheric) prevails in the flues at heating-zone level, and a slight pressure $(\Delta P>0$, i.e. pressure is above atmospheric) prevails in the flues at cooling-zone level. $\Delta \mathrm{P}$ must be zero at the auxiliary fire level or to the right of it, in order to avoid the fumes shooting out of the burner holes. There results an ex-leakage of air from the cooling-zone flues, and more importantly an 
influx of air into the heating-zone flues. The tatter affects the gas temperature and therefore the heat transfer between the gas and the solids.

Heat comes not only from the fuel but volatile matter, mainly hydrogen, methane and tar, evolves from the green anodes under baking, and burns, in part or in whole, instantaneously or with some delay, thus providing another source of heat. As for heat sinks, in addition to the anodes which constitute the payload, the bricks and the packing coke are also heated. There is also a heat loss to the atmosphere by convection-radiation and a heat loss to the foundation by conduction. The fuel consumption of such a furnace is in the order of a few million dollars per year.

\subsection{Cathode Manufacture}

The steel shell of the pot is thermally insulated and lined with non-graphitised carbon. The carbon bottom, covered with molten aluminium, serves as the cell cathode. Electrical connection is made to the carbon cathode by steel bars running through the cell base and embedded in the carbon lining. Cathode carbons are obtained by a basically similar process to that of anode carbons, except that a variety of fillers, for example, electro- or gas-calcined anthracite, petroleum coke, scrap graphite or mixtures thereof, are used.

Intra- and inter-particular voids are present in the uncarbonised green blocks and devoltilisation pores will be generated during pitch phase carbonisation. Like anodes, the cathodes are therefore porous, two-phase carbon/carbon composites so that their strength will be dependent upon both their porous nature and the quality of the interfaces between binder and filler. These properties will also be important in considerations of oxidation resistance and electrical resistivity.

The most obvious properties required in the carbon lining material are: (a) good electrical conductivity, (b) high density or low porosity, and (c) high or adequate strength, normally measured as crushing strength, to resist thermal stresses during use. The active agents which the carbon has to resist would seem to be: (a) electrolytically liberated sodium, (b) molten electrolyte, and (c) molten metal. 
It is common experience that the steel shells of commercial cells become distorted, and sometimes the carbon bottom lining becomes arched upward. These phenomena point to carbon swelling, and it's generally accepted that it's due to penetration into the carbon lattice of sodium atoms generated by the reaction:

$3 \mathrm{NaF}+\mathrm{Al} \longrightarrow \mathrm{AlF}_{3}+3 \mathrm{Na}$ (in metal)

Sodium, which has a high ionisation energy, can enter the graphite structure only with difficulty (one compound, $\mathrm{C}_{64} \mathrm{Na}$, is known (44)), but the nongraphitised carbons used in cell linings have a low Fermi energy (i.e. the electron energy level) and this compensates for the high ionisation energy. At cell temperatures the product is not ordered and does not have a fixed composition; it is best described as a disordered solid solution with the carbon atoms fixed and the sodium ions very mobile - essentially molten (45). The amount of sodium taken up under standard conditions seems to correlate with the Fermi level expected for the carbon, this being governed by the maximum temperature to which it has been heated (45). Under cell conditions a linear dimensional expansion of $1 \%$, corresponding to a sodium uptake of about 5 atom\%, and depending on the $\mathrm{NaF} / \mathrm{AlF}_{3}$ ratio which controls the sodium activity via equilibrium (46), would not be uncommon. This can obviously cause both transient (47) and permanent stresses in the lining.

Another possible cause of the distortion of linings is similar to that which causes frost heaving of wet porous soils in winter. Electrolyte by itself and while remaining molten has practically no effect on cathode carbon, but it can soak through the porous carbon and freeze or crystallise and by so doing disrupt and heave the carbon lining.

Penetration of the carbon by molten metal is perhaps a simpler process, but ultimately more disastrous. Ultimate failure usually occurs by metal penetration to the steel conductor bars, leading to iron pickup, local concentrations of current, and therefore heat, and perhaps final run-out. Aluminium in contact with carbon at the temperatures of the carbon lining, and in the presence of flux, forms aluminium carbide at the interface. The examination of a cathode during dismantling suggests that small veins of aluminium in the carbon may be partially or wholly converted into carbide, 
while in larger veins the carbon surface has the appearance of having been washed or corroded away by the aluminium.

The lining must first be baked or brought up to temperature. Cracks may develop in this process due to shrinkage of the components. Essentially two forms of construction have been used: (a) prebaked block lining, and (b) the rammed monolithic lining.

The smaller celis have monolithic linings that are usually $15-25 \mathrm{~cm}$ in thickness above the steel collector bars. These are made by ramming a hot carbon paste in the cell and baking out the volatile constituents to form the carbon liner. Rammed carbon is unsuitable for higher amperage cells, where prebaked carbon blocks joined together with a carbonaceous paste are used, Fig.2.7.

A prebaked carbon block lining provides higher operating strength, higher density, lower porosity, and lower resistance than a rammed paste lining. The lower resistance results in a lower voltage drop through the lining, which improves the overall power efficiency of the cell. Prebaked block cathodes are preshrunk, which could contribute to their more predictable starting characteristics, and their better ability to be recycled (restarted) when celf lines are shut down for economic reasons, than monolithic linings. This helps increase production and gives longer service life, and will more than compensate for the higher initial cost of the blocks. The same unit mass of prebaked block cathode is more conducive to producing properly baked cathode and sidewalls than one made of rammed paste.

By the use of blocks which have been prebaked at an adequate temperature (say, $1250^{\circ} \mathrm{C}$ ), so that they will not shrink even on prolonged exposure at the operating temperature of about $980^{\circ} \mathrm{C}$, it's possible to ensure that the bulk of the lining will not shrink further. Even such prebaked blocks must be joined, and perhaps surrounded, by some rammed material. To minimise shrinkage of such rammed material surrounding the prebaked blocks, or constituting the entire monolithic rammed lining, the carbon aggregate must be precalcined and fully shrunk. This calcination is also necessary in the aggregate used for the prebaked blocks, if cracking in the prebaking process is to be avoided. 
Two methods of calcining the aggregate are used in practice: (1) electrical calcination, usually in vertical shaft furnaces; and (2) gas or oil-fired calcination in rotary furnaces. The former method is capable of higher temperatures but usually results in a less uniform product. Some of the particles may be fully graphitised while others may be inadequately shrunk. Measurement of the average product properties such as real specific gravity and volatile content may not be adequate safeguards, and direct measurement of shrinkage may be necessary. Calcination in a rotary furnace, oil or gas fired, produces a more uniform product but usually with a lower average level of calcination and no graphitisation. Specific gravity and volatile tests based on experience may give adequate assessments. Even with a fully shrunk aggregate, shrinkage of a rammed monolithic lining can occur if the binder content is not kept to the absolute minimum.

After baking or preheating, the carbon lining cannot be regarded as a perfectly uniform material of given properties. It inevitably contains minor defects, cracks or joints, and these must be taken into account in the starting procedure. 
TABLE 2.1. Typical aluminimm binder specifications.

\begin{tabular}{|c|c|c|c|c|c|c|}
\hline Electrode tyne & Pre-baked & Pre-baked & $\begin{array}{c}\text { Fullure } \\
\text { Pre-baked }\end{array}$ & Pre-bakeri & Pre-baked & Pre-baked \\
\hline 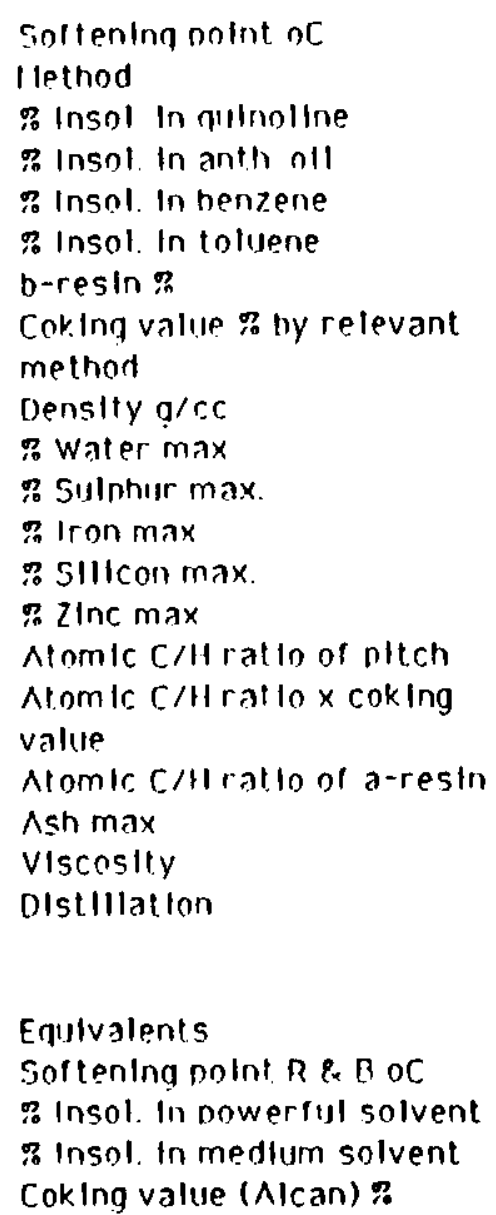 & $\begin{array}{l}110-115 \\
C \ln \wedge \\
10-15 \\
- \\
30 \mathrm{mln} \\
- \\
20 \mathrm{mln} \\
56 \mathrm{mln} \\
1.32 \mathrm{mln} \\
- \\
0.8 \\
0.05 \\
0.03 \\
- \\
- \\
- \\
- \\
0.25 \\
- \\
4 \% \mathrm{C} \\
3600 \mathrm{C} \\
\end{array}$ & $\begin{array}{l}30-90 \\
K \& 5 \\
- \\
12 \\
- \\
37 \\
25 \\
52-54 \\
1,31 \mathrm{~min} \\
- \\
- \\
- \\
- \\
- \\
1,8 \mathrm{~min} \\
- \\
>4 \\
- \\
- \\
-\end{array}$ & $\begin{array}{l}90-95 \\
K \& 5 \\
- \\
- \\
- \\
- \\
- \\
- \\
- \\
- \\
- \\
- \\
- \\
- \\
>1.05 \\
- \\
- \\
- \\
- \\
-\end{array}$ & $\begin{array}{l}105-115 \\
C \& A \\
8-13 \\
- \\
28-34 \\
- \\
- \\
57 \mathrm{~m} / \mathrm{n} \\
- \\
0,6 \\
0,8 \\
- \\
- \\
0,18 \\
- \\
3100 \\
- \\
0,15 \\
- \\
-\end{array}$ & $\begin{array}{l}97-103 \\
K \& 5 \\
10-15 \\
- \\
- \\
32-38 \\
20 \mathrm{mln} \\
55 \mathrm{mln} \\
1.32 \mathrm{mln} \\
- \\
1.0 \\
- \\
- \\
- \\
- \\
- \\
- \\
0.25 \\
- \\
45 \% ? \\
3600 \mathrm{C}\end{array}$ & $\begin{array}{l}B 3-87 \\
K \& 5 \\
- \\
<9 \\
- \\
20-36 \\
22 \mathrm{mln} \\
41-43 \\
1.3 \mathrm{mln} \\
- \\
0.6 \\
- \\
- \\
- \\
- \\
- \\
- \\
0.2 \\
4-70 \mathrm{E} \\
-\end{array}$ \\
\hline
\end{tabular}
$c \ln \wedge=$ cube $\ln \wedge \mathrm{Ir}$
$K \& S=K r$ amer \& Sarnow
$R \& B=R \operatorname{lng} \& B$ all

$R \& B=C \wedge \cdots A$

$=K S \cdot 18$ 
TABLE 2.2. Desired range property values for calcined coke.

\begin{tabular}{|c|c|c|}
\hline \multirow[b]{2}{*}{ Property } & \multicolumn{2}{|c|}{ Property Values } \\
\hline & Delaved Coke & Fluid coke \\
\hline Hardgrove Grindability & $35-45$ & $\overline{28-35}$ \\
\hline Particle sizing & $-1 \mathrm{in} /+28 \mathrm{mesh}$ & $-28 /+200$ mesh \\
\hline Bulk Density $(-8 /+14)$ lbs $/ \mathrm{ft}^{3}$ & $48-58$ & $70-80$ \\
\hline $\begin{array}{l}\text { Real Density (lierosene) g/cc } \\
\text { Volatile Matter: }\end{array}$ & $2.04-2.08$ & $1.92-1.98$ \\
\hline moisture, $: 6$ & $<<0.5$ & $<<0: 5$ \\
\hline VCM,,$\because 6$ & $<0.5$ & $<0.5$ \\
\hline Specific Electrical. & & \\
\hline $\begin{array}{l}\text { Resistivity }(-35 /+65) \text { ohm-in } \\
\text { Ash, }:\end{array}$ & $\begin{array}{l}0.036-0.043 \\
<0.5\end{array}$ & $\begin{array}{l}0.036-0.043 \\
<0: 3\end{array}$ \\
\hline Impurities: & & \\
\hline $3, \therefore$ & ↔ & $<5$ \\
\hline$S i, \Upsilon_{0}$ & $<0.03$ & $<0.02$ \\
\hline $\mathrm{Fe}, g_{\delta}^{0}$ & $<0.03$ & $<0: 03$ \\
\hline $\begin{array}{l}\text { V,:ós } \\
\text { Airburn: }\end{array}$ & $<0.02$ & $<0.04$ \\
\hline $550^{\circ} \mathrm{C}(-28 /+200) \mathrm{mg} / \mathrm{Crl}^{2} / \mathrm{hr}$ & $5-80$ & $100-150$ \\
\hline $\begin{array}{l}\mathrm{CO}_{2} \text { Oxidation: } \\
970^{\circ} \mathrm{C}(-28 /+200) \mathrm{mg} / \mathrm{cm}^{2} / \mathrm{hr}\end{array}$ & $5-20$ & $2-8$ \\
\hline
\end{tabular}




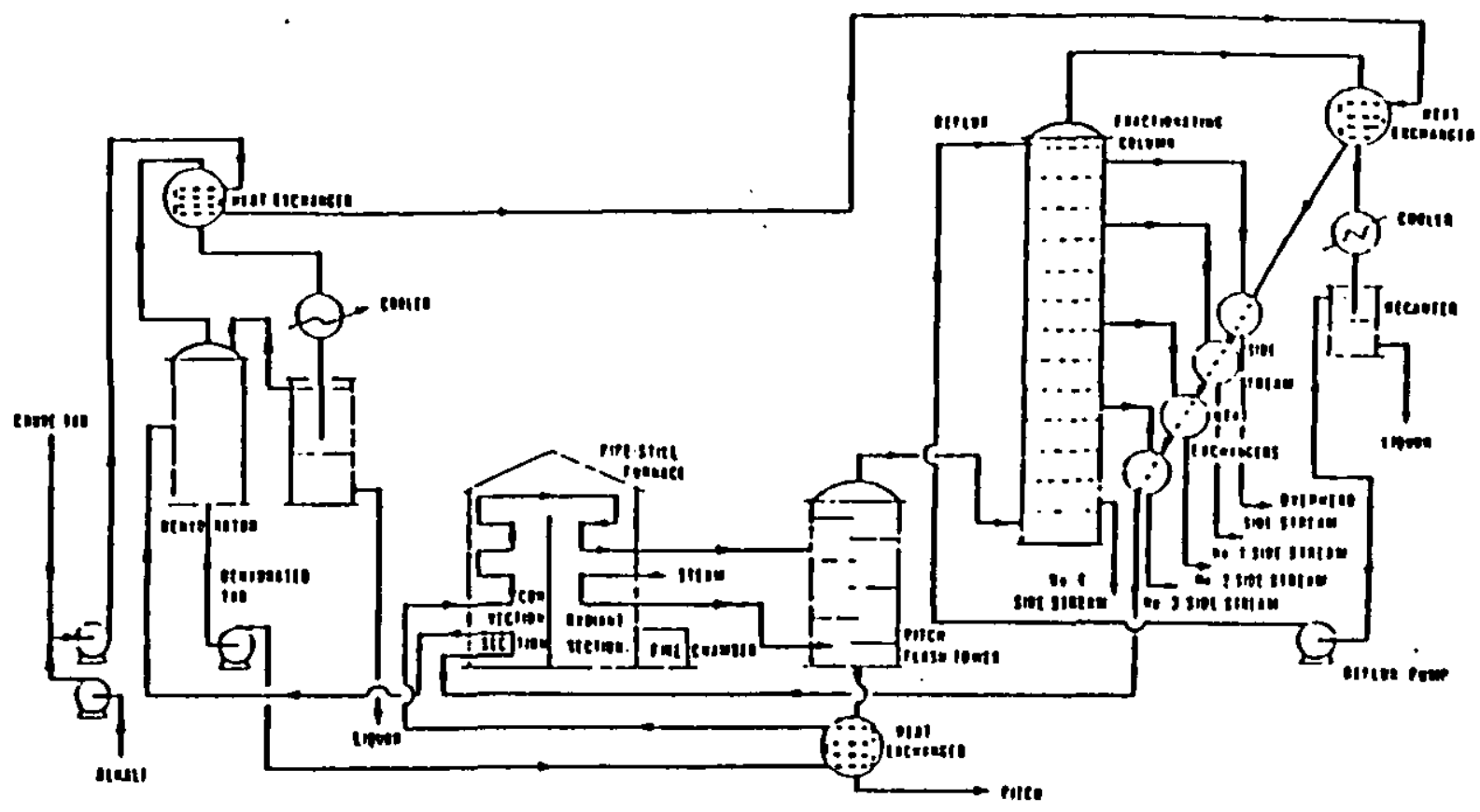

FIG.2.I. ProAbd continuous tar distillation plant.

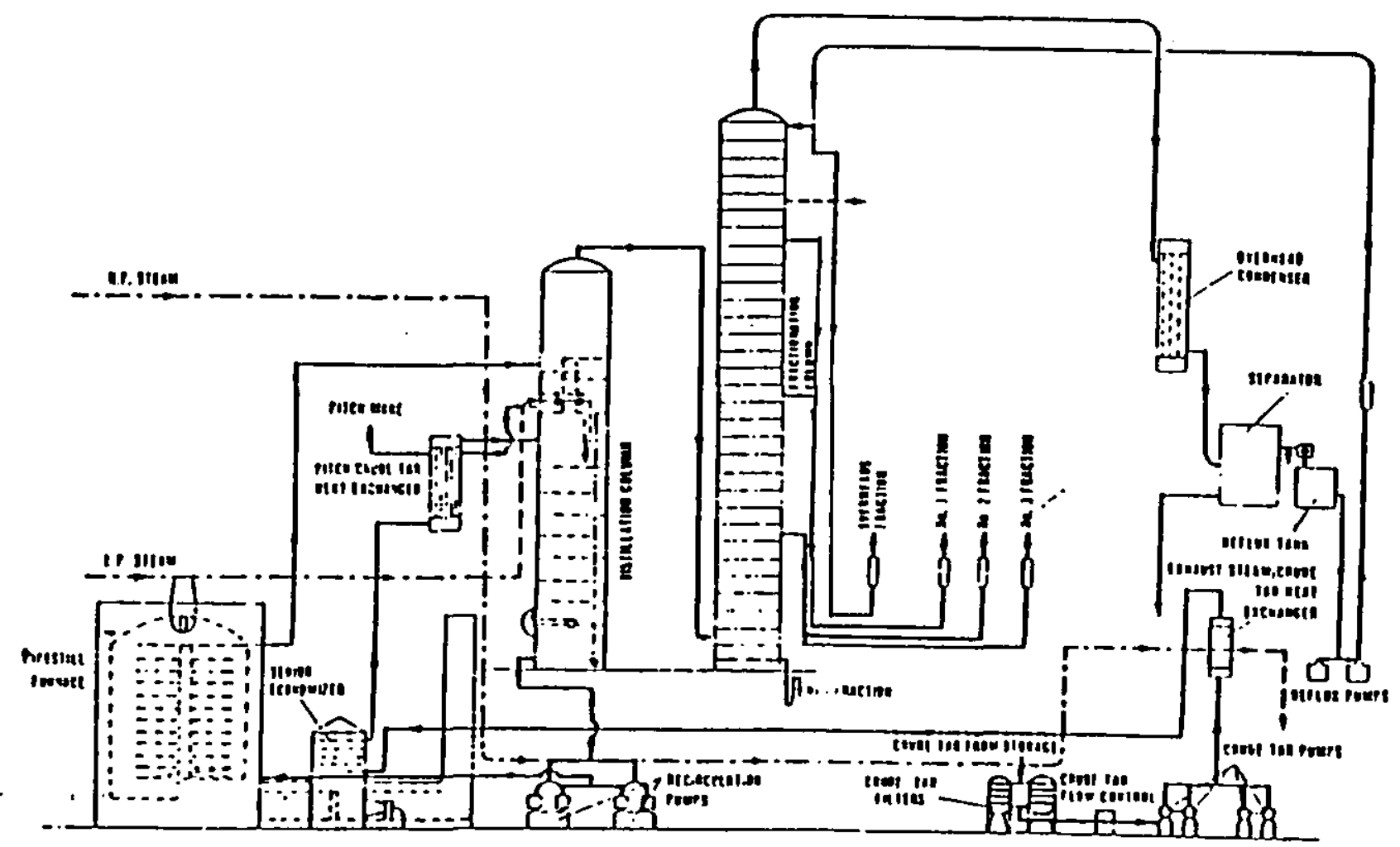

FIG.2.2. Willon continunus tar distillation plant with two-section distillation columnn. 


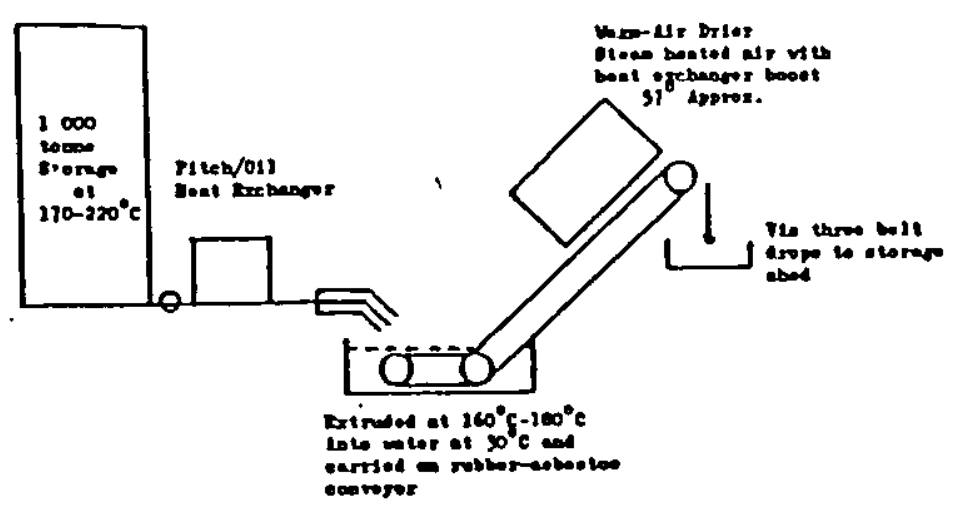

FIG.2.3. Schematic diagram of pitch pencilling plant.

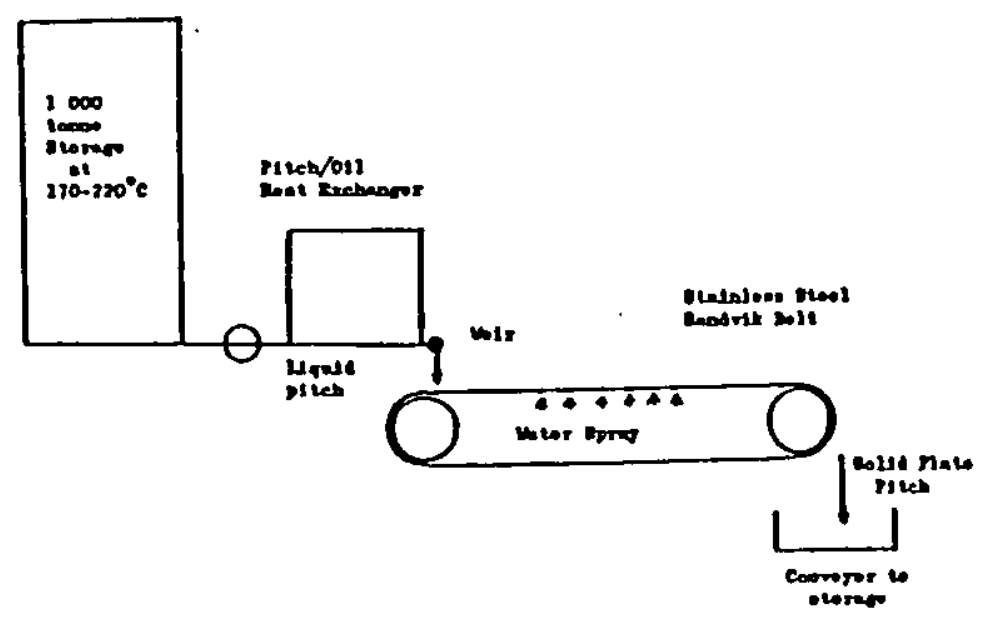

FIG.2.4. Schematic diagram of pitch conditioning plant. 


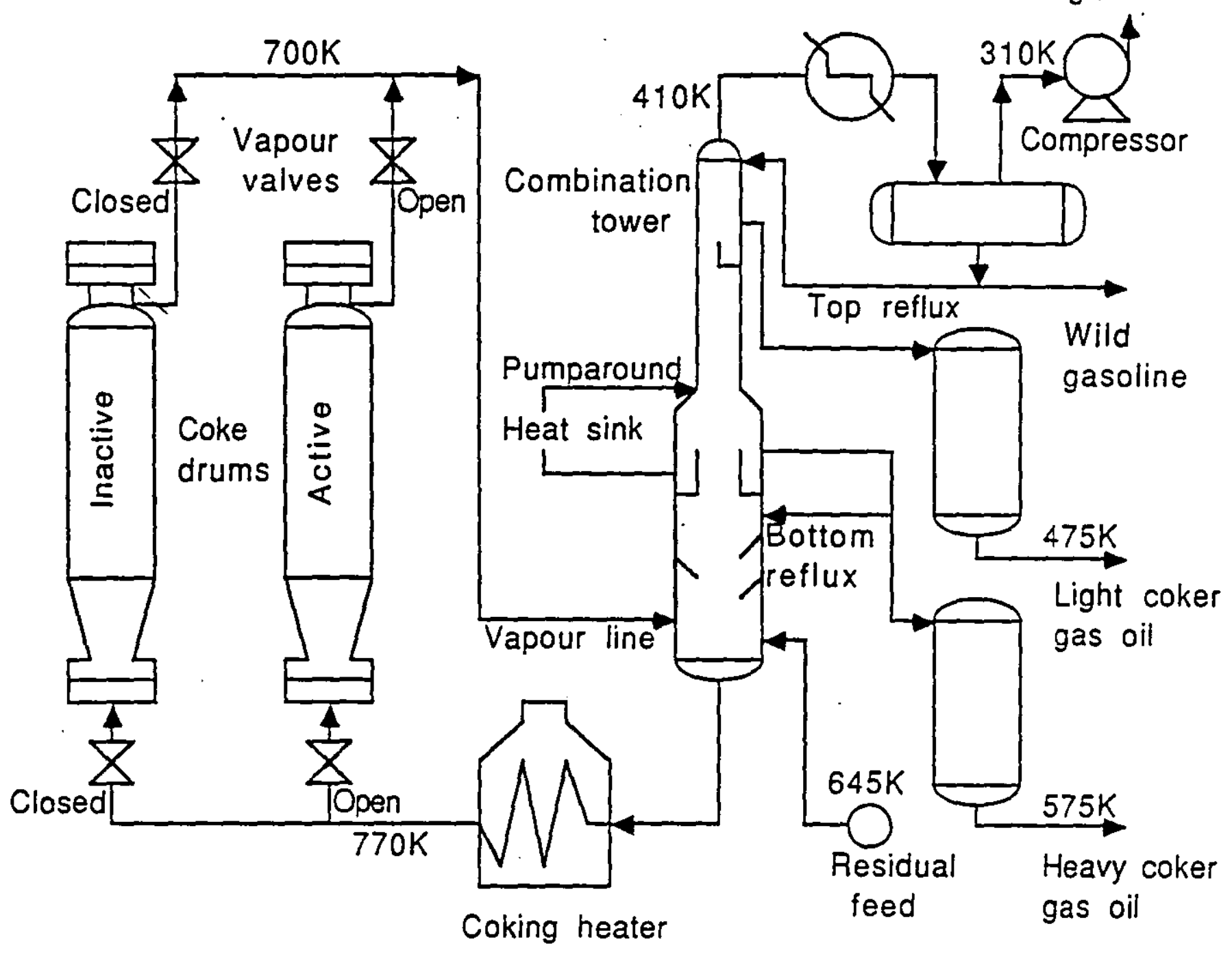

FIG.2.5. Schematic diagram of delayed coker operation. 


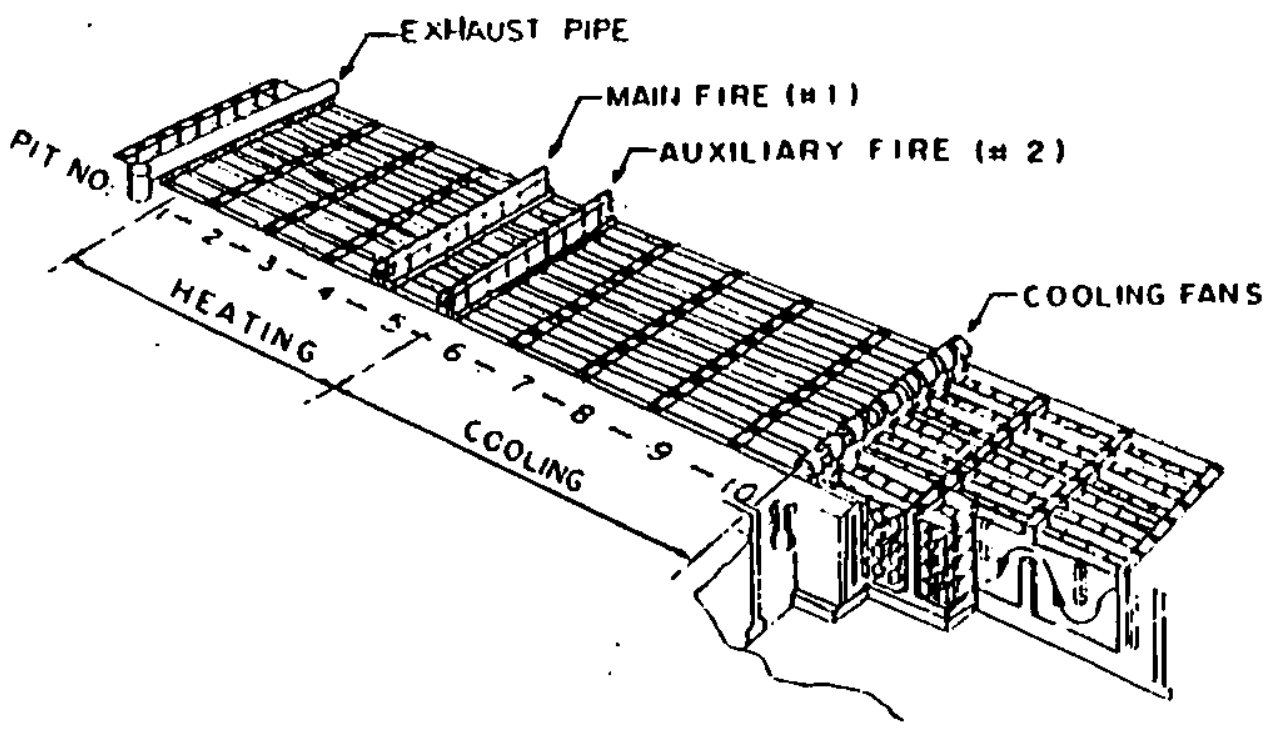

FIG.2.6. A three-dimensional sketch of a baking group of the anode baking ring furnace.

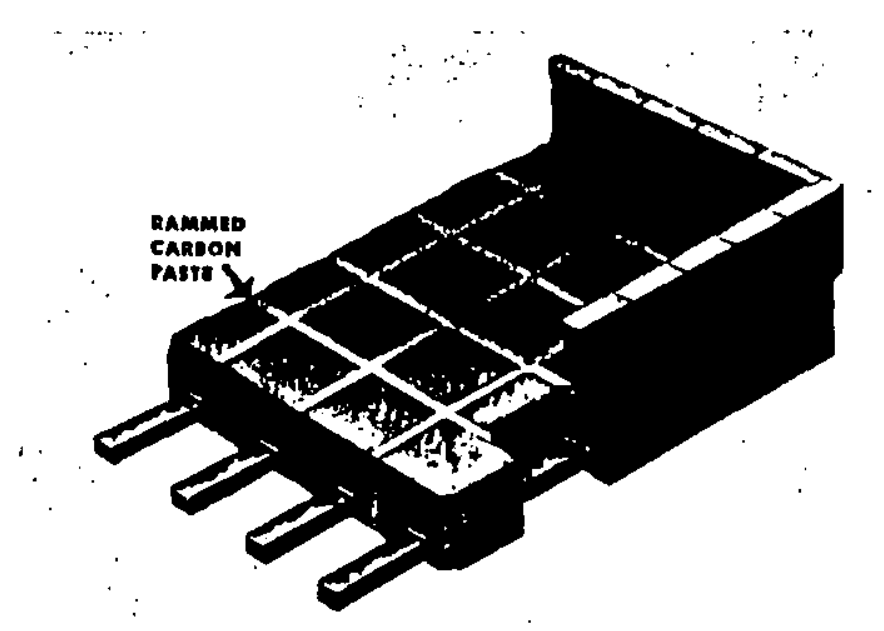

FIG.2.7. Aluminium cell lined with carbon boltom and sidewall blocks. 


\section{STRUCTURE OF CARBONS}

This Chapter introduces the basic structural features of carbon materials, briefly describes the various carbon forms encountered and reviews some of the principal techniques by which the structure of solid carbons can be investigated. For example, by utilizing techniques such as optical and scanning electron microscopy, etc., the structural features of carbon materials can be elucidated at various levels of resolution. For instance, the degree of ordering at the micrometre level can be determined using optical microscopy while electron microscopy can be used to reveal the structure at the graphitic plane level. Image analysis is briefly discussed as a useful tool in carbon porosity measurements. Attention is also given to intercalation of sodium and potassium in carbons with the emphasis on sodium intercalation as a possible explanation of the disruption of anodes when in contact with sodium during aluminium processing.

\subsection{Graphite}

The element carbon has an atomic weight of 12.011 and is element number 6 . With its central position in the first full row of the periodic table, carbon exhibits unique bonding possibilities. In essence, these are relatively simple without the complication of d-orbital involvement. The electronic ground state $1 s^{2}, 2 s^{2}, 2 p^{2}$ is almost unknown because of the energetic advantage of involving all four outer orbital electrons in bonding between carbon atoms themselves, or with other atoms. In fact, carbon displays catenation (bonding to itself) to a unique degree, resulting in structures of chains, rings and networks of carbons.

The formation of $\sigma$ - and $\pi$-bonds between carbon atoms and with other atoms (eg. $\mathrm{N}, \mathrm{O}$, etc.) leads to the possibility of extensive and complex structures. There are two ways of treating the bonding in carbon compounds which give more or less the same results as far as descriptions of the structures are concerned. The first invokes the principle of hybridization where the orbitals in the outer shell are mixed together to form hybrids:- 
One s- and three p-orbitals

$$
\begin{array}{ll}
\rightarrow & \text { Two } s p-\text { and two } p \text {-orbitals } \\
\rightarrow & \text { Three } \mathrm{sp}^{2} \text { - and one p-orbitals } \\
\rightarrow & \text { Four } \mathrm{sp}^{3} \text {-orbitals }
\end{array}
$$

The hybrid orbitals can then be assumed to link with compatible orbitals on other atoms to form o-bonds while the p-orbitals are free to form $\pi$-bonds. The second approach is to consider the formation of molecular orbitals directly from the atomic orbitals. Two principle bonding regimes dominate carbon compounds:-

i. $\sigma$-bond - diamond or aliphatic type, leads to chains of carbon atoms (eg. paraffins) or three-dimensional structures which are quite rigid and isotropic.

ii. $\sigma$-bond and $\pi$-bond - graphite or aromatic type, where the majority of structures are layered with a high degree of anisotropy.

The two regularly ordered allotropes of carbon are graphite and diamond. Diamond is made up of a regular three-dimensional network of $\sigma$-bonds providing a very rigid, stable structure, where the bonding electrons are fixed between atoms so that electrical conductivity is very low.

In graphite, there is both $\sigma$ - and $\pi$-bonding holding the atoms in hexagonal two-dimensional networks. These layers are held rather loosely together by van der Waals forces. The stacking of the layers is principally - A.B.A.B, the hexagonal form, illustrated in Fig.3.1, with a small proportion $(<10 \%)$ in natural graphites stacked - A.B.C.A.B.C, ie. the rhombohedral form. The energy needed to slide the layers over one another is low making graphite a soft material which can be used as a lubricant.

The conjugated $\pi$-bonding of the layered structure results in the electrons being delocalised throughout the structure providing a means of conducting electricity similar to metallic conduction bands. Across the layers, however, there's no electron movement so conduction in this direction is a minimum. This is an excellent example of the anisotropy exhibited by graphite. 


\subsection{Graphitizing Carbons}

Carbon materials are, in general, a mixture of well-ordered material, often of short range $(<100 \mathrm{~nm})$, surrounded by less-ordered material. The principal parts of the more-ordered structures are essentially graphitic. Small volumes often have an almost perfect graphite lattice but, as the volume increases, the presence of defects, distortions and heteroatoms destroys the regularity giving material which is disordered. True single crystal graphite is very rare. All graphites contain defects within their structures, ie. stacking faults, dislocations, vacancies and interstitial atoms (48). (Stacking faults, leading to a ribbon of rhombohedral graphite within the overall hexagonal stacking, require no $\mathrm{C}-\mathrm{C}$ breakage. However, dislocations, of both line and screw types, necessitate the disruption of the lamellae. These, together with point defects, vacancies and impurities, explain the non-planarity of most of the carbon layers which make up carbon materials and are responsible for the crosslinking or pinning between the layers.) The study of defects is important for the understanding of mechanisms of gasification (49).

Most carbon materials are composites in that they are made up of entities which can be separately identified within the overall structure. The principal constituents can be said to be: (a) ordered or graphite-like where there is a high degree of anisotropy; (b) less-ordered where for most tests the structure is isotropic.

The processes of conversion of less-ordered into more-ordered material and can be achieved by heat treatment (carbonization), ageing or other energy input (graphitization). For example, non-graphitizable or hard carbons are those which cannot be transformed into graphitic carbon solely by heat treatment. Graphitizable or soft carbons are those which are so converted.

Non-graphitizable carbons are produced from wood, nut-shells and non-fusing coals. Essentially, the macromolecular (polymeric) structure of these materials remains during heat treatment only losing small molecules by degradation and developing even more cross-linking so that fusion cannot take place. The loss of small molecules and the retention of the complex macromolecular structure leads to high microporosity, with surface areas in the order of $1000 \mathrm{~m}^{2} \mathrm{~g}^{-1}$. 
Most graphitizable carbons pass through a fluid stage during carbonization (see Chapter 4). This allows large aromatic molecules to align with each other so forming the mesophase (discotic nematic liquid crystal) precursor of the graphitic structure (50). Variation in carbons occurs due to the variation in reactivity of the molecules of the parent materials which controls the sizes and shapes of the intermediate liquid crystals (mesophase). Surface areas are often much less than $10 \mathrm{~m}^{2} \mathrm{~g}^{-1}$. The progressive increase in order during carbonization of a material, such as pitch coke, resulting in a highly graphitic carbon serves to illustrate the range of structures encountered, Fig.3.2 (51).

The ordered material within carbons can be thought of as crystallites of graphite and, by measuring the size of these crystallites, an estimate of the range of order can be made.

The kind and range of ordering considered within the structures may depend upon the investigating technique used. The degree of isotropy and anisotropy present in carbon materials is of importance when attempting to assess their properties and performance. For example, macroscopic properties of many carbons are isotropic while, on a microscopic level, the structure presents a high degree of anisotropy. Also the individual parts of the structure may be anisotropic to one examination technique but isotropic to another. An example of this is the optical texture of a carbon when compared with its electron microscope image. Using optical microscopes, features with dimensions less than $\sim 0.5 \mu \mathrm{m}$ can't be resolved and, therefore, some parts are described as isotropic when the electron microscope shows these to be highly anisotropic at the nanometre level.

Heteroatoms within the carbon skeleton are another manifestation of disorder, in this case, at the molecular level. Hydrogen, oxygen, nitrogen, sulphur and halogens are present to some extent in nearly all natural sources of carbon materials. The presence of the other material, such as mineral inclusions or metallic particles, add to the amount of disorder in carbons. 


\subsection{Intercalation of Sodium and Potassium in Carbons}

Another aspect which is a consequence of the layered structure of graphite is that atoms, groups and molecules can be intercalated between the carbon layers (52). In some cases, stoichiometric compounds are formed with graphite (Fig.3.3) while, in very disordered carbons with distorted lamellae (turbostratic structure), intercalation can be considered as a special case of adsorption in ultra-microporosity. That is, it seems illusory to try to distinguish the condensation of a metal in this porosity (where the walls are to a great extent graphitic layers) from intercalation.

Furthermore, the adsorbed species loses its crystalline properties, and there seems to be an electron transfer as in intercalation (53) between the metal and the carbon. It follows that one cannot consider the modification of the electronic properties, the absence of characteristic diffraction lines, or the absence of a differential thermal analysis meiting signal as sure tests of intercalation.

One definition of the term "intercalation", of practical interest in the study of the behaviour of carbon materials, can be used when a reactive species is inserted between graphitic layers which have not been moved aside prior to the reaction. Intercalation is then characterised by a finite deformation of the carbon, which is usually reversible. On the other hand, the filling of the porosity causes much smaller deformations of the carbons. Therefore, $x$-ray crystallography, which is able to show an increase in the average distance between the layers in a carbon, is a direct method of detecting intercalation reactions. Macroscopic effects measured by dilatometry are not reliable since the increase in the crystallites dimensions may be accommodated by the porosity. For a perfect graphite crystal, an intercalation compound is said to be of the $n$th stage when two reactive layers are separated by $n$ carbons layers.

Potassium intercalates in all varieties of carbon. An $x$-ray investigation by Berger et al (54) shows clearly that the potassium/soft carbon compounds are similar to the potassium-graphite compounds, i.e., the first stage has an octal structure, and the second stage has a liquid-like intercalate structure. Large quantities of potassium are sorbed by hard carbons. The $x$-ray investigation showed that this reaction leads to intercalation compounds similar to the compounds formed with nongraphitized soft carbons. However, the reaction products are heterogeneous. 
The structure of the intercalate layer is more compact than the octal structure of the saturated compounds. The presence of an amorphous part of the carbon which is not involved in the reaction could explain the shortage of metal fixation. The volume increase caused by intercalation is mainly absorbed by the coke porosity. The octal structure disappears in the higher-stage compounds as it does with graphite.

The behaviour of sodium in relation to carbons varies markedly, depending on the structure and the specimens texture, This represents a striking difference between sodium and potassium.

The sodium uptake in graphitizable carbons is due mainly to intercalation. Adsorption and capillary condensation could account for only an insignificant fraction of the sodium content since these carbons have a very small microporosity. Adsorption occurs with all graphitic carbons. The phenomenon becomes especially important for carbons of large specific area, for example, microporous hard carbons. In the latter, sodium enters a part of the so-called inaccessible porosity (the amorphous part of the carbon) at temperatures as low as a few hundred degrees centigrade. At $600^{\circ} \mathrm{C}$ the monolayer is completed at a relative pressure of 0.10 , and then the filling and saturation of microporosity occurs.

Intercalation depends on both the graphitizability and the heat treatment temperature. Intercalation is more easily achieved in soft carbons, but it does take place in some hard carbons. It is favoured in both classes of carbons by a lowering of the heat treatment temperature, which is probably related to a lowering of the Fermi level.

Table 3.1 summarises the results of the action of the saturated vapour of sodium or potassium on the two classes of solid carbons, eg. soft carbons: petroleum coke, anthracene coke, etc; hard carbons: saccharose coke, polyvinylidene chloride coke, etc. Due to the use of different wellcharacterised samples by Berger et al (54), these results can be considered to be general. The ability of carbons to form intercalation compounds was long contested, then established in particular cases, and finally generalised. On the other hand, there are important differences between sodium and potassium. Potassium, which is very electropositive (first ionisation at $4.32 \mathrm{~V}$ ), attempts 
to give its electron to the graphitic layers, however disordered they may be. The affinity of the reaction is so high that it can overcome the mechanical stresses which are opposed to layer separation. All carbons should be able to give first-stage compounds, adsorption being negligible. However, sodium intercalation (first ionisation at $5.12 \mathrm{~V}$ ) is sensitive both to heat treatment temperature (which determines the organisation and the Fermi level) and to mechanical stresses. From this ensues a complex behaviour in which the intercalation process can be replaced by considerable adsorption.

The above discussion can be used to explain both the disruption of carbon anodes which are in contact with sodium during the processing of aluminium, and also the large quantities of potassium trapped by nongraphitised carbons.

\subsection{Polarized-Light Microscopy of Carbons}

The ease with which the components of a carbon anode can be identified varies with the nature of the original carbon form and the subsequent processing of the material. In some cases, simple optical microscopic examination is sufficient, identifying differences in the optical texture or morphology of the components, eg. in green anodes, the binder-pitch semi-coke can be distinguished from the grist or filler coke.

For many years, the optical microscope has proved extremely useful in studies, using polarized light, of the optical texture, i.e. the surface appearance or the anisotropic structural components in carbons and cokes (55). The size of these anisotropic structural components, when viewed in polished section, varies from less than $1 \mu \mathrm{m}$ to over $300 \mu \mathrm{m}$. The size and shape of these components or isochromatic areas constitute the optical texture. The mechanism of formation of these anisotropic components, large and small, from the fluid phase of carbonization is generally via the nematic liquid crystal and mesophase (56).

When a polished section of an anisotropic carbon is viewed in plane polarized light, with the polarizer and the analyzer crossed, Fig.3.4, then patterns of extinction contours are to be seen. Extinction contours are black lines defining the loci of points where the layer planes lie either parallel or perpendicular to the polarizing plane of the incident light. Using a rotating stage it is possible to map out how the stacking of the structural planes i.e. the lamelliform structure, varies within the material (57). For example, for pitch coke, 
bends, splays, folds and lamellar stacking defects are indicated but nothing resembling a grain boundary can be detected (57). Alignment of lamellae circumferentially to pore surfaces has been demonstrated (58).

The directions in which the maximum and minimum optical properties, eg. reflectance, refraction and absorbance are observed, are termed the slow and fast directions respectively, the terms relating to the speed of light. When no retarder plate is used, isotropic-crystal surfaces appear grey whatever their orientation on the microscope stage. Anisotropic-crystal surfaces however exhibit a variation in shading depending on the orientation of the slow direction of the crystal relative to the vibration direction of the incident light. If the slow direction is perpendicular to the vibration direction, minimum reflection occurs; if parallel, reflected light is blocked by the analyser filter in the reflected light path. Crystals so orientated thus appear dark while those aligned at $45^{\circ}$ to the vibration direction appear bright. Intermediate alignments result in grey shades.

A related technique which employs a retarder plate in the optical system has been increasingly used in recent years. This technique allows an assessment of the orientation of the lamelliform structures at the surface because different orientations have different colours, e.g. yellow, blue and various purples. Fig.3.4 shows diagrams illustrating the generation of the interference colours. It has been found that a purple coloration originates at a surface of isotropic carbon or when the basal planes are parallel to the polished surface, this coloration being unchanged by rotation of the specimen stage of the microscope. Yellow and blue colours are seen when a prismatic edge is presented at the surface. A rotation of the microscope specimen stage by $90^{\circ}$ will change a yellow colour into a blue colour (through an intermediate purple). Changes in orientation over the surface can thus be assessed by noting how the colours change.

Honda et al. $(59,60)$ use the term pleochroism to describe the colours which are seen when a gypsum plate is used in the microscope with crossed-polars. Reflection pleochroism is a phenomenon which occurs when a polished surface of absorbing, anisotropic material is viewed by reflected polarized light. The ordinary (slow) and extraordinary (fast) waves, which have perpendicular polarization directions, have different reflectivities. This means that different wavelengths of light will be preferentially absorbed in the two principal or 
slow and fast directions leading to different colours seen in the reflected light. The colour derives from the destruction, by interference, of certain parts of the spectrum. On rotation of the specimen relative to the incident polarization plane the colour will vary between the colours seen for the two principal directions. Rather than "reflection pleochroism" (based on analogy with colours seen in transmitted light) the term "dispersion of the bireflection", which illustrates the mechanism, is technically more correct.

Sensitive tint (61) describes the technique when a thin section of an anisotropic material (eg. quartz) is cut, resulting in the path difference of transmitted light in the two principal directions being exactly one wavelength for light of one particular wavelength. This wavelength $\lambda_{0}$ can be chosen by varying the plate thickness. Either a $\lambda$-plate or a $\lambda / 4$-plate is used with crossed polars and a $\lambda / 2$-plate with parallel polars. If $\lambda_{0}$ is chosen in the middle of the visible spectrum, ie. $\lambda_{0}$ corresponds to green light, and this plate is inserted at $45^{\circ}$ between two crossed polarizing plates, the light intensity of wavelength $\lambda_{0}$ is reduced to zero the light colour is purple. Different choices of

$\lambda_{0}$ can be made and it is found that some are more "sensitive" than others, ie. a more rapid colour change from purple to red or blue.

\subsection{Electron Microscopy (SEM and TEM)}

Both the two major types of electron microscopical examination of carbons present opportunities for structural study and, equally, problems in specimen preparation and interpretation of the images produced.

Scanning electron microscopy (SEM) uses the scattering of electrons from the surface of the sample to reveal the topography of the material (see Fig.3.5). It also utilises. the scattering power of different materials to distinguish them. Gold coating the specimens, to eliminate charging, gives a much better resolution of the topographical features. Unfortunately, this procedure cannot be used in conjunction with another useful SEM facility which uses the interaction of the electron beam with some of the surface atoms (up to $100 \mathrm{~nm}$ deep) to give $X$-rays which can be analysed to reveal the surface composition. One such technique uses energy dispersal to analyse the $X$-rays emitted and is usually called EDAX. This technique is limited in most general instruments to elements of higher atomic weight than fluorine. 
Carbon surfaces which have been polished for optical microscopy and those where subsequent heat treatment has produced a relatively uniform optical texture show very few features in a SEM examination (no topography). However, etching the surface either chemically (with chromic acid) or by ion bombardment reveals a wealth of detail which can be related to the optical texture of the sample. A specialised application of this is the "same area" technique where a specific part of a polished surface which has been identified and characterized optically is re-examined by SEM following etching.

SEM is an excellent method for monitoring the changes in topography following various treatments, such as - gasification, heat treatment, etc. For example, etching of the polished surface followed by SEM examination can reveal the differences in reactivity of the binder pitch coke and petroleum filler coke in carbon anodes.

Transmission electron microscopy (TEM) provides a means of obtaining high resolution images of carbon material. Figure 3.5 includes an outline of the general arrangement of a transmission electron microscope.

The preparation techniques for TEM are quite difficult. It is necessary to obtain a very thin section of the carbon, less than $100 \mathrm{~nm}$, of a uniform thickness. Specimen breakage can often give good results but this should be treated with caution as it can lead to random variations in thickness which cannot be fully interpreted in terms of the image produced. A more controlled method of producing suitable material is by cutting a thin section with a microtome and further thinning the centre portion by ion bombardment. The uniform thickness is important because, in these investigations, it is the variation in the amount of material through which the electron beam passes that provides the image contrast and fringe imaging can be an artifact of a tapered sample. When the conditions are correctly established, high resolution TEM can provide direct imaging of the layer planes in carbon materials, to reveal the complexity of the most regular structures and the ordering present down to the nanometre level (62). Figs.3.6 and 3.7 are micrographs showing the resolution of layer planes in both highly ordered and less ordered material obtained by high resolution transmission electron microscope (HRTEM). 


\subsection{Image Analysis}

The limiting resolution of the optical microscope is about $0.3 \mu \mathrm{m}$, so that large macropores in carbons can be observed in flat, polished sections using reflected light. Such images contain information on two-dimensional structure parameters which can be extracted manually using point and line counting techniques, but the procedures are extremely laborious, since a large number of pores must be measured to ensure that results are statistically significant. In recent years the development of automated, quantitative image analysis has rendered manual methods obsolete (63). The essential principles of computerbased image analysis are illustrated in Fig 3.8. The sample to be studied is viewed by a TV camera mounted in this instance on an optical microscope. This produces an image in which contrast is revealed by a range of grey levels from black to white. The signal from the camera is directed to a computer, and the grey image is converted to a binary image by a process called segmentation. In it the features of interest are identified by a narrow range of grey levels which are selected as white (or a colour) in the binary image, all other grey levels being black. The binary image consists of a two-dimensional matrix of picture elements, 'pixels', which are either switched on in the white regions or off in the black regions. This image can then be processed by a computer. In principle the method may also be applied to mesopores and micropores using electron microscopical images.

The main advantage of this technique is that, unlike other methods such as mercury porosimetry, a model pore structure does not initially have to be assumed. Image analysis can provide measurements such as macropore shape factors and spatial distributions, which can not be obtained by other methods. Another useful application is the study of local variations in porosity within a sample. This approach has been applied to the present study of the gasification of anode carbons. The principal limitation of this method is that the information obtained relates to a two-dimensional image of a three dimensional object. 
TABLE 3.1. Action of saturated vapour of sodium or potassium on solid carbons.

\begin{tabular}{|c|c|c|}
\hline & Soft carbons & Hard carbons \\
\hline Potassium & $\begin{array}{l}\text { Massive intercalation, first } \\
\text { stage } \mathrm{KC}_{6} \text { through } K \mathrm{C}_{8} \text { for } \\
\text { all HTT } \\
\text { Almust no adsorption, de- } \\
\text { crensin: with HTT }\end{array}$ & $\begin{array}{l}\text { Massive intercalation, first } \\
\text { stage around } \mathrm{KC}_{20} \text { for all HTT } \\
\text { Limited adsorption, }\end{array}$ \\
\hline Sodium & $\begin{array}{l}\text { Massive intercalation, first } \\
\text { stape NaC f fur HTT } 650^{\circ} \mathrm{C} \text {; } \\
\text { decreases with HTT, zero } \\
\text { for pure graphite } \\
\text { limited adsorption decreasing } \\
\text { with HTT }\end{array}$ & $\begin{array}{l}\text { Limiled intercalation for HTT } \\
\text { lower than } 1500^{\circ} \mathrm{C} \text {, neglingible } \\
\text { above } 1500^{\circ} \mathrm{C} \\
\text { Adsurption and capillary con- } \\
\text { densation; sometimes crystal- } \\
\text { lized metal in big purcs }\end{array}$ \\
\hline
\end{tabular}




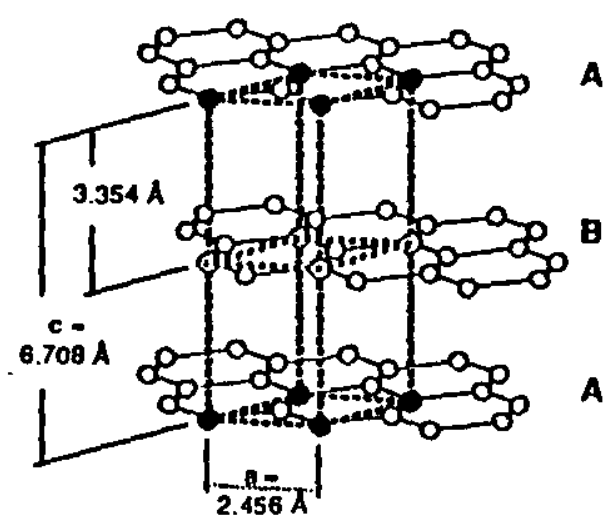

Hexagonal Unit Cell

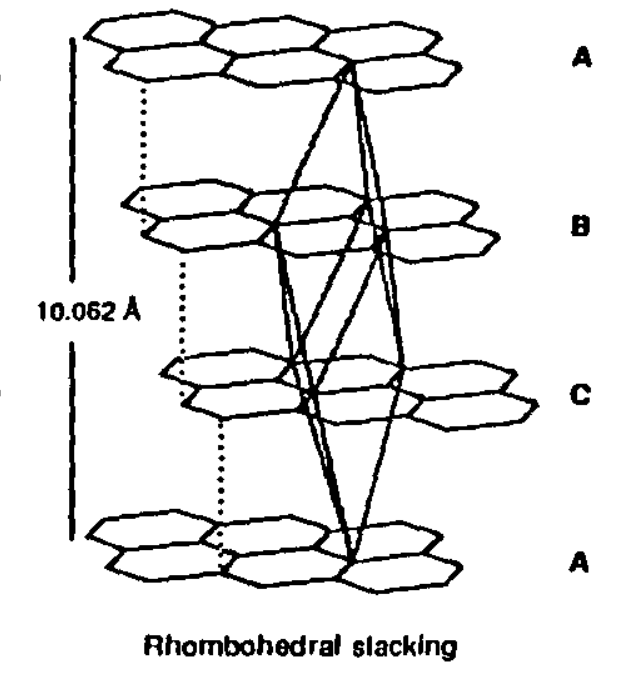

FIG.3.1. Graphite structure.

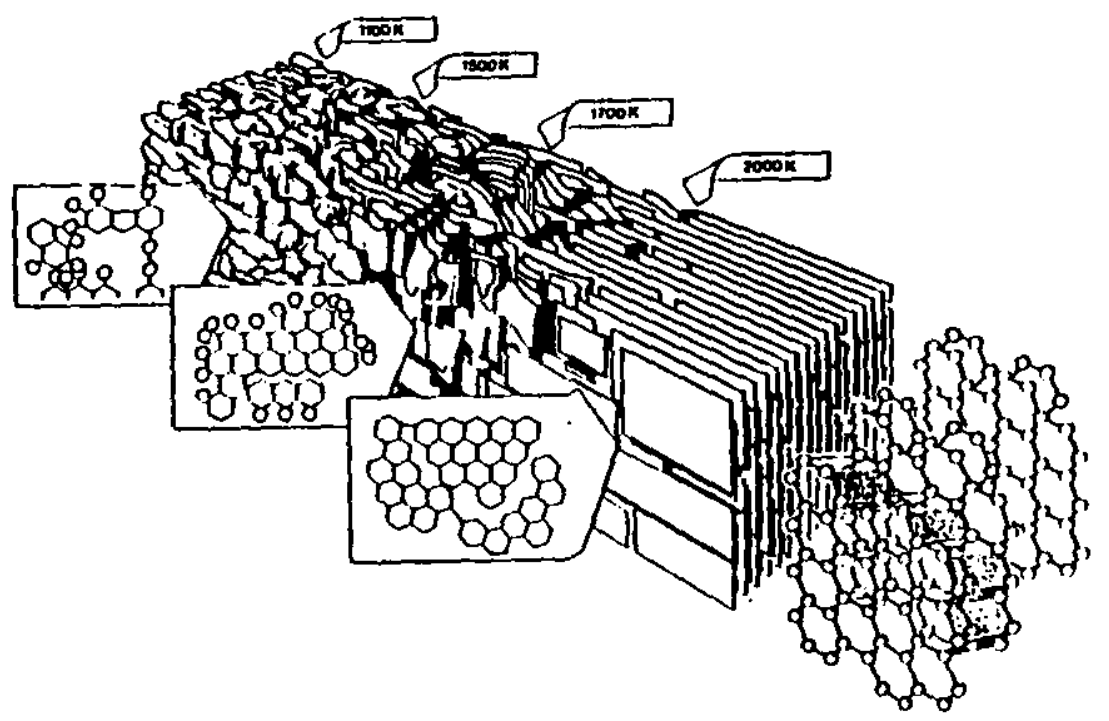

FIG.3.2. Marsh-Griffiths model of carbonisation/graphitisation process. 


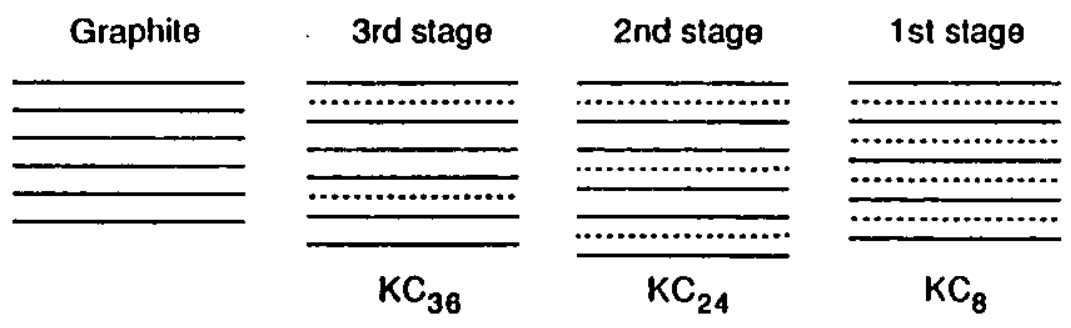

FIG.3.3. Intercalation of potassium in graphite.

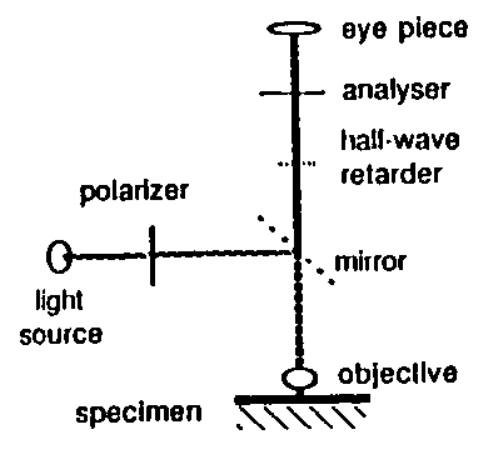

General arrangement

of microscope

for reftectance

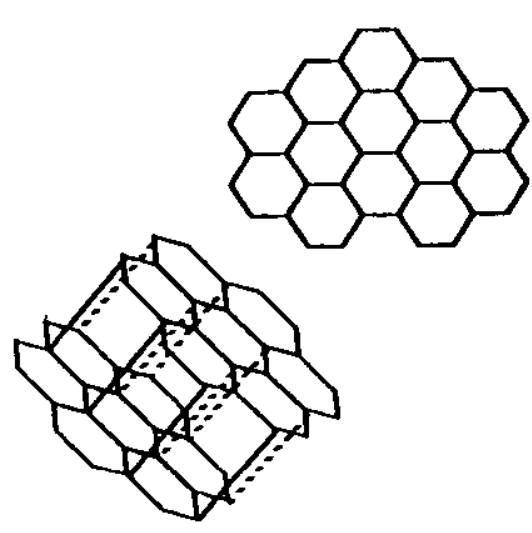

BLUE

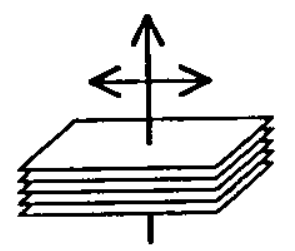

Basal plane tnteraction, near maximum

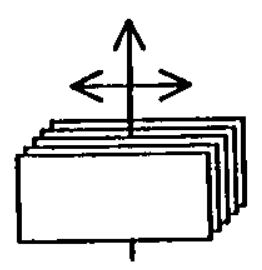

Maximum inleraction: polarisation $/ 10$ planes polarisation $\perp$ to planes

or

PURPLE

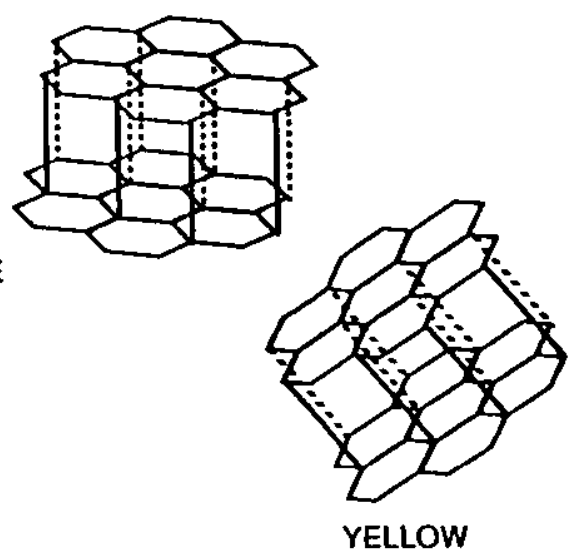

FlG.3.4. Polarised light optical microscopy and interference colours. 

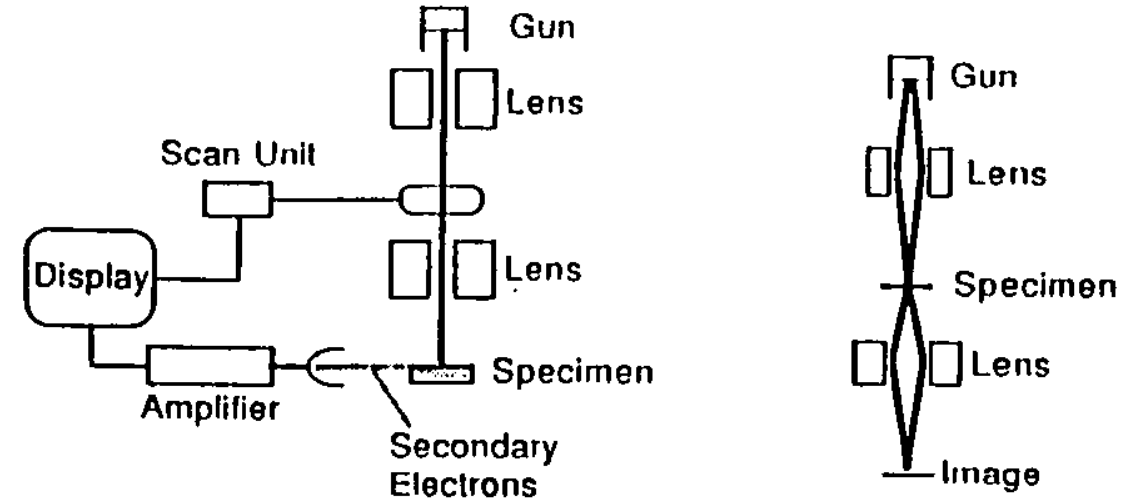

FIG.3.5. Scanning electron microscopy and transmission electron microscopy.

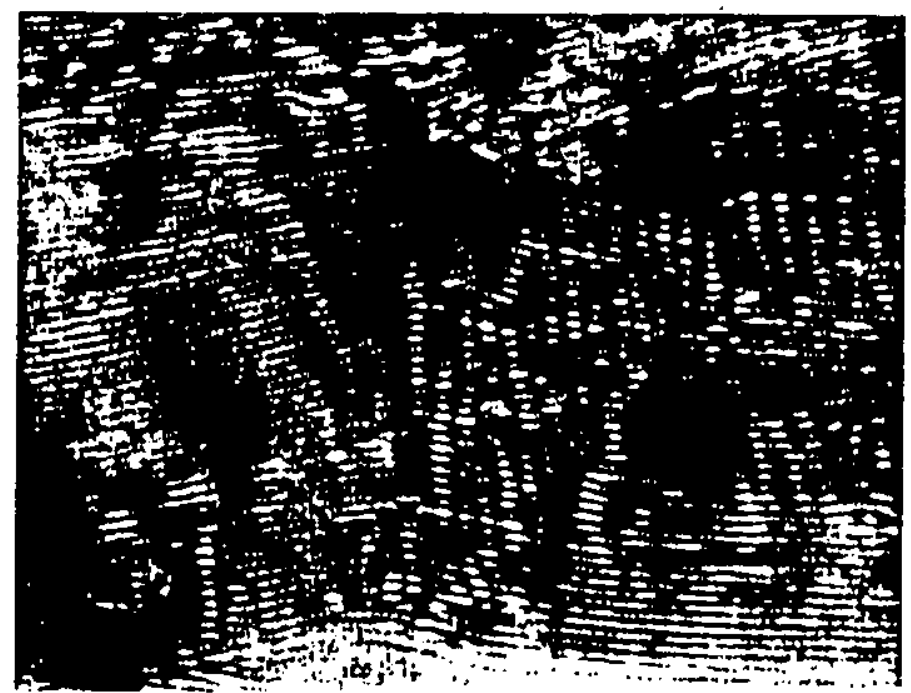

FlG.3.6. HRTEM micrograph of highly graphitic carbon - highly ordered. 


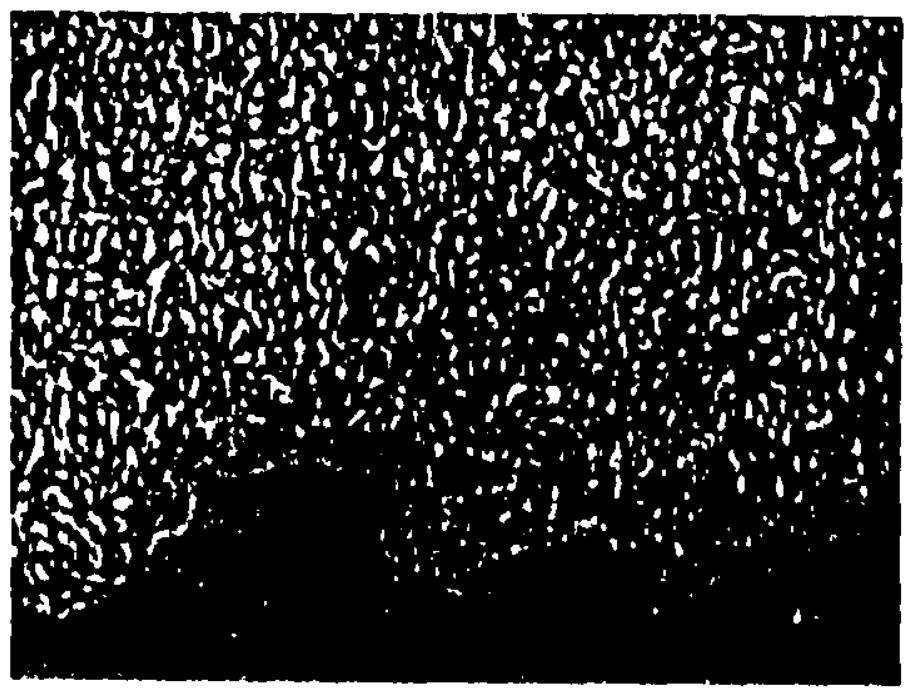

FIG.3.7. HRTEM micrograph of PVDC carbon (IITT 1473K) - disordered.

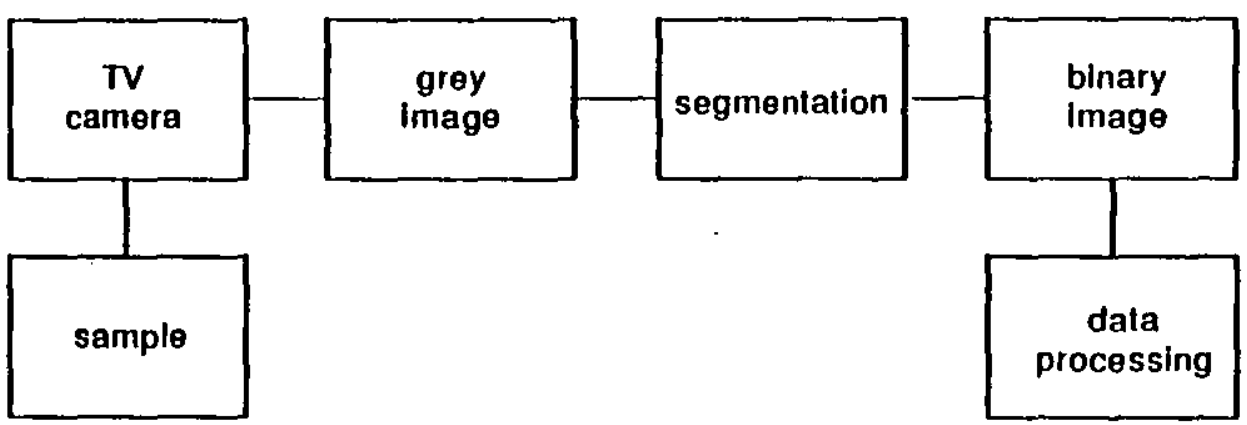

FIG.3.8. The principles of image analysis. 


\section{THE FORMATION OF GRAPHITIZING CARBONS}

\subsection{Early Studies of Coke Texture}

The present understanding of the origin of the texture of cokes and other graphitizing carbons stemmed from the study by Taylor of a heat-affected coal seam in New South Wales (64). As the igneous intrusion was approached, progressively larger optically-anisotropic spheres were observed in the isotropic vitrinite matrix. The structure shown in Fig.4.1 was one of two proposed to account for the variation in appearance of the spheres when the specimen stage was rotated.

Foliowing this pioneering study, investigations were extended, in the early nineteen-sixties by Brooks and Taylor (55) to the study of many carbonaceous feedstocks. These findings opened a new phase in carbonization research which attracted many workers, notable contributions to the literature being made by White $(65,58)$ for his studies of petroleum residues, Marsh $(56,66)$ for his wide-ranging studies of various materials including coals, and by Patrick et al for his extensive work on coal cokes $(67,68,69)$. From such studies, it is now evident that the carbonization behaviour of many materials which form graphitizing carbons falls within a general pattern. It is proposed to review this behaviour and its application to anode carbon production and petroleum coke formation.

\subsection{Formation of Graphitizing Carbons}

Studies of the formation of graphitizing carbons have usually involved heating the chosen precursor at constant rate to selected temperatures within the plastic range, cooling, and examining the product after embedding in resin and polishing (57). However for carbonizing pitches, similar results have been obtained spectacularly by combining cine-photography with hot-stage microscopy (70). Materials reported to conform to the general pattern of behaviour include coal-tar pitches $(55,66)$, petroleum tars and residues (65), solvent-refined coals (66), some polymers eg. poly-vinyl chloride $(55,66)$, and poly-aromatic compounds eg. anthracene and phenanthrene (66). Although quite different in character, all these materials decompose during pyrolysis to give optically-isotropic pitch-like materials which are 
fluid at elevated temperatures, between $400-500^{\circ} \mathrm{C}(66)$. The chemical variety of precursors also suggests that mesophase formation is not sensitive to details of the structure of the constituent molecules (66).

\subsection{Mesophase Development}

Mesophase is not 'precipitated' from pitch solution, rather it's the growth of a new phase by homogeneous nucleation. It does not occur because of insolubility of larger molecules within the pitch but because there's a preference for the formation of liquid crystal phase with its higher stability. Mesophase growth cannot be 'seeded' as can solid crystals from supersaturated solutions. Attempts have been made to 'seed' mesophase growth by carbon blacks but without success.

Liquid crystals have been known from about 1888. Until the recognition of the disc-like nematic liquid crystal formed from pitch, the traditional liquid crystals were all based on polar rod-like molecules. Using essentially molecular engineering techniques a family of rod-like molecules has been synthesized with a range of physical properties, as used in liquid crystal display (LCD) systems. These materials can exist as conventional crystalline solids. However, on heating, they don't pass through a conventional melting point to an isotropic Newtonian liquid, but change into the liquid crystal state. This phenomenon is truly reversible and is known as thermotropy. Here, there are sufficient molecular-molecular interactions to maintain significant structural order and yet sufficient energy to promote liquid or flow properties. Hence, the apparent contradiction of fluid crystallinity. Liquid crystals, for a limited class of molecules only, represent a rather unique equilibrium between molecular kinetic energy and molecular cohesion.

In comparisons with pitch systems, the molecules of mesophase from the pitch are not rod-like but disc-like (discotic) with molecular weights greater than about 500 a.m.u. Molecular cohesion originates not from the dipole interactions of the rod-like molecules but from the van der Waals' forces of overlap of such large molecules.

It has to be appreciated firmly, that, unlike traditional liquid crystals, the liquid crystal forming molecules in pitch (the so-called mesogens) have (a) to be synthesized during the pyrolysis of pitch and (b) these molecules are not 
chemically stable but will continue the macromolecular growth processes. As a result, a continuing kinetic process is established over and above the traditional properties of liquid crystals. A delicate balance of intermolecular reactivities is maintained. Whereas for resin materials reactivity is high and, following carbonization, isotropic non-graphitizing carbons result, with the aromatic pitches, significant macromolecular growth does not occur until after the process of liquid-crystal formation.

In the carbon anode, as it is calcined, the binder pitch will be changing as summarized in the following sequences:-

1. Pitch materials are dominantly aromatic materials with a complex molecular composition. Figure 4.2 , curve $T_{1}$, in diagrammatic form, illustrates the initial range of molecular weight of constituent molecules.

2 As pyrolysis proceeds, volatile matter of smaller molecular weight is lost (aliphatic side chains) and dehydrogenative polymerization reactions result in a shift of the distribution towards higher molecular weights, Fig.4.2, Curves $T_{2}, T_{3}$.

3. At the same time the viscosity of the pyrolysis of the pyrolysing system decreases with increasing heat treatment temperature (HTT). Pitches differ in this respect as shown in Fig.4.3 and discussed by Rand (71). As the viscosity decreases so the possibility of 'run-out' of the pitch from the anode mix will be enhanced. However, an inflexion occurs in the viscosity/HTT curves and it rises again because liquid crystals are forming.

4. The molecular growths and associated molecular cohesions are modelled in Figs.4.4a-4.4c. With increasing HTT so the average molecular weight increases as shown in Figs.4.4a, 4.4b. In the establishment of liquid crystal structures three factors are operating competitively:-

(i) the average molecular weight is increasing

(ii) the viscosity of the pitch material (matrix) is decreasing so increasing the diffusivity or mobility of molecules within the fluid pitch.

(iii) the system temperature is increasing so providing increased energy to the constituent molecules.

5. Liquid crystals will only appear when (a) the molecules size is sufficiently large to generate the intermolecular cohesion forces necessary to stabilize the molecular associations (b) the molecules mobility is sufficiently high to facilitate adequate rates of cohesion (c) there exists a sufficiently high concentration of mesogen molecules synthesized in the pitch and (d) when the HTT is not so high that kinetic energy effects can overcome the cohesion 
energies and the molecular associations are lost. This point is illustrated in Fig.4.5. The line $M N$ represents the pyrolysis process. At point $O$ of the intersection with the phase transition line $X Y$, mesophase will appear in the system. This point $O$ is variable and is a function of pitch composition and pyrolysis conditions. The higher the pyrolysis temperature, the the larger must be the molecular weight of the mesogens to maintain the cohesion of homogeneous nucleation. Consideration of Fig.4.2 now suggests that mesophases formed isothermally, but at different temperatures within a pyrolysing pitch, need not to be chemically similar.

6. Referring again to Fig.4.4c, this diagram shows the initial mesophase development as the mesogen molecules have sufficient size and hence cohesion energy to form stable associations of molecules by the process of homogeneous nucleation. The larger molecules establish the mesophase, but smaller molecules of the pitch matrix can be incorporated.

7. Figure 4.6 is a diagram to show how rates of mesophase formation are controlled chemically only at higher temperatures. However, as the pyrolysis temperature is lowered, a stage is reached when the increased system viscosity is sufficiently high to prevent adequate movement of molecules within the pitch. Accordingly mesophase growth is halted altogether. Figure 4.3 also relates to viscosity. Pitches $A, B, C$ will produce cokes of different structures, as discussed below.

\subsection{Structure of Mesophases}

The above section summarises the mechanism of initial development of mesophase. However, as the process continues isothermally with time or increasing HTT, so the sizes of the associations of molecules increase from a few nanometres to the micrometre size range. In pitch carbonizations, the mesophase appears as spheres about $1 \mu \mathrm{m}$ diameter, as seen by optical microscopy of polished surfaces (55). These spheres grow in size and can coalesce immediately on contact because of the low surface energies involved (72) to form a continuum or bulk mesophase. It has to be stressed that this bulk mesophase is a fluid phase and will move by thermal convection or by gas bubble displacement, etc. The variation of electron diffraction patterns across ultra-thin sections of spheres confirms that the constituent lamellar molecules, as shown in Fig.4.1, are aligned basically parallel to an equatorial plane but curve to meet the pitch interface with high angle (73). 
As the system is still kinectically active, the viscosity continuously increases (Fig.4.3) until finally the structures induced into the mesophase by flow and other movements, eg. the arrays of disclinations, folds, bends and splays, become incorporated into the formed, solid semi-coke. The structure formed depends on several factors: (i) the chemical composition of the pyrolysing system. (ii) the presence and size of solids. (iii) the heating rate. (iv) presence of factors such as convection currents and gas evolution. Furthermore, mesophase formation is influenced by the type (if any) of pretreatment used, such as solvent fractionation or hydrogenation. Also, the heattreatment conditions are significant; these include temperature, residence time, heating rate, gas-blowing rate and stirring rate.

By pitch selection or by pitch blending it is possible to influence the pyrolysis chemistry and mesophase development to create cokes of different optical textures. In general terms, the presence of reactive groupings attached to constituent molecules, including oxygen, sulphur and nitrogen, will promote a smaller size of optical texture. This is chemical modification. The presence of solid particles, the so-called inerts in pitch, will also cause a decrease in optical texture size of the resultant cokes and can be termed mechanical modification to mesophase growth and coalescence. Referring to Fig.4.3, pitch A would provide a coke with a smaller optical texture size than pitch $C$ because the higher viscosities of pitch A prevent extensive coalescence of mesophase developed therefrom.

\subsection{The Role of QI in Pitch Carbonization}

Coal-tar pitch, if free from quinoline-Insoluble (QI) material, will carbonise to a coke with a relatively large size of optical texture. But coal-tar pitches, as supplied as binder pitches, contain 10 to $20 \%$ of QI and this has a profound effect in reducing optical texture size. Naturally occurring primary QI material in coal-tar pitch is made up of solid particles carried over in the heated outlet systems of coke ovens. These particles range in size from about 10 nanometres to $1 \mu \mathrm{m}$ and are usually not associated within the pitch. Their morphology is described by Marsh et al. (74). Kremer (75) discusses the role of primary QI from an industrial viewpoint.

There is no doubt that primary QI influences the carbonization process of the coal-tar binder pitch. It has been suggested (55) that the mesophase growth 
process is nucleated by QI particles. However, current understanding of mesophase initiation processes, as discussed above, is that they are homogeneous nucleation processes and that primary QI has no role at this stage. Stadelhofer (76) made a study of the growth kinetics of mesophase from pitches containing different $\mathrm{Q}$ contents and found no evidence for nucleating mechanisms. This conclusion appears to be correct as QI material has never been reported within mesophase.

During the development stage of fluid mesophase spheres, the primary QI adheres to the surfaces of spheres and this physically prevents their coalescence into larger spheres and crystallites. Hence, the QI material causes a reduction in optical texture size in the resultant coke, so creating the necessary strength but compromising on electrical resistivity and reactivity.

Because of an expressed advantage in having QI material in pitch (75), some pitch producers have introduced a QI content into pitch by heating it to a higher temperature or related process, so creating mesophase spheres insoluble in quinoline. These do not have the size range or structure of the primary $\mathrm{QI}$ and by being a low temperature product, as distinct from the high temperature product $\left(1100^{\circ} \mathrm{C}\right)$ of primary QI, properties must be different. Pitch users appear willing to tolerate only a few percent (less than $3 \%$ ) of secondary QI in their pitch specification (see Table 2.1). More appears to reduce anode efficiency. This problem appears not to have been studied systematically. Possible causes of this suggested non-acceptibility could be that the secondary QI may flow over filler-coke particles so upsetting the pitch wetting process and/or the secondary QI particles become incorporated into the binder-coke bridges but not coalesced into the structure. As such they could act as defect centres and reduce anode strength leading to unwanted cracking.

\subsection{Mesophase Development during Petroleum Coke formation}

Petroleum-derived starting materials also yield a variety of mesophase morphologies, ranging from fine-textured isotropic constituents to the fibrous or acicular structures desired for needle coke. These microconstituents can often be found within a single lump of coke, reflecting the varied nature of the refinery streams fed to the delayed coker. Recent work (58) points to the existence of a systematic pattern for the formation of mesophase microstructures in delayed coking. As illustrated by Fig.4.7, the precursor 
components and reaction sequences in which they participate fall broadly into two groups:

1. Highly aromatic pitches (high temperature coal-tar pitches and petroleum pitches) contain slow reacting components which precipitate mesophase spheres under severe pyrolysis conditions (above $460^{\circ} \mathrm{C}$ [57]). Slow sphere nucleation permits their growth to large sizes before coalescence. Low viscosity then facilitates the rapid reimposition of sphericity and ready realignment of the constituent lamellar molecules. Complete coalescence, on elimination of the isotropic phase, results in a coarse mosaic plastic mesophase which may undergo deformation by mechanical means, bubble percolation or convection currents. Uniaxial and biaxial tensile deformation are considered to result in lamellar or plate-like structures (57). Deformation above $460^{\circ} \mathrm{C}$ is considered essential for the formation of needle coke.

2. Less aromatic pitches (petroleum bitumens and low-temperature coal-tar pitches) contain more-rapidly reacting components. Thus ready precipitation of numerous anisotropic spheres occurs under less severe pyrolysis conditions (under $430^{\circ} \mathrm{C}$ [57]). Little growth occurs before complete coalescence. Low viscosity then restricts molecular realignment so that a fine mosaic of small, randomly-aligned microconstituents is formed. Resolidification follows before much deformation of the structure can occur. 


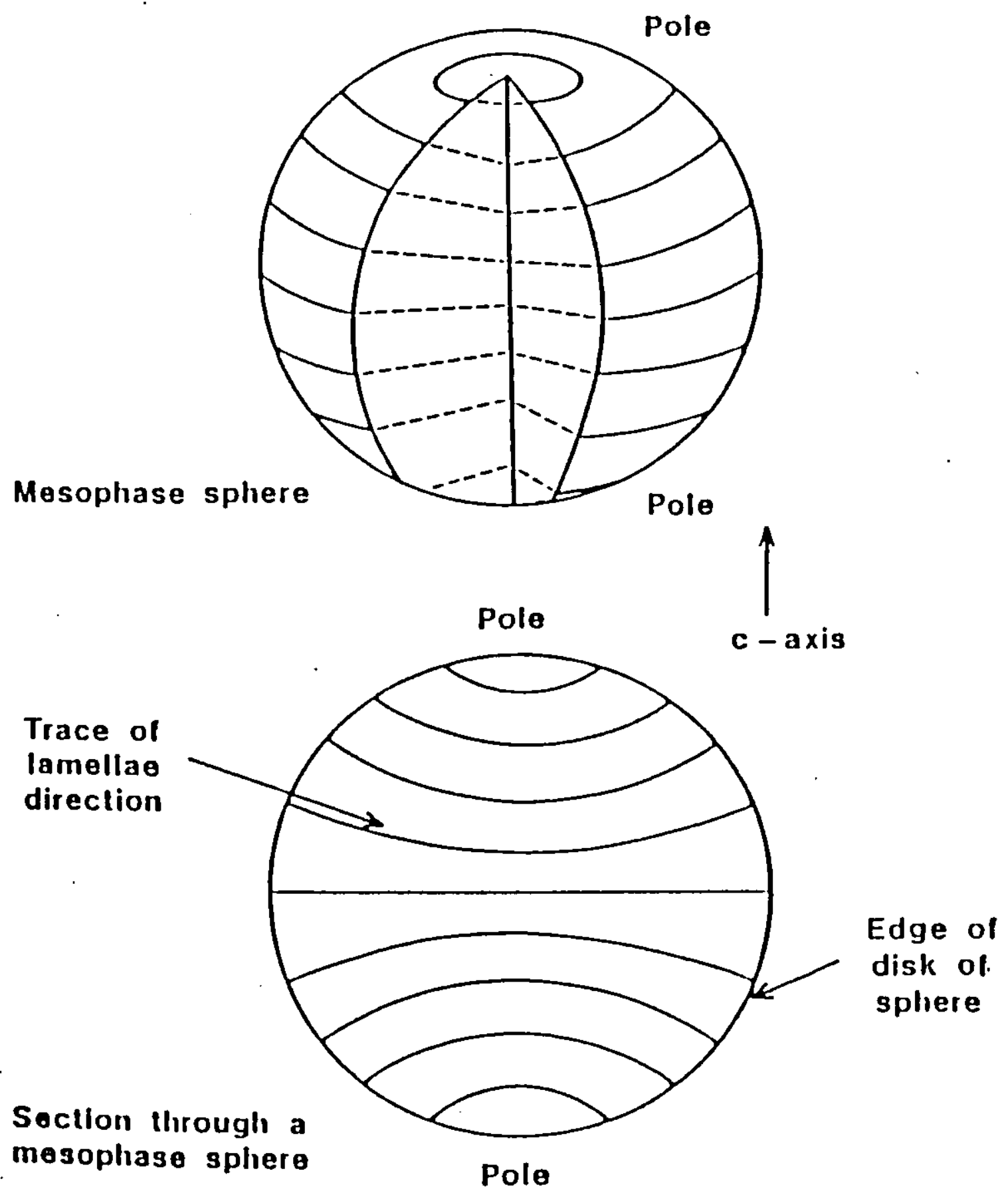

FIG.4.1. Alignment of lamellar molecules in a mesophase sphere. 


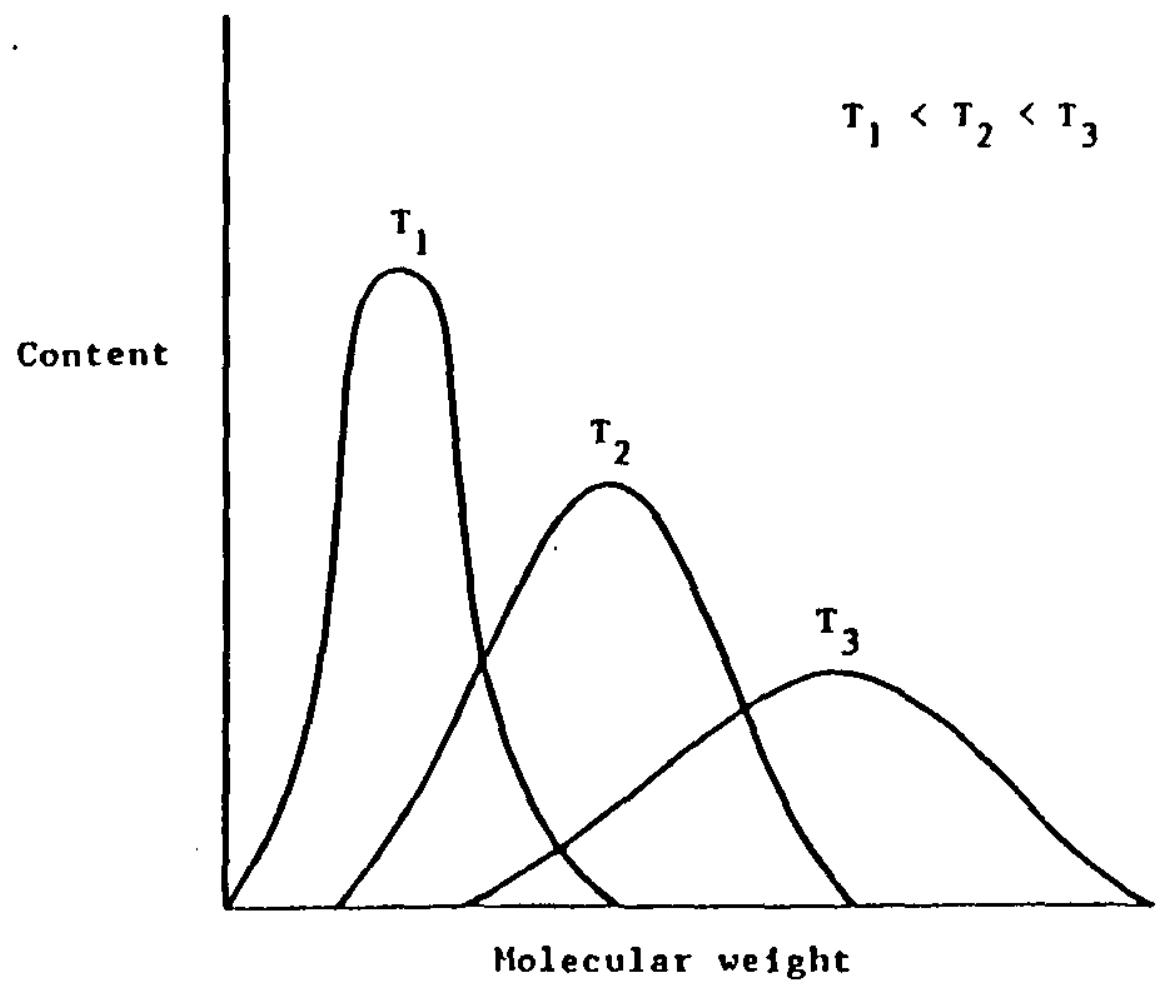

FIG.4.2. Pitch pyrolysis: distributions of molecular weiglat and variation with heat treatment temperature.

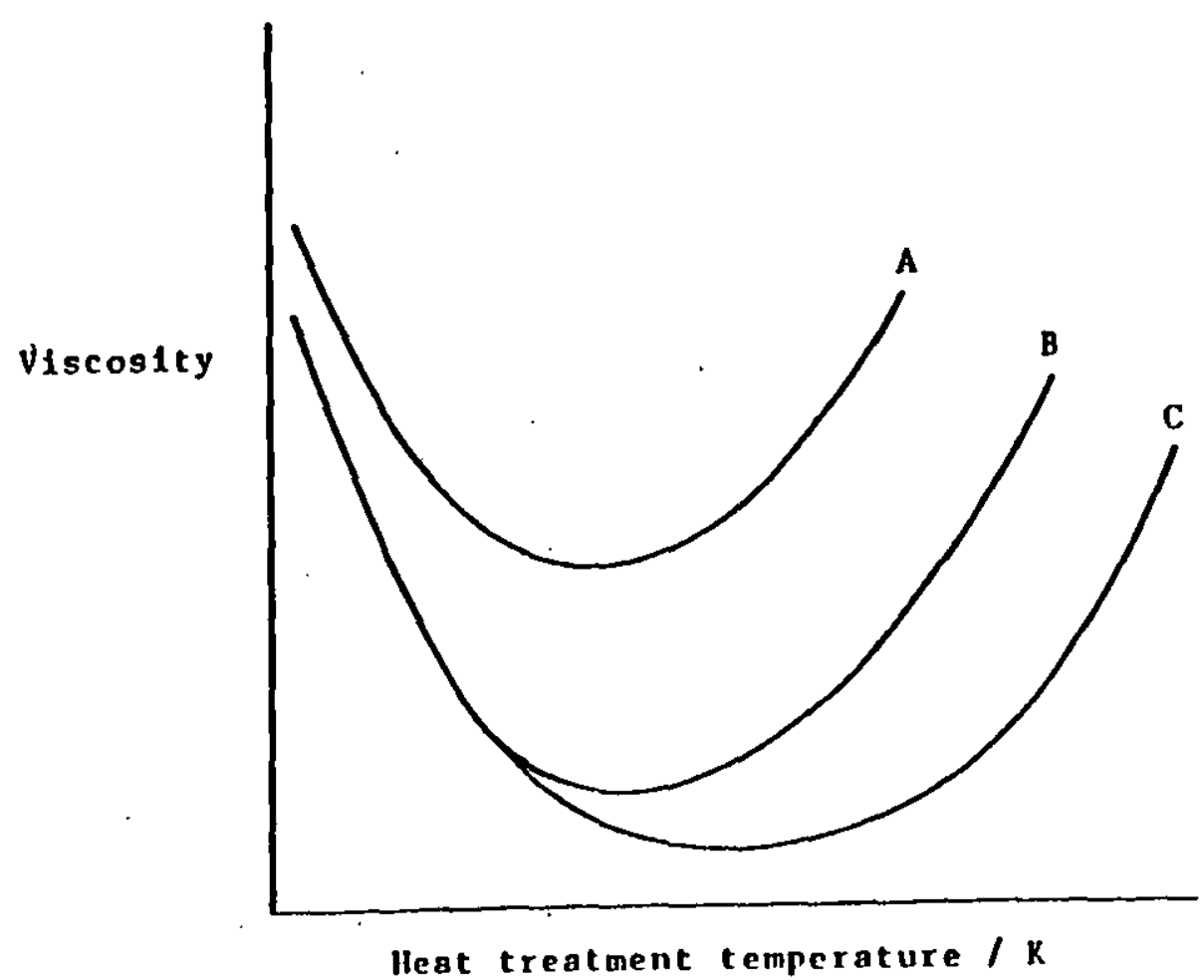

FIG.4.3. Pitch pyrolysis: variation of viscosity with heat treatment temperature (ITT). 


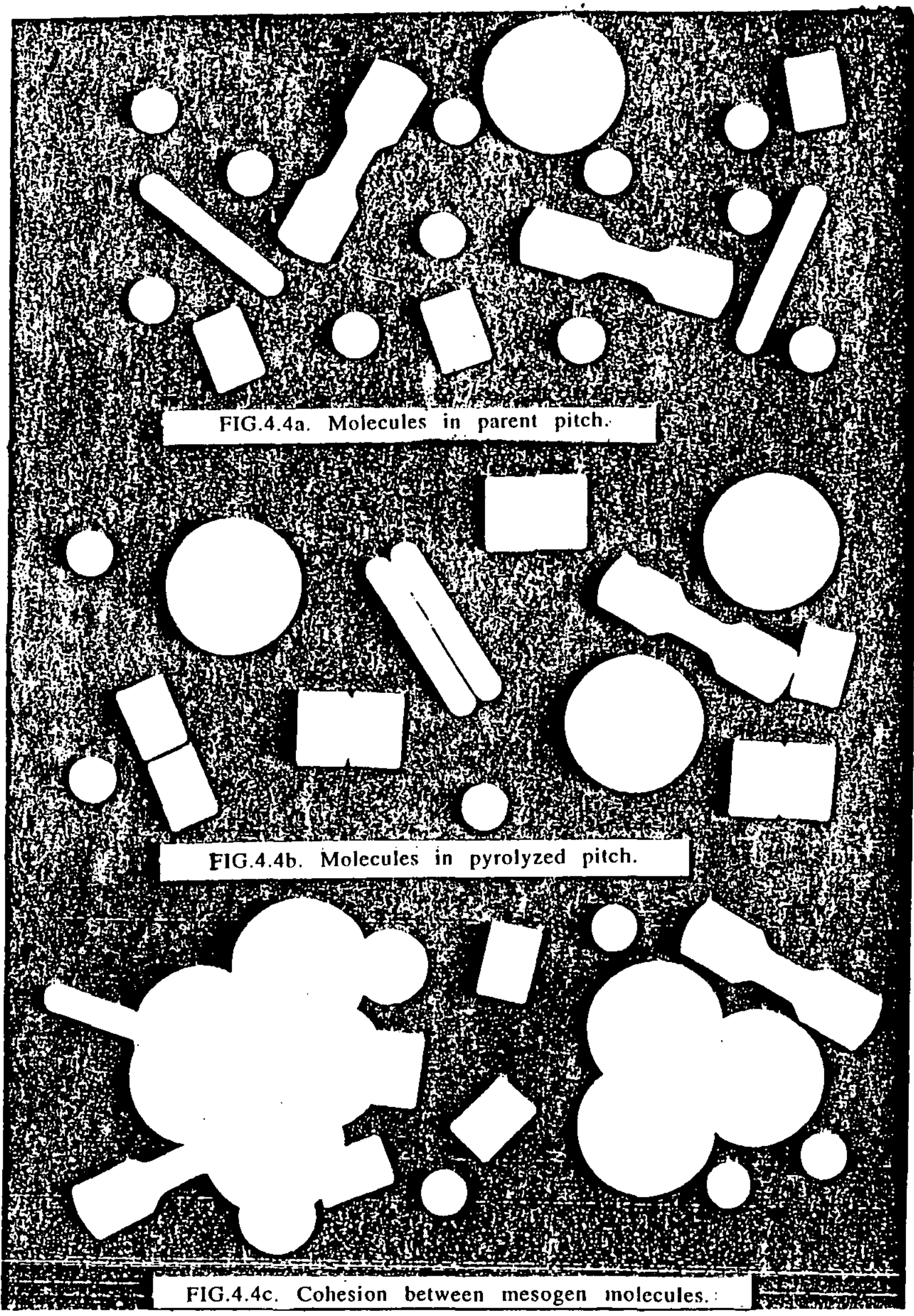




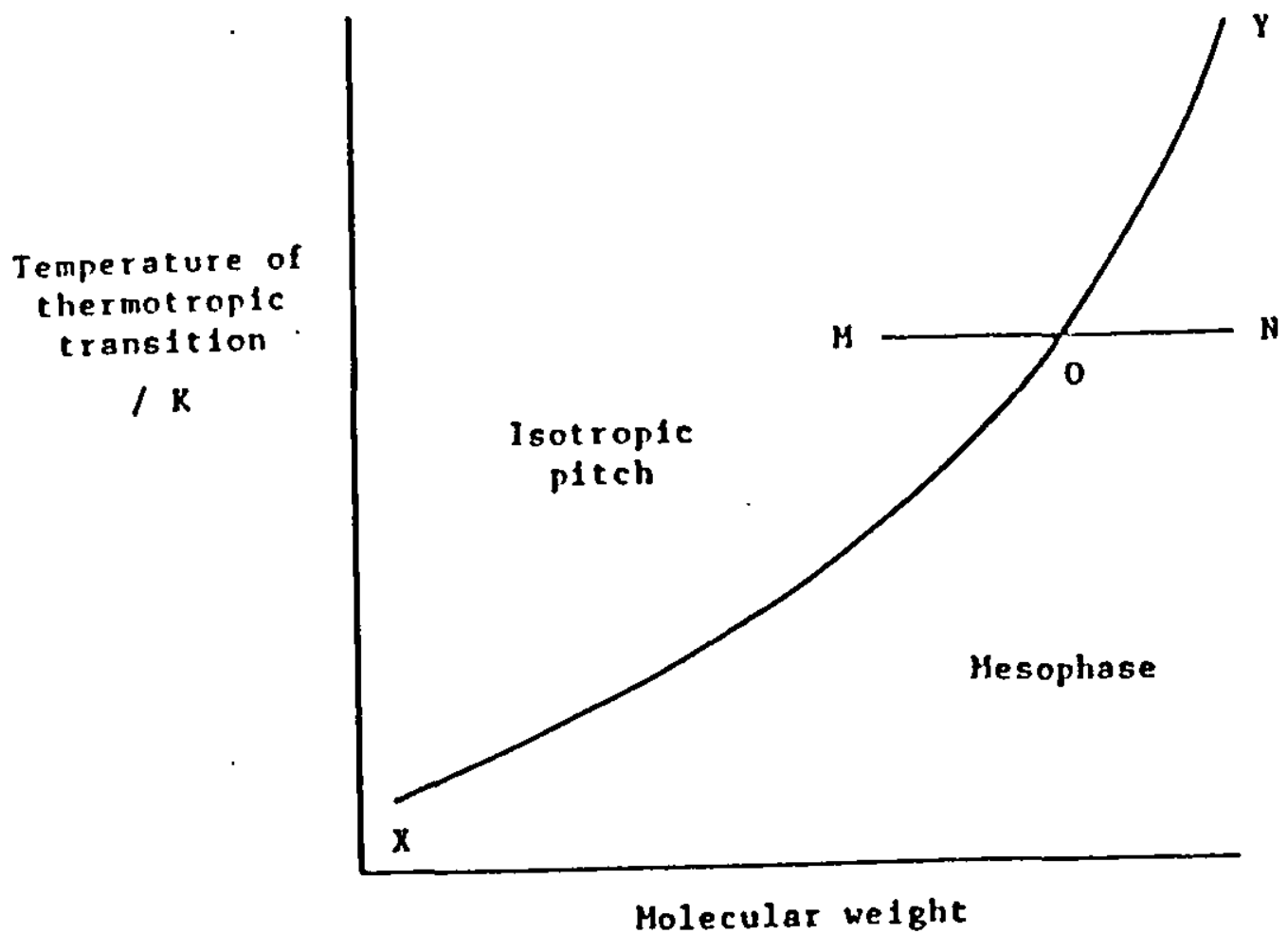

FIG.4.5. Pitch pyrolysis: variation of temperature of thermotropic transition with inolecular weiglit.

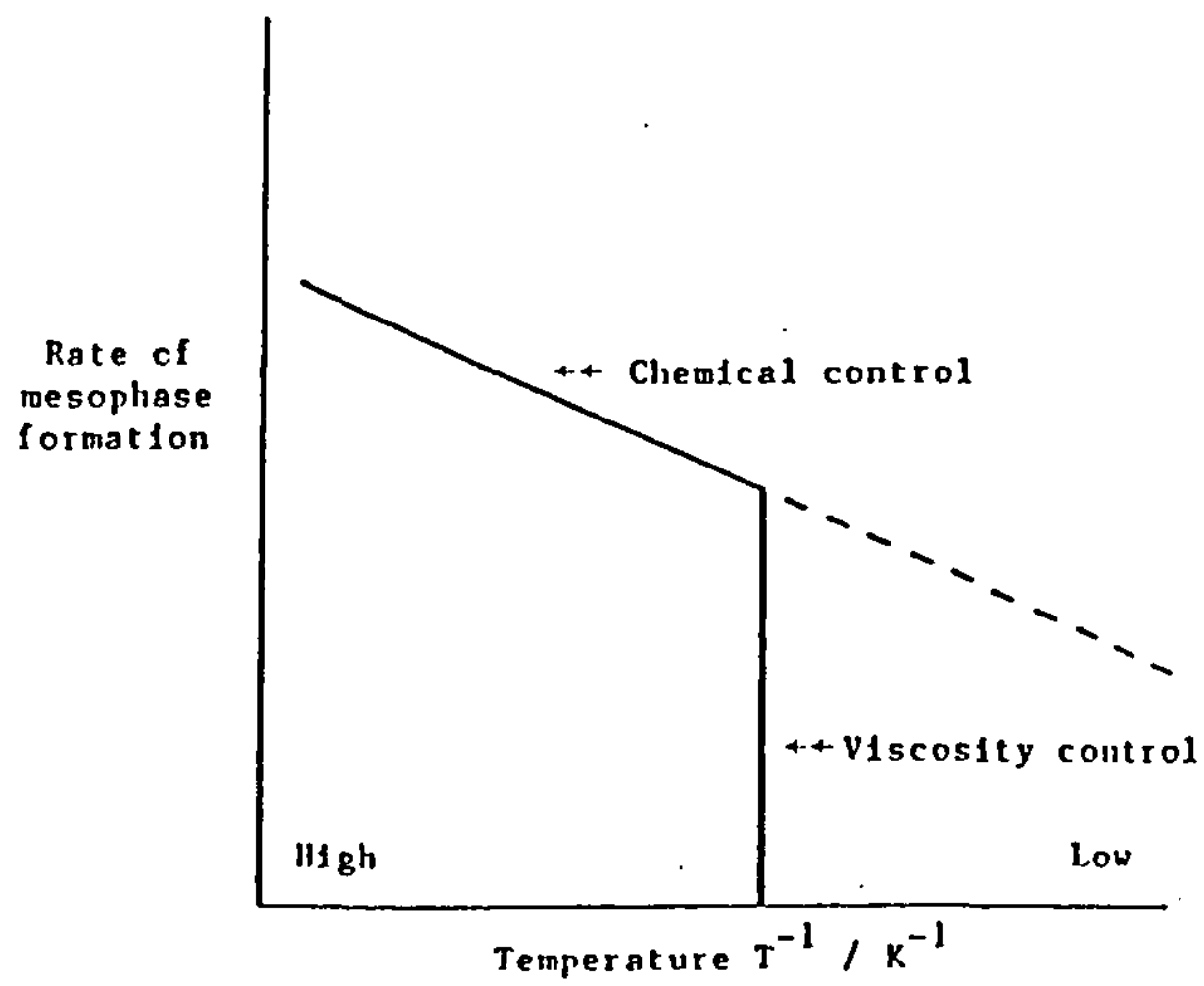

FIG.4.6. Pitch pyrolysis: Arrhenius plots of rates of mesoplase formation showing viscosity control at lower temperatures. 

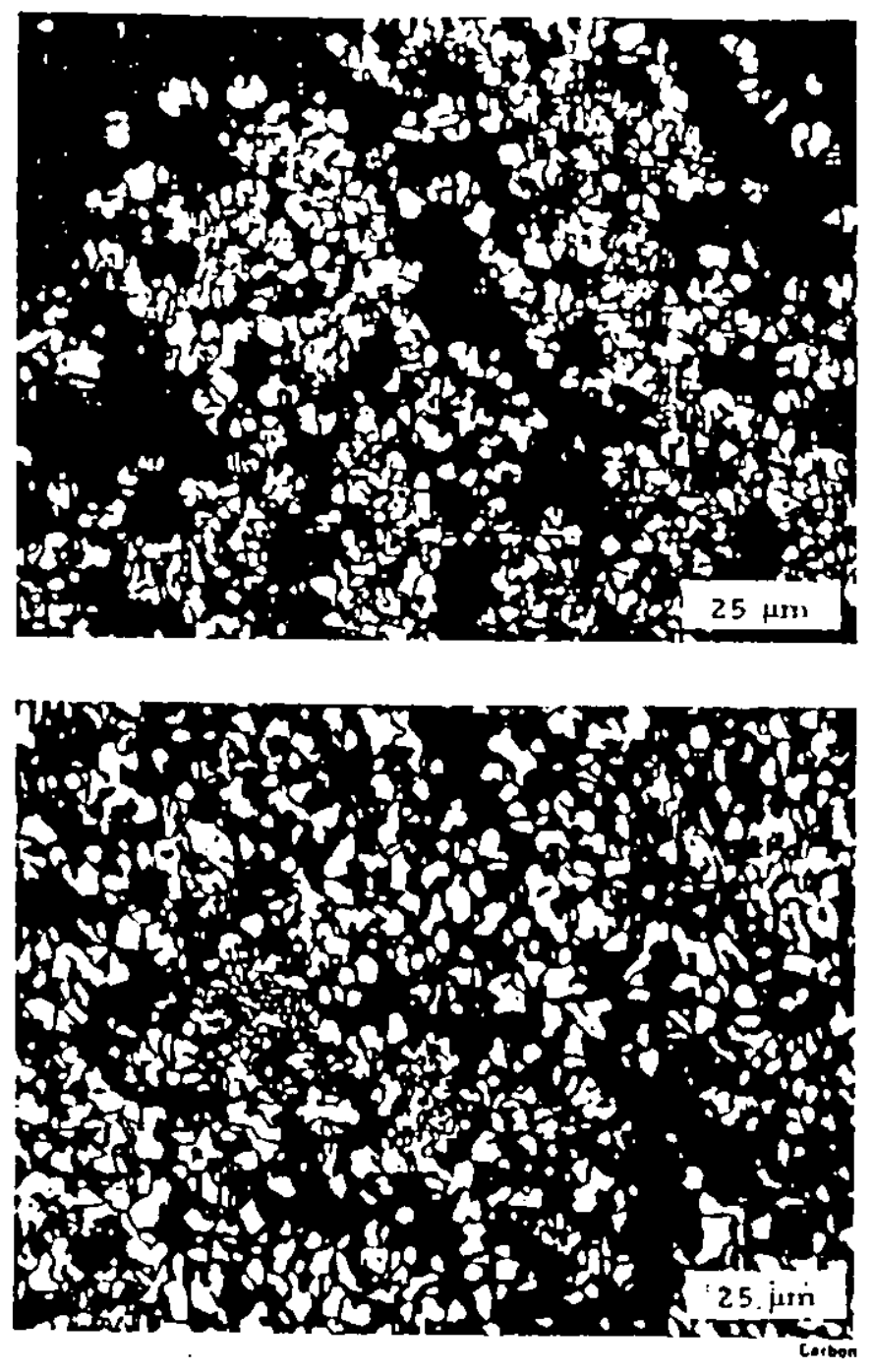

FIG.4.7. Formation of coarse mesophase on framework of fine isotropic mesophase precipitated in earlier stages of isothermal pyrolysis $\left(420^{\circ} \mathrm{C}\right.$. 5h) of asphalt (upper micrograph) and Gilsonite (lower micrograph). 


\section{KINETICS AND CATALYSIS OF CARBON GASIFICATION}

\subsection{Introduction}

Gasification of carbons is of relevance to many industrial processes (77). It includes the combustion of coal and chars as fuels, the production of synthesis gas from coke or chars and the activation of carbons.

However, unwanted gasification also occurs in some processes and needs to be minimised. Thus, gasification of graphite moderators in nuclear reactors occurs by reaction with the moist carbon dioxide coolant gas. Irradiation of the graphite by neutrons and gamma radiation enhances the reactivity but oxidation reduces the graphite's efficiency as a moderator. Carbon/carbon composites are used in high temperature applications in space projects, e.g. in nozzles for rocket motors. These carbon fibre reinforced carbon components can reach temperatures of $3100^{\circ} \mathrm{C}$ in an atmosphere of combustion gases which gasify the nozzle. In the present context unwanted gasification occurs with carbon anodes used in aluminium production where $0.5 \mathrm{~kg}$ of carbon are consumed per $1 \mathrm{~kg}$ of aluminium produced when, theoretically, only $0.33 \mathrm{~kg}$ of carbon should be consumed. The excess consumption is due to unwanted gasification of the carbon anode by carbon dioxide and air, reduction of which is necessary in order to reduce costs.

This Chapter considers the fundamental science of gasification of anode carbons. The distinction is made between chemical and diffusional control of the reaction rate and the influences of porosity in the carbon. Gasification rates, referred to as reactivity parameters, are a function of reacting gas, temperature, pressure, impurity content and carbon structure. The use of active and reactive surface areas to normalise gasification rates as a basis for comparison is explained. Mechanisms of reaction of carbon with atomic and molecular oxygen and carbon dioxide are reviewed. Catalysis of oxidation reactions is assessed in terms of mechanisms involving oxygen-transfer stages and topographical changes causing pitting and channelling. 


\subsection{Reactivity of Carbons}

Discussions of gasification of an anode carbon should give details of the gas used, reaction temperature, reacting gas pressure, purity and flow rate. It must also characterise fully the 'carbon' used, e.g. its purity, parent material, surface area, structure, porosity, heat treatment and optical texture. The kinetics of gasification are a function of the physical and chemical properties of the carbon (78), e.g. particle size, reactor bed packing, carbon origin and heat treatment.

The structure of the anode carbon influences its reactivity. Lander and Marsh (79) showed that the more isotropic a coke the more reactive it is to carbon dioxide. Marsh et al. (12) showed that rates of gasification of graphitizable carbons decreased with increasing heat treatment temperature (HTT) and that the activation energy of gasification increased with increasing HTT, i.e. the more perfect the carbon layer stacking the lower the gasification rate, everything else being comparable.

Despite the extensive literature describing gasification reactions of carbons, there appears to be no systematic study of the effects of variation of HTT upon the kinetics of carbon gasification. Gregg and Tyson (80), studying the reaction of a baked graphite precursor (petroleum coke/pitch) of increasing HTT with oxygen at $10 \mathrm{kPa}$ noted activation energies which increased from 180 to a maximum at $280 \mathrm{~kJ} / \mathrm{mol}(1800 \mathrm{~K})$ and then decreased to about $180 \mathrm{~kJ} / \mathrm{mol}$ $(3300 \mathrm{~K})$. Results were explained in terms of pore diffusion effects (80). McEnaney and Dovaston (81), studying the reaction of non-graphitizing carbons from cellulose triacetate of increasing HTT with carbon dioxide at 10 $\mathrm{kPa}$, noted activation energies which increased from $280 \mathrm{~kJ} \mathrm{~mol}^{-1}$ (1200K) to $420 \mathrm{~kJ} \mathrm{~mol}^{-1}$ (1700K) to decrease to $270 \mathrm{~kJ} \mathrm{~mol}^{-1}$ (2300K). McEnaney and Willis (82) suggest that the maximum in activation energy could result from two competing processes: (a) elimination of hydrogen which reduces retardation effects so creating reactive carbon atoms which may become active sites for gasification, and (b) thermal annealing of active sites.

Topographically, anode carbons don't gasify evenly. Selective gasification occurs at prismatic edges (83) and other imperfections in the graphite layer structure, e.g. vacancies and dislocations, and also where there are impurities in the carbon. It's also thought that heteroatoms influence the initial site of reaction (84). The carbon origin and its heat treatment control these factors. 
The impurity of the carbon also affects its reactivity, impurities which are catalysts of the gasification reaction increase the gasification rate and induce selective gasification at the point of contact between the catalyst and the carbon (Section 5.7). The optical texture of the carbon has been shown to relate to the dispersion of a catalyst and so affects its reactivity (85).

Selective gasification implies that the whole of the surface, i.e. the total surface area (TSA) of the carbon is not involved in the reaction at the same time. The active surface area (ASA) is thought to control the reaction rate of carbons (86), at least, initially.

As carbon is gasified the rate of reaction initially increases. It is thought that the reactivity profile of a reaction, i.e. reaction rate plotted against percentage of carbon gasified, is due to changes in ASA (87). Caustion et al. (88) observed an increase in ASA of a char with 1-2 wt.\% burn-off. As an active carbon site reacts and is removed, the cleavage of the bonds to the surrounding carbon atoms results in the formation of more active sites so increasing the ASA of the carbon which ultimately leads to the removal of individual carbon lamellae.

In the vast literature on the carbon-oxygen reaction, there are literally as many different reactivities reported as there are carbon materials used. Further, the reactivity of a particular carbon material can vary with carbon burn-off. These variations in reactivity have been ascribed to the fact that different carbons have, initially, different amounts of ASA and that their ASA change to different extents with burn-off. The extent of ASA is thought to be a function of such properties of the carbon as crystallite size, crystallite orientation, vacancy concentration in the basal plane, and impurity concentration, type, and location.

ASA is measured by the chemisorption of oxygen on a cleaned (outgassed at $>900^{\circ} \mathrm{C}$ ) carbon surface. This was first carried out by Laine, Vastola and Walker (89) in 1963. It is assumed that one oxygen atom is bonded to one active carbon site at temperatures of $150-300^{\circ} \mathrm{C}$ (depending on the type of carbon used). Negligible amounts of carbon monoxide and dioxide should be formed at these temperatures. Heat treatment to $900^{\circ} \mathrm{C}$ desorbs carbon monoxide and dioxide from the surface. Taking the area occupied by each oxygen atom as $0.083 \mathrm{~nm}^{2}(89)$ the ASA can be calculated from known amounts of 
carbon monoxide and dioxide desorbed. An attempt was made to characterise active sites by Rao et al. (90) using carbon dioxide containing the 180 isotope.

The active site concept has been analysed in terms of electron localisation energies using structure-resonance and Huckel-molecular-orbital theories (91). The larger the size of the aromatic layers the less reactive are the electrons to oxidising gases due to the even distribution and resonance energy of the $\pi$-electrons. The atoms at sites near and on the edges of the basal planes are highly reactive to oxidising gases due to the small energy required to isolate a $\pi$-electron. Thus, active sites are located at edges of basal planes and at defects within the basal planes. These active sites exhibit higher heats of physical adsorption and can chemisorb dissociatively or non-dissociatively (92).

\subsection{Kinetics and Mechanisms of Gasification}

Relative rates of gasification reactions vary with the reacting gas used and the nature of the carbon (77), e.g. the $\mathrm{C}-\mathrm{O}_{2}$ reaction is 100 times faster than the $\mathrm{C}-\mathrm{CO}_{2}$ reaction at $800^{\circ} \mathrm{C}$ and $0.1 \mathrm{~atm}$.

The gasification of anode carbons by air (oxygen) and carbon dioxide are of most relevance to the context of this Thesis.

The rate of gasification of a carbon is usually expressed as:

$$
R=\frac{-1}{W_{0}} \times \frac{d w}{d t}
$$

where: $R$ = reaction rate, $\mathrm{g} \mathrm{g}^{-1} \mathrm{~s}^{-1}\left(\mathrm{~s}^{-1}\right)$

$W_{0}=$ initial weight of carbon, $g$

$$
\frac{d w}{d t}=\text { rate of weight loss of carbon, } g^{-1}
$$

The intrinsic reactivity expressed per unit surface area is usually given by:

$$
R_{i}=k_{i} P A g^{-1}
$$


where: $R_{i}=$ Intrinsic reactivity $\left(\mathrm{g} \mathrm{m}^{-2} \mathrm{~s}^{-1} \mathrm{~Pa}\right)$

$k_{i}=$ Intrinsic rate coefficient

$P=$ partial pressure of reactant gas

$\mathrm{m}=$ true reaction order

$\mathrm{Ag}=$ surface area $\left(\mathrm{m}^{2} \mathrm{~g}^{-1}\right)$

The Arrhenius equation, Eqn.3, is used to determine the activation energy and the value of $A$ of a reaction by plotting the $\log$ of the reaction rate against absolute reciprocal temperature.

$k=A e^{-E_{A}} / R T$

where: $k=$ the rate constant $\left(\mathrm{g} \mathrm{m}^{-2} \mathrm{~s}^{-1} \mathrm{~atm}^{-1}\right)$

$A=$ frequency factor (Arrhenius constant) $\left(\mathrm{g} \mathrm{m}^{-2} \mathrm{~s}^{-1} \mathrm{~atm}^{-1}\right)$

$E_{A}=$ activation energy $\left(\mathrm{J} \mathrm{mol}^{-1}\right)$

$T=$ temperature $(\mathrm{K})$

$\mathrm{R}=$ gas constant $\left(\mathrm{J} \mathrm{mol}-1 \mathrm{~K}^{-1}\right)$

By studying the kinetics if the reaction of molecular oxygen with carbons of different origins and structures and carbons of increasing HTT from the same parent material, Marsh (77) found that $E_{A}$ and $A$ for the carbon-molecular oxygen reaction depend upon the structure of the carbon being gasified. These variations in $E_{A}$ and $A$ lead to discussions of what is known as the "compensation effect" (93). Using Eyring's absolute rate theory (94), Eqn.3 can be expressed as:

$k=\frac{K T}{h} \exp \left(\Delta S^{\dagger} / R\right) \exp \left(-\Delta H^{\dagger} / R T\right)$

where: $\mathrm{K}=$ Boltzmann's constant $\left(1.38 \times 10^{-23} \mathrm{~J} \mathrm{~K}^{-1}\right)$

$\mathrm{h}=$ Plank's constant $\left(6.6 \times 10^{-34} \mathrm{~J} \mathrm{~s}\right)$

$\Delta S^{\dagger}$ and $\Delta H^{\dagger}$ are the difference in entropy and enthalpy, respectively, between the activated, intermediate reaction complex and the reactants. They are known as the entropy and enthalpy of activation. $\Delta \mathrm{H}^{\dagger}$ approximates numerically to $E_{\mathrm{A}}$.

By comparison of Eqn. 4 with Eqn.3, the Arrhenius constant A can be expressed as: 


$$
A=\frac{K T}{h} \exp (\Delta S t / R)
$$

Thus $A$, the frequency factor, is related to the entropy change on formation of the activated complex $\left(\Delta S^{\dagger}\right)$. It's observed that for catalysed reactions, i.e. there is some compensation for the lowered activation energy, Fig.5.1:Diagram $A$ (94). Chemical systems don't permit rate enhancements by decreasing $E_{A}$ and increasing $A$, Fig.5.t:Diagram $B$. Thus, a decrease in $E_{A}$ is accompanied by a decrease in the entropy of activation and hence, a decrease in $A$.

\subsubsection{Transport of Reactants/Products}

As anode carbon gasification reactions are sensitive to mass transfer effects, it's essential to consider the implications of these before embarking on a discussion of kinetics and mechanisms. The reaction between an oxidising gas and the solid anode carbon is a heterogeneous reaction. It can be represented or controlled by five stages (95):

1. Transport of the gaseous reactants from the bulk gas phase to the surface.

2. Adsorption of the reactant on the surface.

3. Reactions on the surface, i.e. occurrence of chemical rearrangements on the surface, mobility and formation of adsorbed products.

4. Desorption of product(s).

5. Transport of the desorbed products from the surface to the bulk gas phase.

Stages 1 and 5 are diffusion/mass transport processes, the relative rates of which vary with temperature. Stage 3 can itself involve several processes. The reaction kinetics will be governed by whichever of these processes is the slowest, i.e. the rate determining step (RDS). The RDS is dependent upon process parameters and carbon properties, e.g (1) Process parameters:- (i) Temperature (ii) Pressure (iii) Particle size. (2) Carbon properties:- (i) Porosity (ii) Active site concentration (iii) Catalytic impurities.

For the gasification of a non-porous carbon, two distinct situations can be identified. At a 'high' reaction temperature, the ROS is transport of reactant gas molecules to the carbon surface i.e. diffusional control. At lower reaction temperatures, the RDS becomes one of chemical control. 
In the case of the porous anode carbon, a further possibility arises. The reaction may be controlled by chemical processes over the accessible external surfaces but controlled by diffusion in the less accessible internal surface porosity (Fig.5.2) because of restrictions on the diffusion of gaseous reactants and products into and out of the pores, particularly micropores. This usually provides an intermediate regime occurring in a temperature range between that where pure chemical or diffusional control of the rate applies.

Thus, gasification processes can be divided into three temperature zones as illustrated in Fig.5.3a, which shows the effect of temperature on the rate of reaction due to mass transport of the reacting gas (stage 1 above) (96). Fig.5.3b shows the variation in the steady-state concentration of the reacting gas(RGC) at the gas/solid surface and at some distance within the porous solid for the three zones.

\section{Zone 1}

At low temperatures the reaction rate is controlled by the chemical reactivity of the solid alone. Mass transport effects are not important. Hence, the measured activation energy in this zone is the true chemical activation energy of the reaction. The RGC is the same within the solid (assuming it to be porous) as in the bulk gas phase.

\section{Zone II}

In this temperature region the RGC decreases to zero within a porous solid at some distance from the exterior surface. The reaction rate is controlled by the mass transfer of the reacting gas from the exterior surface to an active site within the solid and by the chemisorption of the reactant, rearrangement of the chemisorbed species to a desorbable product and desorption of the product. This zone is therefore an intermediate zone between zones $I$ and III. The slope of the Arrhenius plot now yields a value less than (often one-half of) the true chemical (zone I) activation energy. 
At higher temperatures the reacting gas velocity decreases to zero, within which RGC is depleted from its bulk value, at the exterior solid surface due to the formation of a boundary layer. The gas flow sets up a velocity gradient between the solid surface and the bulk gas phase. The reaction rate is controlled by the mass transport of the reacting gas (bulk diffusion) across this boundary layer. The derived activation energy refers to gas diffusion and is lower than that of zone II.

The activation energies determined in Zones 11 and III (shown by the gradient in Fig.53a) are less than that of Zone 1 (77). In practice, a transition region between each of the zones is often observed with deviation from the Arrhenius plot of the chemical reactions.

The concentration of reaction products doesn't affect the reaction rate in Zone I as they can diffuse out of the solid. In Zones II and III their concentration becomes comparable with that of the reactant and can retard the reaction rate and promote back reactions.

\subsubsection{Importance of Active Surface Area (ASA) to Reactivity}

Specimens of carbon produced from different original materials, or in different ways from the same material, are found to burn at very different rates under otherwise similar conditions. The speed at which an individual carbon particle of given size or mass burns depends in part on the rate of oxygen transfer from the bulk gas to the particle, and in part on the particle's reactivity. This reactivity depends on the extent and accessibility to oxygen of the pores within the particle, and on the velocity of chemical reaction between oxygen and pore surface. The latter factor, when properly defined, may be termed the intrinsic reactivity of the carbon, defined as the reaction rate per unit area of pore surface in the absence of any mass-transfer restrictions.

Whereas such carbon properties as its temperature or mass can be evaluated accurately, the 'reactivity' of a carbon cannot be given such precision. The intrinsic reactivity, $R_{j}$ of carbon is a function of the gas used. It does not follow that for several carbons, reactivity will be in the same order for all gasifying 
gases. The $R_{i}$ (Eqn.2) for a heterogeneous carbon surface can be expressed in another way to account for the active sites:

$R_{i}=k_{i}\left[C_{t}\right] W P m$

where: $k_{i}=$ intrinsic rate coefficient

$\left[C_{t}\right]=$ active site concentration

$W=$ mass of carbon atom

$P=$ partial pressure of reactant gas

$\mathrm{m}=$ true reaction order

Often, $R_{i}$, is reported relative to the external surface reactivity, $R_{S}$, where $P=P_{S}$ :

$R_{\mathbf{i}}=R_{S}$ and

$R_{S}=k_{i}\left[C_{t}\right] W\left(P_{S}\right)^{m}$

where: $P_{S}=$ partial pressure of gas at surface

The overall reactivity $R$ is usually related to the intrinsic reactivity, $R_{i}$ (= $\left.R_{\mathrm{s}}\right)$ by:

$R=\mu A g R_{S}$

where: $\mu=$ degree of gaseous penetration

$\mathrm{Ag}=$ total internal surface area $\left(\mathrm{m}^{2} \mathrm{~g}^{-1}\right)$

Combining Eqns. 6 and 7 and assuming an isothermal sample:

$R=k_{i} \mu A g\left[C_{t}\right] W\left(P_{s}\right)^{m}$

Eqn.8 thus implies that $R \infty\left[C_{t}\right] A g$, i.e. carbon reactivity is proportional, not to TSA but to active surface area (ASA).

Laine et al. (see Section 5.2) verified this conclusion by direct measurement of ASA on graphitized carbon black. Jenkins and Piotrowski (97) carried out a study of the degree of gasification (burn-off) on changes in $\left[C_{t}\right]$. The concept of 'reactive' surface area (RSA) was introduced, calculated and utilized to normalize reaction rates in terms of "turn-over number" (TON). The RSA is 
measured in terms of extents of oxygen desorbed from the surface at reaction temperature when the reacting gas is replaced, e.g. by nitrogen or vacuum. More stable chemisorbed oxygen does not relate to reactivity. Values of TON were relatively constant for several chars over a wide range of reaction temperatures. Smith (98) collected published data of intrinsic reactivities of a large variety of carbons and compared them. Such values of the intrinsic reaction rates per unit TSA, at a given temperature and otherwise constant conditions, differ by up to four orders of magnitude (Fig.5.4). The variations can be accounted for, in part, by differences in HTT and impurity levels of the carbon.

\subsubsection{Adsorption and Desorption}

For a heterogeneous reaction which is not controlled by mass transfer effects, whose activation energy of adsorption/desorption is high and whose surface reactions are rapid (which is expected if the adsorbed species are atoms) (95), the adsorption of the reactants or the desorption of the products are expected to be rate controlling steps of the reaction.

The chemisorption of a gas molecule at an active site on the solid surface first involves the formation of an activated complex. The rate of this process depends, in part, on the activation energy required to form the complex, Fig.5.5. Other factors involve the extent of surface accessibility. the complex then reverts to a more stable adsorbed species. Single site chemisorption can lead to the simultaneous formation of products (99). Dual site chemisorption can also occur, rapid surface migration/mobility allowing adjacent sites to interact. Adsorbed molecules can be immobile(remaining where they are until desorbed) or mobile (remaining in an activated state which can move from one active site to another).

Chemisorption takes place when reactant gas molecules reach that part of the surface with active sites which are not already covered by adsorbed species. The Langmuir-Hinshelwood kinetics assume a homogeneous, non-interacting surface, this implying that both the activation energy for adsorption, $\mathrm{E}_{\mathbf{a}}$ and desorption, $E_{d}$ remain constant in time, as well as from site to site. Assuming steady-state, isothermal conditions, $R_{a}=R_{d}$, where $R_{a}$ and $R_{d}$ are intrinsic rates of adsorption and desorption respectively. If $R_{i}$ is controlled by either the rate of adsorption or desorption, then using Langmuir-Hinshelwood kinetics: 


$$
R_{i}=R_{a}=R_{d}
$$

where: $R_{a}=K_{a} P \frac{(1-a P)}{(1+a P)}$

$$
R_{d}=\frac{K_{d}(a P)}{(1+a P)}
$$

where: $K_{a}$ or $K_{d}=$ rate constant for adsorption or desorption $\left(\mathrm{s}^{-1}\right)$

$a=$ constant dependent on temperature

$P=$ partial pressure of the reactant gas (atm)

The reaction rate is dependent on temperature and pressure. This rate equation shows that the reaction order $(\mathrm{m})$ varies between 0 and 1 depending on the temperature and partial pressure of the reacting gas:-

$$
\begin{array}{ll}
\text { For } a P \gg 1 \longrightarrow R_{i}=K_{d} & \text { i.e. } m=0 \\
\text { For } a P \ll 1 \longrightarrow R_{i}=K_{a} P & \text { i.e. } m=1
\end{array}
$$

For a non-homogeneous surface, the kinetics can be developed assuming that most active sites react first, especially at higher temperatures where surface mobility is enhanced. For an interacting surface, filling of nearby sites creates repulsion forces thus inhibiting adsorption (and promoting desorption) of following molecules. Consequently $E_{a}$ increases (and $E_{d}$ decreases) as the surface coverage $(O)$ increases.

$$
\begin{aligned}
& E_{a}=E_{a o}+w_{a} \\
& E_{d}=E_{d o}-w_{d}
\end{aligned}
$$

where $E_{a o}$ and $E_{\text {do }}$ are activation energies at $\varnothing=0 ; w_{a}$ and $w_{d}$ are surface constants.

The chemisorption rate on carbon often follows Eqn.11i via the 'so-called' Elovich equation: 
$R_{a}=R_{a o} e^{-w a ø / R T}$

where $R_{\mathrm{ao}}$ is the adsorption rate at $\emptyset=0$.

\subsubsection{Basic Thermodynamics}

A reaction between a solid and a gas depends, in part, on the temperature and pressure of the system (100). Fig.5.6 shows how the free energy, $\Delta G$, of formation of the reactions of carbon and oxygen and carbon dioxide and of carbon monoxide with oxygen vary with temperature at atmospheric pressure. $\Delta G$ of a reaction can be related to the position of the equilibrium of the reaction by:

$\Delta G=-n R T \ln K_{p}$

The further the equilibrium is in favour of the products, i.e. the greater $K_{p}$, the more negative the $\Delta G$ value. Thus, for the $\mathrm{C}+\mathrm{CO}_{2}$ reaction, which is endothermic, i.e. $\Delta \mathrm{H}$ is positive, with increasing temperature the $\mathrm{CO}$ amount increases at equilibrium, i.e. $\Delta \mathrm{G}$ becomes more negative. For the $\mathrm{C}+\mathrm{O}_{2}$ reaction which is exothermic, i.e. $\Delta \mathrm{H}$ is negative, with increasing temperature $\Delta \mathrm{G}$ remains almost constant for $\mathrm{CO}_{2}$ formation but becomes more negative for $\mathrm{CO}$ formation. At $700^{\circ} \mathrm{C} \Delta \mathrm{G}=-400 \mathrm{~kJ} \mathrm{~mol}^{-1}$ for both reactions, therefore the equilibrium positions of these carbon-oxygen reactions are entirely composed of $\mathrm{CO}_{2}$ and $\mathrm{CO}$ in the absence of residual carbon. In the presence of residual carbon the equilibrium position of the Boudouard reaction would be established and no residual molecular oxygen would remain. Kinetically, the equilibrium of the Boudouard reaction is reached much more slowly than the $\mathrm{C}-\mathrm{O}_{2}$ reaction. In actual combustion processes, as well as primary formation of $\mathrm{CO}$ and $\mathrm{CO}_{2}$, gas phase combustion of $\mathrm{CO}$ and $\mathrm{CO}_{2}$ would also occur. 


\subsection{The Carbon-Carbon Dioxide Reaction}

The reaction of carbon with carbon dioxide was first studied by Boudouard in 1901 (101). The overall reaction is:

$\mathrm{C}(\mathrm{s})+\mathrm{CO}_{2}(\mathrm{~g}) \rightleftharpoons 2 \mathrm{CO}(\mathrm{g})$

The mechanism and kinetics of this reaction have been extensively studied. Two mechanisms have been proposed both of which result in the same rate expression for $k$. The mechanisms differ in the way that carbon monoxide produced by the reaction inhibits the forward reaction rate. Both mechanisms state that the retardation results from a reduction of the active surface covered by oxygen atoms.

Mechanism A

$\mathrm{C}_{\mathrm{f}}+\mathrm{CO}_{2} \rightleftharpoons \mathrm{C}(\mathrm{O})+\mathrm{CO}$

$\mathrm{C}(\mathrm{O}) \longrightarrow \mathrm{CO}$

where: $C_{f}$ is the number of free sites (assumed to remain constant with burnoff)

$\mathrm{C}(\mathrm{O})$ represents an active site occupied by an adsorbed oxygen atom.

This mechanism was proposed by Ergun (102). Single site chemisorption of carbon dioxide leads to the simultaneous formation of carbon monoxide and an adsorbed oxygen atom, Eqn.14. Carbon monoxide inhibits the rate of reaction by the back reaction with the $\mathrm{C}(\mathrm{O})$ complex in Eqn.14 so reducing the concentration of $\mathrm{C}(\mathrm{O})$ complex on the surface and limiting further formation of CO by Eqn.15.

Mechanism B

$\mathrm{C}_{\mathrm{f}}+\mathrm{CO}_{2} \longrightarrow \mathrm{C}(\mathrm{O})+\mathrm{CO}$

$\mathrm{C}(\mathrm{O}) \longrightarrow \mathrm{CO}$

$\mathrm{C}_{\mathrm{f}}+\mathrm{CO} \rightleftharpoons \mathrm{C}(\mathrm{CO})$

where $\mathrm{C}(\mathrm{CO})$ is an adsorbed $\mathrm{CO}$ molecule occupying an active site. 
This mechanism was proposed by Gadsby (103). Carbon monoxide inhibits the reaction rate by chemisorbing on active carbon sites, Eqn.16, thus, reducing the fraction of the active surface covered by adsorbed oxygen which reduces the reaction rate.

Mechanism A is taken as the correct mechanism, numerous workers (96) having shown that the rate of adsorption of carbon monoxide on carbon is negligible and can not account for the retardation.

The overall rate is proportional to the number of sites occupied by adsorbed oxygen which are capable of desorption. However, some chemisorbed oxygen is so stable that it effectively acts as an inhibitor. The number of reacting sites (ASA) is therefore a direct measure of reactivity (102).

Using Langmuir-Hinshelwood kinetics and applying the steady state approximation to the fraction of the surface covered by adsorbed molecules, the rate for the $\mathrm{C}-\mathrm{CO}_{2}$ reaction is:

$R=\frac{k_{1} P_{C O}}{1+k_{2} P_{C O}+k_{3} P_{C O}}$

where: $\mathrm{PCO}_{\mathrm{CO}}$ and $\mathrm{PCO}_{2}$ are the partial pressures of carbon monoxide and dioxide and $k_{1}, k_{2}$ and $k_{3}$ are constants which are a function of the rate constants of the individual steps of the reaction $(96,104)$. The reaction order varies between zero and one depending on the conditions of temperature and pressure (105). Reaction order is zero when:

$\mathrm{k}_{2} \mathrm{PCO} \ll 1$ low temperatures, and $\mathrm{k}_{3} \mathrm{PCO}_{2} \gg 1$ high $\mathrm{CO}_{2}$ pressures.

It is first order when:

$k_{2} P_{C O} \ll 1$ low temperatures, and $k_{3} P_{C O} \ll 1 \quad$ low $\mathrm{CO}_{2}$ pressures.

Also, the constants $k_{2}$ and $k_{3}$ have been found to decrease with increasing temperature as the ratio of $\mathrm{CO}: \mathrm{CO}_{2}$ in the gas phase increases so that at temperatures above $900^{\circ} \mathrm{C}$ and at atmospheric pressure, the equilibrium of reaction (14) favours the formation of the products and the reaction is first order. The activation energy of the reaction has been found to be $300-375 \mathrm{~kJ}$ $\mathrm{mol}^{-1}$ (96). 


\subsection{The Carbon-Molecular Oxygen Reaction}

The reaction of molecular oxygen with carbon produces two primary products, carbon monoxide and carbon dioxide (96). The equations for the reactions are:

$$
\begin{aligned}
& 2 \mathrm{C}_{\mathrm{f}}+\mathrm{O}_{2} \longrightarrow 2 \mathrm{C}(\mathrm{O}) \longrightarrow 2 \mathrm{CO} \\
& \mathrm{C}_{\mathrm{f}}+\mathrm{O}_{2} \longrightarrow \mathrm{C}\left(\mathrm{O}_{2}\right) \longrightarrow \mathrm{CO}_{2}
\end{aligned}
$$

where: $C_{f}$ is a free carbon site.

$\mathrm{C}(\mathrm{O})$ is a chemisorbed oxygen atom.

$\mathrm{C}\left(\mathrm{O}_{2}\right)$ is a chemisorbed oxygen molecule.

However, the simplicity of these equations does not reflect the complex mechanisms of these reactions. The mechanism of the $\mathrm{C}-\mathrm{O}_{2}$ reaction is not as well understood as that of the $\mathrm{C}-\mathrm{CO}_{2}$ reaction. The reasons for this are because the reaction is extremely sensitive to the limitations imposed by energy and mass transfer processes. Eqns. 18 and 19 are a gross over-simplification of the mechanism. Marsh (77) has suggested a series of eleven reaction stages in the mechanism involving chemisorbed molecules and atoms, both mobile and immobile, on the anode carbon surface:

$$
\begin{aligned}
& \mathrm{C}_{f}+\mathrm{O}_{2} \longrightarrow \mathrm{C}\left(\mathrm{O}_{2}\right) \text { or } \mathrm{C}\left(\mathrm{O}_{2}\right)_{\mathrm{m}} \\
& \mathrm{C}\left(\mathrm{O}_{2}\right)_{\mathrm{m}} \longrightarrow \mathrm{C}(\mathrm{O})+\mathrm{C}(\mathrm{O})_{m} \text { and/or } \\
& \mathrm{C}(\mathrm{O})_{m}+\mathrm{C}(\mathrm{O})_{m} \text { and/or } \mathrm{C}(\mathrm{O})+\mathrm{C}(\mathrm{O}) \\
& \mathrm{C}(\mathrm{O}) \longrightarrow \mathrm{CO} \\
& \mathrm{C}(\mathrm{O})_{m} \longrightarrow \mathrm{CO} \\
& \mathrm{C}(\mathrm{O})_{m}+\mathrm{C}(\mathrm{O})_{m} \longrightarrow \mathrm{C}_{f}+\mathrm{CO}_{2} \\
& \mathrm{C}(\mathrm{O})_{m}+\mathrm{C}(\mathrm{O}) \longrightarrow \mathrm{C}_{f}+\mathrm{CO}_{2} \\
& \mathrm{CO}+\mathrm{C}(\mathrm{O}) \longrightarrow \mathrm{C}_{f}+\mathrm{CO}_{2} \\
& \mathrm{CO}+\mathrm{C}(\mathrm{O})_{m} \longrightarrow \mathrm{C}_{f}+\mathrm{CO}_{2} \\
& \mathrm{O}_{2}+2 \mathrm{C}(\mathrm{O}) \longrightarrow 2 \mathrm{CO}_{2}
\end{aligned}
$$

where: $C_{f}=$ free carbon site

$\mathrm{C}\left(\mathrm{O}_{2}\right)=$ chemisorbed, localised molecular oxygen

$\mathrm{C}\left(\mathrm{O}_{2}\right)_{\mathrm{m}}=$ chemisorbed, mobile molecular oxygen

$\mathrm{C}(\mathrm{O})=$ chemisorbed, localised oxygen atom

$\mathrm{C}(\mathrm{O})_{\mathrm{m}}=$ chemisorbed, mobile oxygen atom 
Ahmed and Back (106) proposed mechanisms which involved gaseous, molecularly adsorbed and dissociatively adsorbed oxygen. Vastola et al. (107) using 180 tracer techniques, determined the following expression for the rate equation for the $\mathrm{CO}_{2}$ reaction:

$\frac{-d c}{d t}=\frac{k P_{O_{2}}(A S A)(1-\varnothing)}{[1-\pi(\varnothing)]}$

where: $\mathrm{dc} / \mathrm{dt}=$ rate of carbon consumption $=$ _ rate of oxygen depletion

$\mathrm{k}=\mathrm{a}$ rate constant

$\mathrm{PO}_{2}=$ partial pressure of oxygen

$A S A=$ active surface area

$\emptyset=$ fraction of ASA covered with complexes

$\pi(\varnothing)=$ a participation factor reflecting the involvement of surface complexes.

The gaseous $\mathrm{CO}$ and $\mathrm{CO}_{2}$ are produced through two pathways; (i) a fleeting 'oxygen' surface intermediate, and (ii) via the breakdown of a more stable 'oxygen' surface complex.

Ahmed and Back (106) showed that the $\mathrm{C}(\mathrm{O}) \cdot$ complex is an intermediate in the $\mathrm{C}-\mathrm{O}_{2}$ reaction by studying the reaction of high purity carbon films with oxygen in a static system between $475^{\circ}$ and $900^{\circ} \mathrm{C}$ at $0.13 \mathrm{kPa}$.

There has been much interest in $\mathrm{CO}: \mathrm{CO}_{2}$ product ratio for the $\mathrm{C}-\mathrm{O}_{2}$ reaction. The ratio of the primary products $\mathrm{CO}: \mathrm{CO}_{2}$ from Eqns. 18 and 19 , with no gas phase reactions occurring, is found to increase with increasing temperature (96). An increase in the $\mathrm{CO}: \mathrm{CO}_{2}$ ratio with increasing temperature depends on various equilibria and side reactions of the particular system being considered. For example, a decreasing surface complex concentration reduces the probability of carbon dioxide formation. The $\mathrm{CO}: \mathrm{CO}_{2}$ ratio of the products desorbed from the anode carbon surface is controlled by factors such as the carbon nature, surface functionality, temperature, pressure etc. However, if the products are allowed to react in the gas phase with oxygen present, then the reaction:

$2 \mathrm{CO}+\mathrm{O}_{2} \longrightarrow 2 \mathrm{CO}_{2}$ 
will adjust the $\mathrm{CO}: \mathrm{CO}_{2}$ ratio. If there is residual carbon present then the $\mathrm{CO}: \mathrm{CO}_{2}$ ratio will also be adjusted by the equilibrium of the Boudouard reaction:

$\mathrm{C}+\mathrm{CO}_{2} \rightleftharpoons 2 \mathrm{CO}$

which will depend on the system temperature. Thus, when quoting $\mathrm{CO}: \mathrm{CO}_{2}$ ratios of the $\mathrm{C}-\mathrm{O}_{2}$ reaction, all the reactions which can occur must be considered and experimental conditions clearly stated.

Foord (108), using polyvinylidene chloride carbons of different HTT's and reacting them with isotopically labelled oxygen, $18 \mathrm{O}_{2}$, and studying the composition of the desorbed products, observed a decrease in the $\mathrm{CO}: \mathrm{CO}_{2}$ ratio as the temperature was increased to $200^{\circ} \mathrm{C}$. The increase in the formation of $\mathrm{CO}_{2}$ is due to increased mobility of the surface oxides with temperature so enhancing the possibility of $\mathrm{CO}_{2}$ formation on the surface:

$\mathrm{C}(\mathrm{O})+\mathrm{C}(\mathrm{O}) \longrightarrow \mathrm{C}\left(\mathrm{CO}_{2}\right) \longrightarrow \mathrm{C}_{\mathrm{f}}+\mathrm{CO}_{2} \uparrow$

As the temperature was increased above $200^{\circ} \mathrm{C}$, the $\mathrm{CO}: \mathrm{CO}_{2}$ ratio increased due to the rate of desorption of oxygen complexes from the surface being increased, resulting in lower surface oxygen concentrations and enhanced $\mathrm{CO}$ formation. A decrease in the $\mathrm{CO}: \mathrm{CO}_{2}$ ratio at temperatures above $750^{\circ} \mathrm{C}$ was probably due to the reaction of $\mathrm{CO}$ with an surface oxygen complex forming $\mathrm{CO}_{2}$, i.e. the back reaction in Eqn.14:

$\mathrm{CO}+\mathrm{C}(\mathrm{O}) \rightleftharpoons \mathrm{CO}_{2}+\mathrm{C}_{\mathrm{f}}$

From Walker's review (96), most authors report that the order of the $\mathrm{C}-\mathrm{O}_{2}$ reaction is approximately first order. The activation energy of the reaction has been found to be $220-270 \mathrm{~kJ} / \mathrm{mol}$. The rate controlling step of both the $\mathrm{C}-\mathrm{O}_{2}$ and $\mathrm{C} \cdot \mathrm{CO}_{2}$ reactions is the desorption of $\mathrm{C}(\mathrm{O})$ from the carbon surface although the activation energies of the two reactions differ, $220-270 \mathrm{~kJ} / \mathrm{mol}$ for the C$\mathrm{O}_{2}$ reaction and $300-375 \mathrm{~kJ} / \mathrm{mol}$ for the $\mathrm{C}-\mathrm{CO}_{2}$ reaction. The reactions are usually studied at different temperatures, $>500^{\circ} \mathrm{C}$ for $\mathrm{C}-\mathrm{O}_{2}$ reaction and $>800^{\circ} \mathrm{C}$ for $\mathrm{C}-\mathrm{CO}_{2}$ reaction. The higher temperature of the $\mathrm{C}-\mathrm{CO}_{2}$ reaction results in a lower surface coverage of adsorbed oxygen atoms because more energy is available to desorb the less strongly bound $\mathrm{C}(\mathrm{O})$ molecules which exist at $500^{\circ} \mathrm{C}$ as in the $\mathrm{C}-\mathrm{O}_{2}$ reaction. The lower the surface coverage of 
adsorbed oxygen the higher the energy of desorption of the $\mathrm{C}(\mathrm{O})$ molecule. Thus, the $\mathrm{C}-\mathrm{CO}_{2}$ reaction has a higher activation energy than the $\mathrm{C}-\mathrm{O}_{2}$ reaction.

\subsection{Catalysis of Carbon Gasification Reactions}

Many metals are known to catalyse the gasification reactions of anode carbons, whether indigenous to the carbon or deliberately added. The catalytic effects observed depend upon the metal present, its chemical state when added, oxidation states during gasification and the reaction temperature.

Catalysts usually provide a new reaction pathway, the slow stage of which has a lower activation energy than the uncatalysed reaction. The decrease in activation energy of the rate determining step of the reaction results in an increase in reaction rate.

The change in activation energy, $E$, of a reaction due to the presence of catalysts is accompanied by a corresponding change in the pre-exponential factor, $A$. This inter-dependence of $E$ and $A$ is called the compensation effect and frequently obeys an equation of the form:

$m E$ - In $A=$ constant

where $\mathrm{m}$ is the proportionality constant and $\mathrm{A}$ is indicative of the density of active sites on the carbon surface.

Gasification reactions of carbon are catalysed by group 1, group II and transition metals. The subject has been reviewed by McKee (109).

\subsection{Mechanisms of Catalysis}

Although many attempts have been made to explain the behaviour of alkali metal salts in catalysing the oxidation of carbon by oxygen and carbon dioxide, no single theory has been found capable of interpreting all the observed results. Whereas the oxygen-transfer mechanism, involving an oxidation-reduction cycle, appears adequate in explaining the general features of the catalytic behaviour of the transition metal oxides, the marked catalytic activity of alkali metal salts, particularly the carbonates and oxides, has not been satisfactory explained on this basis. Alternatively, it has been proposed that alkali metal 
atoms on the carbon surface act as sites for the chemisorption of oxygen, thereby weakening $\mathrm{C}-\mathrm{C}$ surface bonds and facilitating the desorption of gaseous oxidation products at low temperatures (110). Neutralization of the acid surface oxide by basic alkali salts has also been advocated as a mechanism for catalysis of the $\mathrm{C}-\mathrm{O}_{2}$ reaction and the formation of alkali metal-carbon complexes in the case of the $\mathrm{C}-\mathrm{CO}_{2}$ reaction (111). In the latter case, the vapourisation of free alkali metal has frequently been reported and a catalytic mechanism involving a gas phase reaction between $\mathrm{CO}_{2}$ and alkali metal vapour has been suggested (112).

Nevertheless, the exact role played by the additives in accelerating the formation of gaseous products is not yet clearly understood. Active catalysts appear to participate in the gasification processes by undergoing chemical or electronic interactions or both, with the carbonaceous substrate but the details of these interactions remain controversial.

Two theories have been proposed to explain how a catalyst increases the gasification rate of a carbon; the oxygen-transfer mechanism and the electrontransfer mechanism.

\subsubsection{Oxygen-Transfer Mechanism}

This mechanism was the first to be proposed to explain the effects of catalysis on gasification reactions of carbon (113). The catalyst is considered as an oxygen carrier and undergoes an oxidation-reduction cycle transferring oxygen from the gas phase $\left(\mathrm{O}_{2}, \mathrm{CO}_{2}\right)$ to the carbon surface as a chemisorbed species $\mathrm{C}(\mathrm{O})$, e.g. catalysis of the $\mathrm{C}-\mathrm{CO}_{2}$ reaction by a metal $\mathrm{M}$ :

$\mathrm{M}+\mathrm{CO}_{2} \longrightarrow \mathrm{M}-\mathrm{O}+\mathrm{CO}$
$\mathrm{M}-\mathrm{O}+\mathrm{C}_{\mathrm{f}} \longrightarrow \mathrm{M}+\mathrm{C}(\mathrm{O}) \longrightarrow \mathrm{M}+\mathrm{C}_{f}+\mathrm{CO}$

where $\mathrm{M}-\mathrm{O}$ is a metal/oxygen complex. 


\subsubsection{Electron-Transfer Mechanism}

Long and Sykes (114) applied electron theories to catalysts. They used the concept that many of the known catalysts of gasification reactions either have unfilled electron shells and so can accept electrons from the carbon matrix or have labile electrons which can be donated to the carbon matrix. Transfer of electrons results in a redistribution of $\pi$-electrons in the carbon matrix. This weakens carbon-carbon bonds at edge sites and allows bond formation with an adsorbed oxygen atom which then requires less energy to be removed as a $\mathrm{CO}$ molecule, e.g. catalysis of the $\mathrm{C}-\mathrm{CO}_{2}$ reaction by a metal carbonate $\mathrm{M}_{2} \mathrm{CO}_{3}$ :

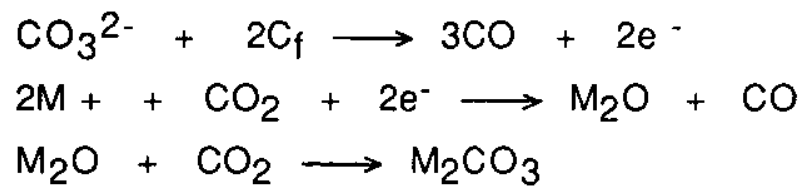

where $\mathrm{e}-$ is an electron.

Today the oxygen-transfer mechanism is the most widely accepted of the two approaches. The catalysts are known to have localised behaviour, i.e. the catalysed reaction only occurs at the point of contact of the catalyst and the carbon surface which is explained by the oxygen-transfer mechanism. Also, it is found (115) that the activation energy of a catalysed oxidation of carbon is independent of the concentration of the catalyst present. This is not expected with the electron-transfer mechanism.

\subsection{Catalysis of the Boudouard Reaction}

The Boudouard reaction is catalysed by group 1, group II and transition metals. Studies of the catalysis of the Boudouard reaction have predominantly used group I metals and their salts as catalysts as these have been found to be the most effective catalysts of the reaction. In particular, potassium carbonate has been used in many studies as the carbonates are thought to be some of the most catalytically active salts (109). Studies of the catalysis of the reaction by transition metals have also been published (79).

The effectiveness of group I metals as catalysts of the $\mathrm{C}-\mathrm{CO}_{2}$ reaction increases in the order $\mathrm{Na}<\mathrm{K}<\mathrm{Rb}<\mathrm{Cs}<\mathrm{Li}(116)$. This is the same order as the decomposition temperatures of the carbonates to the oxides, lithium having the 
lowest decomposition temperature as the oxide is more stable than the carbonate due to the small size of the $\mathrm{Li}^{+}$ion. The catalyst catalyses the transfer of oxygen from the gas to the carbon surface therefore, the more readily formed the oxide or oxygen containing catalyst species the more active the catalyst. Many mechanisms involving metal carbonates have been published, these have been summarised by Moulijin and Kapteijin (117).

Alkali metal catalysis is of most relevance to the context of this Thesis.

A recent comprehensive study of the Boudouard reaction catalysed by potassium, sodium and caesium carbonated has been carried out by Cerfontain et al. (118). From this study, and supported by other authors, the catalysis mechanism of the $\mathrm{C}-\mathrm{CO}_{2}$ reaction by an alkali metal carbonate approximates to:

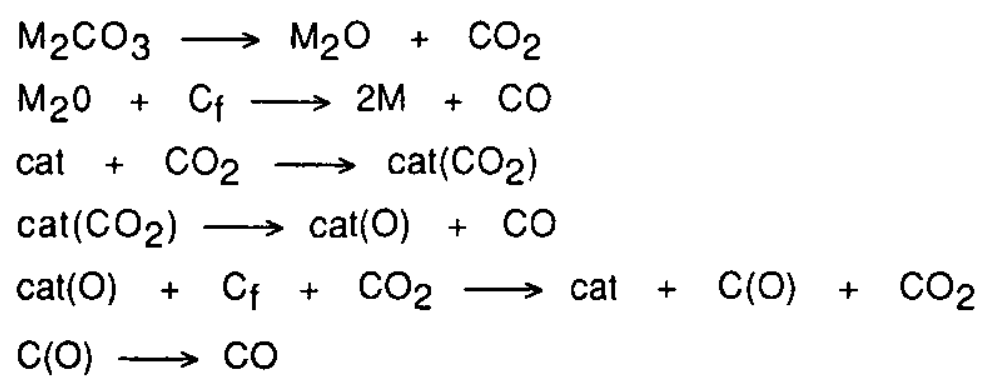

where $M=$ alkali metal, cat $=$ active catalytic species and () represents an adsorbed species.

Upon heating the alkali metal carbonate $\mathrm{M}_{2} \mathrm{CO}_{3}$ can decompose to the oxide or the metal depending on their relative stabilities. The metal in its catalytically active form (cat), the exact nature of which is not known, adsorbs $\mathrm{CO}_{2}$ which transfers an oxygen atom to the active catalyst and releases a molecule of $\mathrm{CO}$. The oxygen containing catalyst species (cat $(O)$ ) transfers oxygen to a free/active carbon site $\left(\mathrm{C}_{f}\right)$ in the presence of $\mathrm{CO}_{2}$ resulting in an adsorbed oxygen atom on the carbon surface, $\mathrm{C}(\mathrm{O})$. Finally, the adsorbed oxygen desorbs from the carbon surface as $\mathrm{CO}$.

This mechanism of Cerfontain et al. (118) is substantiated using in-situ FTIR by the observation that at gasification temperatures the decomposition of potassium carbonate to an oxide occurs. In the presence of $\mathrm{CO}_{2}$ at gasification temperatures, a carbon-oxygen complex was observed the exact nature of which is not determined. 
Cerfontain et al. (118) studied the chemisorption of $\mathrm{CO}_{2}$ between 200 and $700^{\circ} \mathrm{C}$ on alkali carbonate/carbon systems and showed that the catalyst chemisorbed $\mathrm{CO}_{2}$ molecules. The amount of adsorbed $\mathrm{CO}_{2}$ depended only on the metal:carbon ratio and not on the partial pressure of $\mathrm{CO}_{2}$ or the temperature and it was found to exchange rapidly with gas phase carbon dioxide. This supports the assumption that oxygen exchange occurs at the catalyst site and not in the gas phase. If it occurred at carbon sites it would involve $C(O)$ complexes the presence of which is dependent upon the partial pressures of both $\mathrm{CO}$ and $\mathrm{CO}_{2}$.

Cerfontain et al. (118) showed, using FTIR, that chemisorbed oxygen on active sites, $\mathrm{C}(\mathrm{O})$, only occurs in the presence of $\mathrm{CO}_{2}$ and that catalyst sites were responsible for oxygen exchange and $\mathrm{CO}_{2}$ chemisorption without carbon oxidation. Using mass spectrometry, they also showed (119) that the CO produced in the first 4 seconds (in their systems) was due to oxidation of the carbon-catalyst (C-M) complexes by $\mathrm{CO}_{2}$. Using temperature programmed reactivity measurements and step response experiments it was also found (118) that spillover of oxygen from metal-oxygen-carbon clusters to the carbon surface is significant and that oxygen is mobile on the carbon surface. The amount of oxygen taken up by the catalyst increases with temperature. As more oxygen is taken up, oxygen spillover (transfer) can occur from the catalyst on to the carbon surface. Figure 5.7 shows a schematic representation of a spillover mechanism with sodium as the catalyst in the $\mathrm{C}-\mathrm{CO}_{2}$ reaction. A 'spillover' (transfer) mechanism was also suggested by Inul et al. (120). It is also known that catalysts act at the position of contact with the carbon, i.e. there are no induced catalytic effects at a distance from the catalyst.

The rate determining step of the gasification reaction is the decomposition of $\mathrm{C}(\mathrm{O})$ complexes formed by the catalyst on the carbon surface. The desorption of the $\mathrm{C}(\mathrm{O})$ complexes is dependent on the partial pressures of $\mathrm{CO}_{2}$ and $\mathrm{CO} . \mathrm{CO}_{2}$ increase the amount of $\mathrm{C}(\mathrm{O})$ complexes on the surface whereas $\mathrm{CO}$ inhibits gasification by the back reaction with carbon, blocking active sites or by diminishing the steady state amount of $\mathrm{C}(\mathrm{O})$ on the surface in the equilibrium of reaction.

The rate constant for the desorption of $\mathrm{C}(\mathrm{O})$ is the same in the catalysed and uncatalysed reactions (121). Also, with different catalysts, $\mathrm{Na}$ and $\mathrm{K}$, the 
amount of $\mathrm{C}(\mathrm{O})$ complexes formed are different (118) but the rate constant for the desorption of $C(O)$ is the same (116). This leads to the conclusion that: "alkali catalysis of carbon gasification is due to an increase in the number of gasification sites compared with the uncatalysed reaction" because of the enhanced concentration of the $\mathrm{C}(\mathrm{O})$ species.

Although the exact nature of the C-O complex is not known various metalcarbon complexes such as phenolate have also been postulated (117). Carboxylate groups have been observed in alkali carbonate-carbon system (122) as have catalyst clusters, bulk alkali carbonate on the surface and an oxygen-catalyst species. All these catalyst forms and oxygen containing species may be present at once with certain forms in greater abundance and with varying rates of reaction (123). Thus, a non-stoichiometric catalyst-carbon structure may exist at gasification temperatures and species readily identifiable in room temperature studies may not exist at reaction temperatures.

Other authors have also studied alkali metals as catalysts of the $\mathrm{C}-\mathrm{CO}_{2}$ reaction which are comparable with those of Cerfontain et al. (118) but are possibly over simplified. McKee (109) proposed that the mechanism proceeded via a redox cycle involving the metal oxide, e.g. a possible catalytic mechanism for sodium carbonate:

(i) Carbothermic reduction reaction

$\mathrm{Na}_{2} \mathrm{CO}_{3}+2 \mathrm{C} \longrightarrow 2 \mathrm{Na}+3 \mathrm{CO}$

(ii) $\mathrm{C} \cdot \mathrm{CO}_{2}$ reaction

$2 \mathrm{Na}+\mathrm{CO}_{2} \longrightarrow \mathrm{Na}_{2} \mathrm{O}+\mathrm{CO}$

$\mathrm{Na}_{2} \mathrm{O}+\mathrm{CO}_{2} \longrightarrow \mathrm{Na}_{2} \mathrm{CO}_{3}$

McKee's proposed mechanism was seen only to occur at temperatures near the melting point of the carbonate (124), whereas the experiments of Cerfontain were carried out at gasification temperatures. Some authors have proposed mechanisms involving the metal in the gas phase (125) reacting with $\mathrm{CO}_{2}$ as vaporization of the metal into in the gas phase has been observed (126). This is unlikely due to the localised effect at the point carbon-catalyst contact. The formation of alkali-carbon intercalation compounds has also been proposed. These would affect the electron distribution within the carbon, the alkali 
metals donating electrons so facilitating gasification. However, the formation of these compounds is unlikely as they are unstable at gasification temperatures (127).

The introduction of the catalyst into a carbon feedstock, before carbonisation, increases the reactivity of the resultant carbon to $\mathrm{CO}_{2}$ and $\mathrm{O}_{2}$, and affects its strength, pore size distribution and structure (128). Carbonisation to temperatures above the melting point of the catalyst is expected to reduce the amount of catalyst present due to vaporisation. However, the catalyst has been found to remain in the carbon (128). Different HTT's and times of alkalicarbon systems in inert atmospheres before gasification may account for variations observed in mechanisms and gasification rates due to varying amounts of decomposition of the catalyst (118).

\subsection{Catalysis of the Carbon-Oxygen Reaction}

The $\mathrm{C}-\mathrm{O}_{2}$ reaction is catalysed by group I, group $\|$ and transition metals, as is the $\mathrm{C}-\mathrm{CO}_{2}$ reaction. Studies of the catalysis using different metals have been undertaken using graphite as the 'pure' carbon (109). gasification by oxygen occurs at lower temperatures, $\sim 450^{\circ} \mathrm{C}$, than by carbon dioxide.

The mechanism of catalysis of the $\mathrm{C}-\mathrm{O}_{2}$ reaction is comparable with that of the $\mathrm{C}-\mathrm{CO}_{2}$ reaction. The catalyst increases the number of gasification sites on the carbon surface by forming a carbon-metal-oxygen complex, from which, oxygen spillover onto the surface occurs with increasing amounts of oxygen in the catalyst complex.

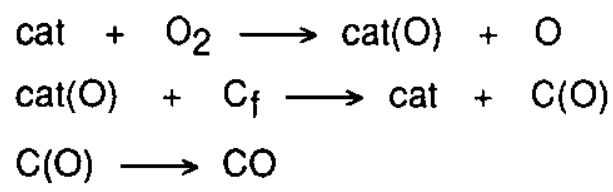

The rate determining step of the reaction is the desorption of $\mathrm{C}(\mathrm{O})$ complexes from the surface, the higher the surface coverage of $\mathrm{C}(\mathrm{O})$ complexes the lower the reaction activation energy because of the variation in enthalpy of chemisorption with surface coverage. Therefore, the catalyst lowers the reaction activation energy by increasing the amount of $\mathrm{C}(\mathrm{O})$ complexes on the surface. 
Such a detailed study as that of Cerfontain et al. (118) on the $\mathrm{C}-\mathrm{CO}_{2}$ reaction has not been undertaken with the $\mathrm{C}-\mathrm{O}_{2}$ reaction and the exact nature of the catalytic species is not known. McKee and Chatterji (124) have shown that the active intermediate in catalysis of the $\mathrm{C}-\mathrm{O}_{2}$ is a metal oxide. As with the $\mathrm{C}-\mathrm{CO}_{2}$ reaction they state that only those metal oxides which are thermodynamically capable of being reduced by carbon to a lower oxide or the metal catalyse the $C$ $\mathrm{O}_{2}$ reaction. On examining catalysis by sodium oxide, it was observed (124) that the temperature at which gasification was first accelerated corresponded closely to the meiting point of sodium peroxide, i.e. $460^{\circ} \mathrm{C}$. Between 250 and $450^{\circ} \mathrm{C}$ a weight gain of the sample was observed. The weight gain corresponded to the formation of sodium peroxide:

$2 \mathrm{Na}_{2} \mathrm{O}+\mathrm{O}_{2} \longrightarrow 2 \mathrm{Na}_{2} \mathrm{O}_{2}$

Sodium oxide, in the absence of oxygen, reacts slowly with graphite above $600^{\circ} \mathrm{C}$, thus, sodium peroxide is thought to be the active intermediate in catalysis of the $\mathrm{C}-\mathrm{O}_{2}$ reaction.

Dunks et al. (129) studied the oxidation of graphite in a molten bath of sodium carbonate through which oxygen or air was bubbled. In this case, the course of the reaction was followed by monitoring the production of $\mathrm{CO}$ and $\mathrm{CO}_{2}$ as a function of temperature between $900-1050^{\circ} \mathrm{C}$. However, virtually no $\mathrm{CO}$ was produced under the conditions of these experiments. The oxidation rate generally increased with increasing temperature, with increasing oxygen pressure ands with increasing graphite surface area. It was found that the beginning of each experiment the $\mathrm{CO}_{2}$ concentration in the product was high but decreased rapidly with time. This initially formed $\mathrm{CO}_{2}$ was apparently produced from the decomposition reaction:

$\mathrm{Na}_{2} \mathrm{CO}_{3} \longrightarrow \mathrm{Na}_{2} \mathrm{O}+\mathrm{CO}_{2}$

although some was probably formed by the reaction:

$\mathrm{Na}_{2} \mathrm{CO}_{3}+1 / 2 \mathrm{O}_{2} \longrightarrow \mathrm{Na}_{2} \mathrm{O}_{2}+\mathrm{CO}_{2}$

It was suggested that, in the early stages of the oxidation, the following sequence of reactions occurred: 


$$
\begin{aligned}
& \mathrm{Na}_{2} \mathrm{CO}_{3}+1 / 2 \mathrm{O}_{2} \longrightarrow \mathrm{Na}_{2} \mathrm{O}_{2}+\mathrm{CO}_{2} \\
& 2 \mathrm{Na}_{2} \mathrm{O}_{2}+\mathrm{C} \longrightarrow 2 \mathrm{Na}_{2} \mathrm{O}+\mathrm{CO}_{2} \\
& \mathrm{Na}_{2} \mathrm{O}+1 / 2 \mathrm{O}_{2} \longrightarrow \mathrm{Na}_{2} \mathrm{O}_{2} \\
& \mathrm{Na}_{2} \mathrm{O}+\mathrm{CO}_{2} \longrightarrow \mathrm{Na}_{2} \mathrm{CO}_{3}
\end{aligned}
$$

with the first reaction being rate limiting when the graphite surface area was high. As the graphite became depleted in the melt, the second reaction became the slowest step. A direct confirmation of the participation of peroxide in this catalysed reaction could presumably be obtained by spin resonance techniques, but this experiment has not yet been attempted.

Many transition metals, e.g. iridium, rhodium, iron, cobalt, and nickel are also known to catalyse the reaction (109). Copper catalyses the reaction by the reduction of $\mathrm{CuO}$ and $\mathrm{Cu}_{2} \mathrm{O}$ to the metal at temperatures above $500^{\circ} \mathrm{C}(130)$. Aluminium, zinc and tin are not catalysts as their oxides are stable in the presence of carbon.

The ratio of $\mathrm{CO}: \mathrm{CO}_{2}$ formed in the oxidation of carbons is seen to decrease with catalysis (131), i.e. more $\mathrm{CO}_{2}$ is formed in the catalysed reaction. This is thought to be due to catalysis of the formation of $\mathrm{CO}_{2}$ by enhanced surface concentrations of $\mathrm{C}(\mathrm{O})$ and not due to the secondary oxidation of $\mathrm{CO}$ to $\mathrm{CO}_{2}$ (131).

Thus, catalysis occurs by the metal catalysing the transfer of oxygen from the gas phase onto the carbon surface as well as the catalyst increasing the number of active sites on the carbon surface at the interface with the catalyst. Once the oxygen is adsorbed on the carbon surface, the adsorbed species may be mobile or immobile and undergo any of the reactions (20) to (28) proposed by Marsh (77). 


\subsection{Topography of Catalytic Gasification}

Catalysis not only changes the kinetics of gasification reactions but also alters surface topography during gasification. Microscopy studies of the oxidation of graphites were first undertaken by Thomas (132) and Hennig (133) around 1960.

Mckee (124) observed the oxidation of graphite flakes with sodium (Fig.5.8) and rubidium carbonates using a hot stage microscope. He observed mobility of the catalyst particles was accompanied by the formation of a gasified channel on the graphite basal plane and concluded that mobility and catalytic channelling were associated with the formation of the liquid peroxide.

Marsh et al. (134) using transmission electron microscopy observed the topographical effects of oxygen and atomic oxygen on graphite and on graphite with iron. They observed the formation of hexagonal pits and hillocks on the graphite surface.

Uncatalysed gasification occurs at imperfections in the graphite basal plane, e.g. vacancies, point defects, screw dislocations, edges of basal planes and steps where one basal plane ends but a plane underneath continues. Catalysts are found to accumulate on a carbon surface at these sites due to the availability of electrons at imperfections in the lattice (135). The following modes of surface gasification are attributed to carbon-catalyst interactions (135):

\section{Pitting}

It has been found that catalysts located at vacancies within a graphite basal plane form pits in the plane surface, Fig.5.9. The catalyst particle attacks perpendicular to the basal plane so forming a hexagonal hole. This can continue to increase in depth due to penetration of the catalyst and can also expand due to the edge recession of the hole. The larger the pit becomes the more circular it appears. The formation of the pit is slower than the process of edge removal. 


\section{Edge Recession}

Catalysts situated on graphite edge atoms and which have a very strong interaction with the carbon form a thin film of catalyst over the edge carbon atoms. Catalytic attack is then by edge recession, Fig.5.10.

\section{Channelling}

Catalyst particles at edges or steps of the graphite lattice act specifically on the edges and channel into the graphite layers. This mode of attack, observed by Baker (135) occurs when the degree of interaction between the catalyst and the carbon, ie. the degree of wetting, is less than that observed when edge recession occurs. During the formation of a channel the catalyst particle appears to be fluid. Fig.5.8 shows channelling patterns produced on graphite flakes at $600^{\circ} \mathrm{C}$ by $\mathrm{Na}_{2} \mathrm{CO}_{3}$. In some cases, as the channel proceeds catalyst particles are left behind on the channel walls. This allows the walls to gasify further and the channel to increase, whereas the catalyst particle itself becomes smaller and the progressing channel becomes narrower. The result is a channel with a fluted appearance, Fig.5.11a. The channel can be straight or can change direction due to structural changes in the carbon being gasified, Fig.5.11b.

The mode by which a catalyst operates is governed to a large degree by the strength of the interaction between the metal and the graphite edge atoms. This aspect is already outlined above, and is now described from a thermodynamic standpoint by reference to Young's equation (136). For a metal-gas-support system at equilibrium:

$\Omega_{\mathrm{gs}}=\Omega_{\mathrm{ms}}+\Omega_{\mathrm{mg}} \cos \sigma$

where: $\varnothing$ is the contact angle between the metal particle and the support

$\Omega$ is the surface energy

Subscripts s, $m$ and $g$ refer to support, metal and gas, respectively.

The ability of particles to undergo a transformation from a non-wetting to wetting state suggests that a significant degree of atomic mobility exists, certainly in the surface layers. The extreme conditions of wetting, spreading in the form of a thin film on the support surface, occurs when the work of 
adhesion exceeds the work of cohesion within the metal particle, which is expressed as:

$\Omega m s>\Omega g s+\Omega m g$

for the intermediate wetting state where the catalyst is present as a discrete cap-shaped particle, the mode of attack would be expected to proceed by a channelling action. For the situation where catalyst particles exhibit a strong interaction with the graphite edge atoms and as a consequence undergo spreading to form a thin film, then the subsequent catalytic mode of attack occurs via edge recession. Spreading of the catalyst in this manner results in the most efficient use of the additive in that the contact area between catalyst and graphite edge atoms is maximized. This is a simple thermodynamic approach to the morphological behaviour of metal particles on graphite supports.

Controlled atmosphere electron microscopy (CAEM) has been used to study the topographical action of a catalyst on graphite during gasification as was first used by Thomas et al. (132) in 1964. Baker (135) has undertaken many studies using CAEM to observe the catalytic behaviour of metals with different oxidising gases. The technique allows a sample to be studied in situ. The specimen, a single graphite crystal $15-100 \mathrm{~nm}$ thick, is surrounded by reactant gas at high pressure, while the rest of the microscope remains evacuated. The catalyst particle appears to eat its way through the carbon structure by pitting, edge recession or channelling. Thus, the catalyst acts at its point of contact with the carbon which complies with the theories that a metalcarbon interaction occurs (118). Rodriguez et al. (137) used CAEM to study the mode of catalytic attack for carbons with different optical textures. It was found that:

(i) isotropic carbons or carbons with very little anisotropy formed shallow pits at lower $\left(375^{\circ} \mathrm{C}\right)$ temperatures.

(ii) anisotropic carbons formed deep pits at higher $\left(>525^{\circ} \mathrm{C}\right)$ temperatures and edge recession occurred especially in areas with highly ordered structures.

Recently, Baker (138) has explained, using thermodynamics, that metals which adsorb oxygen dissociatively and readily form oxides, form strong interfacial bonds with carbons and so result in edge recession. Whereas metals which adsorb oxygen non-dissociatively do not exhibit a strong interaction with 
oxygenated carbons and exist as discrete particles at graphite edges which they attack by the channelling mode.

Anode carbons are readily gasified by carbon dioxide above $900^{\circ} \mathrm{C}$ and by oxygen above $450^{\circ} \mathrm{C}$. both reactions are catalysed by alkali metals, transition metals and the alkaline earth metals, a metal-carbon-oxygen complex being the catalytic intermediate which promotes gasification. The topography of gasification is also altered by catalysts, which act at their point of contact with the carbon. 

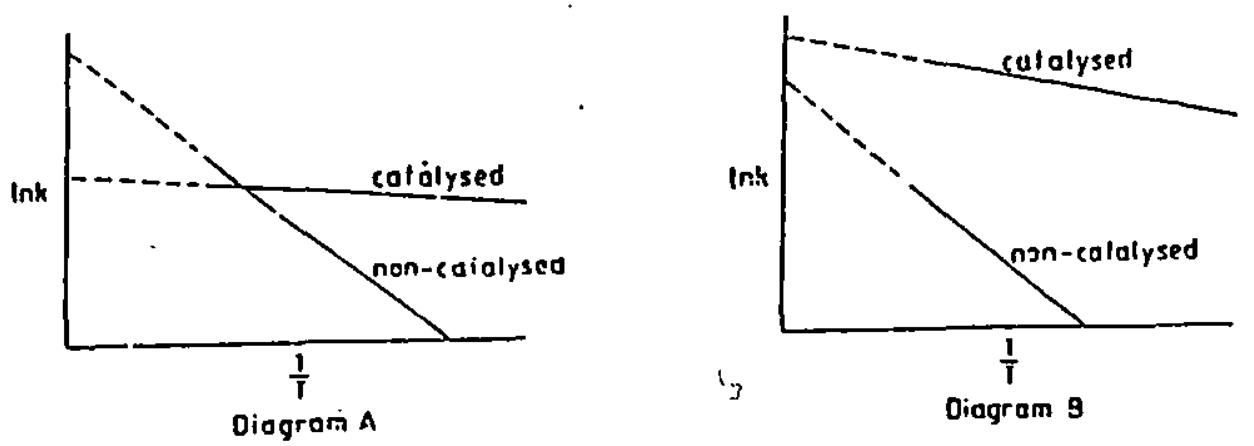

FIG.5.1. Arrhenius plots for catalysed and non-catalysed reaction.

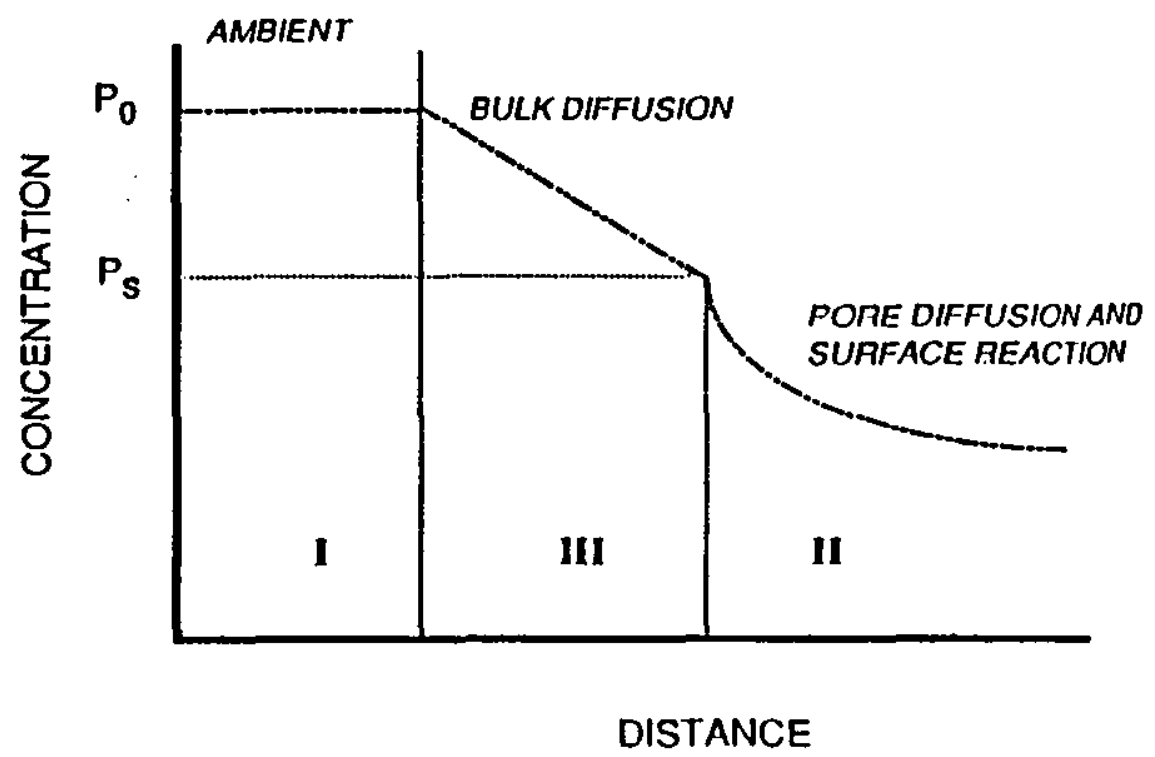

FIG.5.2. Concentration profile for gaseous reactant near and within a porous char particle. 


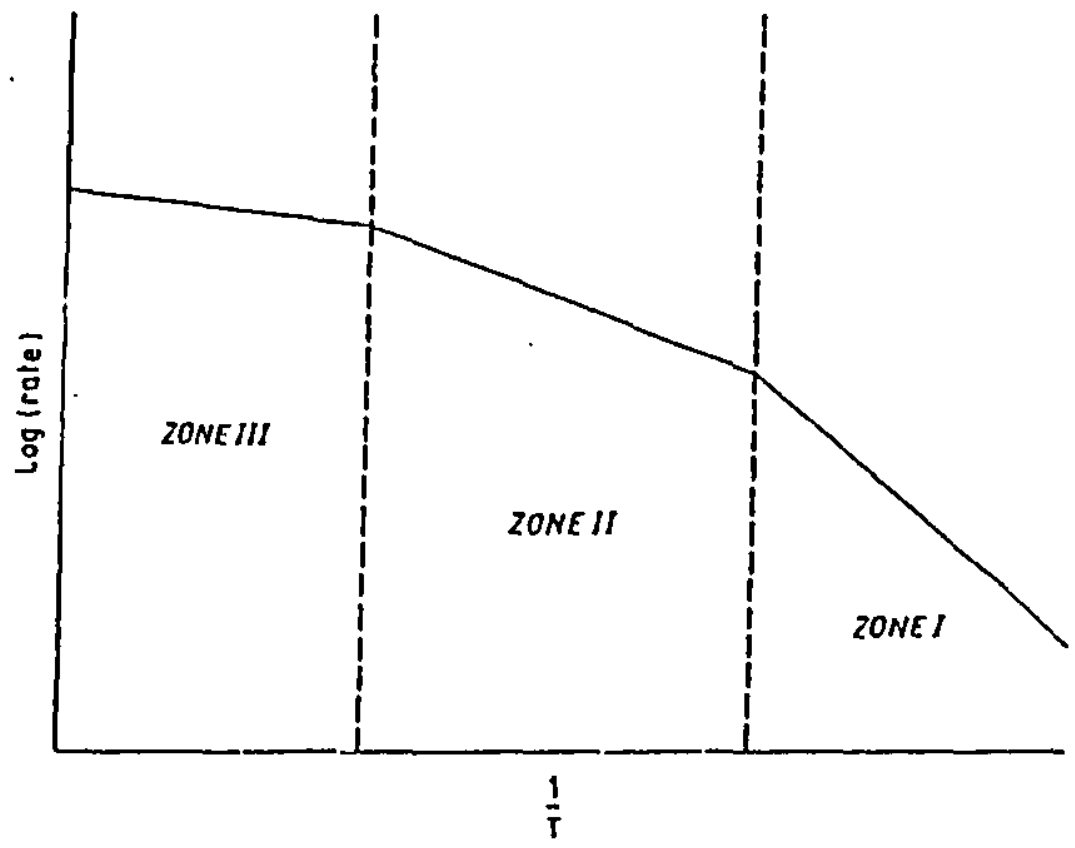

FIG.5.3a. Variation of reaction rate with temperature for gas-carbon reactions.
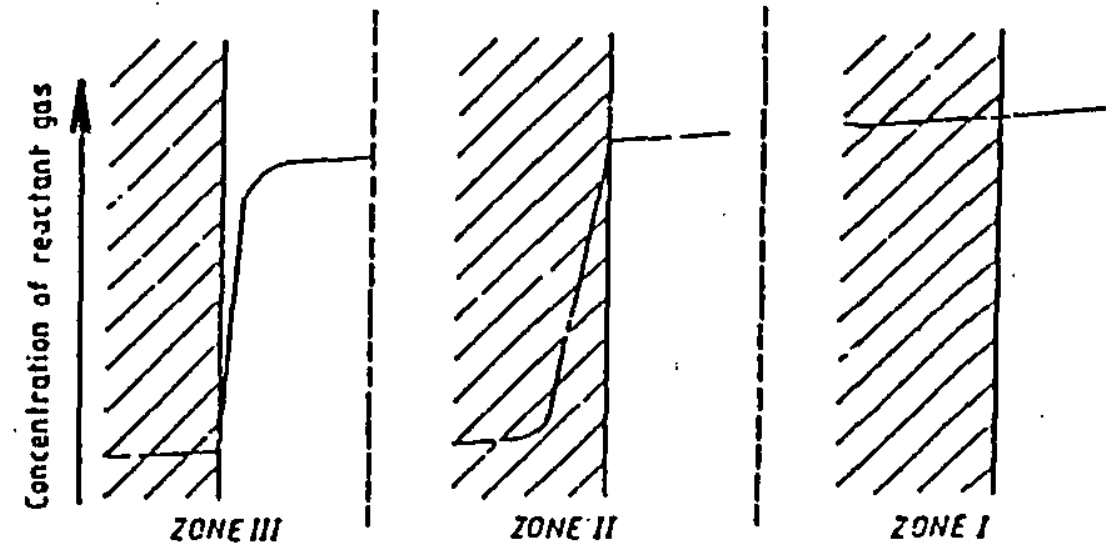

FIG.5.3b. Variation of reactant gas concentration at the sample surface with rate controlling zone. 
$\mathrm{T}\left({ }^{\circ} \mathrm{C}\right)$

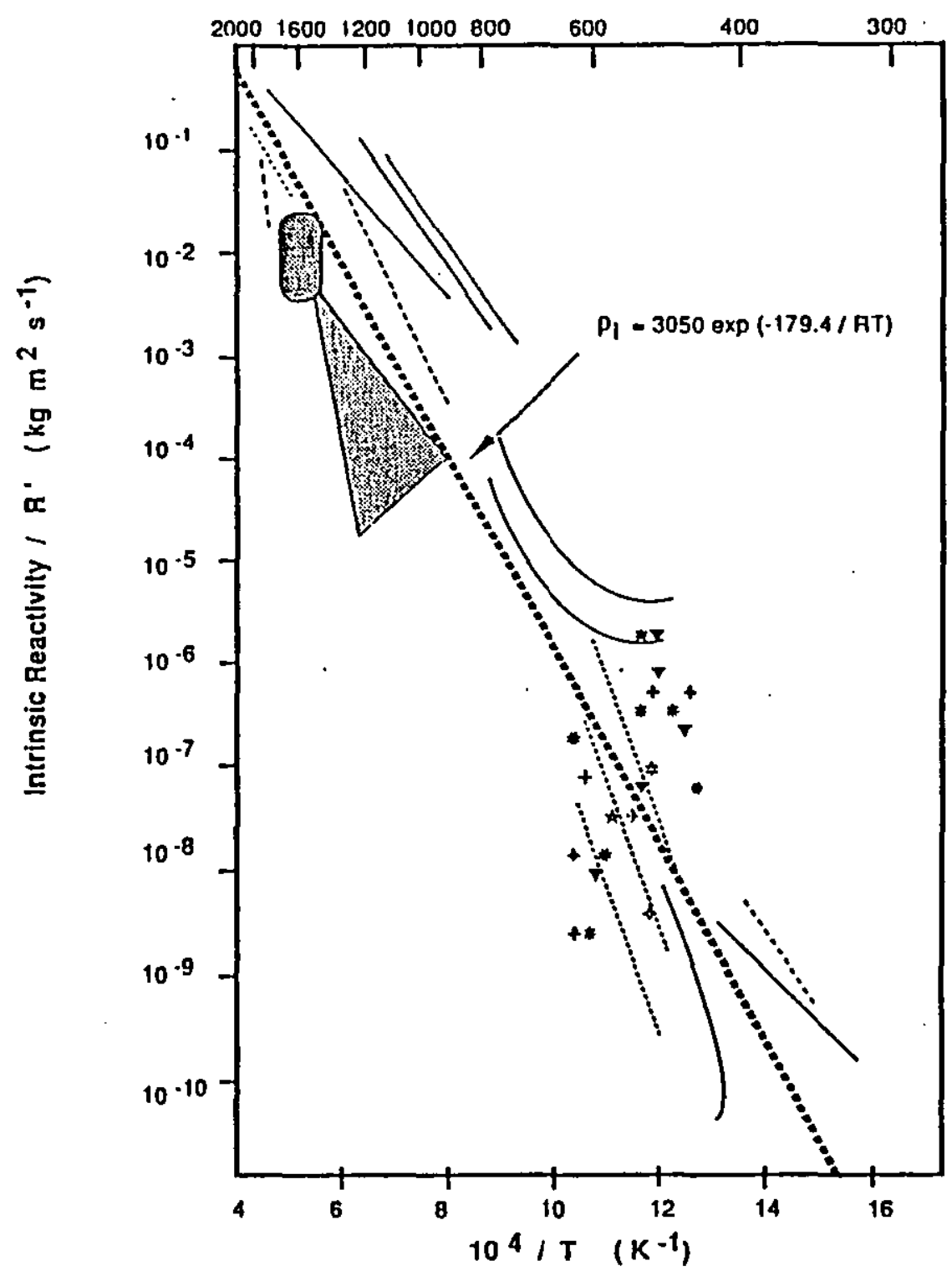

FIG.5.4. Variation of intrinsic reactivity of various carbons with temperature and oxygen pressure of $101 \mathrm{kPa}$ (5.24). 


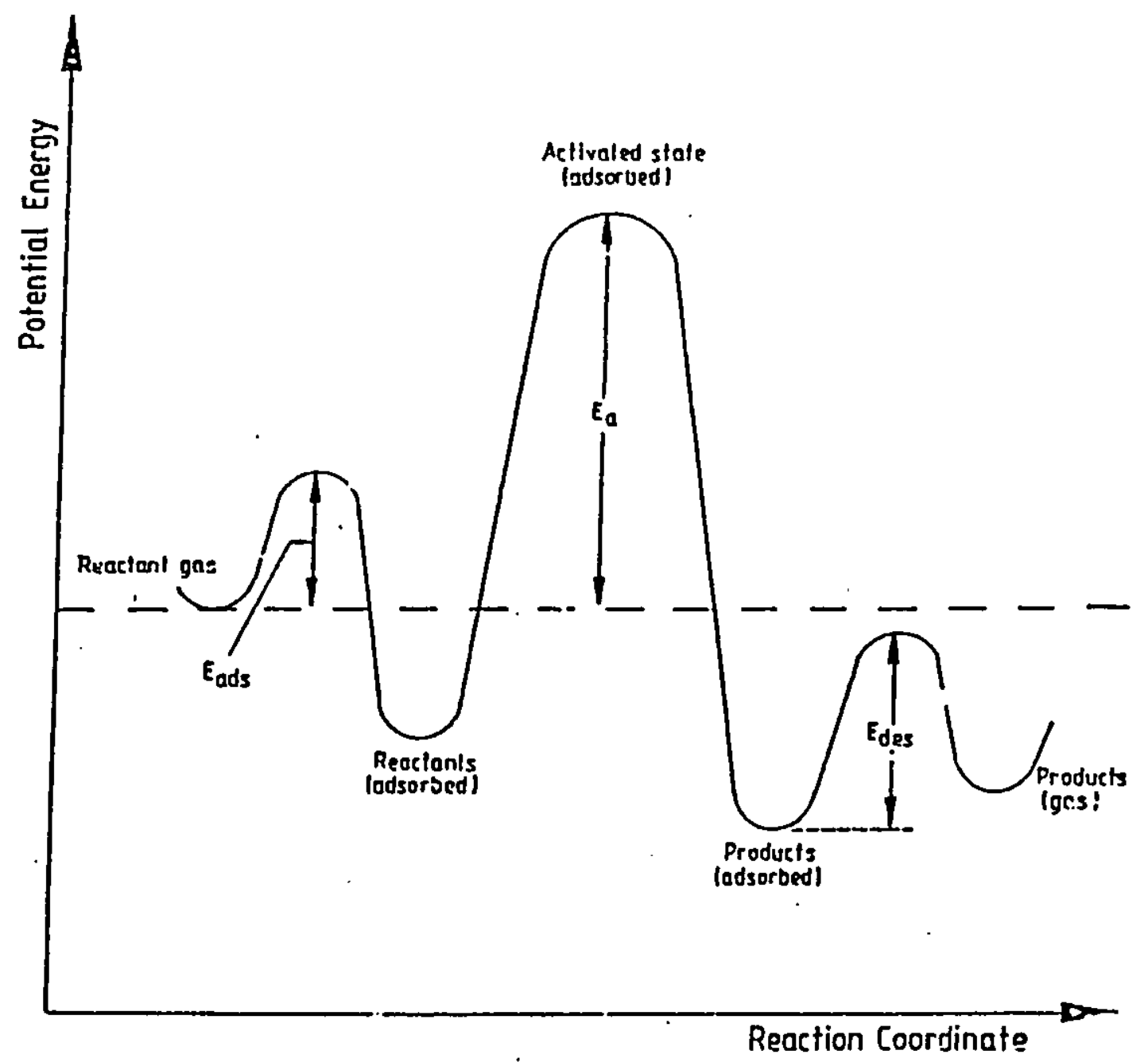

$E_{\text {ads }}=$ energy of adsorption.

$E_{a}$ experimental activation en:rgy of the reaction.

$E_{\text {des }}=$ energy of desapplion.

FIG.5.5. Potential energy curve for the reaction between a gas and a solid surface. 


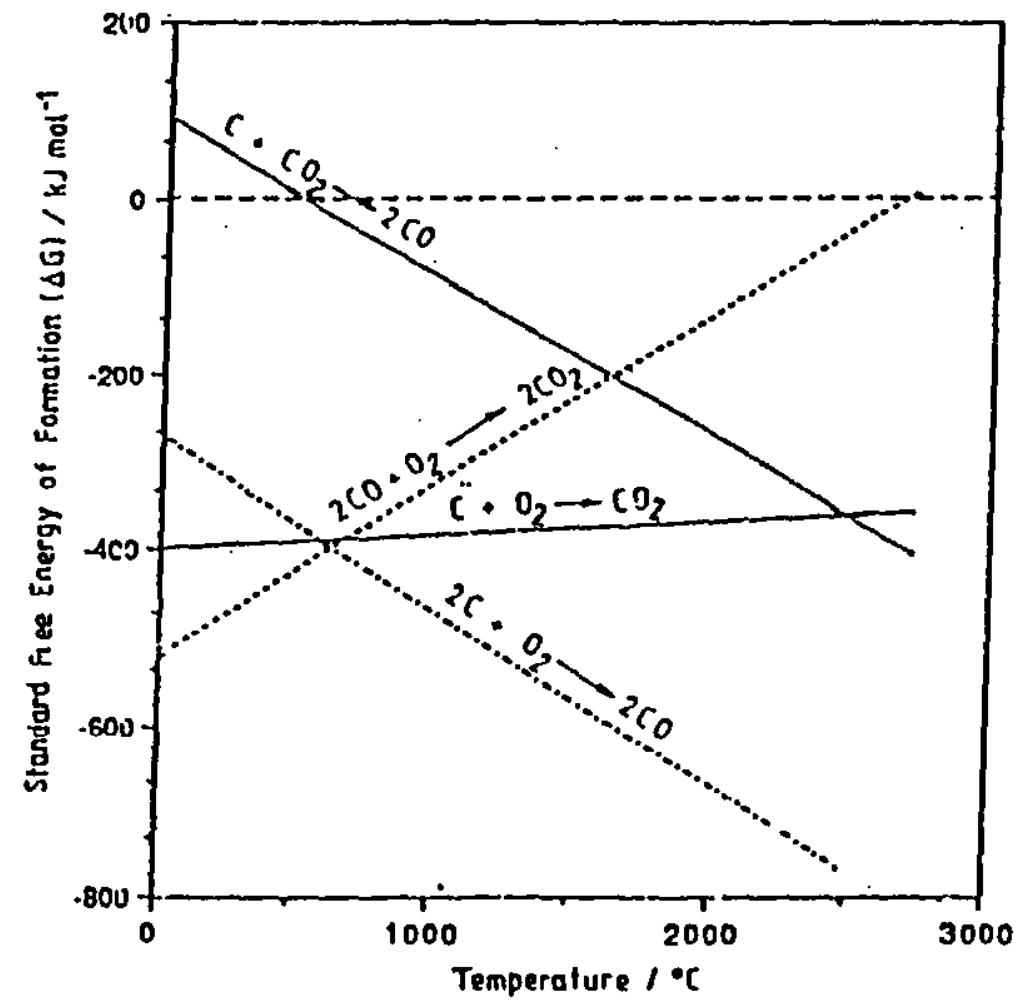

FIG.5.6. Variation in the standard free energy of formation of the oxides of carbon with temperature. 


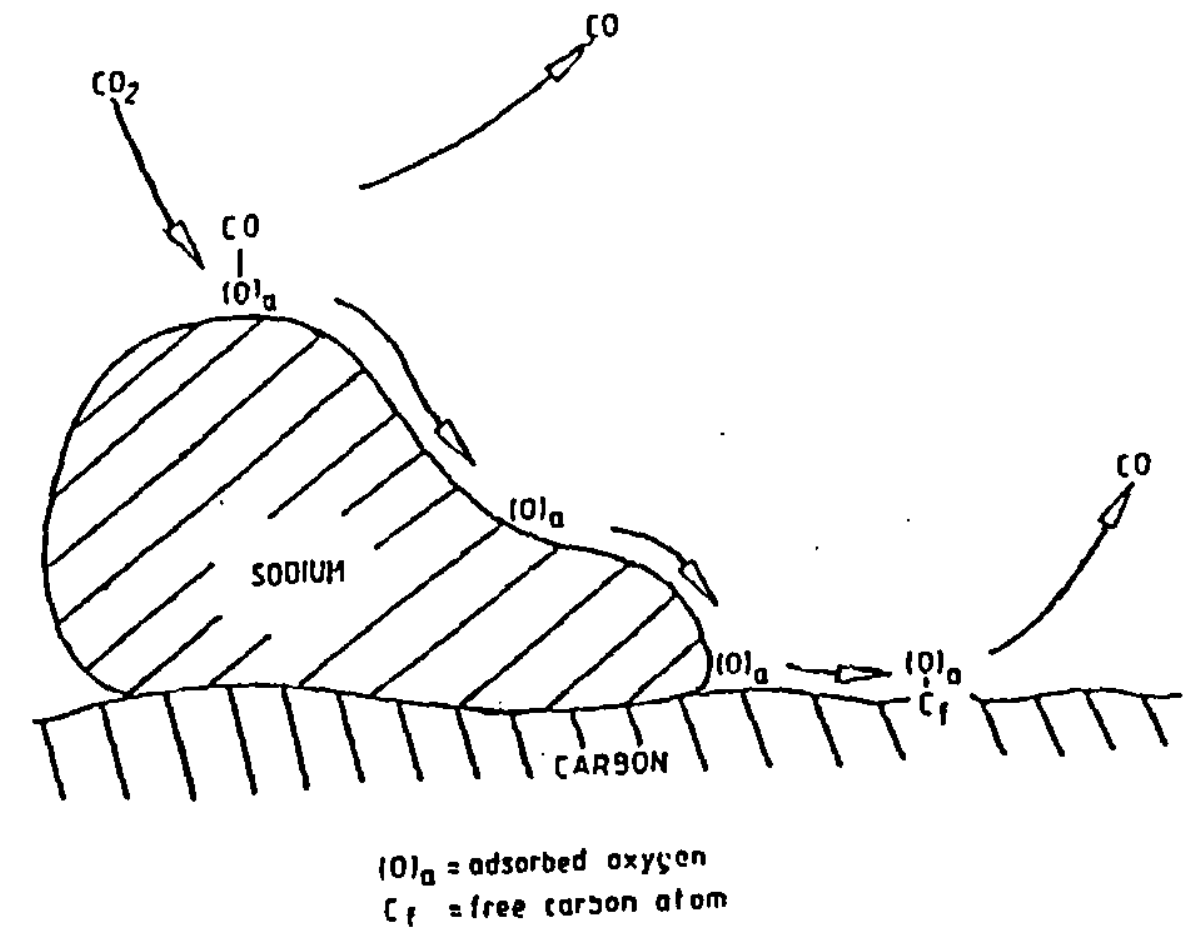

FIG.5.7. Spillover mechanism of the catalysis of the Boudouard reaction by sodium. 


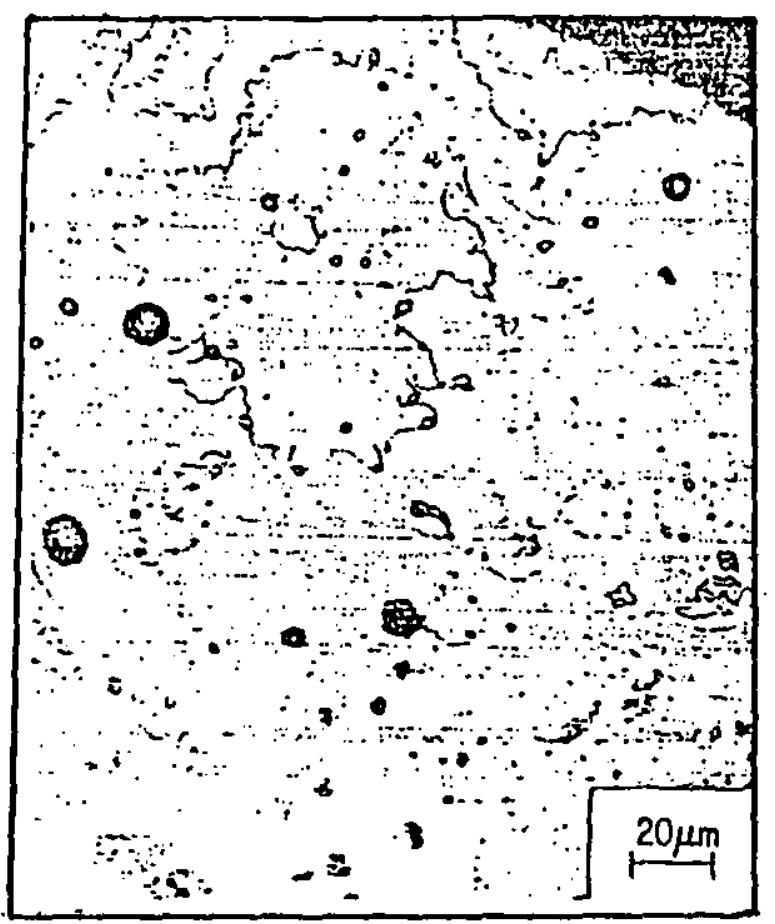

FIG.5.8. Catalytic channelling on graphite basal plane surfaces by $\mathrm{Na}_{2} \mathrm{CO}_{3}$ at $600^{\circ} \mathrm{C}$ in $\mathrm{O}_{2}$. 


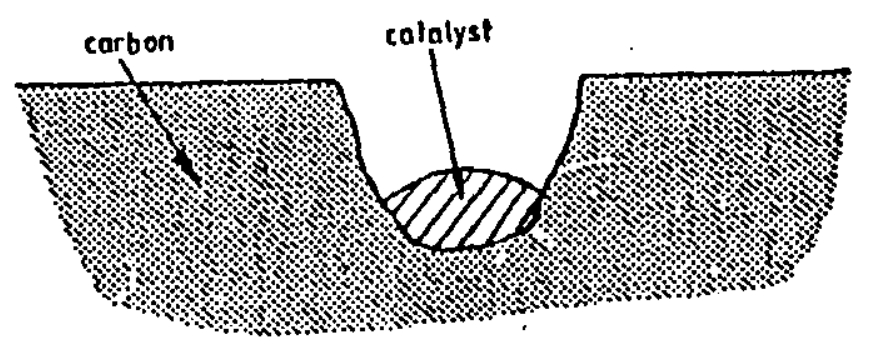

FIG.5.9. Pitting of a graphite basal plane.

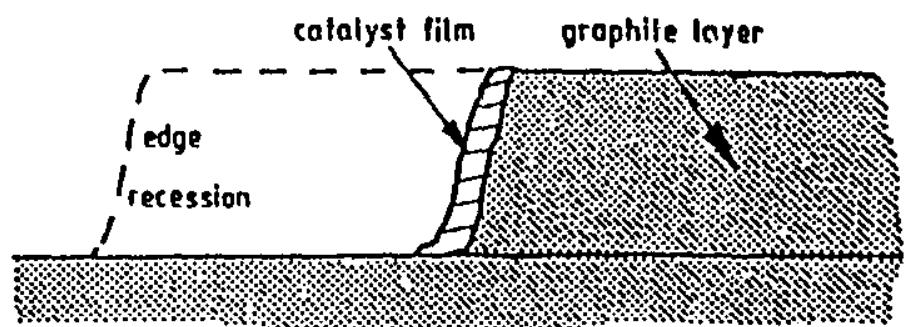

FIG.5.10. Edge recession of graphite basal plane due to the presence of a calalyst film. 

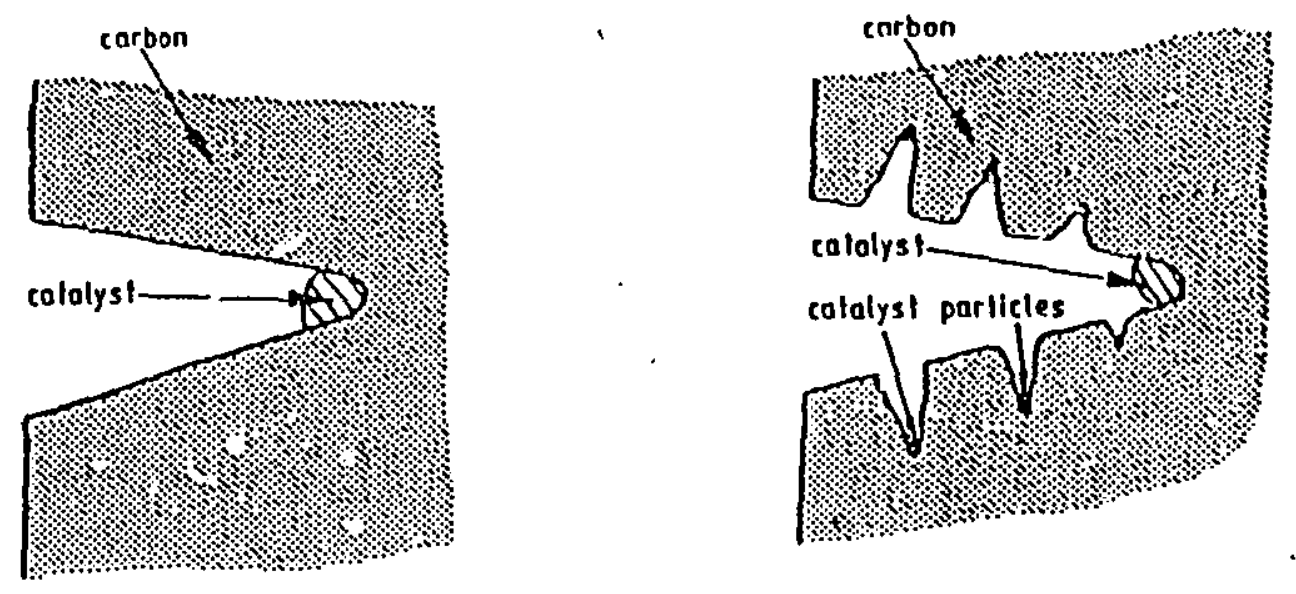

FIG.5.11a. Channelling action of a catalyst resulting in fluted channels.

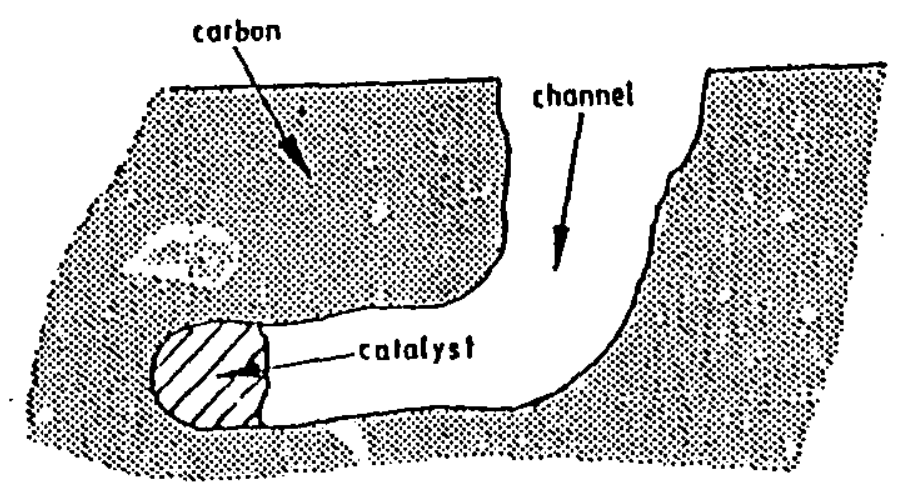

FIG.5.11b. Changing direction of a channclling catalyst. 


\section{PROGRAMME OF RESEARCH}

The objective of this research project was to investigate the gasification, in air and carbon dioxide, of anode carbons typical of those used in the aluminium industry, to identify any differences in the behaviour of filler coke and the coke from the coal-tar binder pitch, and to study the effect of pitch quality, especially the type and proportion of quinoline insolubles and the sodium content, on those processes which contribute to excess anode consumption.

The approach adopted was to prepare on a pilot scale, carbons, typical of those used in aluminium extraction, on a pilot scale and to investigate their gasification behaviour, in air or carbon dioxide, using facilities designed to obtain different types of information and to produce different samples for further examination.

Two series of carbons were prepared for study of their gasification behaviour. To obtain data on the influence of pitch sodium content on anode carbon oxidation, carbons were produced using a typical binder pitch into which regulated amounts of sodium had been incorporated. Pitches, varying more widely in primary quinoline insoluble content than those normally used commercially, were used to produce test anodes for the study of the effect of pitch quality on anode carbon oxidation.

All materials produced were tested in three ways. Small specimens were oxidised in air, and their air reactivity measured, before their surface friability was assessed. These tests were designed to simulate the air burn and dusting phenomena experienced in aluminium extraction cell operation. Similar specimens were used to assess the variation of air reactivity with temperature and to establish when the mechanism of oxidation changed from chemical to diffusion control. Larger specimens were gasified in air and carbon dioxide before studying the variation in their porosity with distance from the external surface.

The important influence on anode consumption, and aluminium extraction costs, of anode carbon gasification in air and carbon dioxide at elevated temperatures is now readily apparent. With existing plant configurations, there is little that can be done to minimise contact between the anode carbon and the reactant 
gases. Hence attention becomes focussed on the anode carbon itself and, in particular, on the effect of raw materials on its gasification behaviour. It is this aspect of the problem which is addressed by this study, and which will try to answer some or all of the following questions:

i. What effect do variations in the sodium content of the binder pitch have on the oxidation rate, dusting rate, and abrasion loss of laboratory anode carbons?

ii. How does oxidation effect the structure of anode carbons, eg. the porosity of the outer layers?

iii. What part of the structure is gasified?

iv. Is the pitch coke removed preferentially?

v. Is dusting associated with preferential removal of pitch coke, and is this associated with the QI content of the pitch?

vi. What effect does the presence of sodium have on structure changes on gasification?, is pitch coke oxidised even more strongly than filler coke?, does it induce even more dusting and abrasion loss.

vii. Where is sodium, in the pitch coke or distributed throughout the anode structure? 


\section{EXPERIMENTAL PROCEDURES}

\subsection{Introduction}

In this study anodes were produced on the laboratory/pilot scale from a wider range of raw materials than is normally used in industrial anode manufacture so that effects could be emphasised and more readily identified. Test carbons were subjected to oxidation and abrasion testing. The oxidation test was carried out under conditions that diffusion within the pores was rate controlling so that the product had a friable surface surrounding a durable core. The aim of the abrasion test was to compare the friability of the surface layers of the carbons. The methods used are described in this section. Also described are techniques used for examining the structure of the carbons by scanning electron microscopy (SEM) and image analysis (IA).

\subsection{Materials Used}

The anode carbons used were produced on the pilot scale from a mix consisting of a calcined petroleum coke, produced in the UK by Conoco, typical of that supplied to UK aluminium producers and a coal-tar pitch supplied by the UK pitch producer Bitmac. The properties of the regular-grade petroleum coke are in Table 7.1. Pitch properties are in Table 7.2, which shows a quinoline insoluble content of $10 \%$ and a sodium content of $400 \mathrm{ppm}$. The softening point was measured by the Mettler method. This pitch was used in the study of the influence of sodium content on anode carbon air reactivity and differed from four coal-tar pitches, supplied from a producer in Germany (Table 7.3). These four were used in the study of the effect of $Q$ l content on anode carbon gasification. As Table 7.3 shows, the four pitches used varied in softening point, by the Mettler method, from 101 to $106^{\circ} \mathrm{C}$ and in QI content from 3.7 to $11.5 \mathrm{wt} \%$. Examination of a polished surface of each pitch revealed only a very small number of mesophase spheres, and so it was concluded that the observed QI in each pitch was primary QI. 


\subsection{Sodium doping of pitch}

To increase the sodium content of the pitch, the required quantity of sodium, as carbonate, was dissolved in a small amount of distilled water and mixed with $600 \mathrm{~g}$ of finely-crushed pitch to form a homogeneous paste. This quantity of pitch was that required to make a batch of test carbons. The mixture was allowed to dry at room temperature and was then heated above the softening point of the pitch before being mixed with the filler. Sodium-modified pitches containing sodium contents 500,1000,1500,2000 and 2500ppm above the original as-received level were prepared for the study of the influence of pitch sodium content on the oxidation behaviour of anode carbons produced from them.

\subsection{Sodium analysis of pitch by AA Spectroscopy}

Sodium analysis of the four pitches listed in Table 7.3 was carried out using a Model 1100 Perkin-Elmer Atomic Absorption Spectrometer. A schematic of the optical system is depicted in Fig.7.1, which includes a optional deuterium background corrector.

A hollow cathode lamp or electrodeless discharge lamp serves as the element specific (primary) radiation source. The primary source is modulated by pulsing the lamp current. A deuterium arc lamp serves as the continuum source for operation with simultaneous background correction. In atomic absorption (AA) mode only radiation from the primary source passes through the atomizer and the monochromator to the detector, while in back-ground $(B G)$ mode only radiation from the continuum source passes to the detector. For operation with background correction ( $A A-B G$ mode), radiation from both sources passes to the detector.

The process of atomic absorption is illustrated in Fig.7.2. Every element has a specific number of electrons associated with its nucleus. The normal and most stable orbital configuration of an atom is known as the "ground state." If energy is applied to an atom, the energy will be absorbed and an outer electron will be promoted to a less stable configuration known as the "excited state." The "ground state" atom absorbs light energy of a specific wavelength from the primary light source as it enters the "excited state". As the number of atoms in the light path increases, the amount of light absorbed also increases. By 
measuring the amount of light absorbed, a quantitative determination of the amount of analyte can be made. The use of special light sources and careful selection of wavelengths, eg. sodium wavelength: $589 \mathrm{~mm}$, allow the specific determination of individual elements.

The adopted procedure was to dissolve a known amount of finely crushed pitch in $20 \mathrm{ml}$ of distilled water. This solution was then refluxed in $20 \mathrm{ml}$ of 32 molar nitric acid for eight hours, after which it was filtered. For analysis $1 \mathrm{ml}$ of the filtrate was made up to $25 \mathrm{ml}$ with distilled water.

\subsection{Test Anode Production}

Before producing test electrodes it was necessary to find the proportions and sizes of filler coke to obtain a high packing density. Firstly, this was investigated by determining the filler coke granulometry. Based on the filler sizes used in anode production by Alcan, Lynemouth, the filler particle sizes given in Table 7.4 were arbitrarily decided upon.

To find the proportions of fine, medium and coarse sizes to give a high packing density, the following procedure was undertaken:

(i) Weighed amounts of coarse and medium fractions in the ratio 50:50 were put into a measuring cylinder. The cylinder was shaken and the tap volume was measured.

(ii) 10 parts by weight of the fine fraction were then added to the cylinder, and after shaking, the tap volume and tap density, $\mathrm{g} \mathrm{ml}^{-1}$, were determined. The reason for shaking the cylinder was in order to give a uniform packing density.

(iii) Different parts by weight of the fine fraction were added to the cylinder and further tap densities calculated.

(iv) Steps (i) to (iii) were also carried out for a $60: 40,40: 60$ and $75: 25$ ratio mixture of coarse and medium fractions.

The proportions, percentage by weight, for all of the coarse, medium and fine fractions were plotted on a triangular grid, along with the tap densities as shown in Fig.7.3. The grid was analysed for a maximum in the tap density 
values. It was decided that the proportions given in Table 7.4 were satisfactory for a high packing density.

To produce pilot-scale anode carbons for test purposes the following general procedure was used. $3 \mathrm{~kg}$ of filler coke, sized as shown in Table 7.4, were electrically-heated to $165^{\circ} \mathrm{C}$ in a 4.51 capacity Z-blade mixer. This hot filler grist was then mixed for ten minutes with $600 \mathrm{~g}$ of the selected binder-grade, coal-tar pitch before the resulting paste was moulded for one minute at a temperature of $150^{\circ} \mathrm{C}$ and a pressure of $2.5 \mathrm{MPa}(367 \mathrm{psi})$, on a 1.57 in diameter ram (equivalent to a total load of 3000 psi or $20.69 \mathrm{MPa}$ on a 4.5 inch diameter), to form a cylindrical green block $43 \mathrm{~mm}$ in diameter by $100 \mathrm{~mm}$ tall. These conditions are similar to those used in commercial anode production. All test anodes were produced using a calcined petroleum coke typical of that supplied to aluminium producers in the UK.

As mentioned above the filler coke sizes were mixed in the proportions shown to maximise the tap density of the pitch-free mix. Previous study had shown that this filler size mix with the proportion of pitch used, $16.7 \mathrm{wt} \%$ of the green block (or $20 \mathrm{wt} \%$ of the filler weight), gave an anode with good strength while avoiding any tendency for deformation (slumping) or coke pick-up during carbonisation. The aim of the moulding stage, apart from obtaining a suitable size and shape of anode, is to eject air trapped in the mix so that both maximum green block density and good adhesive binder/filler contact are achieved. To convert the moulded green block into anode carbon, it was carbonised in flowing nitrogen in a tube furnace at $15 \mathrm{~K} / \mathrm{min}$ to $1200^{\circ} \mathrm{C}$. After soaking for 12 hours, it was then cooled to room temperature at $20 \mathrm{~K} / \mathrm{min}$. Cylindrical cores, $15 \mathrm{~mm}$ in diameter were cut from the baked electrodes using a diamond tipped core drill. The principal difference between this procedure and that used commercially lies in the smaller size of filler coke particles used. This change was made to match more closely the filler and mould sizes; larger filler particles, in the $43 \mathrm{~mm}$ diameter mould used for test anode moulding, would have introduced unacceptable edge effects. 


\subsection{Gasification test methods}

To obtain information on the gasification behaviour of anode carbons three basic test procedures were developed. In the first, small test pieces, cut from the $43 \mathrm{~mm}$ diameter by $100 \mathrm{~mm}$ tall carbon cylinders, were exposed to air at elevated temperature and, after test, were subjected to a technique designed to assess the friability of the oxidised surface. To obtain oxidised samples suitable for studying, by image analysis, the depth of the gasification attack, samples $43 \mathrm{~mm}$ diameter by $40 \mathrm{~mm}$ tall were oxidised in a tube furnace in air and carbon dioxide. The third procedure, designed to obtain data on the variation of oxidation rates, in air, with temperature, were carried out using an electromagnetic balance. Details of these test procedures are given below.

\subsubsection{Test 1. Air oxidation / Friability test}

Several procedures have been reported in the literature in order to evaluate oxidation selectivity with air $\left(\mathrm{O}_{2}\right)$ and $\mathrm{CO}_{2}$. A mechanical treatment after controlled air oxidation, was adopted for this study.

In the air-oxidation test developed for pilot-scale anode carbons, twenty cylindrical test pieces $15 \mathrm{~mm}$ diameter by $15 \mathrm{~mm}$ tall were cut from $60 \mathrm{~mm}$ lengths of two test anodes. These were then oxidised in air for various times up to two hours and at temperatures in the range 520 to $595^{\circ} \mathrm{C}$ in the muffle furnace illustrated in Fig.7.4. Results from these runs indicated that appropriate oxidation test conditions for comparing anode carbons produced from the range of sodium doped pitches were $550^{\circ} \mathrm{C}$ for one hour.

To perform a test, the furnace, with all the firebricks $(\mathrm{Fb})$ in position and with air flowing through the air inlet (Ai) at a rate of $1.6 \mathrm{~L} / \mathrm{min}(760 \mathrm{~mm} \mathrm{Hg}$ and $25^{\circ} \mathrm{C}$ ) was heated to temperature, this being measured by the control thermocouple (Ctc). The door (D) and the two firebricks nearest to it were removed and quickly replaced, the small firebrick now bearing the dry, weighed test specimen (S) contained in a shallow silica crucible. The specimen thermocouple (Stc) was then inserted. After the chosen test period, the temperature of the specimen thermocouple was noted and the specimen was removed and cooled in a dessicator. Usually some particulate carbon debris had collected in the crucible. The total weight and the weight of the remaining lump 
of specimen were determined and used to obtain the percentage oxidation and dusting losses, according to:

Oxidation loss $=100 \cdot\left(W_{1} \cdot W_{2}\right) / W_{1}$

Dusting loss $=100 .\left(W_{2}-W_{3}\right) / W_{1}$

where $W_{1}$ is the original specimen weight, and $W_{2}$ and $W_{3}$ are the total weight (lump plus debris) and the weight of the lump remaining after the oxidation test.

To assess the surface friability of the oxidised material, ten individual surviving lumps together with three steel balls, $8 \mathrm{~mm}$ in diameter, were placed in a $315 \mathrm{~mm}$ long by $25 \mathrm{~mm}$ internal diameter steel tube fitted with dust-proof end caps. These ten lumps, five from each test anode, were representative of the twenty specimens oxidised. The tube was then rotated, end-over-end, at $18 \mathrm{rpm}$, the weight of the lumps being determined after every 40 revolutions up to 160 revolutions. The weights of debris formed on oxidation and during the abrasion test were used to obtain a cumulative debris loss expressed as a percentage of the original specimen weight, i.e:

Cumulative debris loss $=100 \cdot\left\{\left(W_{2}-W_{3}\right)+\left(W_{3}-W_{r}\right)\right\} / W_{1}$

where $\mathrm{Wr}$ is the weight of the lump after $r$ revolutions. The total or cumulative debris loss provides an indication of the structural damage, caused by oxidation, to the external layers of the anode carbon.

\subsubsection{Test 2. Oxidation of specimens for examination using image analysis}

To produce samples for examination by image analysis, the $43 \mathrm{~mm}$ diameter by $40 \mathrm{~mm}$ tall pieces cut from two nominally identical $100 \mathrm{~mm}$ long test electrodes, were used to determine gasification rates on exposure to air at $550^{\circ} \mathrm{C}$ and to carbon dioxide at $1000^{\circ} \mathrm{C}$ for one hour in a tube furnace at an oxidising gas flowrate of $0.75 \mathrm{~L} / \mathrm{min}$. Two samples from each of the two nominal carbons were tested, so that data for porosity changes was made consistent and reproducible. Samples were weighed before and after each test. 
Each $43 \mathrm{~mm}$ diameter specimen was then sliced into four approximately $10 \mathrm{~mm}$ thick discs which were embedded individually in epoxy resin. Samples were sectioned and examined at the completion of a run so to visually determine the extent of reaction. Polished sections, each containing the surface of the circular disc originally positioned nearest to the centre of the $40 \mathrm{~mm}$ tall cylinder, were prepared for incident light microscopy and image analysis by cutting back and smoothing the surface using various grades of silicon carbide paper, and finally polishing to a scratch- and relief-free finish using alumina powder on a cloth pad.

Measurement of the volume porosity variation across each section was carried out using a Joyce-Loebel mini-Magiscan image analysis system. In this system, a TV image of an optical microscope field of view is captured as a $512 \times 512$ pixel array, the brightness of each pixel being allocated to one of sixty-four grey levels. The particular TV camera used generated pixels which were rectangular in shape, having a size of 3.3 by $2.9 \mu \mathrm{m}$ when the $x 4$ objective lens used in this study was fitted to the microscope.

The grey-level microscope image was converted by the system into a red and white image in which the epoxy-resin filled pores were red and the carbon white. The proportion of the number of red pixels to the total number of pixels in a measuring frame then gave a measure of the volume porosity of the carbon under examination.

Using a measuring frame 1.7 by $1.5 \mathrm{~mm}$, volume porosity data were then obtained along sixteen traverses from edge to centre of each circular cross section, twelve measurements being obtained for each traverse. Mean volume porosity values for each position in each electrode were obtained by averaging the data from the sixty-four traverses of the four sections from each test electrode. The system was controlled and the output monitored by means of a desktop computer.

\subsubsection{Air oxidation using a magnetic balance}

Samples from both series of laboratory-produced carbons were studied in the investigation of the variation of air oxidation rate with temperature of the test anode carbons. Selected individual cylinders of carbon, $15 \mathrm{~mm}$ diameter by $15 \mathrm{~mm}$ tall, were suspended, from one arm of a Cahn D100 digital recording 
balance (Fig.7.5), into an electrically-heated, vertical reaction tube through which a flow of air could be maintained at a flowrate of $120 \mathrm{cc} / \mathrm{min}\left(20^{\circ} \mathrm{C}\right.$, $760 \mathrm{~mm} \mathrm{Hg}$ absolute). The temperature was raised from ambient at $1^{\circ} \mathrm{C} / \mathrm{min}$ and, as gasification proceeded, the time and weight of sample were logged by an IBM XT computer. From these data and the carefully-calibrated rate of heating, the rate of gasification and the temperature, in degrees Kelvin, were computed. The rate of reaction in $w t \% / m i n$ was obtained from:

$k=100^{*}\left(W_{t}-W_{t-8}\right) / 8^{*} W_{0}$

where $W_{t}, W_{t-8}, W_{0}$ are the weight at time $t, t-8$ minutes and zero time respectively. Activation energies were obtained from Arrhenius plots of $\log _{10} \mathrm{k}$ versus the reciprocal of the absolute temperature. This method has the advantage that the whole temperature range can be studied in a single experiment, but, as will be seen later, the method does have some limitations.

\subsubsection{Principles of operation of Cahn balance}

The D-100 Series balance is a very sensitive weight and force measurement instrument. It is designed for weights and forces up to $100 \mathrm{~g}$ and is sensitive to changes as small as $1 \mu \mathrm{g}$ depending on the model. The balance is divided into two sections. One is the control unit where most electronics and outputs are contained. The other section is the weighing unit which detects the actual weight or force. The weighing unit may be operated in a variety of environments such as vacuum, flowing gas or atmospheric conditions.

The D-100 series balance may be described as a force-to-current converter. It consists of (1) a balance beam mounted to, supported by and pivoting about the centre of a taut ribbon; (2) a torque motor coil located in a permanent magnetic field and also mounted to the taut ribbon; (3) sample suspension fixtures; (4) a beam position sensor system; and (5) controls, circuitry and indicators (see Fig.7.6).

Weights or forces to be measured are applied to the sample (left) side of the beam which produces a force about the axis of rotation (Fig.7.6). An electric current flowing in the torque motor also produces a force about the same axis which is equal and opposite to the force from the beam if the beam is at the beam reference position. This reference position is detected by the beam 
position sensing system. A greater force on the beam will require a greater opposite force from the torque motor in order to maintain the beam at its reference position. Therefore, the current necessary to produce the required torque motor force is a direct measure of the force on the beam. The process of calibration allows this current to be measured in units of weight (grams) or force (dynes).

The control unit processes the signals from the weighing units. These signals are amplified, digitized, filtered for noise, temperature compensated, calibrated and then converted into the standard RS-232 format which can be read by a computer.

\subsubsection{Specimen preparation for SEM examination}

Individual $15 \mathrm{~mm}$ diameter specimens of anode carbon, made using the undoped pitch and that to which 2500ppm sodium had been added, were examined in a Cambridge Instruments $\mathrm{S} 604$ scanning electron microscope (SEM) before and after oxidation. Specimens were embedded in epoxy resin and a polished surface prepared by the method outlined previously. The polished surface was then etched by the highly reactive species, presumed to be atomic oxygen, formed in air by an electrodeless discharge, power being supplied by Microtron 200 microwave power generator. This method was chosen primarily because of the availability of the generator for use as a power source, but it has proved to be quick, simple and effective.

The discharge tube was fitted with a needle valve to control the gas flow, the pressure within the system being determined by the gas flow and the unthrottled suction of a rotary pump. Pressure and power settings were chosen so that under standard operating conditions, adequate change in surface topography was attained in about $10 \mathrm{~min}$.

The etched specimens were cleaned ultra-sonically and then attached to the SEM stub using a vacuum sealing compound, electrical contact being assured by using a silver paint. All samples were gold coated, using a Nanotech Semprem 2 sputter coater, to give an electrically conducting surface, before SEM examination. 
TABLE 7.1. British Alcan Specilication for Convco Petroleum Coke.

$\begin{array}{lll}\text { Property } & \text { Conoco Petcoke } & \text { Typical Value } \\ \text { Real density, g/cc } & 2.04 \text { minimum } & 2.09 \\ \text { Heat treatment to } 1200^{\circ} \mathrm{C} & & \\ \text { Bulk density, g/cc } & 0.82 \text { minimum } & 0.92 \\ 20-35 \text { mesh } & & \\ & \% & \% \\ \text { Ash } & 0.5 \text { max } & 0.13 \\ \mathrm{~S} & 3.0 \mathrm{max} & 1.2 \\ \mathrm{Si} & 0.05 \mathrm{max} & 0.01 \\ \mathrm{Fe} & 0.06 \mathrm{max} & 0.01 \\ \mathrm{~V} & 0.045 & 0.016 \\ \mathrm{Ni} & 0.045 & 0.010\end{array}$

TABLE 7.2. Properties of Bitmac Pitch.

\begin{tabular}{|c|c|c|}
\hline Property & Bitmac Pitch & Typical Value \\
\hline \multirow[t]{2}{*}{ Softening point } & $104.108^{\circ} \mathrm{C}$ & $100^{\circ} \mathrm{C}$ \\
\hline & \%solid & \\
\hline Alcan coking value, $\%$ & 56 minimum & $58-59$ \\
\hline Quinoluene Insolubles & $10 \%$ & 12 \\
\hline \multirow[t]{2}{*}{ Mesophase } & 2 & 1.9 \\
\hline & 0 & - \\
\hline Toluene Insolubles & $32 \%$ & 33 \\
\hline Ash & 0.3 & 0.27 \\
\hline S & 0.8 & 0.06 \\
\hline $\mathrm{Fe}$ & 0.03 & 0.01 \\
\hline $\mathrm{Si}$ & 0.03 & 0.01 \\
\hline $\mathrm{Na}$ & 0.04 & 0.01 \\
\hline $\mathrm{Zn}$ & 0.03 & 0.017 \\
\hline
\end{tabular}


TABLE 7.3. Cliaracterisation data for pitches.

\begin{tabular}{|c|c|c|}
\hline Pitch & Softening point, ${ }^{\circ} \mathrm{C}$ & Quinoline insolubles, wt\% \\
\hline 1 & 101 & 11.5 \\
\hline 2 & 102 & 6.5 \\
\hline 3 & 104 & 5.3 \\
\hline 4 & 106 & 3.7 \\
\hline
\end{tabular}

TABLE 7.4. Sizing of filler coke.

\begin{tabular}{|c|c|}
\hline Filler size & Proportion, wt\% \\
\hline Coarse $(3000-1200 \mu \mathrm{m})$ & 38 \\
\hline Medium $(1200-300 \mu \mathrm{m})$ & 25 \\
\hline Fine $(<300 \mu \mathrm{m})$ & 37 \\
\hline
\end{tabular}




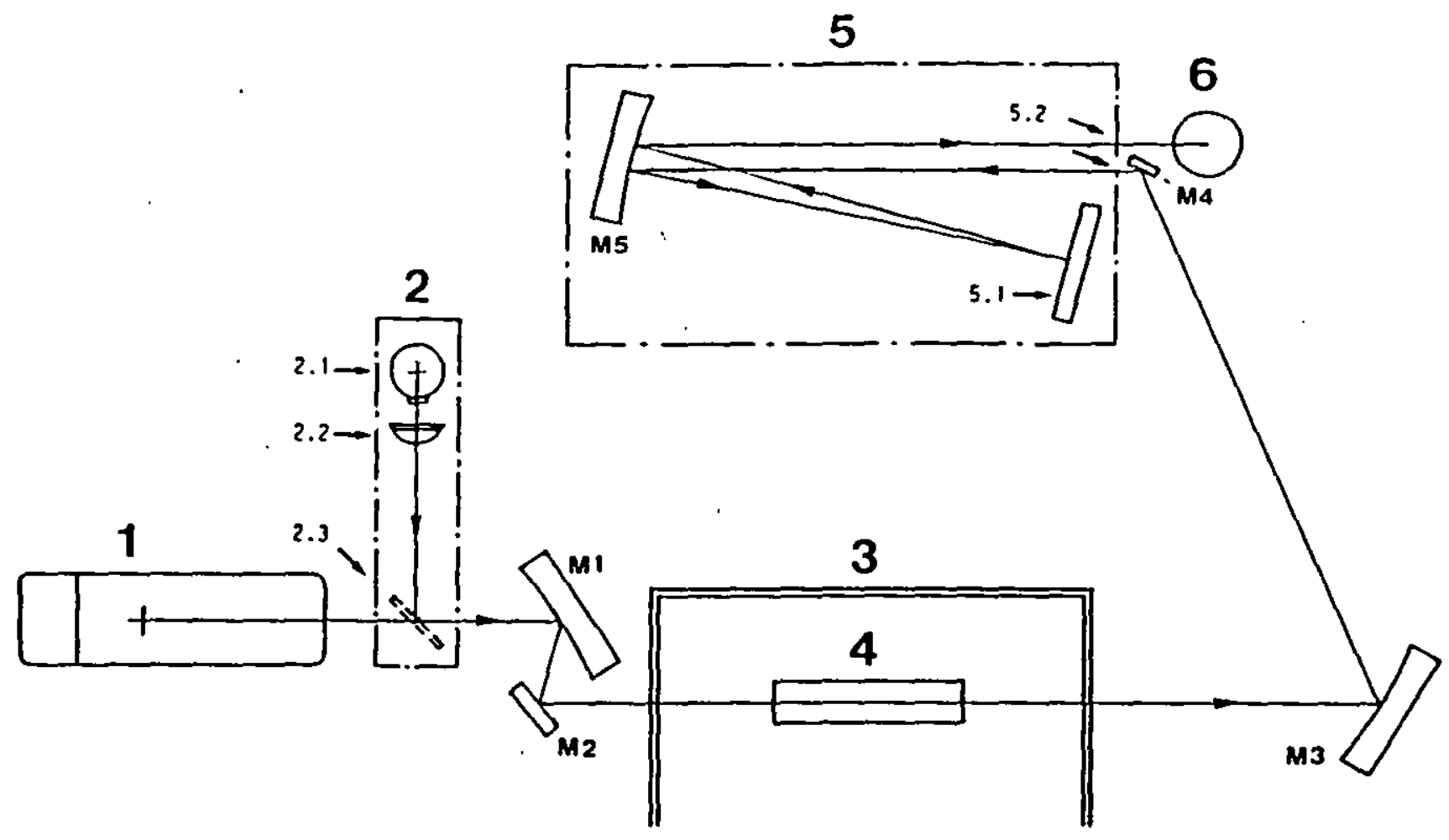

1 Primary Radiation Source (HCL or EDL)

2 Deuterium Background Corrector (Option)

2.1 Deuterium Lamp

2.2 Lens

2.3 Beam Combiner

3 Atomizer Compartment

4 Atomizer (Flame, HGA Graphite Furnace, or MHS Cel1)

5 Monochromator

5.1 Grating

5.2 Slits

6 Detector (Photomultiplier)

FIG.7.1. Optical schematic of the Model 1100 AA Spectrometer. 


\section{ATOMIC ABSORPTION PROCESS}

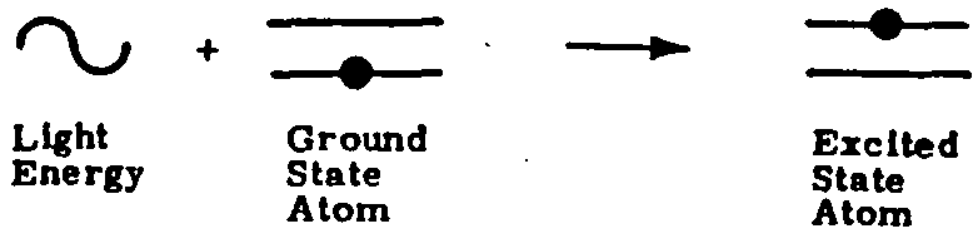

FIG.7.2. Atomic Absorption process. 


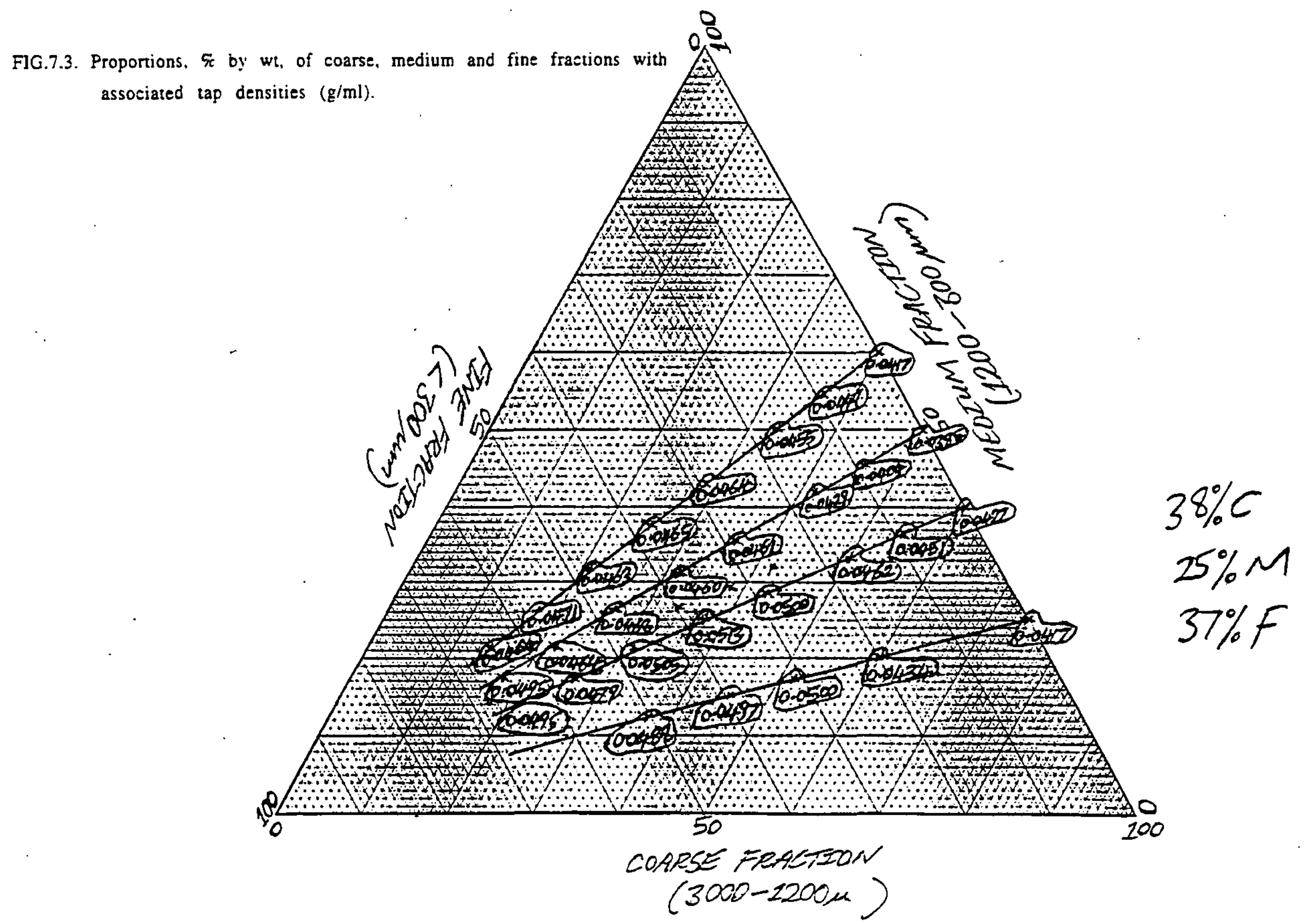




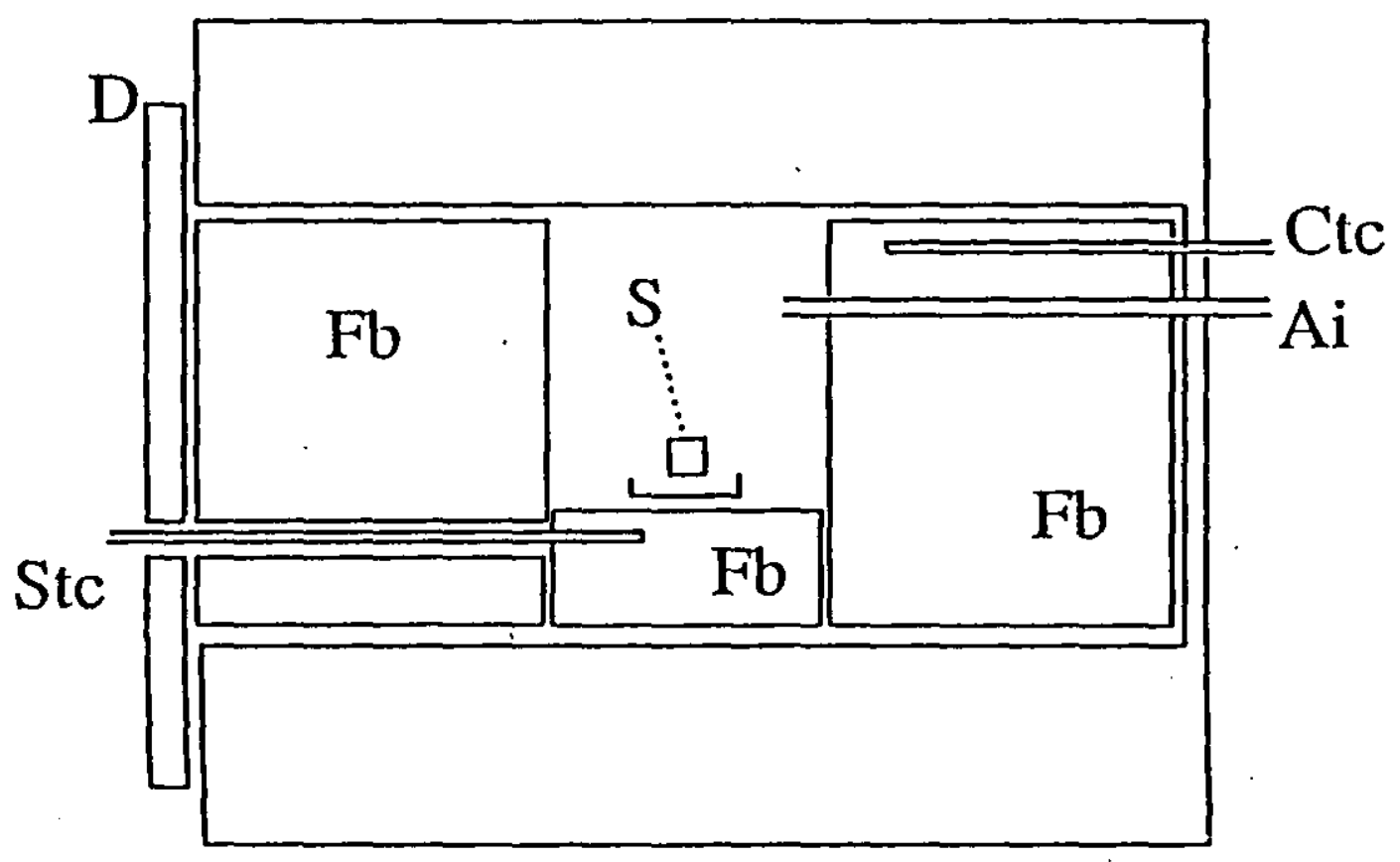

FIG.7.4. Arrangement of furnace used for oxidation lests. 


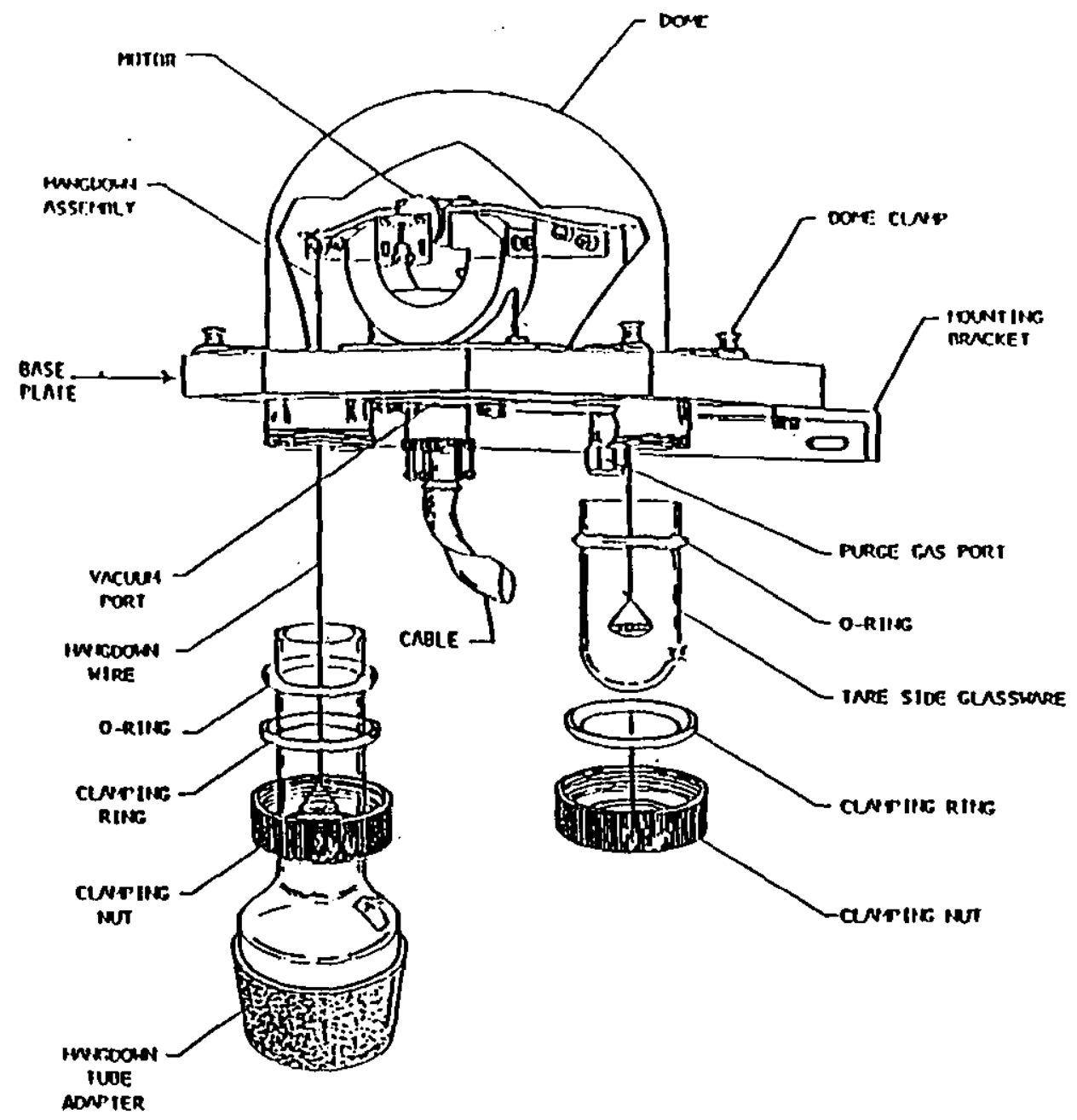

FIG.7.5. Weighing unit of the Cahn gravimetric balance. 


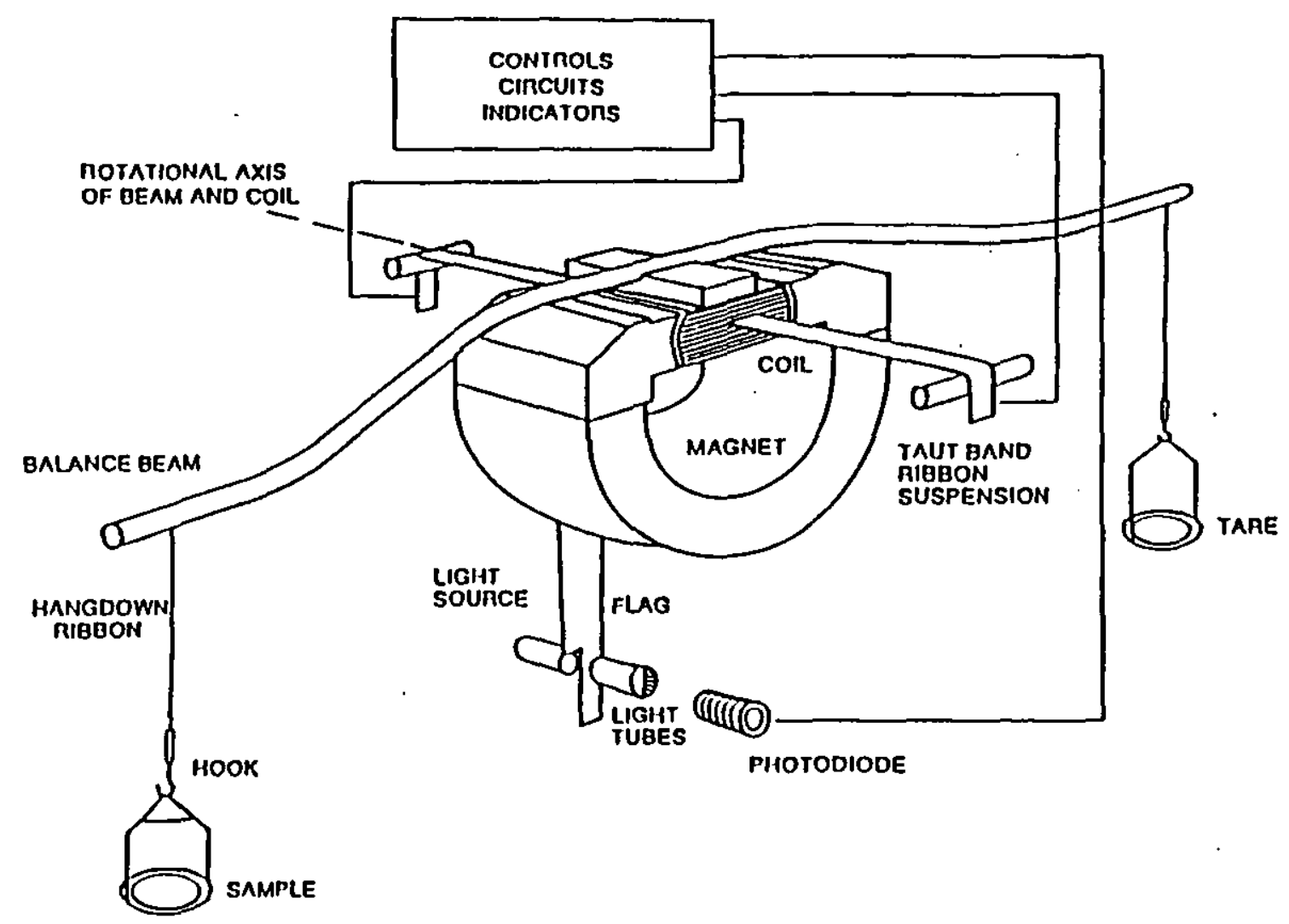

FIG.7.6. Principles of operation. 


\section{RESULTS}

\subsection{Air reactivity / friability studies}

\subsubsection{Preliminary experiments}

Preliminary experiments, to establish test conditions for both the air reactivity and friability tests suitable for comparison of the test electrodes, were carried out using anode carbons made from undoped pitch and from pitch containing $2500 \mathrm{ppm}$ additional sodium. Of the materials to be tested, it was considered that these would exhibit extremes of reactivity towards air. Individual specimens were oxidised at various temperatures and for various times before being subjected to the friability test.

Oxidation test data obtained are summarized in Tables 8.1 and 8.2. With control thermocouple readings of $500,525,550$ and $575^{\circ} \mathrm{C}$, the final specimen temperature readings lay in the ranges 520-524, 544-552, 568-580, and $593-595^{\circ} \mathrm{C}$ respectively, the higher readings in each range being observed for the longest duration tests. The difference between the temperatures measured by the control and specimen thermocouples reflects their positions relative to the oven centre while the range of specimen temperatures represents the slow approach of the thermocouple to its final temperature. Therefore, in later tests, some repositioning of the thermocouple was made.

Data in the tables refer to individual specimens so that some specimen-tospecimen variation in behaviour is to be expected. Generally, however, the oxidation weight losses increased with temperature and duration of the test, the values for the anodes from the pitch high in sodium, a known carbon oxidation catalyst, being two to five times those from the anode made with undoped pitch. The increase in the specific rate of reaction, in $\mathrm{mg} / \mathrm{g} / \mathrm{h}$, observed at all temperatures with increasing test duration, implies an increase in reaction rate with increasing burn-off.

For these sample, the weights of debris generated after 40,80,120 and 160 revolutions in the friability test were measured. Cumulative debris weight losses are plotted against the number of revolutions for the oxidised test pieces of anode carbons made from as-received and doped pitches respectively in 
Figs.8.1 and 8.2. As the temperature and duration of the test, and hence the oxidation loss increases, behaviour in the abrasion or friability test changes. At lowest temperatures and short test durations, weight losses tend to increase almost linearly with the number of revolutions while after more severe high temperature oxidation, higher rates of weight losses were observed at the beginning of the test but they later decreased. Thus, for the latter specimens, oxidation appears to have resulted in the outer layers being more friable than the central core.

The cumulative debris weight losses quoted in Tables 8.1 and 8.2 were mean values calculated from the data after forty revolutions ie. from the linear portions of the graphs in Figs. 8.1 and 8.2. Both the dusting loss and the cumulative debris loss after forty revolutions appear to increase systematically with the weight loss on oxidation, as shown in Figs.8.3 and 8.4, the effect saturating at higher oxidation losses. Higher losses of dusting and abrasion were observed for anodes from the doped pitch. This would be expected if higher sodium contents enhanced any preferential loss of the pitch coke on oxidation.

From these data, it was evident that to make a valid comparison of the different anode carbons, it was necessary to establish a mean oxidation rate for each anode carbon by oxidising a number of specimens under identical conditions. A number of specimens were also needed for the surface friability test to provide mean data representative of test anode behaviour, and also material for examination by optical and scanning electron microscopy. Ideally, the oxidation test should result in a specimen where, as in anode usage within the aluminium industry, oxidation has occurred preferentially near the outer surface leaving a stronger central core.

Based on these preliminary results, the standardised test procedure adopted was to oxidise twenty individual test pieces, cut from two nominally identical blocks, in air at $550^{\circ} \mathrm{C}$ for one hour. The twenty oxidised specimens were then split into two groups of ten, each group covering the weight loss range. Ten specimens were embedded for polishing for microscopy while the remainder were subjected, individually, to 160 revolutions in the friability test, the debris loss being assessed after every 40 revolutions. Mean values of oxidation loss, dusting loss and cumulative weight loss, calculated from the test data for individual specimens, are reported. 


\subsubsection{Studies of anodes made using sodium-doped pitch}

Oxidation and abrasion test data, obtained under the standard operating conditions, for the series of test anodes made using sodium-doped pitch are summarised in Table 8.3. For each property quoted, some scatter of the measured values about the mean was observed. Some indication of this scatter is given by the standard deviation for each data point as shown in Table 8.4. These values are fractions of the mean. However, considering the number of individual specimens examined, the mean values are considered representative of the test anode behaviour.

Simple linear regression analysis was carried out on the correlations of Figs.8.5, 8.12, 8.6 and 8.7 so to obtain a better understanding of the influence of sodium content on oxidation, dusting and cumulative debris loss. The correlation coefficient, $r$, was used as the indicator of the suitability of a correlation, where: $-1<r<1, r=1$ for perfect positive correlation, $r=0$ for no correlation, and $r=-1$ for perfect negative correlation. For Fig.8.11, multivariable linear regression was used in which the multiple correlation coefficient squared multiplied by $100, r^{2}$, indicated correlation suitability.

In accord with the often-reported efficiency of sodium as a catalyst of carbon oxidation, the mean air oxidation weight loss (AO) significantly increased, almost linearly with sodium content of the pitch as shown in Fig.8.5, which corresponds to the following equation:

$A O=0.006(\mathrm{Na})+10.876 \quad, \quad r=0.983$

Dusting losses during the oxidation test also showed a general increase with sodium content of the binder pitch used but the trend was less regular (Fig.8.6). After oxidation the surface of the lumps was very friable so that any differences in care of handling would lead to differences in the amount of carbon dislodged from the surface. This could account for the slight irregularity of the trend between dusting loss and additional sodium content of the pitch. However, a linear relationship was sought between dusting loss, D, and pitch sodium content, giving:

$D=0.001(\mathrm{Na})+0.695 \quad, \quad r=0.975$ 
It appears that a doubling in oxidation loss causes about a four fold increase in dust loss, as the sodium content is increased from AR to AR+2000. Thus, it is likely that sodium induces even more dusting than would occur in the undoped condition. Furthermore, this dusting loss varies with increased oxidation loss as shown in Fig.8.7 and expressed by:

$D=0.103(A O)-0.391 \quad, \quad r=0.952$

Since the burning (oxidation) loss is a measure of the reactivity of the anode, then the ratio of loose particles (dusting loss, $D$ ) to the burning loss $(A O)$ is an expression of the specific surface disintegration ("soot factor") and gives an indication of selective $\mathrm{O}_{2}$ burn of the binder matrix. Fig.8.8 illustrates the correlation.

The variation of the cumulative debris loss, ie. dusting plus friability test loss, with the number of revolutions in the friability test is illustrated for the six test anodes in Fig.8.9. In each case there is a tendency for the rate of loss to decrease slightly with increasing number of revolutions implying that the degree of oxidative damage to the specimen decreased with distance from the surface. It is considered that it is the friability of the outer layers of an oxidised anode carbon which is important in the dusting which occurs during aluminium extraction and that this is best represented in the present tests by the cumulative debris loss after the first forty revolutions in the friability test. Hence such data is included in Table 8.3 under the cumulative debris loss heading. This is further evident by the surface texture of the samples after air oxidation and mechanical treatment following forty revolutions, Fig.8.10. Severely oxidised samples show an extremely irregular surface with protruding coke particles.

The variation of this cumulative debris loss (CDL) with the sodium content of the binder pitch used in the anode production is shown in Fig.8.11, which fits the following second -order polynomial:

$C D L=-0.001(\mathrm{Na})^{2}+0.016(\mathrm{Na})+13.496 \quad, \quad r^{2}=0.979$

The loss increases with sodium content, the rate of increase slowing as the sodium content increases beyond 2000ppm. This supports the above proposition that the total structural damage caused by oxidation decreases with 
distance from the surface. The cumulative debris loss for the six anodes increased with the oxidation loss, Fig.8.12, according to the following equation:

$\mathrm{CDL}=1.328(\mathrm{AO})+2.527 \quad, \quad r=0.897$

The increase in debris loss on increasing the sodium content of the pitch was about twice that for the oxidation loss. The explanation could be that the higher sodium content in the binder pitch enhances preferential oxidation of the pitch coke leaving loosely bound grist particles in the outer layers of the carbon. This point however required further investigation by PLM and SEM to identify reaction sites. Moreover, the dust collected within a silica crucible after each test run consisted predominantly of filler coke particles, so most of the burning must have taken place within the binder coke phase or at the binder coke/filler coke interface. Since the dusting tendency increased with sodium content, this suggests that the sodium was distributed largely within the binder coke. This situation is much more severe than if the catalytic impurity is located mainly within the petroleum coke, because it will greatly exaggerate any existing tendency towards dusting. Furthermore, it is evident from the above correlations that the sodium content has strong influence on air reactivity and subsequently on dusting.

Apparent densities for the six anodes are given in Table 8.4, which indicates that the presence of sodium does not affect the volume and hence the structural porosity of the anode carbons after carbonisation. But, as will be seen later, the sodium content affects the anode porosity on gasification with air or carbon dioxide.

Other catalytic metals- iron, nickel and vanadium are also contained within the petroleum coke and coal-tar pitch (Tables 7.1 and 7.2). When compared to sodium, these metals are not considered to have any significant influence on anode carbon gasification because (i) sodium has the strongest catalytic effect at the levels encountered within the doped anodes, and (ii) the actual metal contents do not correlate well with oxidation results from previous studies. Previous workers $(139,140,16)$ using regression analysis were able to establish correlations between the $\mathrm{O}_{2}$ and $\mathrm{CO}_{2}$ reactivity and the $\mathrm{Fe}, \mathrm{Ni}$ and $\mathrm{V}$ levels. Comparison of the models illustrated the stronger influence of $\mathrm{Na}$, since any model not containing $\mathrm{Na}$ as a variable had a low correlation coefficient $(r<0.8)$ and a higher percentage error associated with the coefficient of the 
independent variable. Other models showed that, even when $\mathrm{Na}$ and these metals were taken together in different combinations, to describe the reactivity, the correlation coefficient was always less than the value obtained for the simple linear regression employing $\mathrm{Na}$ as the lone variable. Consequently, it was concluded that despite the presence of these other catalytic metals, sodium had the strongest influence on reactivity.

\subsubsection{Studies of anodes made using pitches varying in quinoline insolubles content}

In the first phase of this project, it was shown that increasing the sodium content of the binder pitch increased the reactivity towards air of the anode carbons produced using it, the increase being accompanied by a corresponding increase in the friability of the surface of the oxidised material. In the second phase, a similar study was carried out to investigate the effect of different quantities of quinoline insolubles in the pitch on the oxidation behaviour of anode carbons.

Oxidation and friability test data for the series of test anodes made using pitches varying in quinoline insolubles content are summarised in Table 8.5. For each property quoted, some scatter of the measured values about the mean was observed, but again considering the number of individual specimens examined, the mean values were considered representative of the test anode behaviour. Thus, standard deviations are given in Table 8.6, which represent the scatter of the measures values about the mean. As before, simple and multivariable linear regression was utilized to determine the observed correlations.

On oxidation in air, the mean weight loss increased with the quinoline insolubles content of the pitch (Fig.8.13), the rate of increase decreasing with increasing QI content. This variation corresponds to a second-order polynomial such as:

$A O=-0.092(Q \mathrm{I})^{2}+2.180(\mathrm{QI})+0.174, \quad r^{2}=1.000$

Based on the multiple correlation coefficient, $r^{2}=1.000$, which indicates a perfect positive correlation, one can say that the above equation best represents the relationship between the air oxidation loss $(A O)$ and pitch $Q$ I content (QI). Dusting losses, (D) during the oxidation test showed a linear 
increase with $\mathrm{Q}$ l content of the binder pitch, Fig.8.14, according to the following equation:

$D=0.105$ (QI) $-0.010 \quad, \quad r=0.996$

Also Fig.8.15 illustrates an increase in dusting with oxidation loss, according to an linear curve fit:

$D=0.134(A O)-0.629 \quad, \quad r=0.963$

The ratio of dusting loss to oxidation loss indicates selective airburn of the binder matrix (Fig.8.16). It appears that an increase in pitch QI content from 3.7 to $11.5 \mathrm{wt} \%$, causes the oxidation loss to approximately double and with a threefold increase in dusting loss.

The variation of the cumulative debris loss with the number of revolutions in the surface friability test is illustrated for the four test anodes in Fig.8.17. In each case there is a tendency for the loss to decrease with increasing number of revolutions implying that the degree of oxidative damage to the specimen decreased with distance from the surface. It is considered that the cumulative debris loss after the first forty revolutions in the abrasion test, since it reflects the friability of the outermost layers, best represents the dusting which occurs during aluminium extraction. Hence such data is included in Table 8.5 under the cumulative debris loss heading.

The variation of this cumulative debris loss (CDL) with the $\mathrm{Q}$ content of the binder pitch used in the anode production is shown in Fig.8.18. The loss increases with QI content, the rate of increase appearing to accelerate as the QI content increases, and is related by a second-order polynomial:

$\mathrm{CDL}=0.085(\mathrm{QI})^{2}-0.098(\mathrm{QI})+1.752, \quad \mathrm{r}^{2}=1.000$

The cumulative debris loss for the four anodes increased with the oxidation loss, Fig.8.19, the increase in debris loss accelerating as the oxidation loss increased. This correlation can be described by an exponential of the type:

$\mathrm{CDL}=0.394 \times 10^{0.109(\mathrm{AO})}, \mathrm{r}^{2}=0.956$ 
The immediate impression given by these results is that the quinoline insolubles in a pitch influence the oxidation behaviour of the anode carbon produced using it. However, in view of previous results which showed that increasing the sodium content of a pitch produced almost identical effects, the sodium content of the pitches used in the present work were measured before trying to draw any firm conclusion.

\subsection{Atomic absorption spectroscopy results}

Quantitative measurements in atomic absorption are based on Beer's Law, which states that concentration is proportional to absorbance $(C=k A)$. Five solutions of known sodium concentration were used to obtain absorbance values for a calibration curve for sodium (wavelength $589 \mathrm{~mm}$ ) as shown in Fig.8.20. Table 8.7 gives the absorbance values and the corresponding sodium concentrations, read from the calibration graph, for the prepared samples. Actual sodium concentrations were then calculated and these are also given in Table 8.7.

Previous results indicated that the chemical reactivity to oxidising gases of anode carbons increases with increasing sodium and $\mathrm{Q}$ contents of the binder pitch. However, closer compositional examination of the pitches containing the different $Q$ l contents revealed that these pitches had significantly different sodium amounts, as is evident from the above analysis (Table 8.7). This suggests that it is more likely for the sodium content and not the QI content to significantly affect the anode carbon gasification, since sodium is a known catalyst of oxidation reactions. Nevertheless, it is established that during the development stage of fluid mesophase spheres, the primary QI adheres to the surfaces of the spheres and this physically prevents their coalescence into larger spheres and crystallites. Therefore primary $\mathrm{Ql}$ causes a reduction in the size of the optical texture of the resultant pitch coke. Also the presence of QI can be detrimental to the production of carbon artefacts by decreasing the efficiency of wetting of filler by binder pitch. Consequently leading to a carbon with poor interfacial bonding between binder coke and filler coke and which is more susceptible or prone to dusting after oxidation. Thus, primary QI must also influence anode carbon reactivity but to a lesser degree than sodium. This presumably explains why the graphs obtained for the different QI pitches are not identical to those observed for the sodium doped pitches. 
There is no doubt that primary QI influences the carbonisation process of binder pitch. Pitch with no QI material carbonises to a coke with a relatively large size of optical texture. But pitches which contain 10-20\% QI have a profound effect in reducing the size of the optical texture of pitch coke $(141,142,143,144)$. Decreases in size of optical texture can increase the strength and reactivity of oxidising gases of the resultant coke, as recently put forward by Markovic et al (145). According to Jones (23), QI in coal-tar pitches (eg. $10-20 \%$ ) is beneficial and gives a better (denser, stronger, more conductive) carbon at levels up to at least $20 \%$. Thus, to explain the variation of airburn with pitch QI content (Fig.8.13) consideration must be given to the foregoing and to the observation that although three of the four pitches have QI contents below $10 \%$ thereby resulting in a slight or small reduction in the optical texture of the resultant pitch cokes. Consequently, there is a retardation in oxidation rate with increasing QI content from a virtually constant rate between 3.7 and $6.5 \mathrm{wt} \%$ QI content to a distinctly lower rate above $10 \mathrm{wt} \%$ QI.

Because primary QI increases coke yield so presenting more active carbon sites at which the sodium particle can catalyse the carbon-oxygen reaction. It is proposed that the QI influence operates in conjunction with the sodium influence but to a less significant degree, ie.the presence of pitch $Q 1$ enhanced the catalytic activity during anode gasification. Evidence for this comes from Figs.8.14, 8.18, 8.18 and 8.15 which suggest that more of the carbon is being oxidised with distance from the external surface when compared to that previously obtained with just the sodium effect. Consequently increased outer layer friability and dusting ensues. Another possible interpretation of the correlation in Fig.8.13 could be that as the anode carbon bulk density is increased, following an increase in QI content, there will be a slight tendency towards lower reactivities.

\subsection{SEM studies of oxidised $15 \mathrm{~mm}$ diameter specimens}

One factor influencing the quality of pre-baked anode carbons for the aluminium industry is the character of the pitch used as the binder. Coal-tar pitches are usually preferred to their petroleum-derived counterparts, the preference having been associated with the nature of the binder coke formed in the electrode during baking. The desired material is one which exhibits optical anisotropy under polarized light but in which the isochromatic areas so 
revealed are small and randomly orientated. It's likely, therefore, to be isotropic in bulk properties and for these reasons such binder cokes have been described as 'disordered' or 'isotropic'. The structural units of which anode carbons are composed can also be revealed by examination of fractured or etched surfaces in a SEM.

The objective of the first phase of this project was to investigate the effect of sodium content of the pitch on the oxidation behaviour of the anode carbon produced using it. In the previous section it was shown that, when small cylinders, $15 \mathrm{~mm}$ tall by $15 \mathrm{~mm}$ diameter, of pilot-scale anode carbon were oxidised in air at $550^{\circ} \mathrm{C}$, the oxidation rate increased linearly as the amount of added sodium in the pitch used as binder increased from zero to $2500 \mathrm{ppm}$. This increased oxidation rate was accompanied by an increase in the amount of debris loss experienced when the samples were subjected to a surface abrasion test. In the next phase, attempts were made to investigate the mechanism of this increased abrasion loss. Firstly, etched surfaces of oxidised, small-diameter specimens $(15 \mathrm{~mm}$ by $15 \mathrm{~mm}$ tall) were examined initially by PLM and then in a SEM in an attempt to identify the sites of oxidative attack. Secondly, polished sections of larger-diameter $(43 \mathrm{~mm}$ by $40 \mathrm{~mm}$ tall) oxidised anode carbon specimens were examined, by image analysis, to seek variations in porosity caused by oxidation (see section 8.4 ).

To prepare surfaces for examination in the SEM, polished surfaces suitable for examination by optical microscopy were first prepared. They were then etched in atomic oxygen formed in air at low pressure by a microwave discharge (see section 7.6.4).

As the low-magnification view of an unoxidised test electrode surface in Fig.8.21 shows, the etchant attacked the resin preferentially leaving the carbon standing slightly proud. The general view of Fig.8.21 also shows the macroporosity of the carbon, consisting of irregularly shaped inter-particle voids due to the enhanced attack by the etchant on the impregnating resin. At higher magnification (Fig.8.22) the surface topography of the etched carbon becomes apparent and it was found that the binder coke could be differentiated from the petroleum coke filler particles, although not always with complete certainty, by the darker appearance of the latter, a difference in carbon texture, or by a discontinuity at the binder-filler interface. 
Carbon textural components in metallurgical cokes have been classified into categories termed lamellar, intermediate and granular. Although the appearance of the components in anode carbons is not precisely identical, it was nevertheless possible to classify the components into similarly named categories. The classification is subjective since the various textural components appear to form a series continuously varying in appearance.

The higher magnification view in Fig.8.22, shows the granular isotropic appearance of the binder phase at $B$ to consist of small petroleum coke particles embedded in pitch coke. It is within this granular texture that primary Q1 particles are evident as circular cup-shaped features, typically of diameter size $1 \mu \mathrm{m}$. These are considerably coarser than carbon black particles. The larger petroleum coke particle at A displays a lamellar texture consisting of an arrangement of long ridges and channels which are indicative of a well ordered carbon, and implies that groups of layer planes, usually about $0.5 \mu \mathrm{m}$ thick, differ in reactivity across the carbon surface. The reason for this behaviour is not known.

The particle at $C$ is less-well ordered as indicated by the smaller areas of parallel ridges and channels. The underlying structure of the lamellar, intermediate and granular components is considered to be lamelliform, the apparent variation in the size of the structural units reflecting the size and alignment of the constituent lamellae. Lamellar textural components have their lamellae well-aligned and stacked approximately parallel to each other. They may be identified with structures exhibiting 'domain' or 'flow-type' anisotropy under polarized light. During petroleum pitch carbonization their formation is facilitated by the low viscosity which permits ready mesophase coalescence and subsequent alignment of lamellar molecules. If, following mesophase coalescence, alignment of lamellar molecules is restricted, less-well ordered intermediate components result. The granular components of the anode carbon optical texture may exist in two forms, one arising from mesophase coalescence with little subsequent alignment, while the other merely consists of compressed mesophase units.

Small pores are evident along the interface between the filler particle at $A$ and the particle at $C$. Also there is good binder/filler contact along the length of interface (particle at $\mathrm{C}$ ). Interlamellar fissures within the optical, texture are also observed in Fig.8.22. The fissures are "crescent-shaped" and follow the 
crystallographic orientation of the lamellae as deduced from changes in colour of the optical image.

After oxidation, the appearance of the etched surfaces is quite different. Near the edge of the sample (Fig.8.23), all the binder phase appear to have been oxidised away leaving minimal evidence of contact between the large filler-coke particles. Also the less-well ordered filler particles (for example at A) have been severely attacked. Moving toward the centre of the specimen, areas of binder phase appear to have been attacked less severely. Initially only the larger filler particles of binder-phase remained, ie. no pitch coke as illustrated in Fig.8.24, but at the centre even smaller particles are evident. No obvious differences could be seen between specimens containing different amounts of sodium.

Before oxidation, Fig.8.22 illustrated good binder/filler contact along the length of the interface. But after oxidation, as is evident from Fig.8.24, the interface can be described as a fissure which is interrupted by the areas of large petroleum filler coke particles $(>50 \mu \mathrm{m})$ and the smaller filler particles of the binder phase.

Furthermore, it can be observed from Fig.8.24 that the lamellae of the large filler particies intersect the interface at an angle. The lamellae are identified with graphite-like structures having few valency electrons parallel to the basal planes but many at the prismatic edges and this implies that valency electrons in the carbon are likely to become involved in bonding at the binder/filler interface on carbonisation. Based on the earlier finding that the sodium is located within the binder phase, it is considered that such electrons play a role in the sodium catalysed gasification of anode carbons.

It is assumed that the strength of an interface is dependent only on the degree of contact between the binder phase and filler particle. The weaker the interface, the more likely it is that a fracture crack will propagate by interfacial separation. On this basis, enhancement of dust formation will occur after gasification at a weak interface, ie. when airburn is confined to a small number of preferred sites, the break-down in anode structure could be very severe and lead to pronounced strength reduction and much dusting. Moreover, it is known that impurities tend to diffuse to and concentrate at crystallite edges (basal plane edges in this case) during heat treatment at high temperatures. Therefore 
reactivity is higher at the edge carbon atoms because of the reaction being catalysed by sodium concentrated at these locations. The interlamellar fissure at $A$ of Fig.8.24 may have resulted from the channelling catalytic action of a sodium particle 'eating' its way through the petroleum coke particle.

Thus the SEM study, which is an excellent method for monitoring changes in topography following gasification, indicates that the oxidation of anode carbons in air results in preferential attack on the binder phase, and probably on the pitch coke therein. This leaves a high-porosity outer layer in which the filler coke particles are only loosely bound as revealed by image analysis studies undertaken in the next phase. Hence the surface is very friable and susceptible to high weight losses on abrasion testing and to dusting losses in aluminium cell operation.

Two surface sensitive or analysis techniques were applied to prepared $15 \mathrm{~mm}$ diameter anode carbon specimens in order to locate whether the sodium was in the pitch coke or distributed throughout the anode structure. The first technique used was a SEM facility which uses the interaction of the electron beam with some of the surface atoms (up to $100 \mathrm{~nm}$ deep) to give X-rays which can be analysed to reveal the surface composition, eg. the EDAX technique uses energy dispersal to analyse the $X$-rays emitted. This technique proved unsuccessful. The second technique used was SIMS - secondary ion mass spectrometry where a beam of low energy ions bombards the sample; sufficient energy is transferred to the surface for atoms to be sputtered into the vacuum where the ionised material is analysed using a mass spectrometer. The approach adopted was to image the carbon surface, of about $150 \mu \mathrm{m}$ diameter, and identify precisely selected areas for analysis. Sodium along with other elements was detected but SIMS imaging did not help in establishing with certainty where the sodium was located. It proved difficult because of the heterogeneity of carbon layer stacking across the anode carbon surface. However, PLM and SEM analysis of dust collected after each oxidation test run consisted predominantly of filler coke particles, similar in appearance to the oxidised large filler particles of Fig.8.23. This substantiates the above findings which suggest that most of the burning must have taken place within the binder coke phase or at the binder coke/filler coke interface. Moreover, because the dusting tendency increased with sodium content (section 8.1.2), this implies that the sodium was distributed largely within the binder coke. This situation is much more severe than if the sodium catalyst is located mainly within the 
petroleum coke, because it will greatly exaggerate any existing tendency towards dusting.

\subsection{Image analysis studies of carbons oxidised in air and carbon dioxide}

In previous studies carried out as part of this project, it was shown that the reactivity of anode carbons towards air is influenced by the sodium- and the quinoline-insolubles (QI) content of the binder pitch used in their production. In both cases, the increasing reactivity was accompanied by a corresponding increase in the friability of the surface of the oxidised material. The effect of sodium will now be shown to be associated with the increased porosity of the outer layers, as measured by image analysis techniques. SEM indicated preferential attack by the oxidant on the binder phase (ie. the pitch-coke rich phase consisting of pitch coke and small filler-coke particles) in the outer layers of the anode carbon. In this next relevant phase of this work, image analysis was used to assess the variation of porosity, with distance from the external surface, of carbons made using pitches varying in sodium and QI contents, after air oxidation. The two series of carbons were also studied after exposure to carbon dioxide at elevated temperatures.

For the two series of carbons, gasification rates of $15 \mathrm{~mm}$ diameter specimens, determined previously during studies of surface friability after air oxidation at $550^{\circ} \mathrm{C}$, are compared with rates for $43 \mathrm{~mm}$ diameter specimens gasified in air at $550^{\circ} \mathrm{C}$ and in $\mathrm{CO}_{2}$ at $1000^{\circ} \mathrm{C}$ (Tables 8.8 and 8.9).

For both gases, the rates of attack on the carbons made using sodium-doped pitches are greater than those on carbons from undoped pitches, reaction rates in air of $15 \mathrm{~mm}$ specimens are considerably greater than those sustained by the corresponding $43 \mathrm{~mm}$ diameter specimens and, for the conditions chosen, rates in $\mathrm{CO}_{2}$ are lower than those in air. An identical behaviour exists for pitches with varying QI contents, although with lower gasification rates for similar specimen sizes. The gasification rates obtained in Table 8.9 can not be explained solely on the basis of the influence of pitch Q1 content, because there are significant amounts of sodium within each pitch as shown in Table 8.7, section 8.2. In view of this, it is believed that the sodium content of the pitch plays the superior or dominant role in affecting the gasification rates, while the pitch QI content has a subordinate role. 
Figures 8.25 to 8.28 show the variation of volume porosity with distance from the external surface of test specimen, obtained by image analysis, for the two series of carbons after exposure to air and carbon dioxide at elevated temperatures. The curves in Fig. 8.25 show that for all specimens the volume porosity at the surface after oxidation was very high. It fell, rapidly initially and then more slowly, with distance from the surface but was still decreasing at the centre of the specimen. With increasing sodium content the curves were shifted to higher volume porosity values. The apparent density data given in Table 8.4 (see section 8.1.2) indicates that the addition of sodium to the pitch had little effect on the density, and by implication, the volume porosity of the original test electrodes. Also shown in Fig.8.25 is the volume porosity across the surface of an undoped, unoxidised (AR, UnOx.) anode which appears to be more or less constant. Using this as a base, it is thus observed that the curves in Fig.8.25 are indicative of higher weight losses by high-sodium test electrodes both at the edge and at the centre of the specimens.

The curves for Figures 8.26 to 8.28 fall into the same general pattern as that of Fig.8.25. That is, all show higher porosity, due to higher gasification rate, at the edge than at the centre of the specimen, the difference between edge and centre increasing with the overall gasification rate as determined from weight changes. Also, as the overall gasification rate increased with either sodium or QI content of the pitch, the porosity measured by image analysis increased both at the edge and at the centre of the specimen, and was predominantly open or interconnected.

Because the same pitch was used in the preparation of all of the anodes in Fig.8.26, it was possible to compare their volume porosity changes with that of the undoped and unoxidised anode. However, for the test electrodes in Figures 8.27 and 8.28 it was not possible to do this because of the different pitches used for each anode. These results are in accord with data given earlier regarding the friability of specimen surfaces after gasification in air.

Moreover, they agree with diffusion control of gasification by both gaseous air and carbon dioxide under the conditions used. The speed at which an individual anode carbon particle of given size or mass burns depends in part on the rate of oxygen transfer from the bulk gas to the particle, and in part on the particle's reactivity. This reactivity depends on the extent and accessibility to oxygen of 
the pores within the particle, and on the velocity of chemical reaction between oxygen and the pore surface. In the present case of a porous carbon, the reaction is controlled by chemical processes over the accessible external surfaces but controlled by diffusion in the less accessible internal surface porosity because of restrictions on the diffusion of gaseous reactants and products into and out of the pores, particularly micropores of size less than $2 \mathrm{~nm}$.

The curves obtained for Figures 8.25 to 8.28 agree with the concentration profile for gaseous reactant near and within a porous char particle operating under the Zone $\|$ reaction scheme of Hedden and Wicke (see Walker et al. (146)). This means that the reaction between gaseous reactant and carbon is sufficiently rapid to set up a concentration gradient within the specimen. As the overall reaction rate increases, the concentration gradient increases. Gasification, and hence porosity changes, reflect the concentration gradient. Reactant concentrations are higher within small diameter specimens hence their gasification rate is greater than those of larger diameter specimens. One consequence of the operation of a diffusion control mechanism is that, as the temperature rises, the slope of the Arrhenius plot should depart from linearity and an apparent decrease in activation energy ensues. Studies of the effect of temperature on gasification in air were therefore carried out in the next phase to confirm this view.

\subsection{Variation of air oxidation rates with temperature}

Previously it was shown that the reactivity of anode carbons towards air is influenced by the sodium- and the quinoline-insolubles (QI) content of the binder pitch used in their production. In both cases, the increasing reactivity was accompanied by a corresponding increase in the friability of the surface of the oxidised material. This was shown to be associated with the increased porosity of the outer layers, as measured by image analysis techniques, the implication being that, under the oxidation conditions used, the gasification reaction was being controlled by diffusion of reactant into, and diffusion of products out of, the porous structure of the anode carbons.

At low temperatures, diffusion control theory of oxidation of porous anode carbons helps to explain that as the reaction temperature increases, the reacting gas is initially transported from the exterior surface to an active site 
beneath the surface and the products are transported in the opposite direction, more quickly than the reactant is consumed by the reaction. Hence the reaction is controlled solely by the chemistry of the process and the activation energy measured in this temperature regime truly represents that of the chemical reaction.

As the temperature continues to increase, eventually a situation will arise when the reaction at the carbon surface is so rapid that the reactant is consumed more quickly than it can diffuse into the porous structure, causing the concentration of the reactant species to go to zero at a distance from the exterior surface less than the sample radius. Thus, the reaction enters the temperature regime of diffusion control, where the activation energy falls to one-half that in the chemical control region, as shown by Wheeler (147).

Further increases in temperature affects the reaction rate by determining how much additional reactant can reach the exterior surface per unit time, ie. reactant concentration goes to a small value at the exterior surface of the solid. (This does not necessarily mean that reaction penetration into the porous carbon is zero). The rate is controlled by mass transport of reactant and product across a relatively stagnant gas film between the exterior solid surface and the main gas stream. Hence the activation energy drops to that reflecting gaseous diffusion.

To establish the gasification control mechanism for the air oxidation studies of this project, carbons have been exposed to air at increasing temperatures and the oxidation rate and activation energy measured. The following Arrhenius equation shows that the temperature dependence of reaction rate, $k$ can be written in terms of an activation energy $E$ and frequency factor $A$, which has the same units as $\mathrm{k}$ :

$k=A \exp (-E / R T)$, or

$\log k=\log A-E / 2.303 R T$

Hence if $k$ is evaluated from the weight loss-time data obtained at different temperatures, then a plot of $\log k$ versus $1 / T$ should give a straight line of slope $=-E / 2.303 R$. 
From the data obtained using the Cahn electronic balance, an Arrhenius plot for an anode made using a pitch containing $3.7 \mathrm{wt} \%$ of primary quinolineinsolubles is shown in Fig.8.29. This is typical of all the Arrhenius plots obtained in this study, Figures 8.30 to 8.38. They all show a low-temperature straight-line region, followed by an upward sloping curve and then a further straight-line region. For Fig.8.29 activation energies of $123 \mathrm{~kJ} / \mathrm{mol}$ and 64 $\mathrm{kJ} / \mathrm{mol}$ were obtained from the straight-line low and high-temperature portions of the plot respectively, as shown in the enlarged Fig.8.29a. Within experimental error, the ratio of these and other values calculated from Figs.8.30 to 8.38 are in accord with the rate controlling mechanism changing from chemical control at low temperature to diffusion control at high ones.

It is recognised that to obtain activation energies for carbon gasification with high accuracy, when simple $\mathrm{g} / \mathrm{g} / \mathrm{h}$ or $\mathrm{wt} \% / \mathrm{min}$ reaction rates are used they should refer to similar degrees of burn-off. This ensures that the surface activity and the porous structure remain comparable. In the present method, however, the burn-off increases with temperature so that the reaction rate at high temperature may be influenced by the burn-off. The most reasonable explanation for the upward sloping curve at intermediate temperatures in Fig.8.29 and other graphs is that the higher than expected reaction rates result from an increase in the number of active reaction sites as reaction proceeds. An increase in the number of active sites could result from either the existing surface becoming more reactive, the surface reactivity remaining the same but the total surface area increasing as a result of either (a) the porous structure being modified by burn-off or (b) the opening of previously closed pores.

These factors have only a marginal effect on the activation energies but they influence the temperature at which gasification control changes from chemical to diffusion; increasing the total activity of the surface reduces the changeover temperature while opening the porous structure increases it. Since the present results show an upward trend of overall rate at intermediate temperatures, this means that, in the present situation, the effect of increased activity over-shadows any effect of pore structure changes. Activation energies calculated from the Arrhenius plots for all the materials examined are listed in Table 8.10. As expected on the basis of diffusion control theory, the activation energies for the high-temperature region of the Arrhenius plot approximate to one-half that for the low-temperature region. 
It is evident from the table that the activation energy for the chemical control region falls with the amount of sodium added to the pitch. This is in accord with literature results which show that the activation energy falls with the sodium content of the carbon. The activation energies measured in this work were therefore plotted against the sodium content of the binder pitch either asreceived or as-received plus added, as shown in Fig.8.39. This shows a good correlation of activation energy with sodium content. This casts some doubt on the conclusions made earlier regarding the effect of QI content on gasification behaviour. Present results suggest that all the data can be explained in terms of pitch sodium content. These findings are substantiated by earlier atomic absorption spectroscopy studies which revealed that the four pitches of varying QI contents also contained significant amounts of sodium (Table 8.7). 
TABLE 8.1. Oxidation and abrasion test data for the anode from undoped pitch.

\begin{tabular}{|c|c|c|c|c|c|}
\hline $\begin{array}{l}\text { Specimen } \\
\text { temperature } \\
{ }^{\circ} \mathrm{C}\end{array}$ & $\begin{array}{c}\text { Duration } \\
\qquad \mathbf{h}\end{array}$ & \multicolumn{2}{|c|}{$\begin{array}{l}\text { Oxidation } \\
\text { loss }\end{array}$} & $\begin{array}{c}\text { Dusting } \\
\text { loss } \\
\text { wi\% }\end{array}$ & $\begin{array}{c}\text { Cumulative } \\
\text { debris loss } \\
\text { wt\% }\end{array}$ \\
\hline 520 & 1.0 & 0.29 & 2.9 & 2.0 & 4.9 \\
\hline 521 & 2.0 & 0.90 & 4.5 & 5.7 & 13.6 \\
\hline 544 & 0.5 & 0.28 & 5.5 & 3.9 & 5.8 \\
\hline 547 & 1.0 & 1.35 & 13.5 & 7.3 & 28.1 \\
\hline 550 & 2.0 & 10.69 & 53.5 & 14.2 & 49.5 \\
\hline 568 & 0.5 & 0.26 & 5.2 & 4.4 & 8.6 \\
\hline 578 & 1.0 & 5.79 & 57.9 & 12.7 & 37.7 \\
\hline 593 & 0.5 & 0.55 & 11.0 & 5.5 & 27.6 \\
\hline
\end{tabular}

TABLE 8.2. Oxidation and abrasion test data for the anode from doped pitch.

\begin{tabular}{|c|c|c|c|c|c|}
\hline $\begin{array}{c}\text { Specimen } \\
\text { temperature } \\
{ }^{\circ} \mathrm{C}\end{array}$ & Duration & \multicolumn{2}{|c|}{$\begin{array}{c}\text { Oxidation } \\
\text { loss } \\
\mathrm{w}\end{array}$} & \multicolumn{1}{c|}{$\begin{array}{c}\text { Dusting } \\
\text { loss } \\
\mathrm{mg} / \mathrm{g} / \mathrm{h}\end{array}$} & $\begin{array}{c}\text { Cumulative } \\
\text { debris loss } \\
\mathrm{wt} \%\end{array}$ \\
\hline 522 & 1.0 & 0.57 & 5.7 & 5.1 & 7.9 \\
\hline 524 & 2.0 & 1.58 & 7.8 & 8.5 & 20.1 \\
\hline 546 & 0.5 & 1.11 & 22.2 & 6.7 & 10.0 \\
\hline 547 & 1.0 & 4.68 & 46.8 & 11.7 & 50.6 \\
\hline 552 & 2.0 & 21.58 & 107.9 & 13.7 & 63.1 \\
\hline 570 & 0.5 & 1.40 & 28.0 & 7.6 & 24.1 \\
\hline 580 & 1.0 & 10.69 & 106.9 & 14.5 & 47.7 \\
\hline 595 & 0.5 & 2.18 & 43.6 & 8.9 & 35.1 \\
\hline
\end{tabular}


TABLE 8.3. Oxidation and friability test data for anodes from asreceived and sodium-doped pitches.

\begin{tabular}{|c|c|c|c|}
\hline $\begin{array}{c}\text { Sodlum } \\
\text { content } \\
\text { ppm }\end{array}$ & $\begin{array}{c}\text { Mean } \\
\text { oxldation } \\
\text { loss } \\
\text { wt } \%\end{array}$ & $\begin{array}{c}\text { Mean } \\
\text { dusting } \\
\text { loss } \\
\text { wt \% }\end{array}$ & $\begin{array}{c}\text { Mean } \\
\text { cumulative } \\
\text { debrls los s } \\
\text { wt \% }\end{array}$ \\
\hline$\Lambda R$ & 11.5 & 0.5 & 14.0 \\
$A R+500$ & 14.0 & 1.2 & 19.2 \\
$\Lambda R+1000$ & 16.4 & 1.4 & 28.5 \\
$A R+1500$ & 17.6 & 1.6 & 30.5 \\
$A R+2000$ & 22.9 & 1.9 & 32.7 \\
$A R+2500$ & 26.1 & 2.2 & 34.4 \\
\hline
\end{tabular}

TABLE 8.4. Standard deviations for oxidation and friability data.

\begin{tabular}{|c|c|c|c|c|}
\hline $\begin{array}{c}\text { Sodlum } \\
\text { content } \\
\text { wt } \%\end{array}$ & $\begin{array}{c}\text { Standard } \\
\text { deviatlon } \\
\text { Ox. loss } \\
+/-\end{array}$ & $\begin{array}{c}\text { Standard } \\
\text { deviation } \\
\text { Dust loss } \\
+/-\end{array}$ & $\begin{array}{c}\text { Standard } \\
\text { deviation } \\
\text { C.D. loss } \\
+/-\end{array}$ & $\begin{array}{c}\text { Apparent } \\
\text { density } \\
\mathrm{kg} / \mathrm{m}^{3}\end{array}$ \\
\hline$A R$ & 0.75 & 0.03 & 0.67 & 1.39 \\
\hline$A R+500$ & 0.93 & 0.08 & 0.81 & 1.36 \\
\hline$A R+1000$ & 1.00 & 0.09 & 1.20 & 1.37 \\
\hline$A R+1500$ & 1.13 & 0.10 & 1.25 & 1.39 \\
\hline$A R+2000$ & 1.54 & 0.13 & 1.44 & 1.37 \\
\hline$A R+2500$ & $1: 83$ & 0.20. & 1.61 & 1.38 \\
\hline
\end{tabular}


TABLE 8.5. Oxidation and friability lest data for anodes made from pitches varying in QI content.

\begin{tabular}{|c|c|c|c|}
\hline $\begin{array}{c}\text { Quinoline } \\
\text { Insoluble } \\
\text { content } \\
\text { wt } \%\end{array}$ & $\begin{array}{c}\text { Mean } \\
\text { oxldation } \\
\text { loss } \\
\text { wt } \%\end{array}$ & $\begin{array}{c}\text { Mean } \\
\text { dustling } \\
\text { loss } \\
\text { wt\% }\end{array}$ & $\begin{array}{c}\text { Mean } \\
\text { cumulative } \\
\text { debrls loss } \\
\text { wt\% }\end{array}$ \\
\hline 3.7 & 7.0 & 0.4 & 2.6 \\
5.3 & 9.1 & 0.5 & 3.5 \\
6.5 & 10.5 & 0.7 & 4.8 \\
11.5 & 13.1 & 1.2 & 11.9 \\
\hline
\end{tabular}

TABLE 8.6. Standard deviations for oxidation and friability data.

\begin{tabular}{|c|c|c|c|c|}
\hline $\begin{array}{c}\text { Quinoline } \\
\text { Insoluble } \\
\text { content } \\
\text { wt } \%\end{array}$ & $\begin{array}{c}\text { Standard } \\
\text { deviation } \\
\text { Ox. loss } \\
+/-\end{array}$ & $\begin{array}{c}\text { Standard } \\
\text { deviation } \\
\text { Dust loss } \\
+/-\end{array}$ & $\begin{array}{c}\text { Standard } \\
\text { devlation } \\
\text { C.D. los s } \\
+/-\end{array}$ & $\begin{array}{c}\text { Apparent } \\
\text { density } \\
\mathbf{~} \mathbf{k g} / \mathbf{m}^{3}\end{array}$ \\
\hline 3.7 & 0.47 & 0.02 & 0.23 & 1.41 \\
5.3 & 0.53 & 0.04 & 0.34 & 1.39 \\
6.5 & 0.63 & 0.05 & 0.44 & 1.42 \\
11.5 & 0.86 & 0.08 & 0.68 & 1.40 \\
\hline
\end{tabular}


TABLE 8.7. Atomic Absorption Spectroscopy of pitches varying in QI content.

\begin{tabular}{|c|c|c|c|}
\hline \multirow{2}{*}{$\begin{array}{c}\text { Pltch } \\
\text { Sample }\end{array}$} & \multirow{2}{*}{ Absorbance } & \multicolumn{2}{|c|}{ Sodlum concentration ppm } \\
\cline { 3 - 4 } & & Graph & Calculated \\
\hline $3.7 \% \mathrm{Ql}$ & 0.031 & 0.291 & 182 \\
$5.3 \% \mathrm{Q}$ & 0.040 & 0.382 & 239 \\
$6.5 \% \mathrm{Q}$ & 0.065 & 0.609 & 382 \\
$11.5 \% \mathrm{Q}$ & 0.089 & 0.827 & 517 \\
\hline
\end{tabular}

TABLE 8.8. Gasification rates for sodium doped carbons.

\begin{tabular}{|c|c|c|c|}
\hline \multirow{3}{*}{$\begin{array}{l}\text { Addltional } \\
\text { Na In pitch } \\
\text { ppm }\end{array}$} & \multicolumn{3}{|c|}{ Gasification rate. wt \%/hr } \\
\hline & \multicolumn{2}{|c|}{ alr at $550^{\circ} \mathrm{C}$} & \multirow{2}{*}{$\frac{\mathrm{CO}_{2} \text { at } 1000^{\circ} \mathrm{C}}{43 \mathrm{~mm}}$} \\
\hline & $15 \mathrm{~mm}$ & $43 \mathrm{~mm}$ & \\
\hline 0 & 11.5 & 3.5 & 1.2 \\
\hline 500 & 14.0 & 5.3 & 1.3 \\
\hline 1000 & 16.4 & 7.5 & 1.4 \\
\hline 1500 & 17.6 & 8.7 & 1.4 \\
\hline 2000 & 22.9 & 11.4 & 1.5 \\
\hline 2500 & 26.1 & 12.6 & 1.5 \\
\hline
\end{tabular}


TABLE 8.9. Gasification rates for carbons from pitches varying in QI content.

\begin{tabular}{|c||c|c||c|}
\hline \multirow{2}{*}{$\begin{array}{c}\text { QI content } \\
\text { of pltch. }\end{array}$} & \multicolumn{3}{c|}{ Gasification rate. wt \% / hr } \\
\cline { 2 - 4 } wt \% & alr at $550^{\circ} \mathrm{C}$ & $\mathrm{CO}_{2}$ at $1000^{\circ} \mathrm{C}$ \\
\cline { 2 - 4 } & $15 \mathrm{~mm}$ & $43 \mathrm{~mm}$ & $43 \mathrm{~mm}$ \\
\hline 3.7 & 7.0 & 1.3 & 0.8 \\
\hline 5.3 & 9.1 & 2.1 & 0.9 \\
\hline 6.5 & 10.5 & 2.4 & 0.9 \\
\hline 11.5 & 13.1 & 4.1 & 1.2 \\
\hline
\end{tabular}

TABLE 8.10. Activation energies for chemical and diffusion control regions.

\begin{tabular}{|c|c|c|}
\hline Carbons studied & \multicolumn{2}{|c|}{ Activation energy, $\mathbf{k J} / \mathrm{mol}$} \\
\hline & Chemical control & Diffusion control \\
\hline Sodium added to pitch : & & \\
\hline 0ppm & 118 & 58 \\
\hline $500 \mathrm{ppm}$ & 113 & 47 \\
\hline $1000 \mathrm{ppm}$ & 108 & 57 \\
\hline $1500 \mathrm{ppm}$ & 107 & 48 \\
\hline $2000 \mathrm{ppm}$ & 100 & 44 \\
\hline $2500 \mathrm{ppm}$ & 93 & 42 \\
\hline Pitch QI content & & \\
\hline $11.5 \mathrm{wt} \%$ & 111 & 48 \\
\hline $6.5 \mathrm{wt} \%$ & 122 & 61 \\
\hline $5.3 \mathrm{wt} \%$ & 121 & 66 \\
\hline $3.7 \mathrm{wt} \%$ & 123 & 64 \\
\hline
\end{tabular}




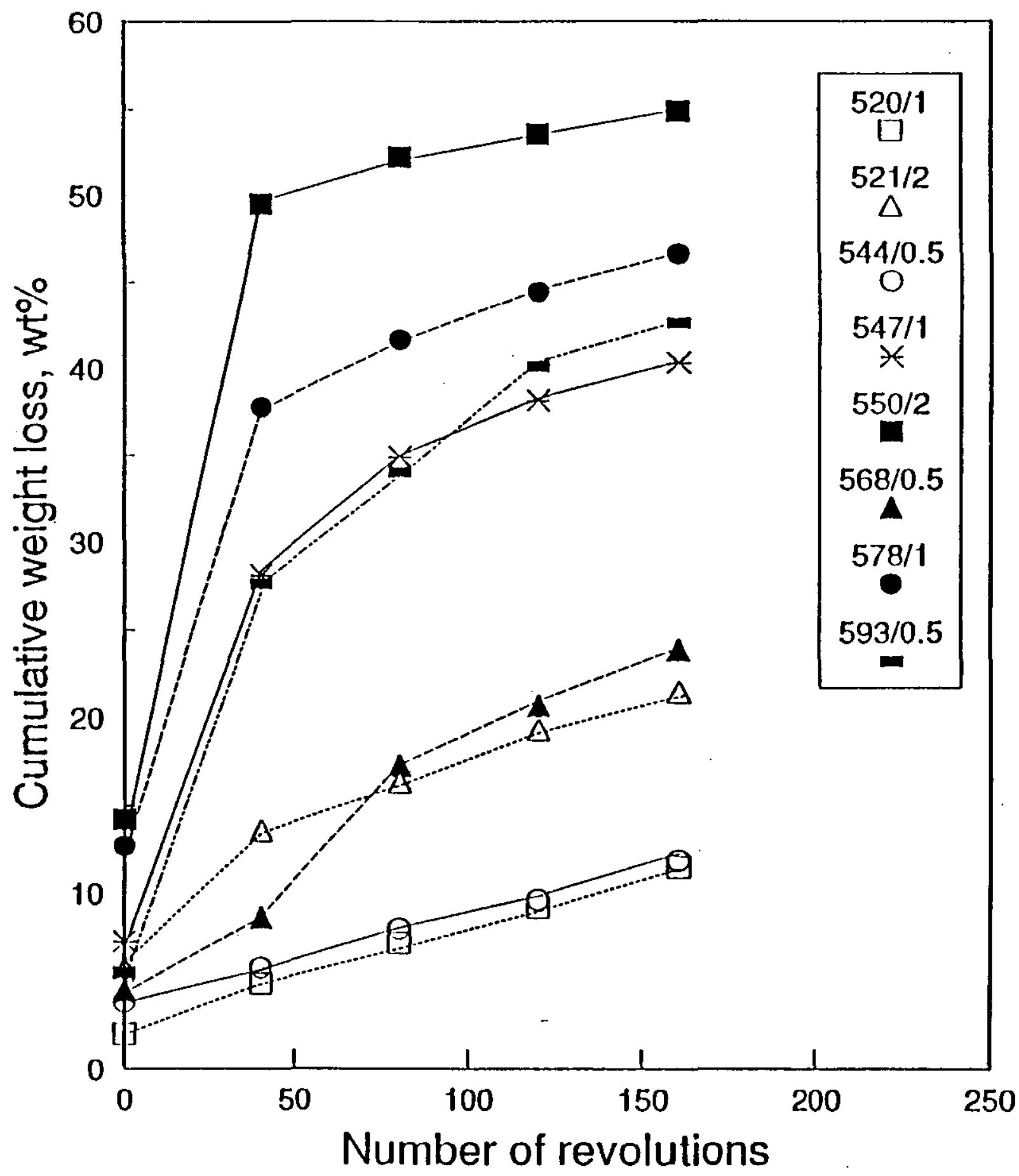

FIG.8.1. Abrasion test data for oxidised specimens of anode carbon from undoped pitch. (The figures in the boxed legend, eg. $520 / 1$ refer to the temperature and duration of the oxidation test). 


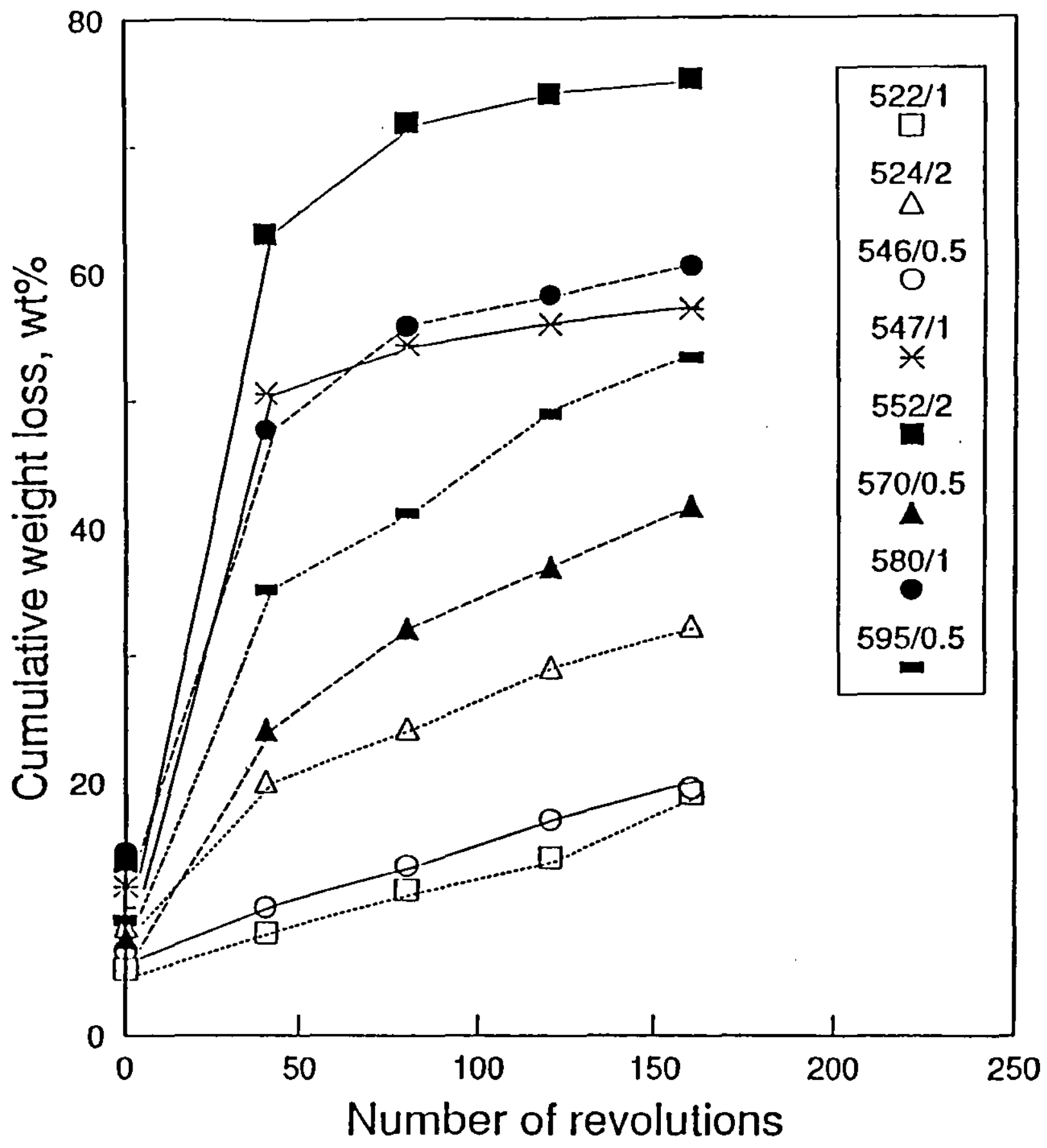

FIG.8.2. Abrasion test data for oxidised specimens of anode carbon from doped pitch. (The figures in the boxed legend, eg. $520 / 1$ refer to the temperature and duration of the oxidation lest). 


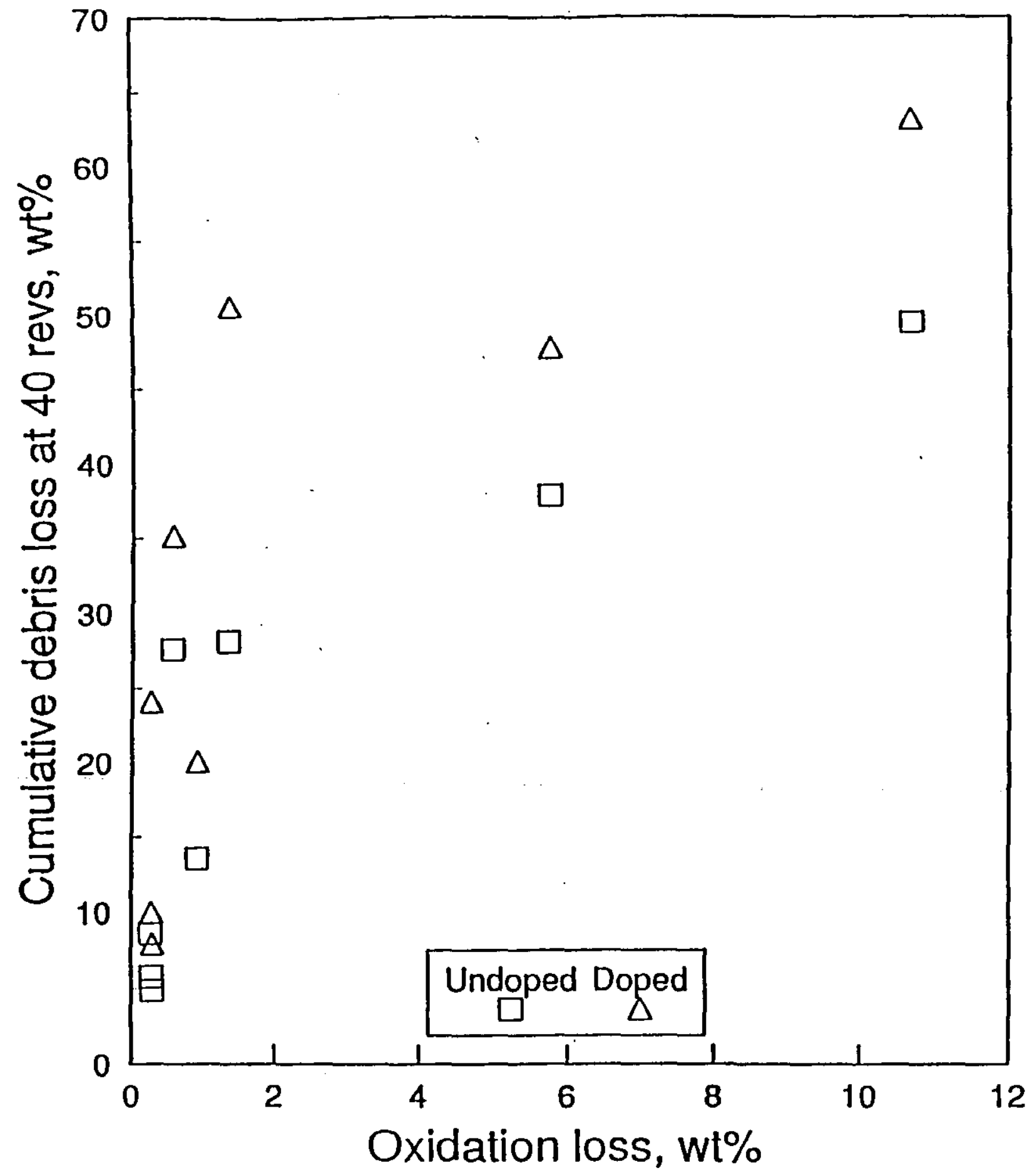

FIG.8.3. Variation of cumulative debris loss with oxidation loss for anode carbons from doped and undoped pitches. 


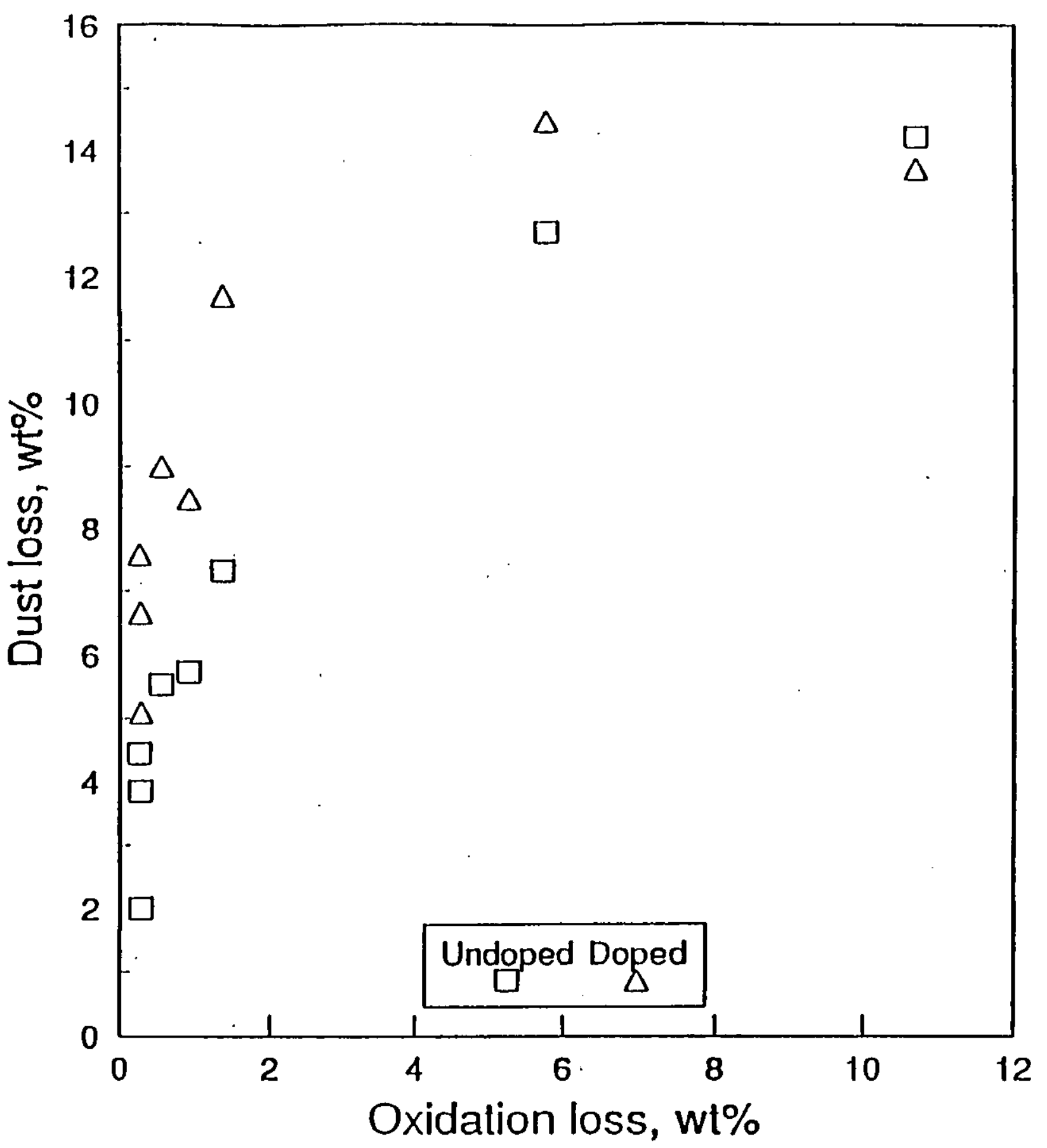

FIG.8.4. Variation of dusting loss with oxidation loss for anode carbons from doped and undoped pitches. 


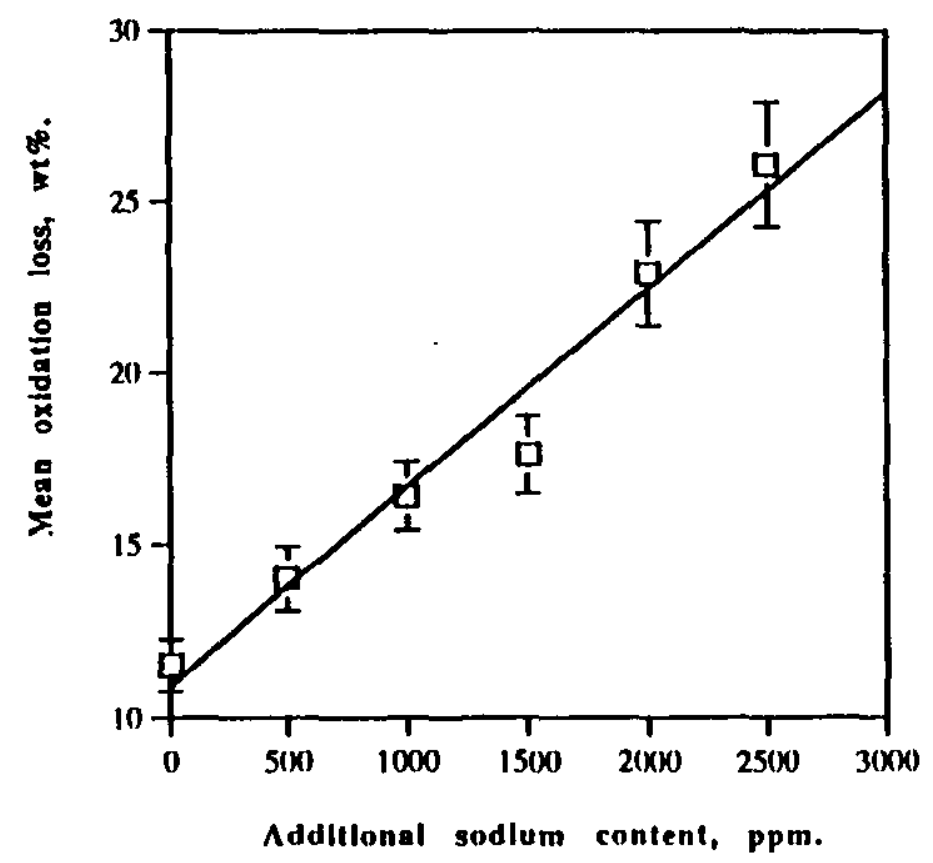

FIG.8.5. Variation of the oxidation loss of test anodes with the additional sodium content of the pitch.

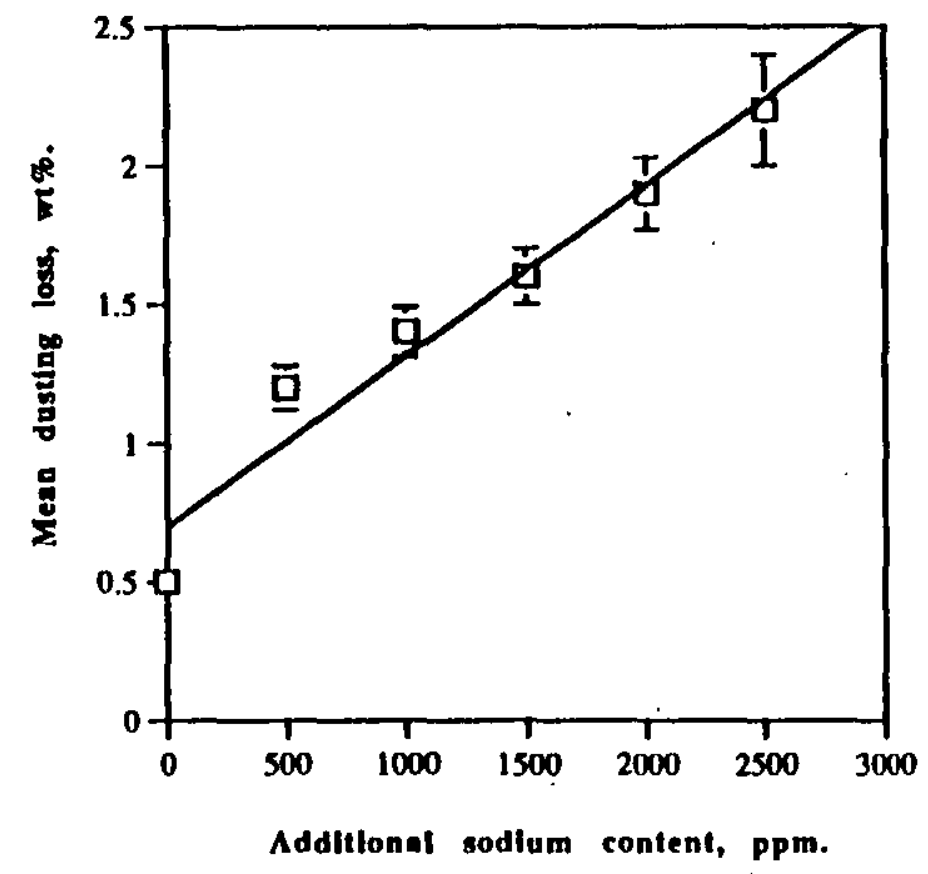

FIG.8.6. Variation of anode dust loss with the sodium content. 


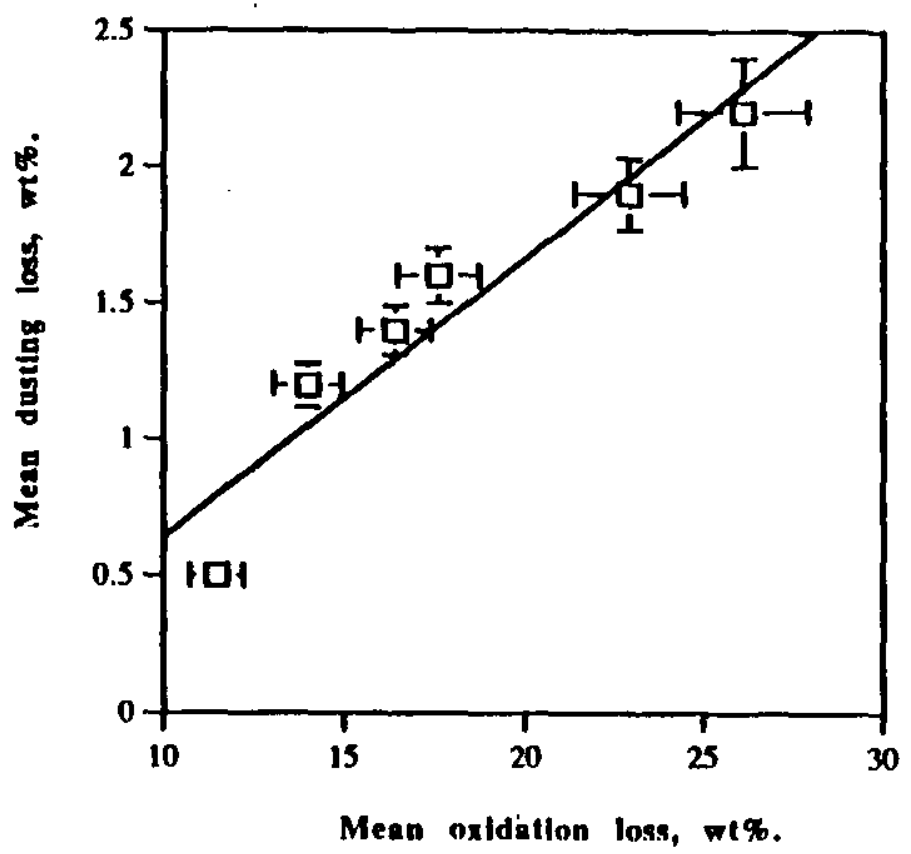

FIG.8.7. Variation of mean dusting loss with oxidation loss.

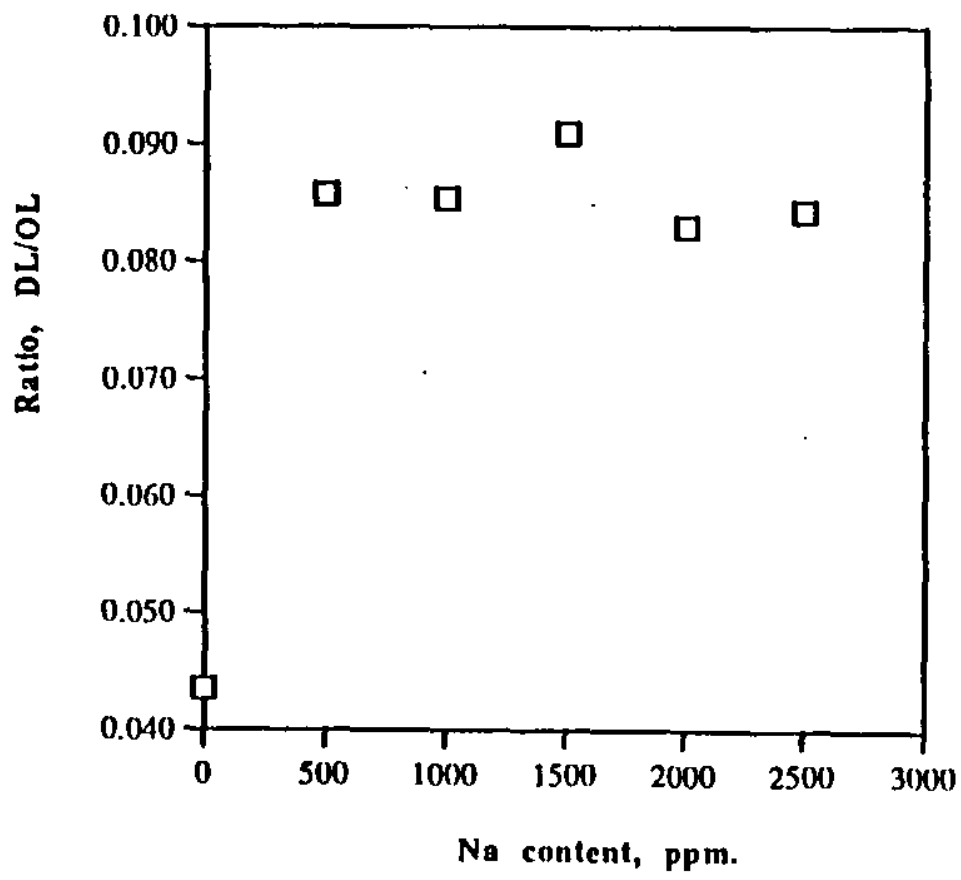

FIG.8.8. Variation of the ratio: dusting/oxidation loss with pitch sodiun content. 


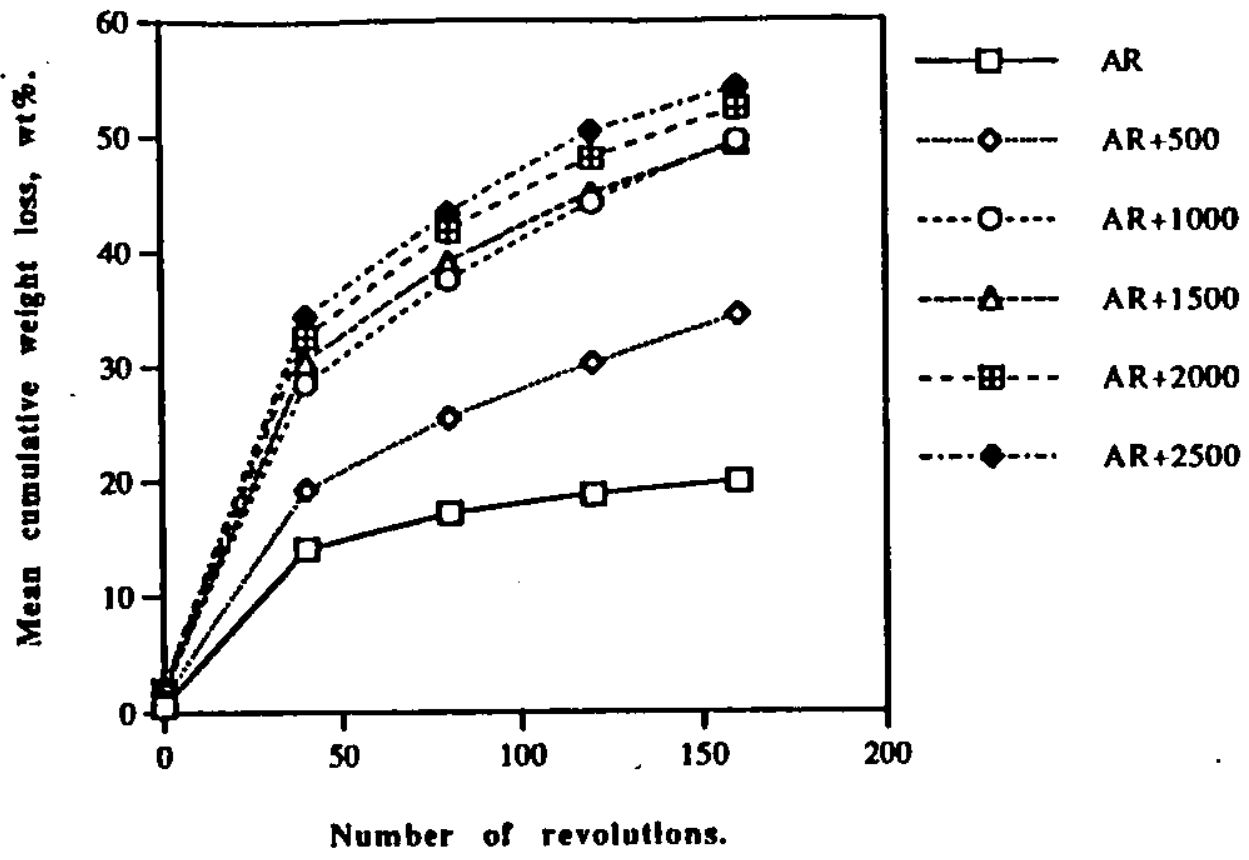

FIG.8.9. Friability test data for oxidised anode carbons prepared from pitches containing varying amounts of sodium.

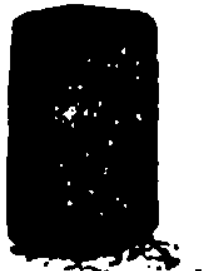

a

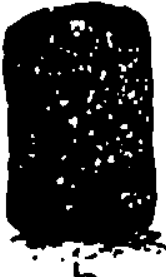

b

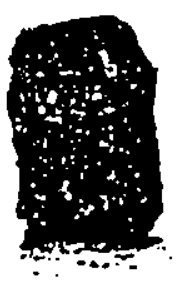

C

FIG.8.10. Aspect of samples after air oxidation at $550^{\circ} \mathrm{C}$ and mechanical treatment after 40 revs. (a) original sample (b) mild oxidation of undoped sample (c) severe oxidation of doped sample. 


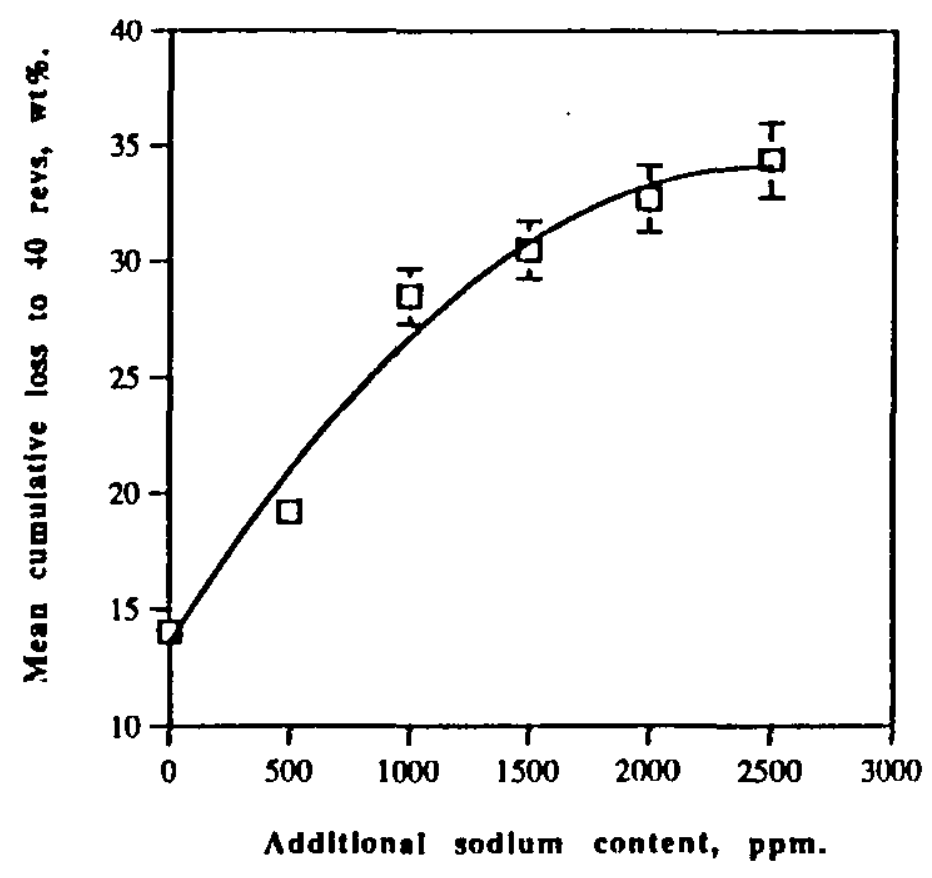

FIG.8.11. Variation of the cumulative debris loss to 40 revolutions with the additional sodium content of the pitch.

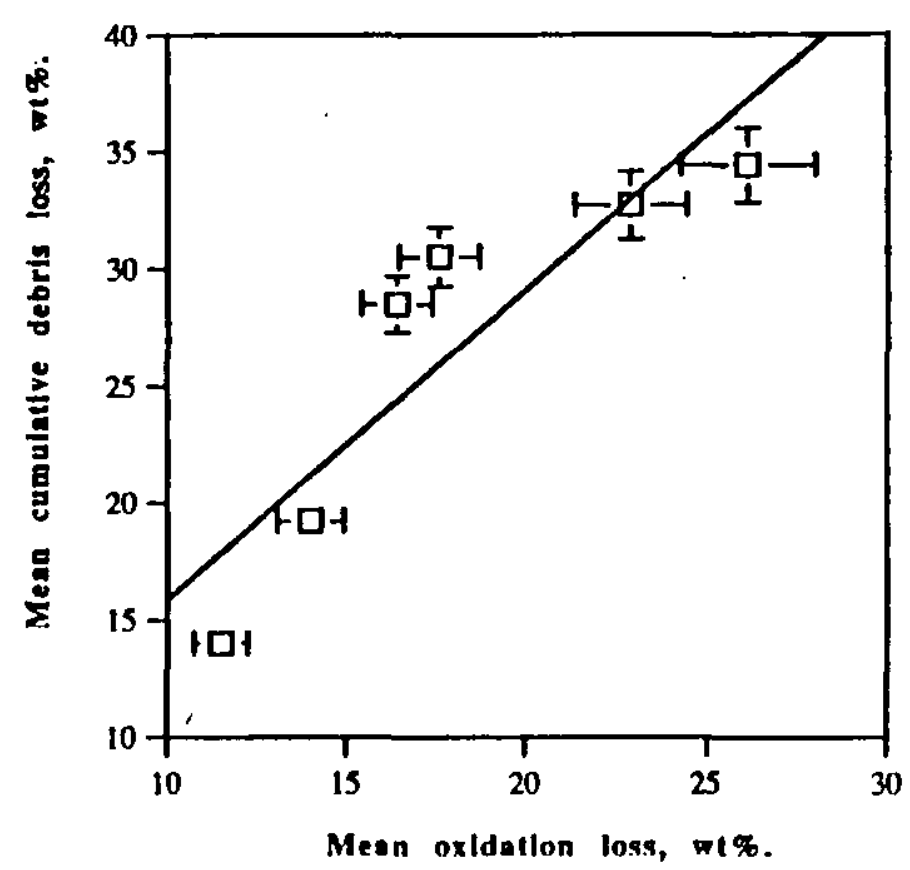

FIG.8.12. Variation of the cumulative debris loss to 40 revolutions with the oxidation loss. 


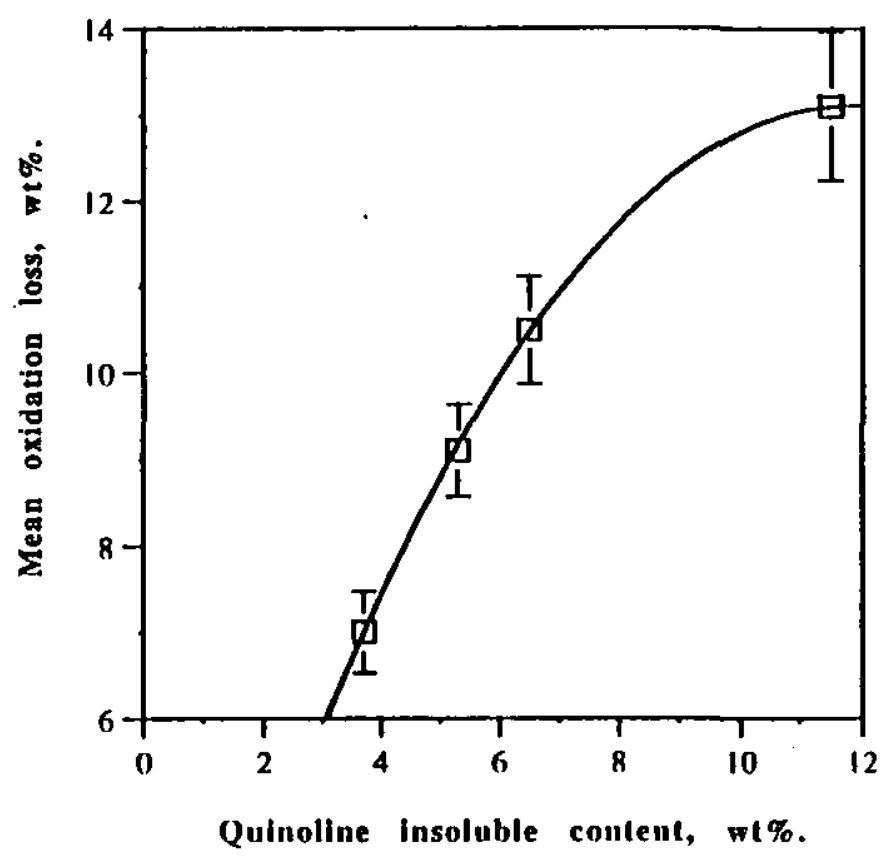

FIG.8.13. Variation of anode oxidation loss with QI content of binder pitcl.

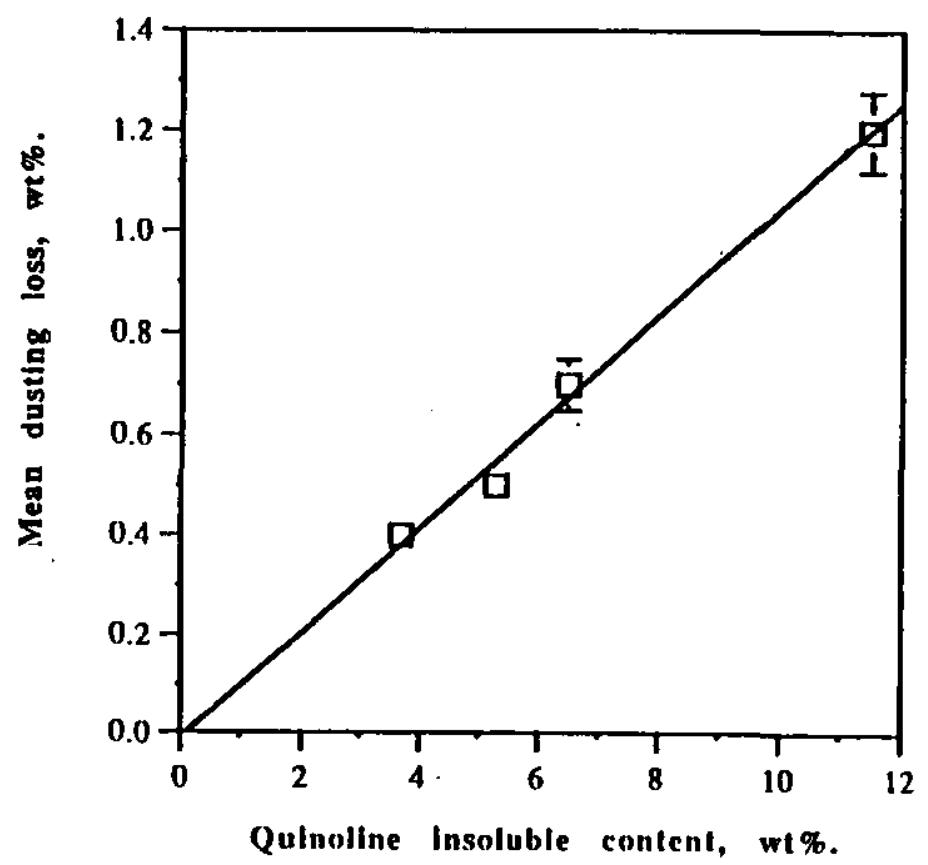

FIG.8.14. Variation of anode dusting loss with Q1 content of binder pitch. 


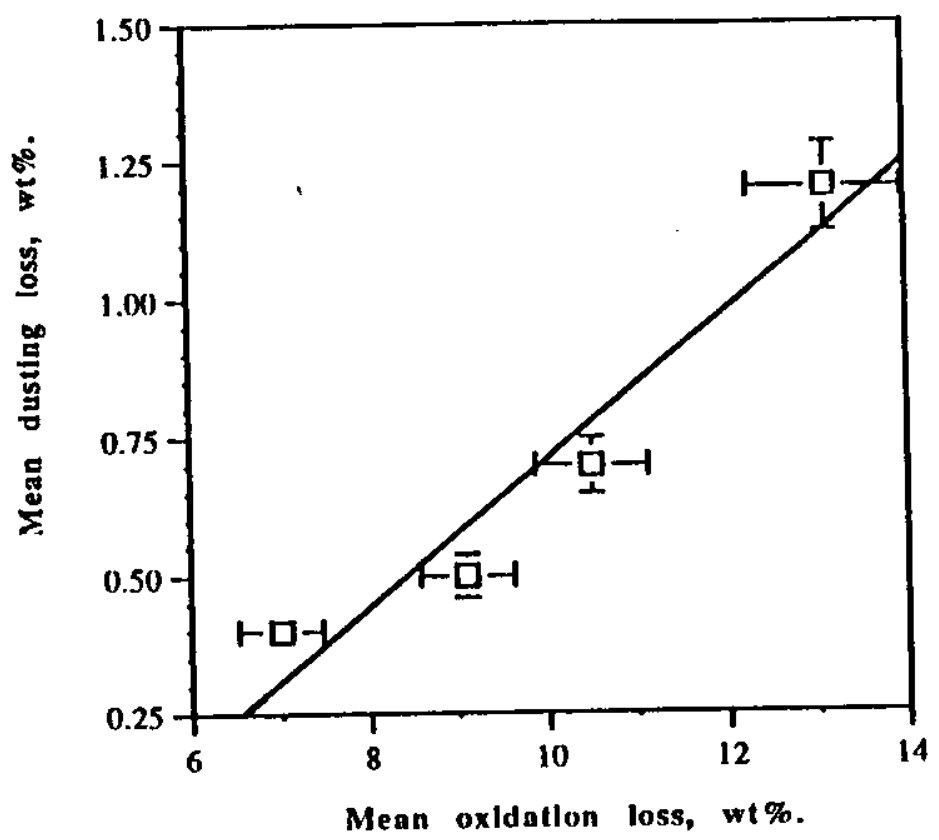

FIG.8.15. Variation of anode dusting loss with oxidation loss.

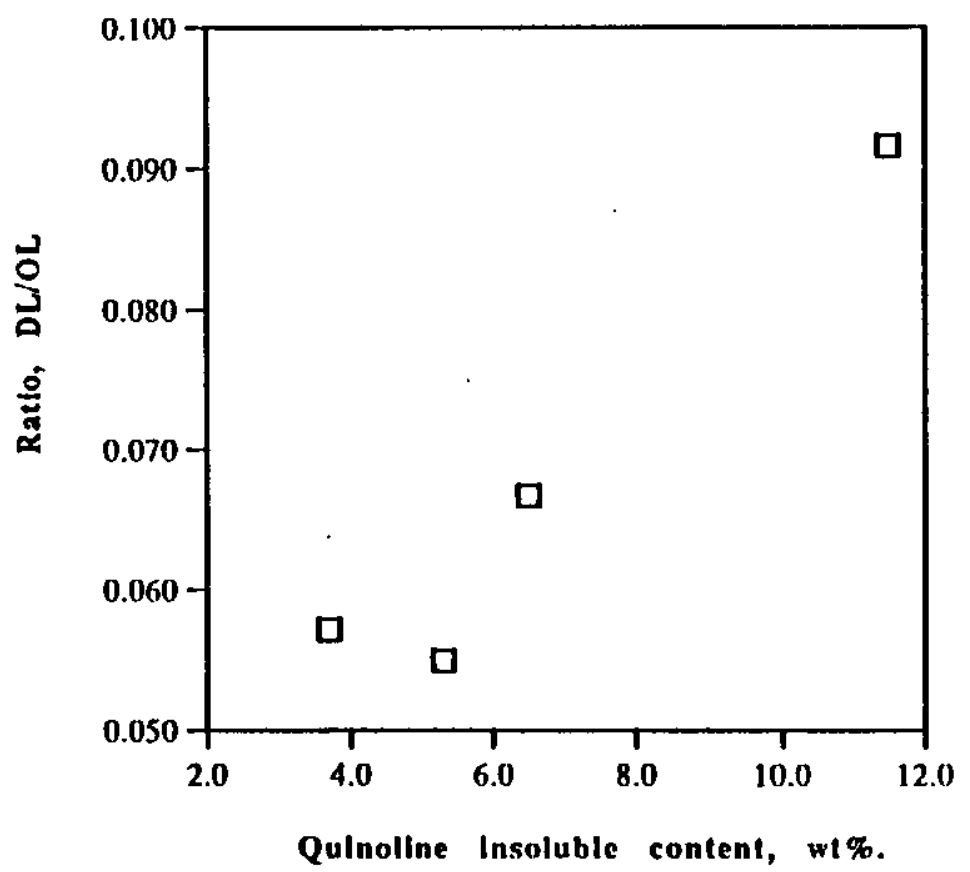

FIG.8.16. Variation of the ratio: dusting/oxidation loss with pitch QI content. 


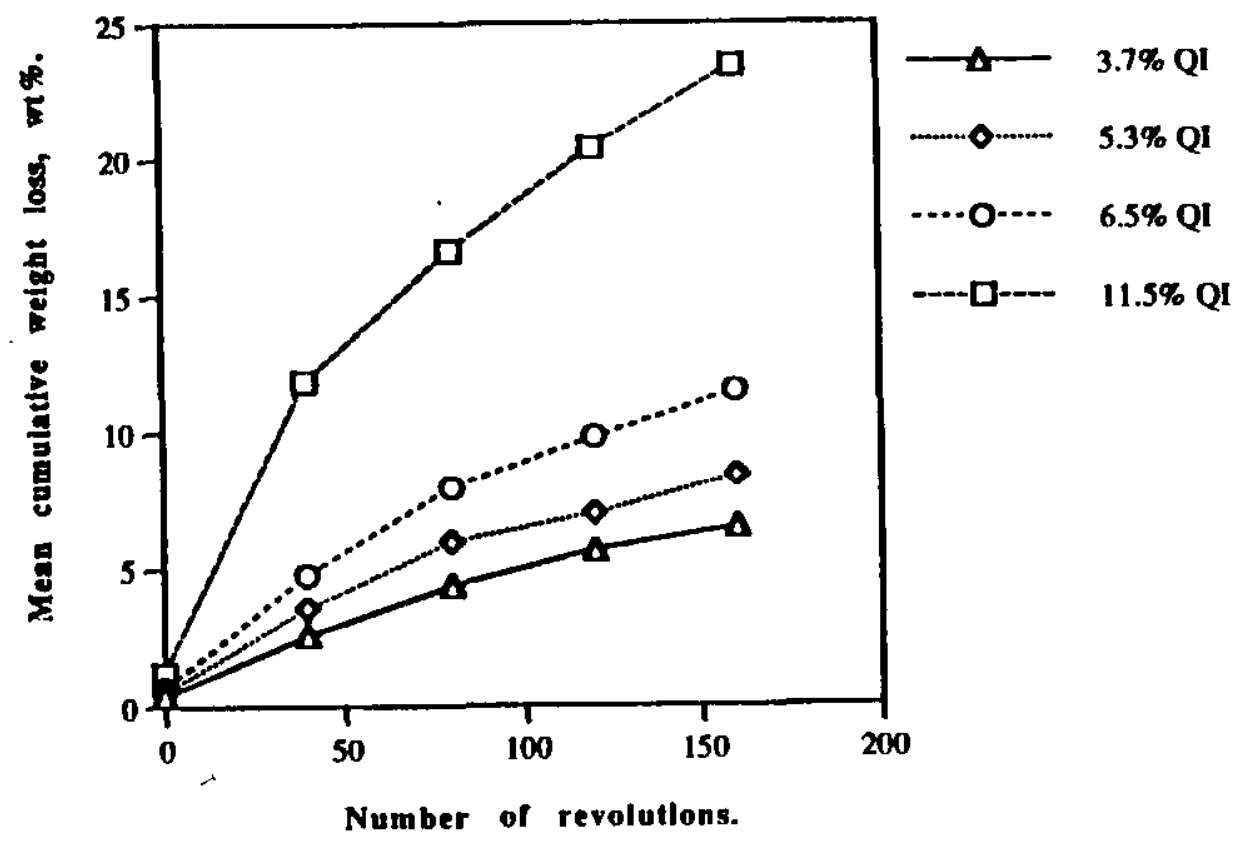

FlG.8.17. Influence, of binder pitch QI content on behaviour of oxidised anode in surface friability test.

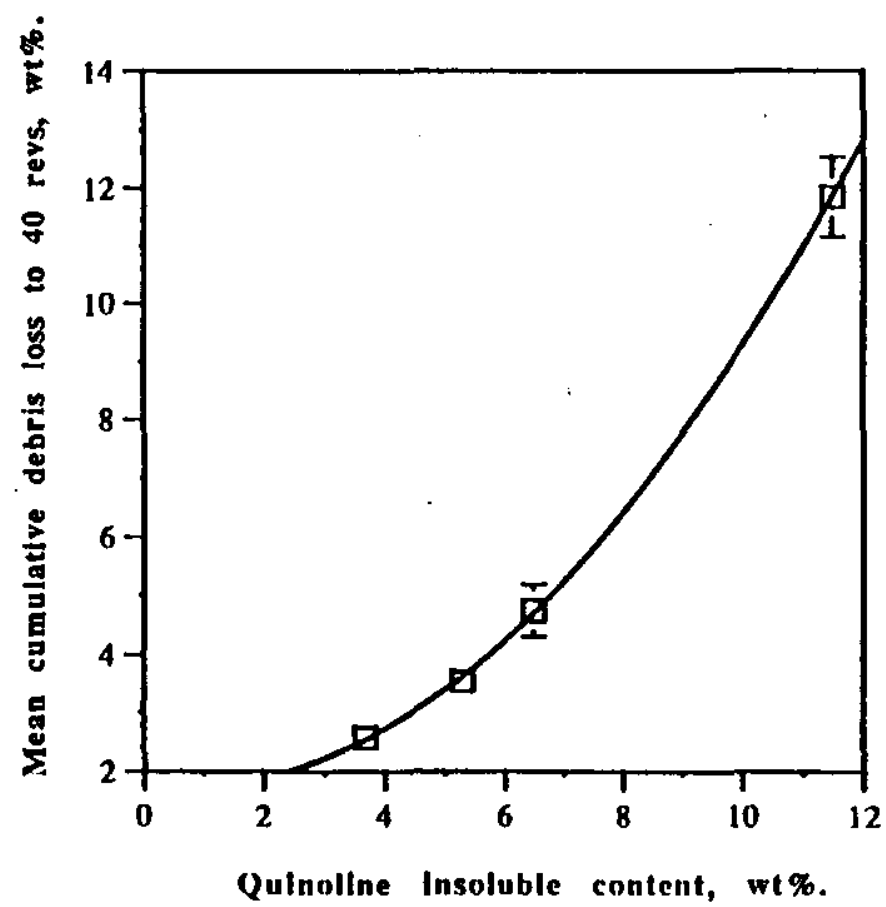

FIG.8.18. Variation of cumulative debris loss, to 40 revolutions, with QI content of binder pitch. 


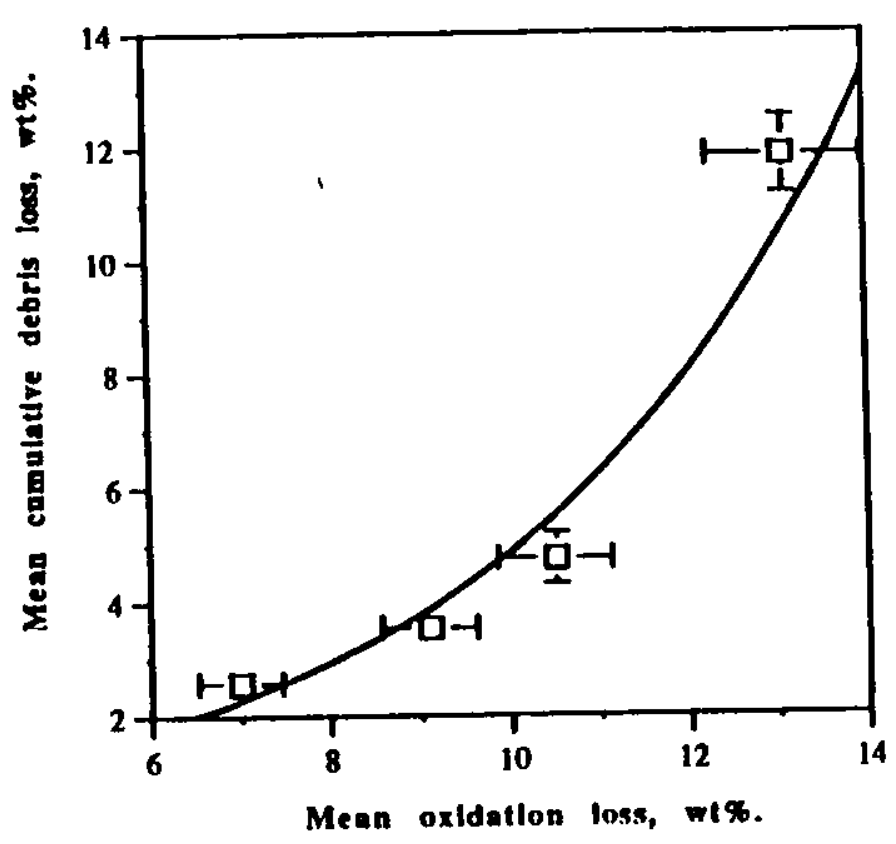

FIG.8.19. Variation of cumulative debris loss with oxidation loss.

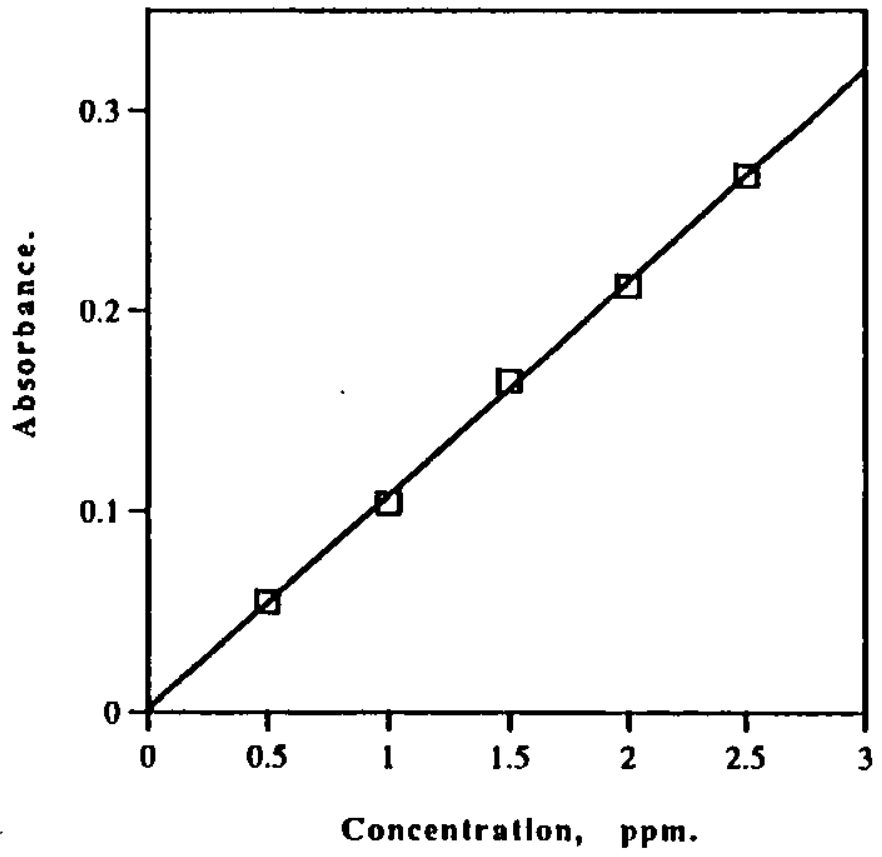

FIG.8.20. Calibration graph for sodium. 


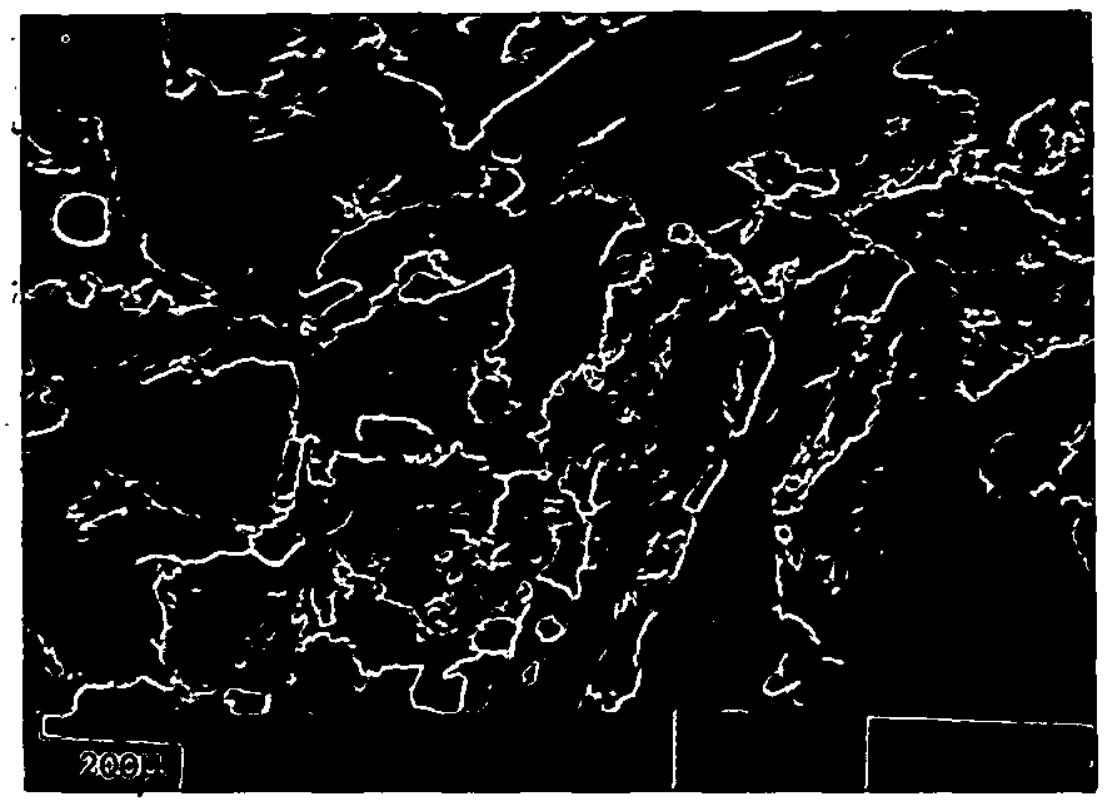

Fig.8.21. Low-magnification SEM view of the etched surface of an unoxidised anode carbon.

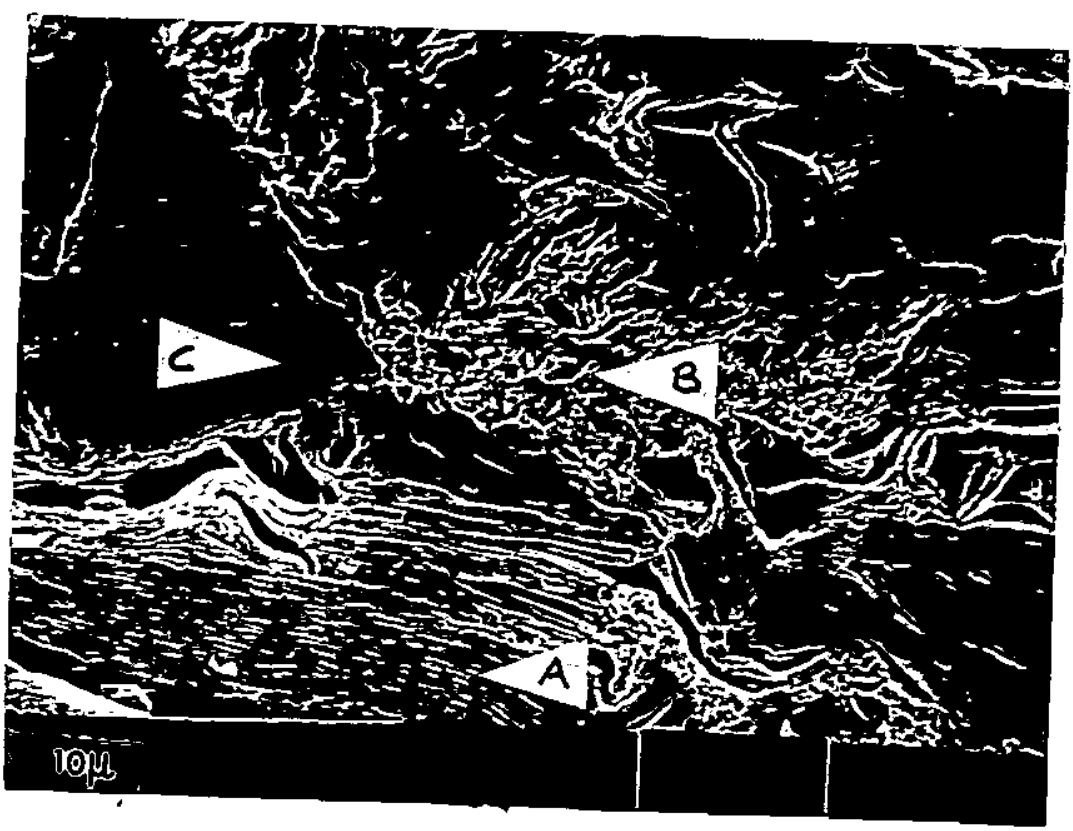

Fig. 8.22. High-magnification view showing binder phase (B) and petroleum coke filler particles (A \& C) differing in degree of ordering. 


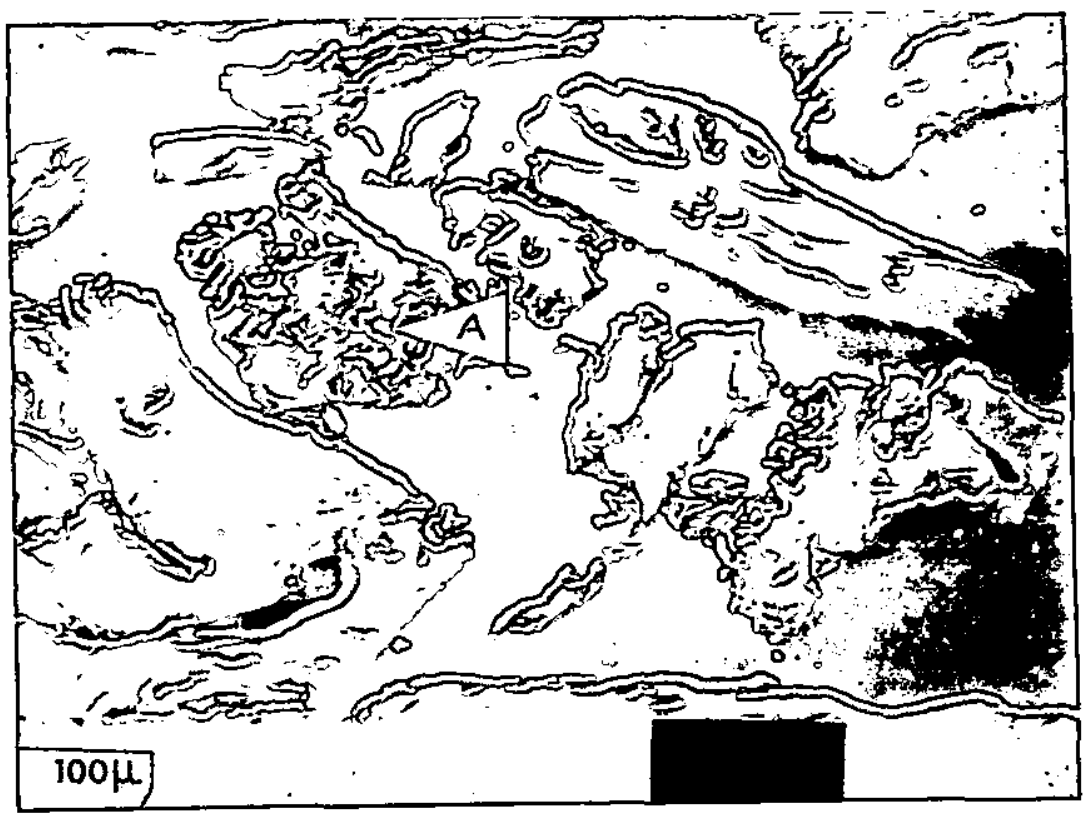

Fig. 8.23. No binder phase is present near the edge of oxidised specimens.

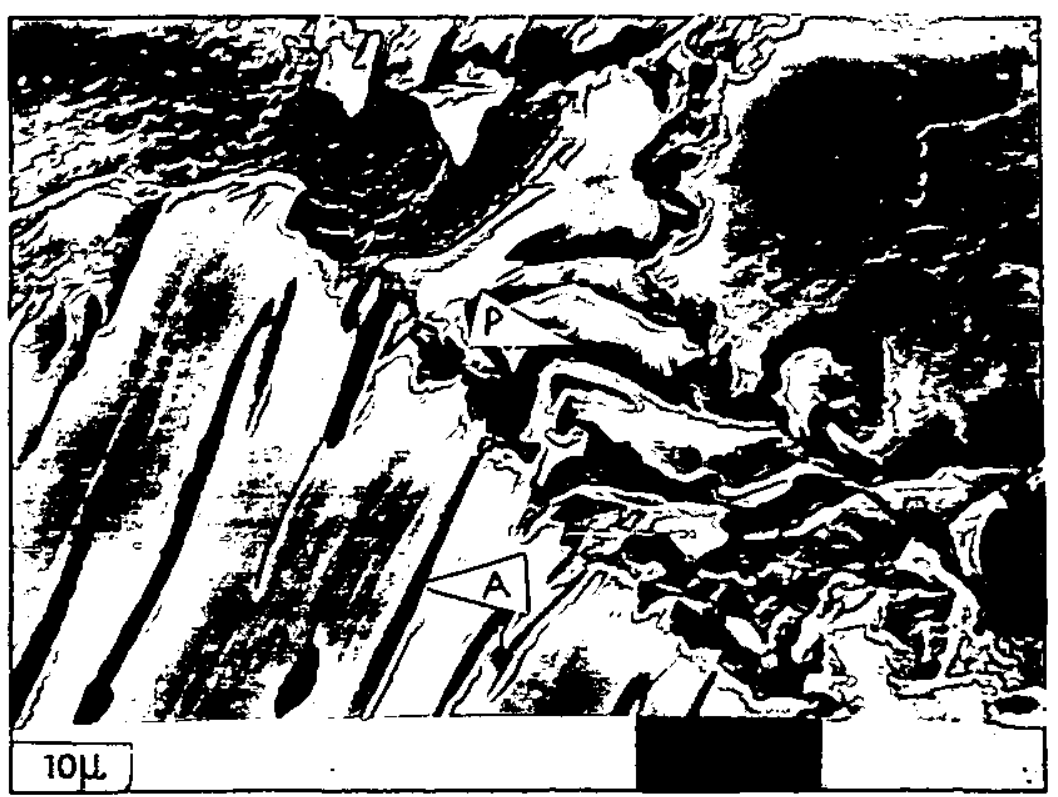

Fig. 8.24. Near the centre of oxidised specimens, small filler particles from the binder are evident at $P$. At $A$, a filler particle has been oxidised along an interlamellar fissure. 


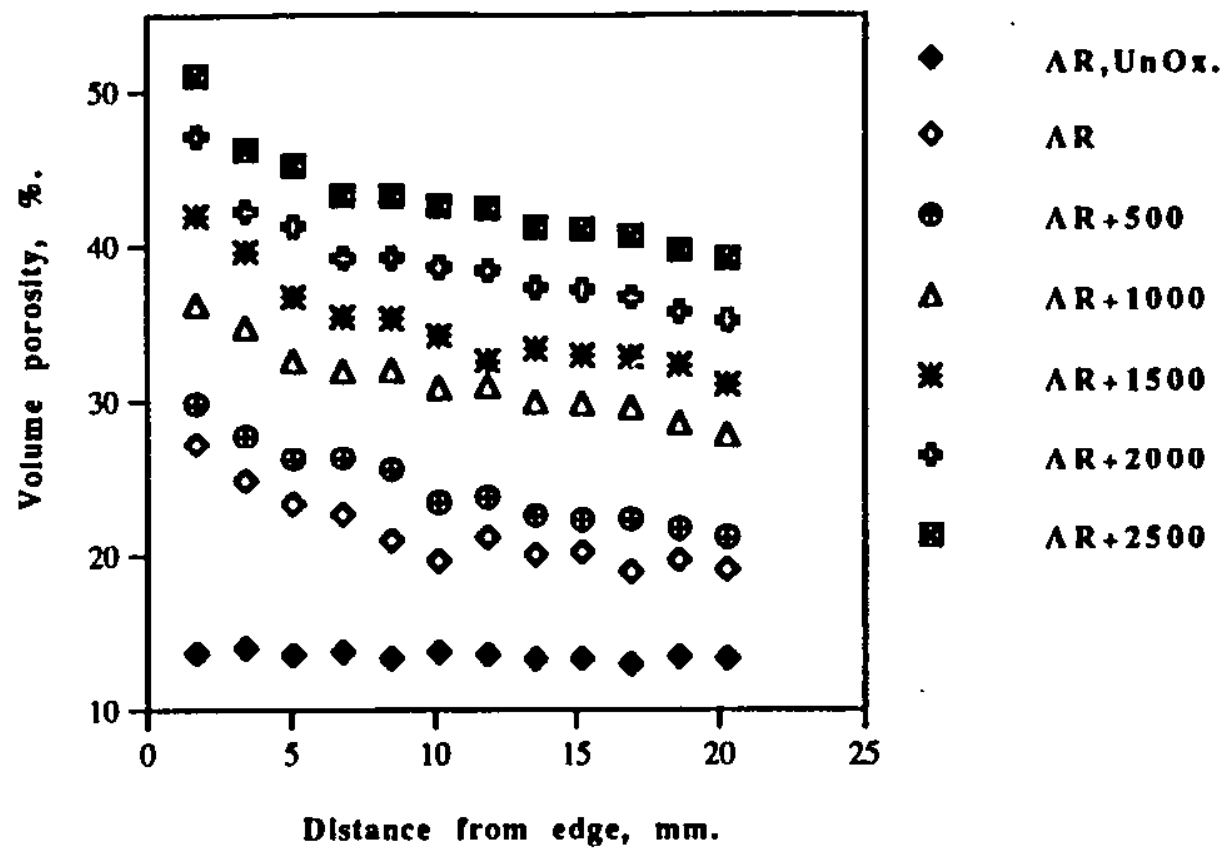

FIG.8.25. Variation in volume porosity across sections of anodes, made using sodium-doped pitches, after gasification in air at $550^{\circ} \mathrm{C}$ for $1 \mathrm{~h}$.

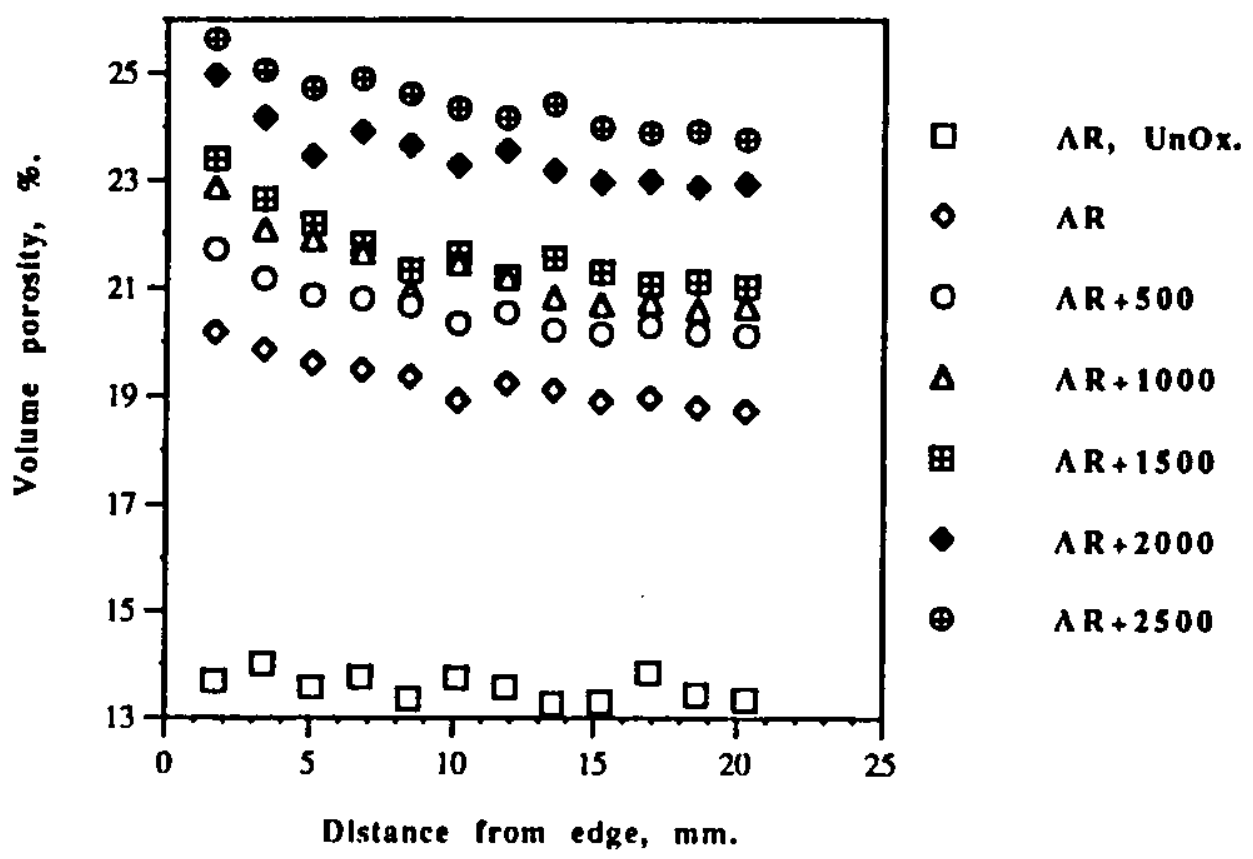

FIG.8.26. Variation in volume porosity across sections of carbons, made using sodium-doped pitches, after gasification in $\mathrm{CO}_{2}$ at $1000^{\circ} \mathrm{C}$ for $1 \mathrm{~h}$. 


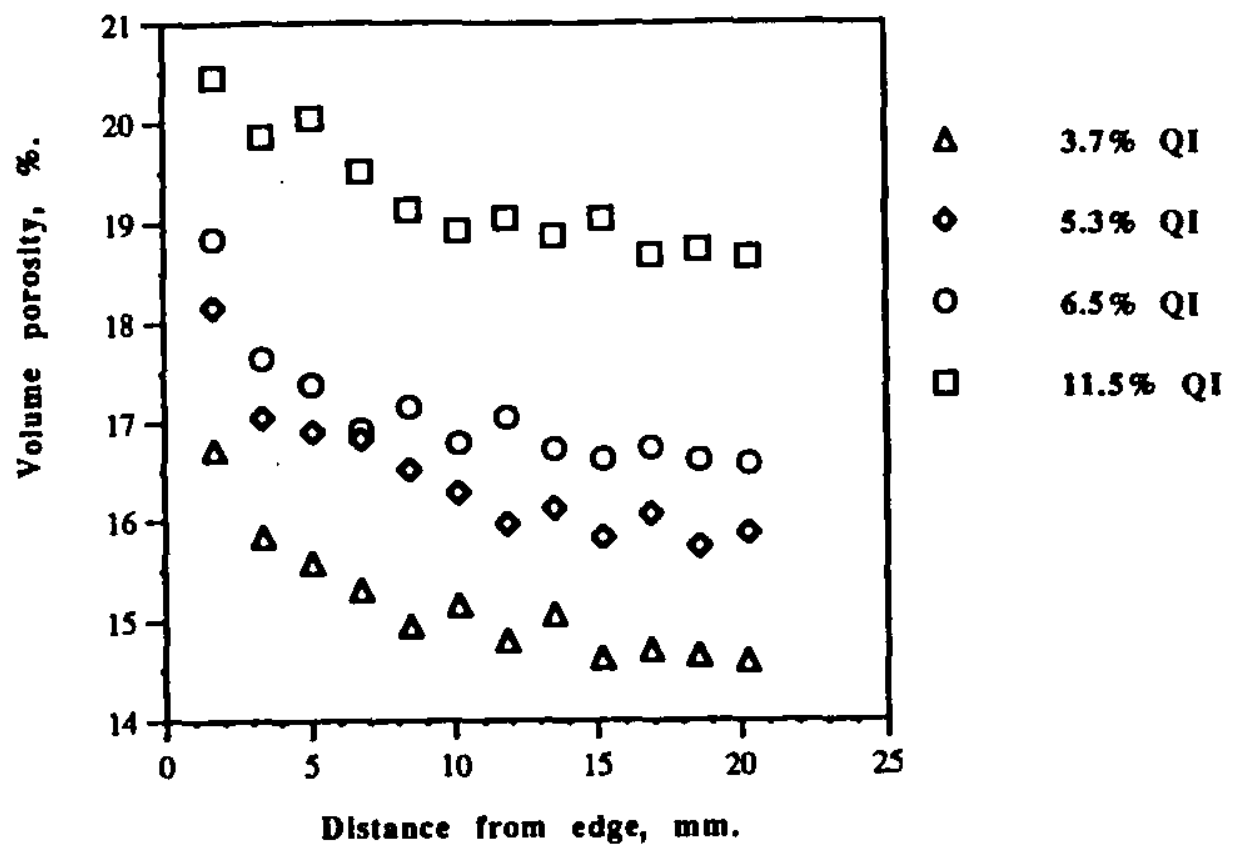

FIG.8.27. Variation in volume porosity across sections of carbons, made using pitches varying in QI content, after gasification in $\mathrm{CO}_{2}$ at $1000^{\circ} \mathrm{C}$ for $\mathrm{th}$.

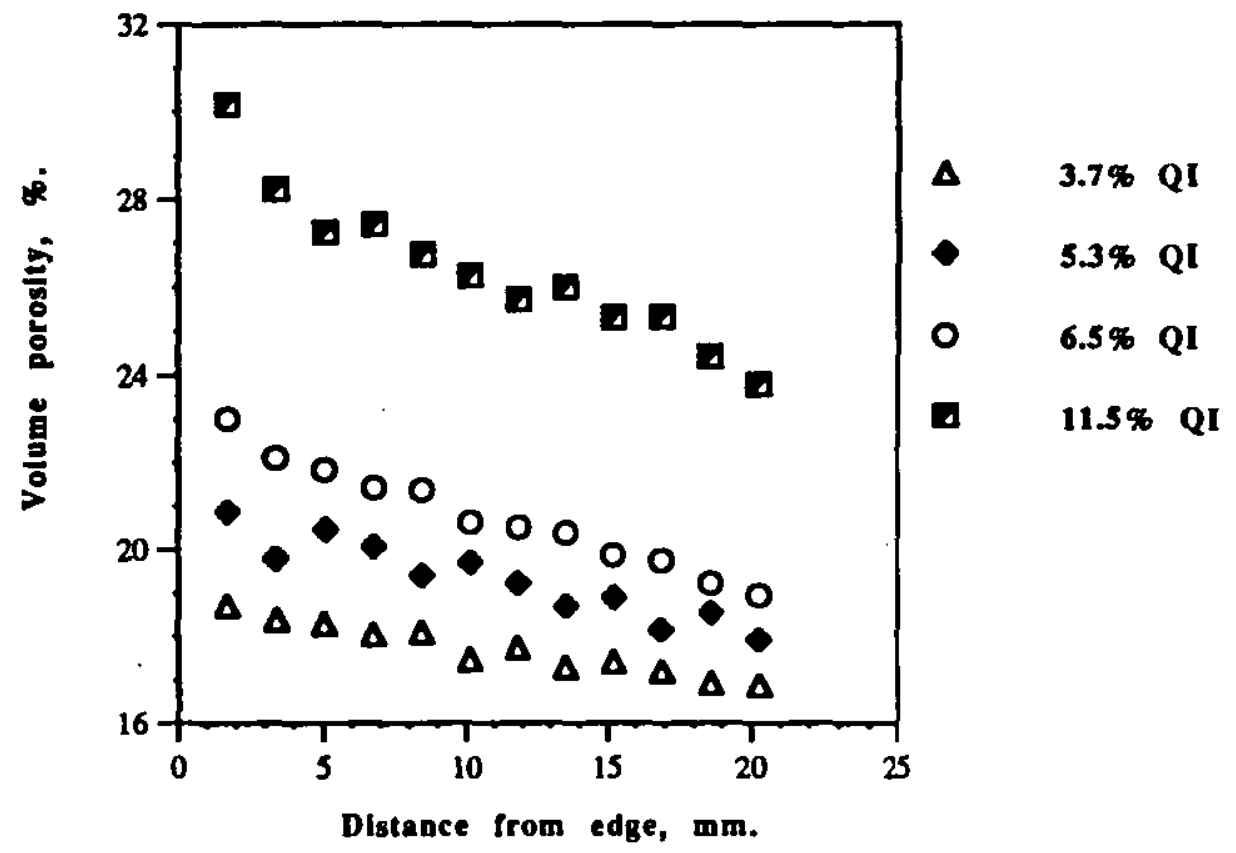

FIG.8.28. Variation in volume porosity across sections of carbons, made using pitches varying in QI content, after gasification in air at $550^{\circ} \mathrm{C}$ for $1 \mathrm{~h}$. 


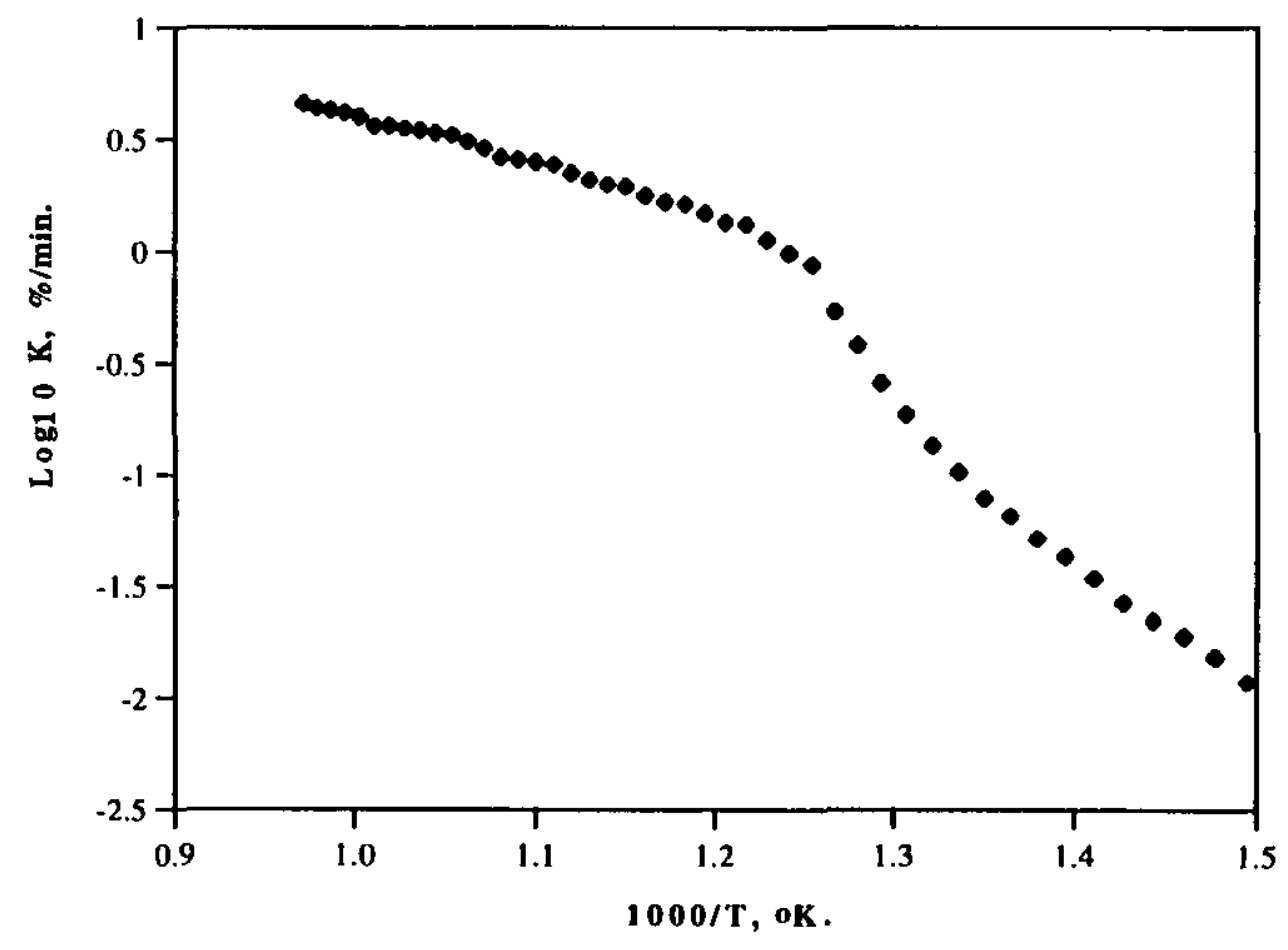

FIG.8.29. Arrhenius plot showing effect of temperature on gasification rate in air of a carbon made using a pitch containing $3.7 \mathrm{wt} \% \mathrm{QI}$.

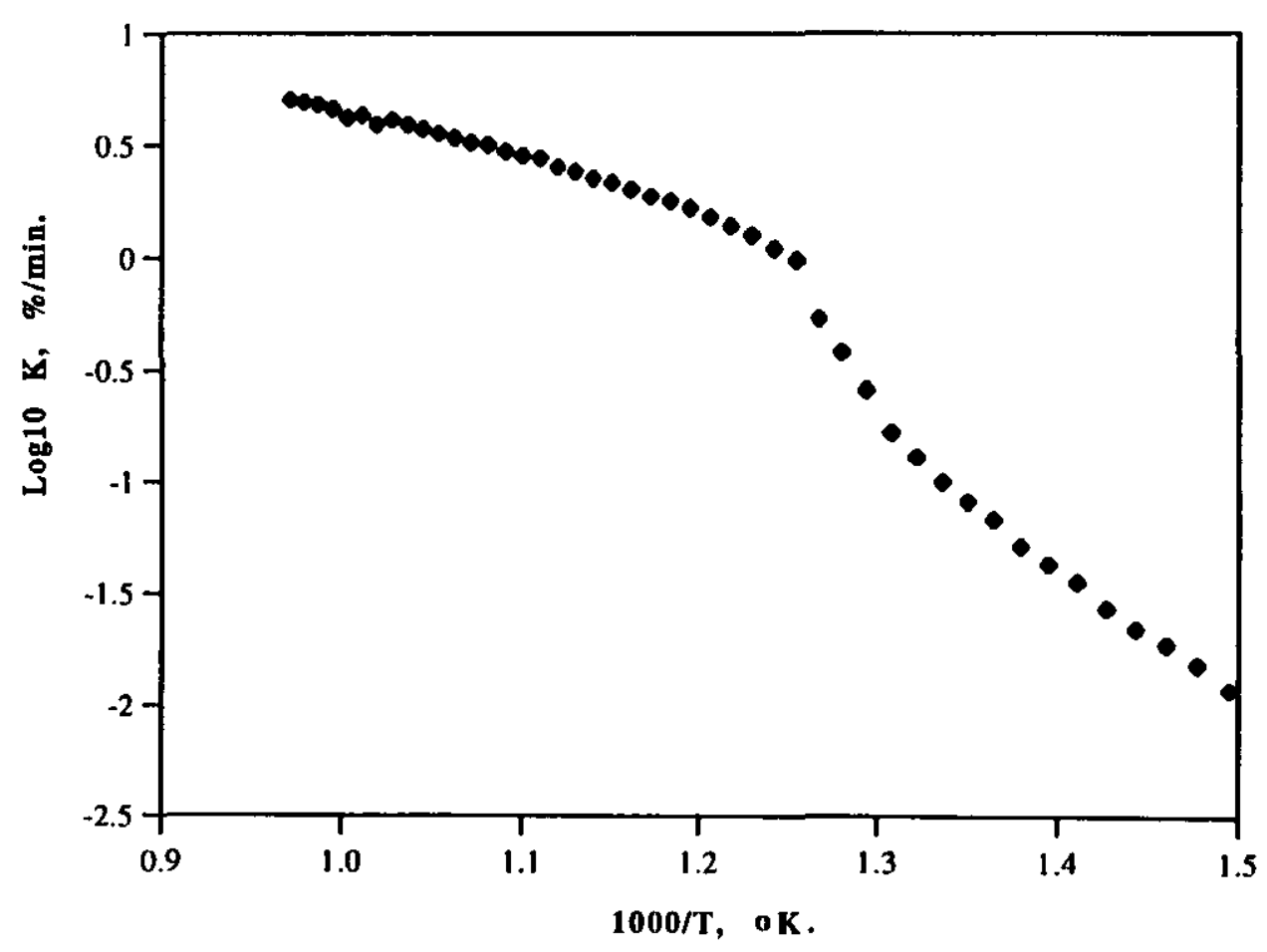

FIG.8.30. Arrhenius plot showing effect of temperature on gasification rate in air of a carbon made using a pitch containing $5.3 w t \%$ Ql. 


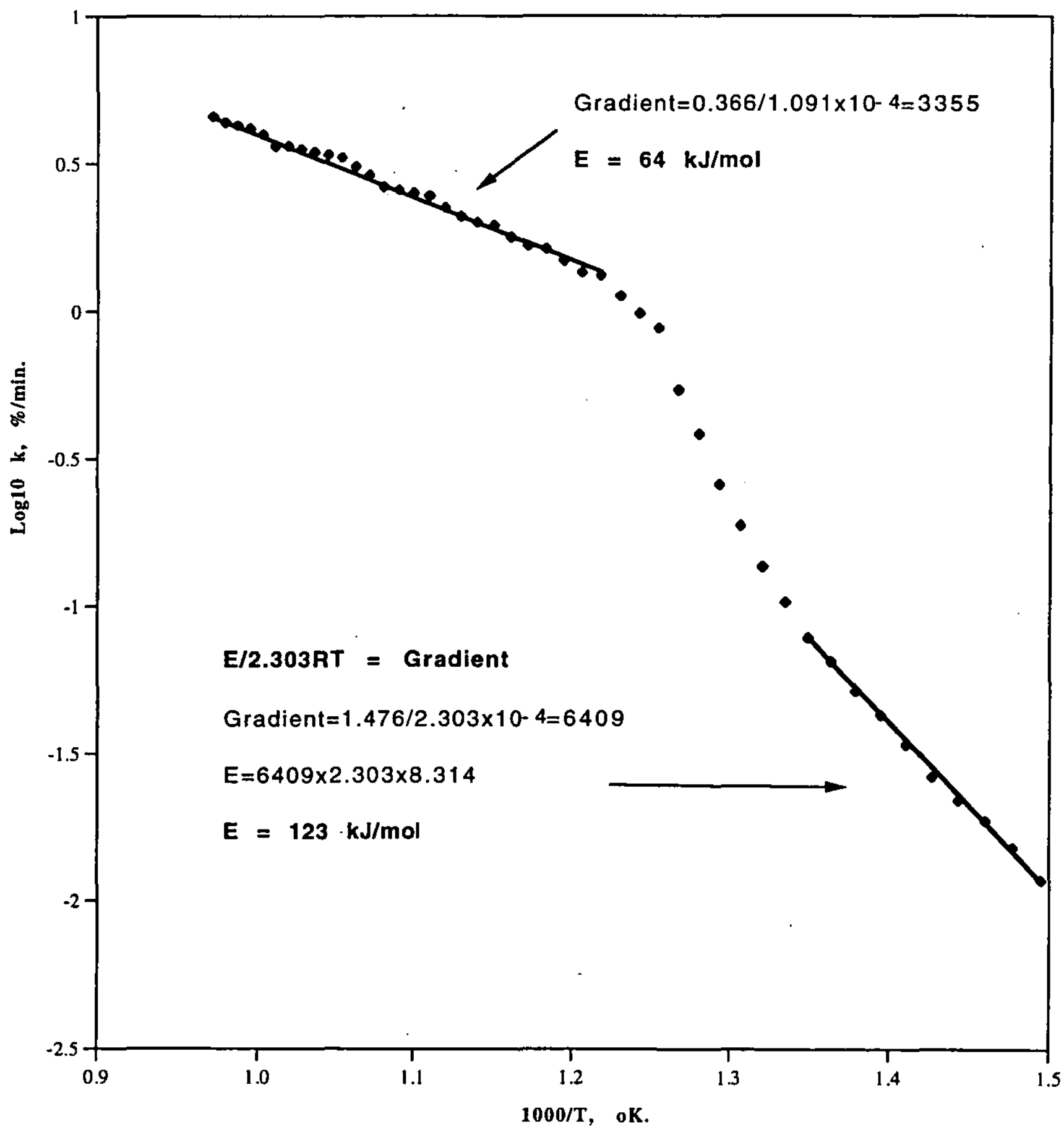

FIG.8.29a. Enlarged FIG.8.29 showing how activation energies were calculated. 


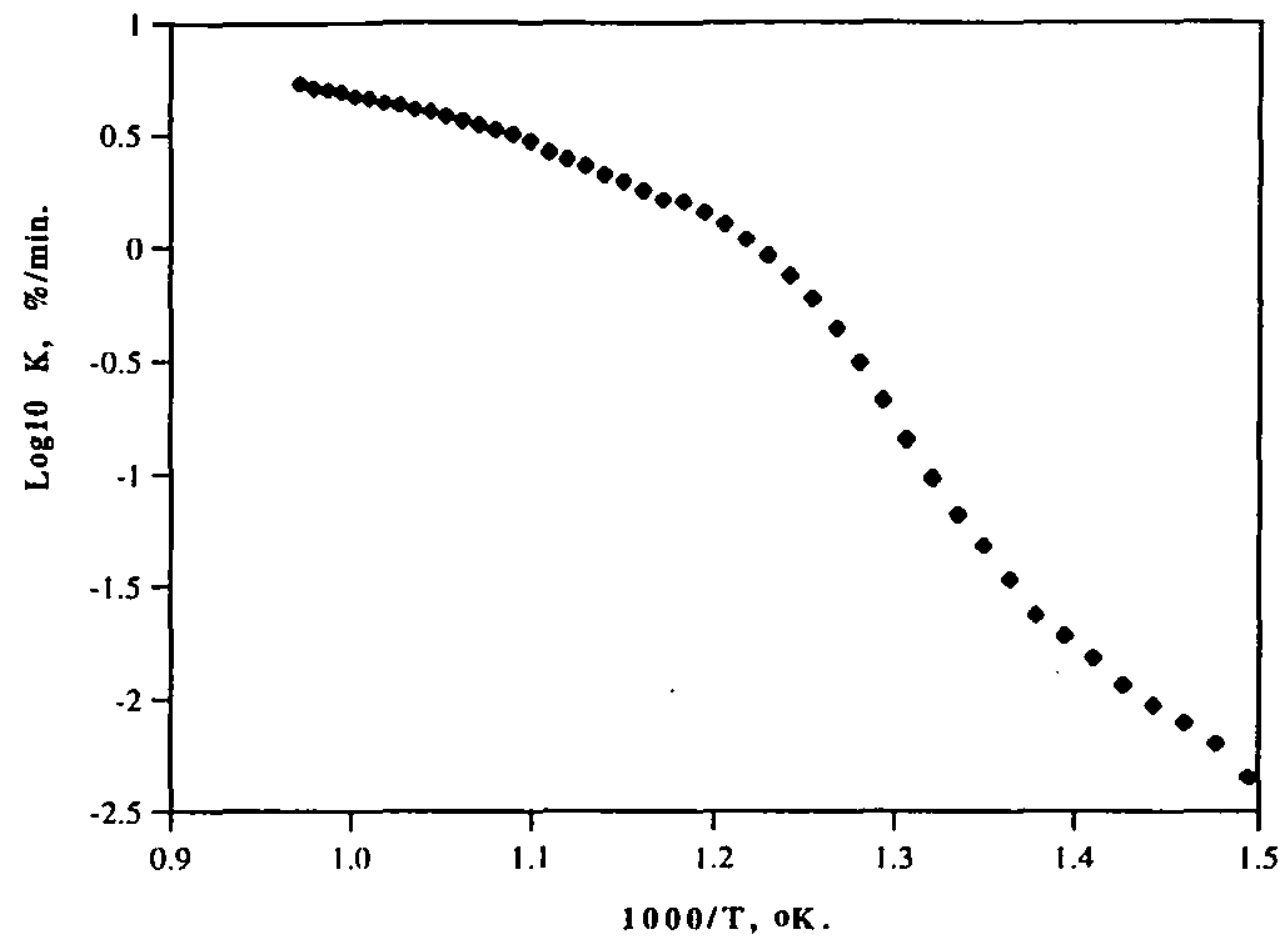

FIG.8.31. Arrhenius plot showing effect of temperature on gasification rate in air of a carbon made using a pitch containing $6.5 \mathrm{wt} \%$ QI.

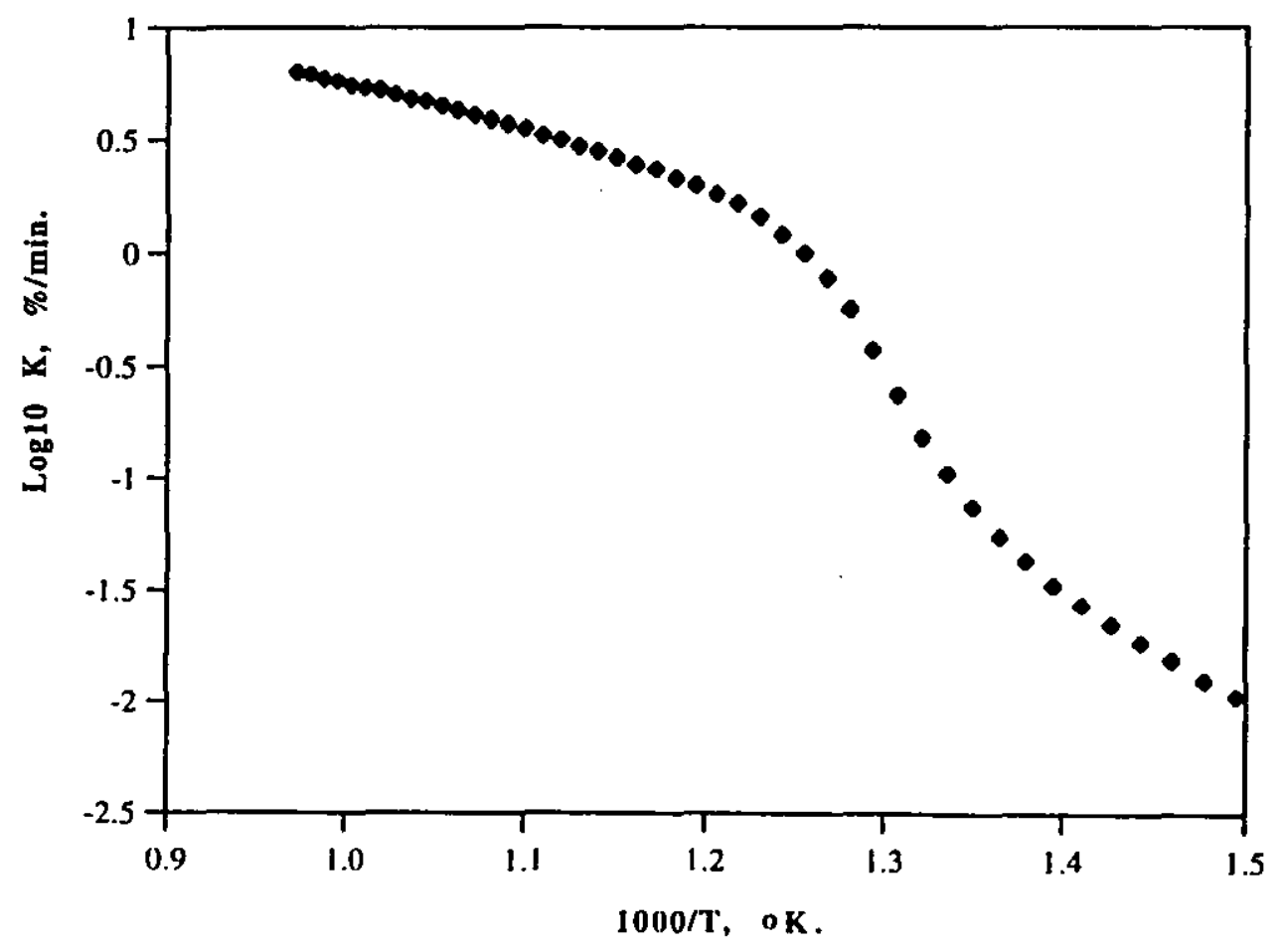

FIG.8.32. Arrhenius plot showing effect of temperature on gasification rate in air of a carbon made using a pitch containing $11.5 w t \%$ QI. 


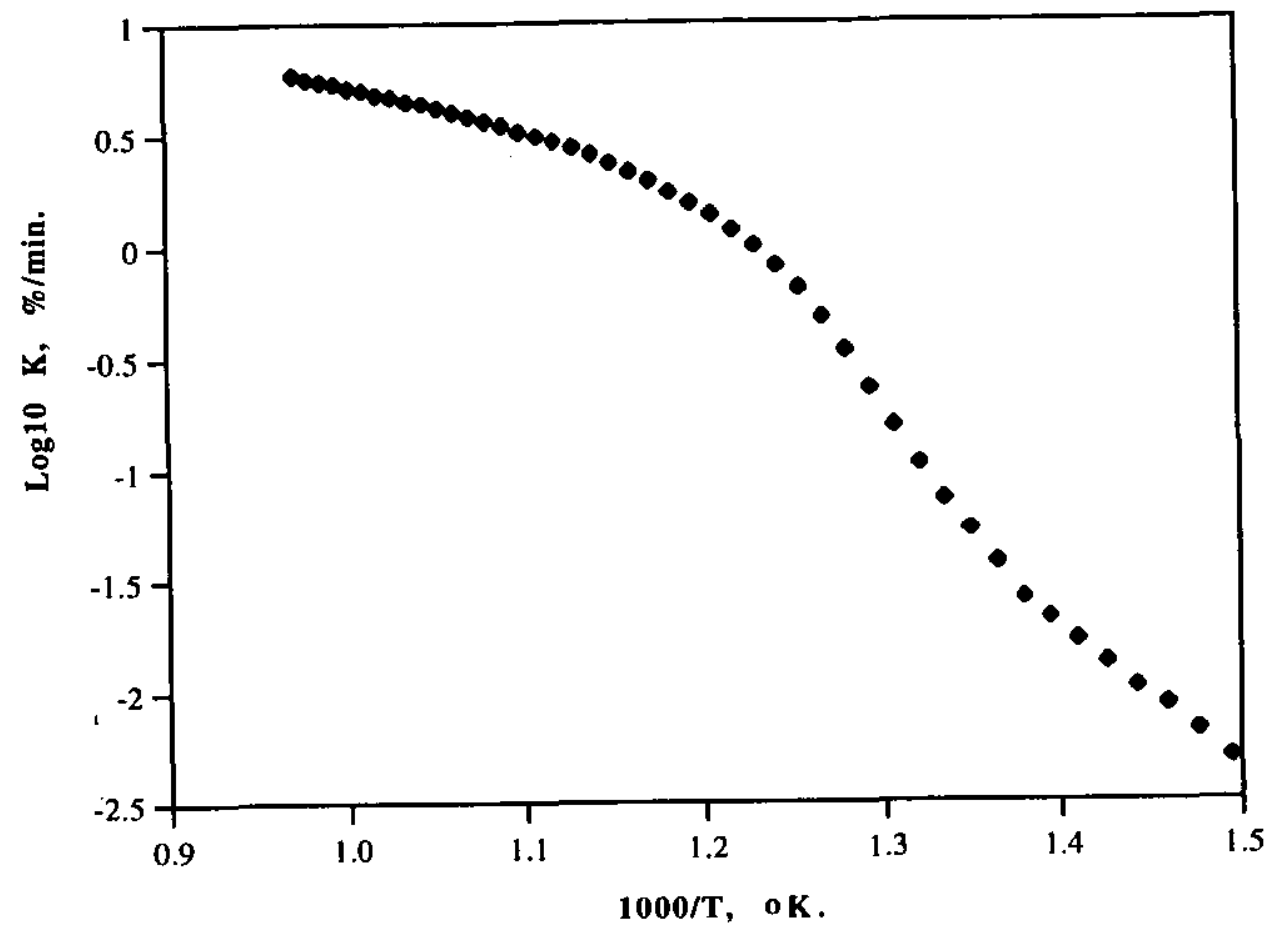

FIG.8.33. Arrhenius plot showing effect of temperature on gasification rate in air of a carbon made using a pitch containing 0ppm additional sodium.

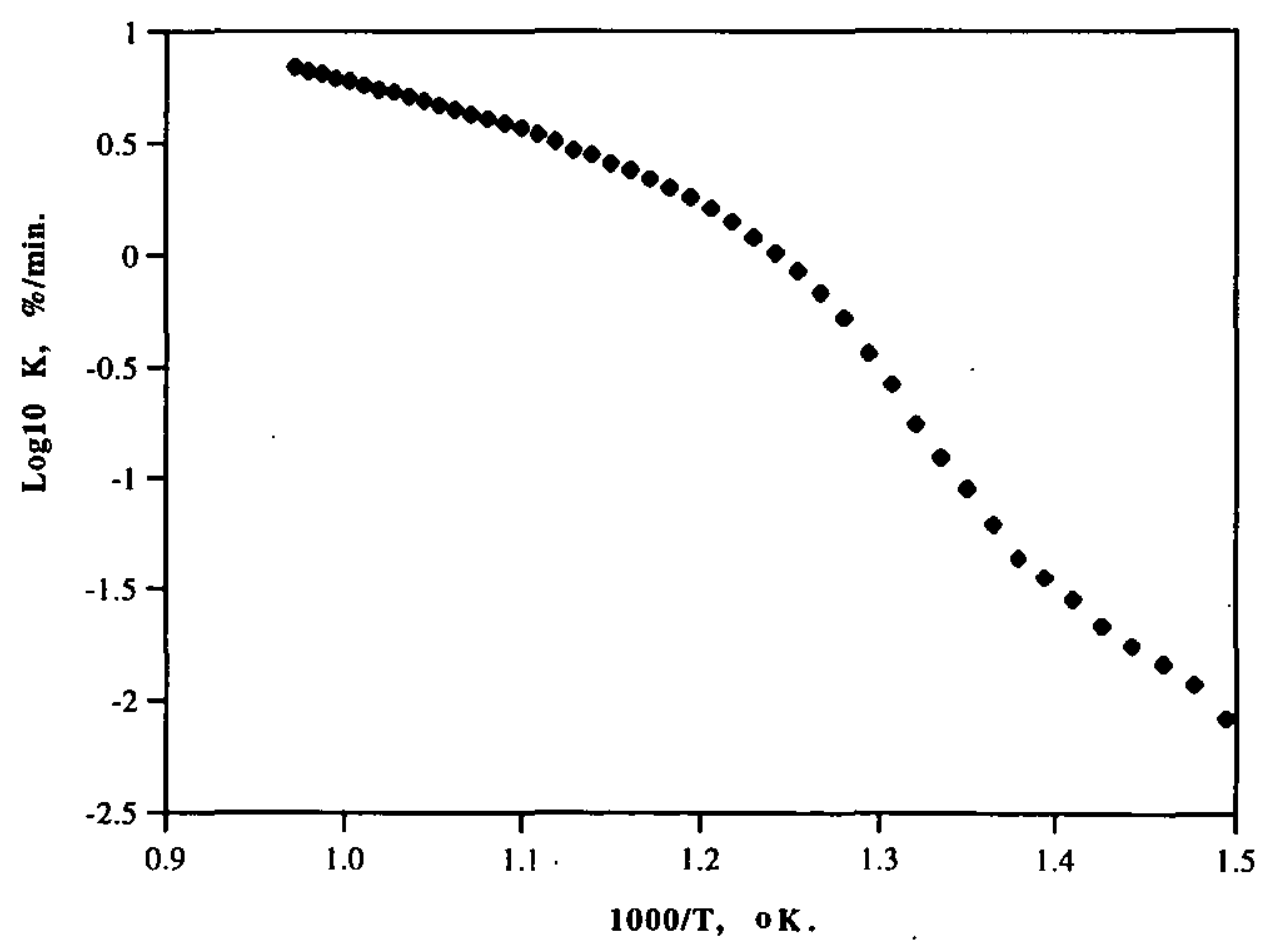

FIG.8.34. Arrhenius plot showing effect of temperature on gasification rate in air of a carbon made using a pitch containing 500ppm additional sodium. 


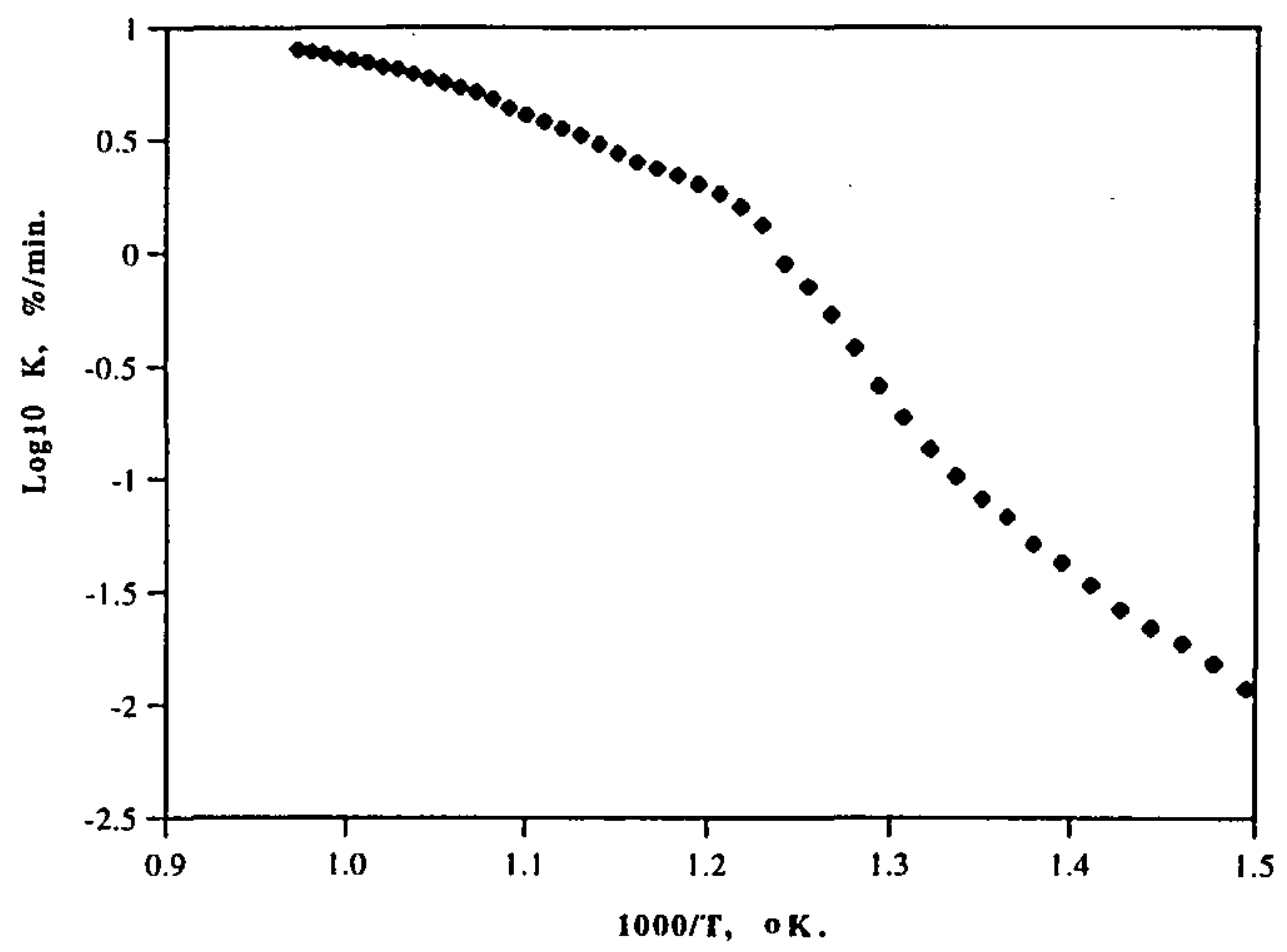

FIG.8.35. Arrhenius plot showing effect of temperature on gasification rate in air of a carbon made using a pitch containing 1000ppm additional sodium.

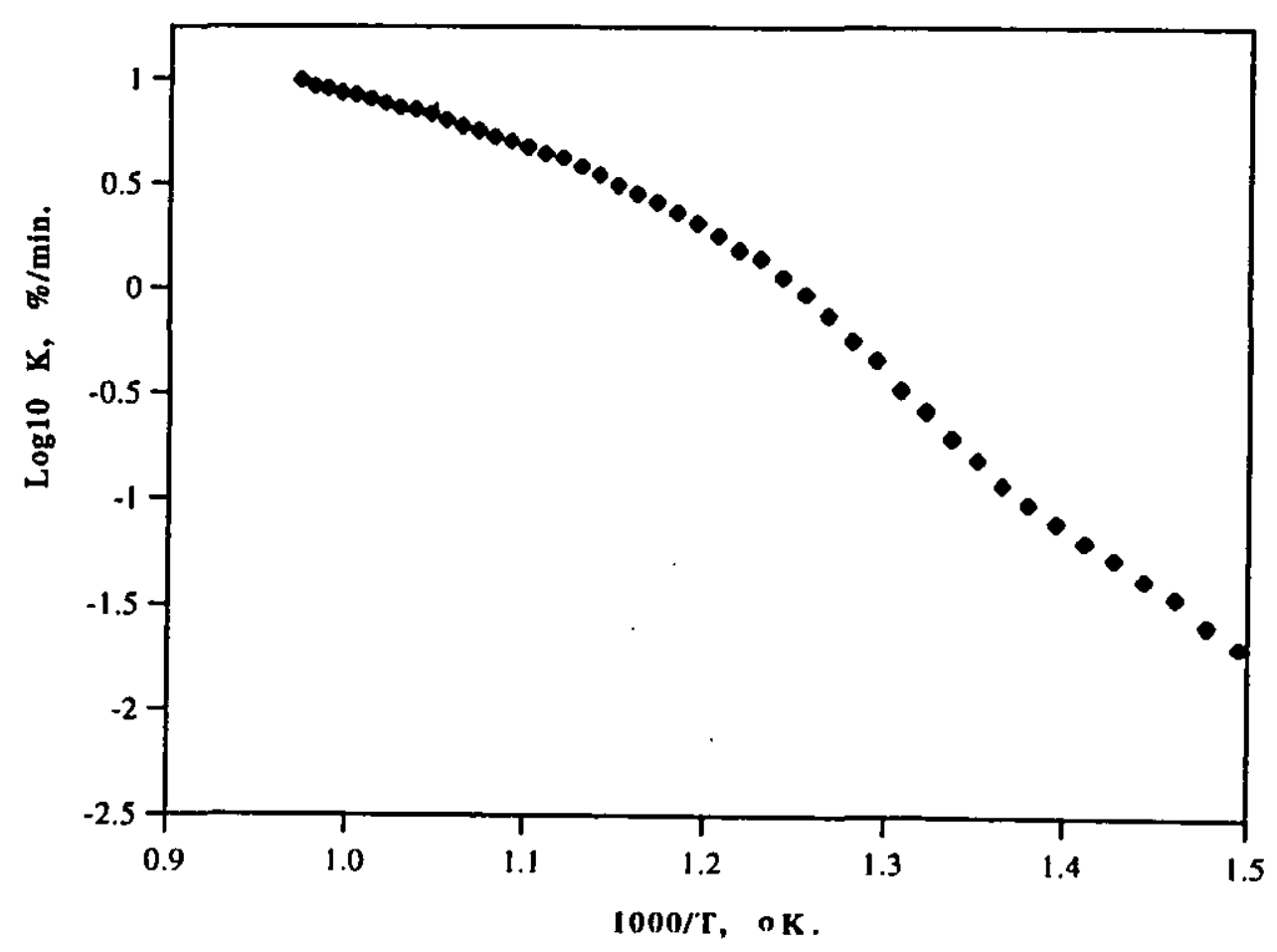

FIG.8.36. Arrhenius plot showing effect of temperature on gasification rate in air of a carbon made using a pitch containing $1500 \mathrm{ppm}$ additional sodium. 


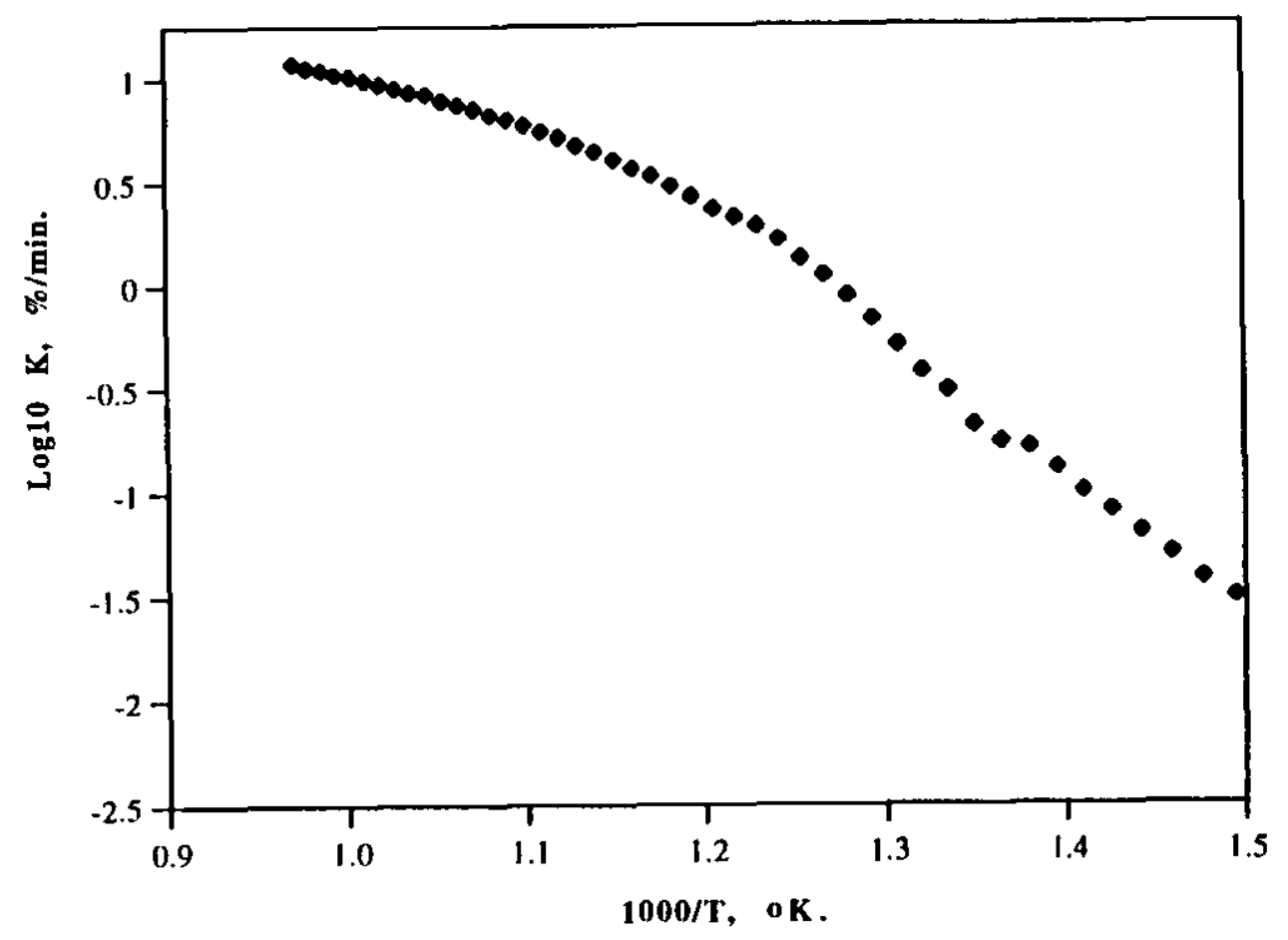

FIG.8.37. Arrhenius plot showing effect of temperature on gasification rate in air of a carbon made using a pitch containing $2000 \mathrm{ppm}$ additional sodium.

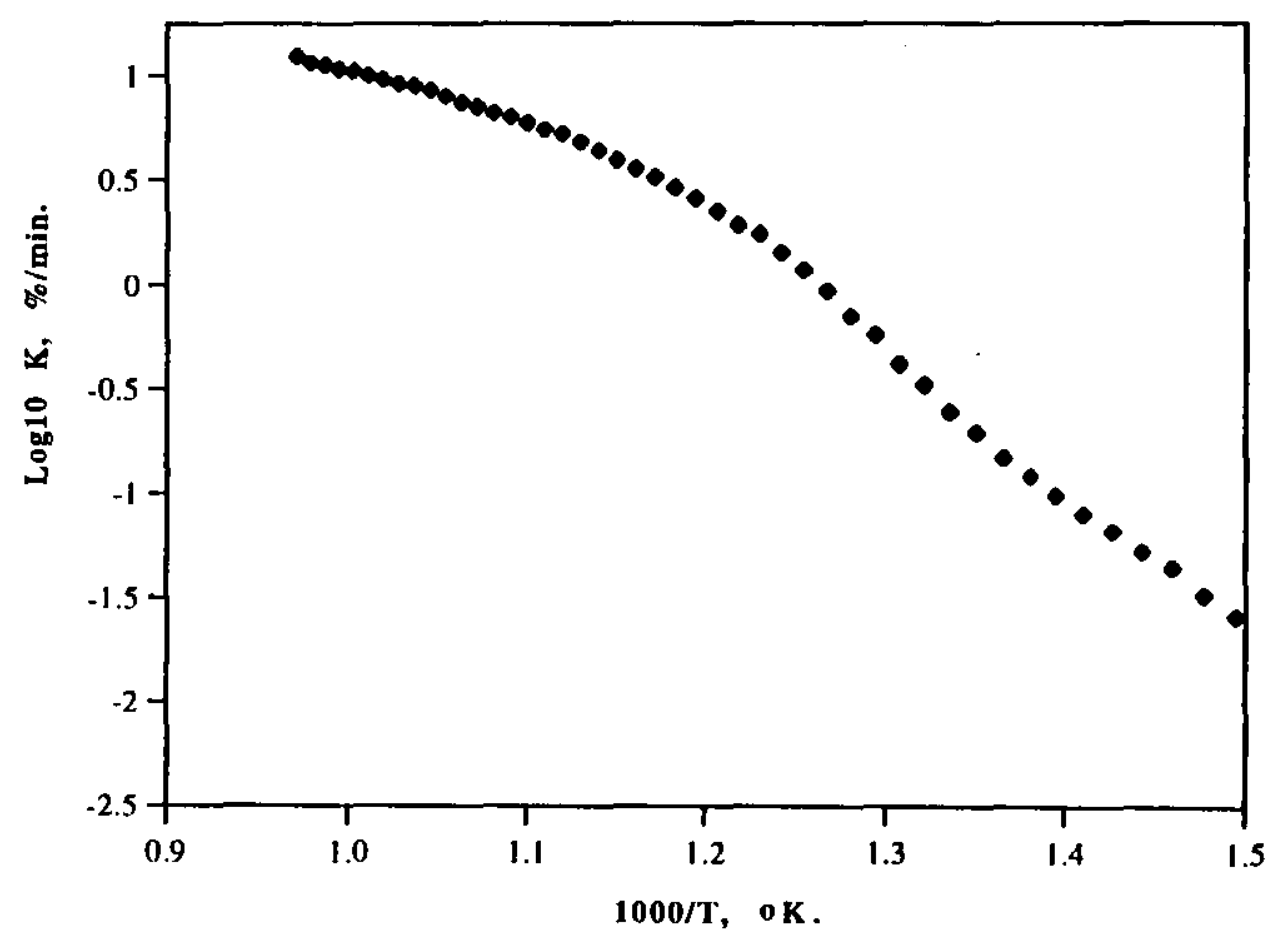

FIG.8.38. Arrhenius plot showing effect of temperature on gasification rate in air of a carbon made using a pitch containing 2500ppin additional sodium. 


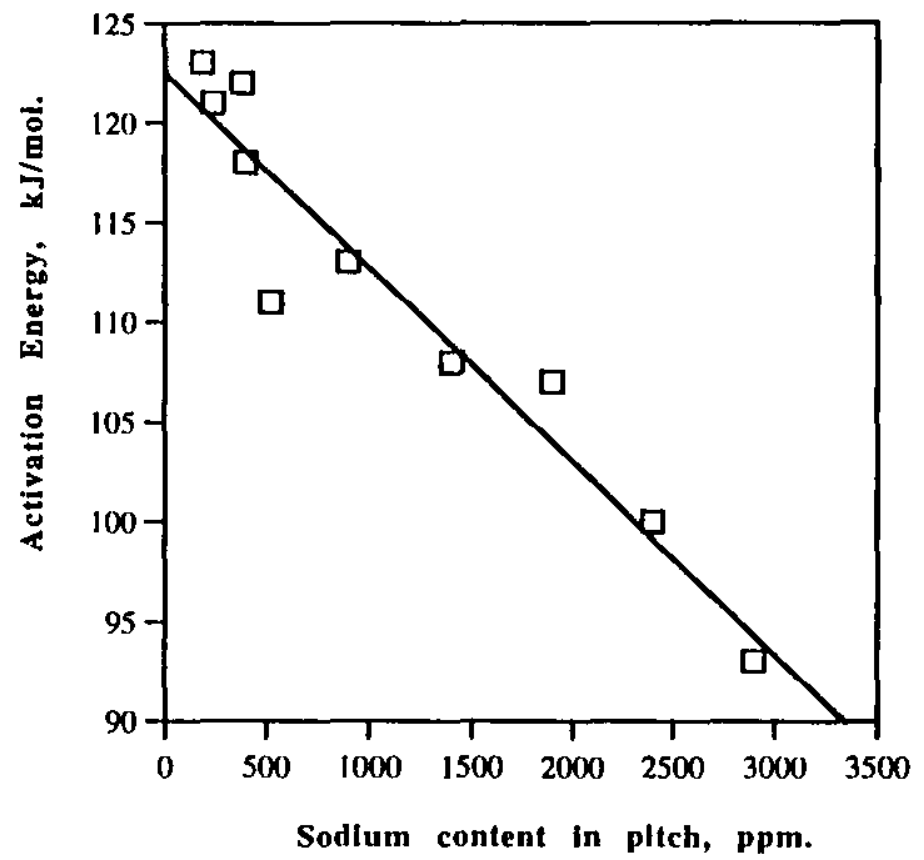

FIG.8.39. Activation energies vs. the pitch sodium content of all the carbons. 


\section{DISCUSSION}

\subsection{The influence of mass transport on gaseous oxidation rates}

Before proceeding to the general discussion on the experimental results, it is considered to be advantageous to give a brief but pertinent discussion of gaseous mass transport inside carbonaceous materials and its influence on the oxidation rate. In fact, although the influence of mass transport on reaction rate has been extensively discussed in the literature on carbon oxidation $(96,148)$, the available information related to carbon anodes within the aluminium industry is very scarce.

In an anode, as well as in most carbonaceous materials, the surface able to react is mainly located inside the pores. In consequence, three major steps must be distinguished for the proper understanding of the reaction mechanism:

(a) transport of reactive gas and products between the external surface and the bulk of the gas,

(b) transport between the external surface and the reactive surface inside pores, and

(c) reaction on pore surface.

Depending on the reaction conditions each of these steps will contribute differently to the overall process. With regards to the present study, step (i) can be safely disregarded because external transport becomes important at temperatures well above $700^{\circ} \mathrm{C}$ for the $\mathrm{C}-\mathrm{O}_{2}$ reaction and above $1000^{\circ} \mathrm{C}$, for the $\mathrm{C}-\mathrm{CO}_{2}$ reaction. Conversely, as discussed later, transport inside pores is often a limiting factor on the oxidation rate.

\subsubsection{Air oxidation}

Considering the air oxidation of exposed parts of the anode, mass transport is achieved by in-pore diffusion. A rigourous analysis of reaction conditions should include consideration of sample geometry, temperature distribution, anode properties and surface reaction kinetics. However, qualitatively correct discussions can be performed on the basis of simplified kinetics and disregarding the effect of sample geometry (149). 
Sattersfield (149) has considered the case of a reaction which is first order in oxidant concentration, and conditions such that diffusion does not influence the overall reaction rate, ie. the reaction occurs in Zone I (see Figs. 5.3a and $5.3 b)$. Therefore, this means that the mass transport of the oxidant gas is sufficiently fast to keep its concentration essentially constant throughout the sample and equal to the external value, $c$, in the gaseous phase. (Obviously, there must be some concentration gradient of reactant through the sample, even in Zone I; but it is so small that a concentration of $c$ can be assumed). At the same time, the concentration of products within the porous sample is negligible. In this case, Sattersfield (149) used the following rate equation to represent the Zone I reaction:

$v_{0}=k_{0} s \mu c$

where, $v_{0}=$ reaction rate expressed by unit volume in the absence of any

diffusional limitation $\left(\mathrm{mol} / \mathrm{cm}^{3} \mathrm{sec}\right)$

$\mathrm{k}_{\mathrm{o}}=$ rate constant $\left(\mathrm{cm}^{3} / \mathrm{m}^{2} \mathrm{sec}\right)$

$\mathrm{s}=$ specific surface $\left(\mathrm{m}^{2} / \mathrm{g}\right)$

$\mu=$ apparent density $\left(\mathrm{g} / \mathrm{cm}^{3}\right)$

$\mathrm{C}=$ oxidant gas concentration in bulk gaseous phase $\left(\mathrm{mol} / \mathrm{cm}^{3}\right)$

When the reaction ocurrs in Zone I, ie. chemically controlled, it must be taken into account that as carbon is burnt off, the values of $s, \mu$ and $k_{0}$ can change so that, even in this simple case, the rate usually changes as the reaction proceeds. This is of great importance when the carbon reactivity is to be measured accurately. The rate constant varies with temperature according to the Arrhenius relation and activation energies of about $146-167 \mathrm{~kJ} / \mathrm{mol}$ are found for the $\mathrm{C}-\mathrm{O}_{2}$ reaction when impure carbons are used (148):

$k_{0}=k_{0}^{\circ} \exp \left(-E_{a} / R T\right)$

where, $k_{0}{ }^{\circ}=$ pre-exponential factor in Arrhenius relation $\left(\mathrm{cm}^{3} / \mathrm{m}^{2} \mathrm{sec}\right)$

$E_{a}=$ activation energy $(\mathrm{kJ} / \mathrm{mol})$

However, gaseous diffusion has a very low activation energy, $(<13 \mathrm{~kJ} / \mathrm{mol}$ (149)). Therefore, at high temperatures, the reaction rate increases to a point in which diffusion rates are not fast enough to keep the oxidant concentration 
uniform over the whole specimen. The reaction is then influenced by diffusional limitations and a concentration gradient develops in the specimen (see Fig. $5.3 b)$, ie. the reaction occurs in Zone 11 or under internal diffusion conditions.

Sattersfield (149) has also considered this Zone II reaction, in which the oxidant concentration goes to zero at a certain distance from the external surface. He showed that the overall reaction rate in the sample now was:

$v=\left(k_{0} s \mu D_{\Theta}\right)^{1 / 2} c$

where, $v$ = reaction rate expressed by unit of external surface under in-pore diffusion conditions $\left(\mathrm{mol} / \mathrm{cm}^{2} \mathrm{sec}\right.$ )

$D_{e}=$ effective diffusivity in porous medium $\left(\mathrm{cm}^{2} / \mathrm{sec}\right)$

It is evident from equation (3) that the influence of the product $k_{0} s \mu$, which can be considered the intrinsic or chemical reactivity of the material, is smaller than in the chemically controlled reaction (eqn.1). However, the overall reaction rate is now influenced by the porous texture of the material, through the presence of $D_{e}$ in equation (3). It has been shown by Sattersfield (149) that if $3\left|D_{e} / k_{o} \mu s\right|^{1 / 2}$ is much smaller than the dimensions of the specimen, then the reaction is restricted to a relatively small region near the outer surface. Paulin (150) has measured gas compositions inside prebaked anodes during operation in the pot, and has found that $\mathrm{O}_{2}$ is effectively exhausted in the inner part of the anode. Then, the reaction conditions are similar to those described above in the Zone II reaction.

Further evidence comes from the study of specific surface gradients in anodes that were taken out of the pot after several days of use. As shown in Fig.9.1, the specific surface is higher near. the outer surface but rapidly falls to a normal value in the interior. This demonstrates that the anode is oxidised only in a zone near the external surface. In fact, the analysis of reaction conditions in an anode is more complex due to the existence of temperature gradients. However it can be shown that the reaction rate is controlled by the same factors as in the case of a Zone II, isothermal reaction. The use of a simple model in which a linear temperature gradient exists near the surface was considered by Boero et al (151). They showed that in a real case the influence of the chemical reactivity, $k_{0} s \mu$, is even lower than that showed in eqn.(3). Conversely, the influence of $D_{e}$ is greater (see Section 9.1.3). 


\subsection{1 $\mathrm{CO}_{2}$ oxidation}

It is a well known fact that a small upward flow of $\mathrm{CO}_{2}$ exists through the anode, coming from the anode-bath interface where it is generated by the electrolytic reaction. According to Paulin (150) about $5 \%$ of the $\mathrm{CO}_{2}$ formed in the pot escapes through the anodes. As the $\mathrm{CO}_{2}$ percolates through the anode, it reacts with $C$ to form $C O$. Paulin (150) has found that this occurs over a small length near the anode-bath interface, and most of the $\mathrm{CO}_{2}$ is transformed into $\mathrm{CO}$.

Rhedey (40) has estimated that the contribution of this reaction to the total carbon consumption is about $1.5 \%$ of the purely electrolytic reaction. A reasonable agreement between both estimations is observed. Now the relevant mechanism of mass transport is not diffusion. In fact, a pressure gradient exists between the lower and the upper face of the anode (see Fig.1.4, Chapter 1). Then, the flow is due to this pressure gradient and its magnitude is controlled by the permeability of the medium. In this case, as pointed out by Barillion (152), specific surface and density gradients appear near the anodebath interface due to oxidation by $\mathrm{CO}_{2}$.

\subsubsection{The relation between mass transport properties and porous texture}

Gaseous diffusion inside a pore can follow quite different laws depending on the ratio between pore diameter, $d$, and the mean free path of molecules, $\pi$. If $\pi / d>1$, the mass transport is controlled by collisions between the molecules and the pore walls. This is called "Knudsen diffusion" and the pore diffusion coefficient is proportional to $d(149)$. On the other hand, if $\pi / d<<1$, diffusion is controlled by collisions between molecules (molecular or bulk diffusion) and the pore diffusion is independent of $d$. Certainly, these are limit conditions and in other cases, $d$ and $\pi$ are of the same order of magnitude.

In a porous medium, things are very complex as an extended range of pore dimensions exists and different diffusion mechanisms can occur in different pores. Considering some numerical values, the mean free path of air molecules at standard conditions is $\pi=0.1$. The value of $\pi$ at $500^{\circ} \mathrm{C}$, a typical temperature in anode operation, is calculated to be 0.28 . Figure 9.2 shows mercury intrusion curves of typical samples. It can be seen that most of the pore volume 
corresponds to pores with $d>>\pi$. In fact, when average diameters were evaluated from these and similar curves, values higher than $10 \mu$ were always found (149). According to this, it is clear that bulk diffusion is the predominant mechanism, in which case the diffusion coefficient is not dependent upon pore diameter. The effective diffusion coefficient $D_{e}$ is related with total connected pore volume through the relation:

$D_{\theta} / D_{0}=ø / q$

where, $q=$ tortuousity factor for bulk diffusion

$D_{0}=$ diffusion coefficient in bulk gaseous phase $\left(\mathrm{cm}^{2} / \mathrm{sec}\right)$

$\emptyset$ = porosity

Several authors have attempted to evaluate $q$ using simplified models of the porous structure, but clear conclusions have not been reached. Walker et al (96) have experimentally found a relation between $D_{\Theta}$ and $D_{0}$ as follows:

$D_{\theta} / D_{0}=\emptyset^{2}$

which means that in this case

$q=1 / \varnothing$

This relationship, also finds some theoretical support when considering the model of porous diffusion developed by Wakao and Smith (149). This model leads to equation (5) when conditions are such that the predominant mechanism is bulk diffusion of molecules with not too dissimilar molecular weights. In consequence, this equation can reasonably be used to semiquantitatively consider the influence of porous texture on reaction rate.

In principle, only those pores connected to the outer surface are able to transport the reactive gas. The open porosity, usually different from the total porosity, must then be considered and the diffusivity must, in principle, be independent of pore size distribution. When $\mathrm{CO}_{2}$ flow is considered as mentioned previously, the relevant parameter is the permeability (153).

Also in this case two types of flow must be considered. In small pores, where $\pi>>d$, the flow occurs through a "Knudsen" mechanism, as it is controlled by collision between the molecules and the pore walls. On the other hand, in large pores, where $d>>\pi$, viscous flow is present. If $d$ and $\pi$ are of the same order of 
magnitude, viscous flow with slip takes place, with contribution of both mechanisms. Consideration of pore distribution in anodes (Fig.9.2), as well as the experimental study of the relation between permeability and pressure allowed Boero et al (151) to conclude that the slip contribution is small and a purely viscous flow can be considered (151). The permeability constant $B_{0}$, which fully characterises the properties of the medium when only viscous flow is relevant, can be expressed as (153):

$B_{0}=ø \bar{d}^{2} / 40 q_{v}^{2}$

where: $q_{v}^{2}$ is a tortuousity factor which consider deviations from a straight path, as well as the additional resistance due to pore constrictions. $\bar{d}^{2}$ is a mean value defined by:

$\overline{d^{2}}=1 / \pi \int_{0}^{\sigma} d^{2} d \emptyset$

Comparing with expression (6), important differences between viscous flow and bulk diffusion are evident. In fact, while bulk diffusion is independent of pore dimensions, this is not the case for viscous flow. Thus, in an anode, $\mathrm{CO}_{2}$ flow will depend not only on connected pore volume but also on the pore size distribution. A coarser porosity will allow a greater $\mathrm{CO}_{2}$ flow through the anode.

\subsection{General discussion}

In general, at low temperatures, the reactions of carbon with oxidizing gases are controlled by the following chemical processes occurring at the carbon/gas interface:

i (1) Adsorption of reactant gas on the carbon surface.

(2) Chemical reactions at active surface sites leading to the formation of adsorbed products.

(3) Desorption of products.

The kinetics of the reaction will be governed by whichever of these processes is the slowest, ie. the rate determining step. The rate determining step is dependent upon reaction conditions, eg. temperature and pressure, and the 
nature of the carbon eg. active site concentration on the surface, heattreatment temperature, catalytic impurities, porosity, etc.

However, at higher temperatures a common feature of the reaction of air and carbon dioxide with porous carbons, similar to the anode carbon used in this study, is the preferential attack of the reactant on the outer layers of the specimen. An explanation for this phenomenon is provided by the theory of diffusion control of gasification which is concerned with the transport of the reactant to the point of adsorption and of the products away from the point of desorption. This recognises three basic temperature zones for the gasification reaction (Figure 5.3) differing in the factors which have a decisive influence on the mechanism of reaction control.

The theory of diffusion control of gasification of porous carbons indicates that, as the temperature of reaction increases, initially the reactant is able to diffuse into the porous structure, against the counter flow of reaction products, more quickly than it is consumed by the reaction. Hence the reaction rate is controlled solely by the chemical considerations outlined above. It takes place over the entire accessible pore surface of the specimen under test, the reactant concentration is uniform throughout the specimen and is equal to the concentration in the gas phase surrounding the specimen (Figure 5.3a). The activation energy measured in this temperature regime truly represents that of the chemical reaction taking place. For gasification in the chemical control region to occur, the rate should be low, this being favoured by low temperatures and low pressures, and diffusion paths should offer low resistance, ie. wide pores or small size of specimen under test.

Under otherwise fixed conditions, as the temperature continues to increase, eventually a situation will arise when the reaction at the carbon surface is so rapid that the reactant is consumed more quickly than it can diffuse into the porous structure. The reaction then enters the temperature regime of pore diffusion control. Here, since the reactant can no longer penetrate sufficiently quickly into the pore structure of the carbon, its concentration at the centre of the specimen falls (Figure 5.3b). As the temperature continues to rise, the concentration at the centre first falls to zero and then zero concentration moves towards the external surface as the temperature rises further. In this pore diffusion control temperature zone, the activation energy falls to one-half that in the chemical control region. 
At even higher temperatures, the reaction rate is so high that any reactant reaching the external surface of the specimen reacts immediately. Thus no reactant penetrates into the pore structure and the reactant concentration falls to zero at the external surface and the rate becomes controlled by the diffusion of the reactant across the boundary layer of gas at the external surface. Hence the activation energy drops to that reflecting gaseous diffusion.

From this discussion several points relevant to the present study emerge. In the chemical control temperature zone, the reaction rate will depend on the nature of the reacting gas, and the reactions which occur once the gas has been adsorbed on the carbon surface, and the nature of the carbon. Even for pure solid carbons, the degree of order of their structure, and the influence this has on the concentration of surface active sites at which the gasification reaction takes place, results in differences in their reaction rates, while high impurity contents, eg. hydrogen, as an indicator of structural disorder, or sodium, as an example of a gasification catalyst, can have a profound effect.

The factors influencing the rate of reaction in the chemical control temperature zone also play a role at high temperatures. Thus for materials with similar activation energy in the chemical control zone, the temperature at which reaction changes from being chemically controlled to pore diffusion controlled depends on the chemical control rate and the pore structural characteristics of the carbon, as discussed above. The higher the chemical control reaction rate and the smaller the pore size then the lower the temperature at which control changes from chemical to pore diffusion control. The ratio of the reaction rates of carbons differing in reactivity tend to decrease as the temperature moves through the pore diffusion control zone, that with the lower inherent rate is less susceptible to diffusion control. Only when the rate is controlled by diffusion across the external boundary layer is the inherent rate no longer important until in the gaseous control zone they are equal.

Considering first the data for gasification in air at $550^{\circ} \mathrm{C}$, Figures 8.5 and 8.13 indicate that, for the pitches studied, the rate increases with the level of sodium added to the pitch from which the carbon was produced and with the quinoline insolubles content of the pitch. Sodium is a well known catalyst for the reaction of oxygen with carbon, the catalytic effect being accompanied by a reduction in activation energy. Thus, this catalytic effect can be invoked with 
confidence to explain not only the enhancement of the rate of weight loss but also the reduction in activation energy observed as the sodium content increased (Table 8.10).

The position with regard to the effects observed when studying the gasification behaviour of carbons made using pitches containing differing contents of quinoline insoluble material is less clear. There is evidence that carbon from pitches with a very low quinoline insoluble content have a well-organized arrangement of graphite-like layers and that as the quinoline-insoluble content rises the proportion of well-ordered material in the carbon product decreases. Whether this is true for the pitch coke produced on carbonizing the pitch within the moulded green block can not be established. The pitch in this case is present as only a thin coating on and between filler particles so that there may be geometric constraints on the formation and growth of mesophase spheres in the pitch during heat treatment; it is this process of mesophase growth and coalescence which is responsible for the formation of the wellordered carbon structure after carbonization to $1200^{\circ} \mathrm{C}$.

For carbons heat-treated to similar temperatures, variations in temperature influence the hydrogen content and the gasification behaviour, it can be expected that the rates of reaction with both air and carbon dioxide at elevated temperatures will be influenced by the degree of ordering of the carbon structure and the influence this has on the concentration of active sites at the carbon surface. Highly-ordered materials have fewer free valencies and hence fewer active surface sites. On this basis, the anticipated effect on oxidation behaviour of increasing the quinoline-insolubles content would be that found experimentally in this study. However, there is an alternative explanation based on the sodium content of these different pitches, as revealed by atomic absorption spectroscopy studies. Thus, the air-burn values given in Table 8.5 can be attributed to the sodium effect rather than to any influence by quinoline insolubles content of the pitch.

Moreover, a plot of air-burn against the sodium content for all the pitches studied showed them all to fall reasonably on one line (Figure 9.3). Also, evidence from the thermogravitmetric studies have indicated that all the data can be explained in terms of pitch sodium content. Although this casts some doubt on the conclusions made earlier regarding the effect of quinoline insolubles content on gasification behaviour, the quinoline insolubles influence 
can not be overlooked or discounted; since Figures 8.13 to 8.19 are not identical to Figures 8.5 to 8.12 .

In general, the behaviour over a range of temperature of the carbons studied was in accord with the theory of pore diffusion control of gasification. Thus for oxidation in air, when the reaction temperature was raised into the diffusion control temperature zone, the activation energy fell to one half its value in the chemical control zone. This low activation energy region was reached at a temperature near $500^{\circ} \mathrm{C}$ thus all the carbons exposed to air at $550^{\circ} \mathrm{C}$ were oxidised under conditions where the reaction was occurring preferentially near the outer layers of the test pieces. These are the conditions under which oxidation and dusting occurs when anode carbons are used in an extraction cell, as discussed above. In accord with this view, the porosity of the outer layers of the carbon specimens was higher than at the centre (Figs. 8.25 to 8.28). Even in this temperature zone, the effect of the sodium and/or quinoline insoluble content of the pitch plays an influential role. As the oxidation rate increases, the porosity of the outer layer increases and the extent to which the high oxidation region protrudes into the interior of the specimen increases. Exposing the carbons to carbon dioxide at even higher temperatures has an analogous effect.

When the attack of the oxidising gas is concentrated on the outer layers of the carbon, then the carbon may either be lost uniformly from the surface of the pores or preferentially from certain parts of the carbon structure. Both effects would lead to the outer layers having higher porosity and being more friable than the central core and would lead to dust loss if loosely bound material were mechanically shaken from the external surface. The friability tests developed and used in this study amply demonstrate the enhanced friability of the outer surface but do not identify the mechanism of particle loosening. However, the studies of the etched surfaces of oxidised and unoxidised carbons using scanning electron microscopy show clearly that the structure consists of filler particles bound together by a binder mixture of pitch coke and small filler particles; areas of pitch coke can not be separately identified with certainty. After oxidation, near the exterior of the specimen the binder phase is in such poor evidence that it is difficult to see how the material holds together (Figure 8.23). Nearer the centre of the specimen, small filler particles can be identified in the interstices between filler particles and this points to the pitch coke as the position where preferential attack on the anode carbon structure 
originally occurs. This leads inevitably to the conclusion that the dusting of carbon anodes, seen in aluminium extraction, is associated with the preferential attack on the pitch coke within the binder phase in the outer layers of the carbon structure. Factors which influence the oxidation rate of the pitch coke appear from this work to have a crucial bearing on the friability of the outer layers of oxidised anode carbon and, by inference, dusting. The sodium and to a lesser degree quinoline insolubles content of the pitch are two such factors.

\subsection{Recommendations for further work}

Some of the work described in this thesis has provided fundamental data but in addition there is considerable technical relevance. The work may be usefully extended following both approaches.

On the basic scientific level, further work aimed at obtaining a more complete understanding of the factors controlling the gasification of anode carbons is recommended. The present work has shown that the chemical reactivity to oxidising gases of resultant carbons increases significantly with increasing sodium and primary QI contents of the pitch. The primary QI material is thought to be associated with the sodium whereby it influences the catalytic activity of the sodium. Thus, the primary QI material may have further roles to play in addition to the mechanical modification of the coalescence process. Results from the studies have suggested that the mechanisms of growth in size and structure of molecular constituents of pitch are being modified, and possibly that the resultant molecules are more "defective" and hence more reactive than in the absence of $Q$ I.

It is perhaps overlooked that the primary QI is highly dispersed within the pitch during the carbonisation process. The QI only becomes readily apparent when it is seen as an agglomeration on the surfaces of the spheres of mesophase. Consequently, there exists the possibility that the surfaces of the primary QI are effective as "catalysts" during carbonisation and that the mesophase, as formed in the presence of primary QI, is already chemically different from the mesophase formed from the pitch in the absence of $Q$. The interference of coalescence by surface agglomeration of primary QI may be a secondary and less important effect because the viscosity of the mesophase is already higher as a consequence of modified pyrolysis chemistry. 
On a technical level, the obvious way in which this work could be extended would be to confirm the above conclusion and postulate. This could be achieved by carbonising a pitch in the presence of so-called inert material using the analytical techniques of optical microscopy, ESR and high temperature ${ }^{1} \mathrm{H}$ NMR. Also primary QI from different coals may behave differently, and so these coals could be carbonised under the same conditions, and then analysed using the same techniques. If the spin concentrations are found to increase in the presence of increased contents of $\mathrm{Ql}$, and if the NMR suggests that molecular motions are restricted in the presence of $Q I$, then these observations would substantiate the above findings.

Again on the scientific level, further work aimed at obtaining a better understanding of the catalysis by sodium, in the form of sodium carbonate, of the $\mathrm{C}-\mathrm{O}_{2}$ reaction is recommended. It is suggested that, in the early stages of the oxidation of graphite in a molten bath of sodium carbonate through which oxygen or air is bubbled, the sequence of reactions (Equations (54) to (57), Chapter 5, section 5.9) occur. The first reaction being rate limiting when the graphite surface area is high. But as the graphite becomes depleted in the melt, the second reaction becomes the slowest step.

Therefore, on a technical level, a direct confirmation of the participation of peroxide in this catalysed reaction could presumably be obtained by electron spin resonance spectroscopy, ie. because ESR spectra have been extremely useful for detecting small concentrations of radicals, therefore ESR could be used to detect, in dilute solution, any peroxide radical anion, $\mathrm{O}_{2}{ }^{2-}$, that is present. Also the course of the reaction for the experiment as described above could be followed by monitoring the production of $\mathrm{CO}$ and $\mathrm{CO}_{2}$ as a function of temperature between $900-1050^{\circ} \mathrm{C}$. 


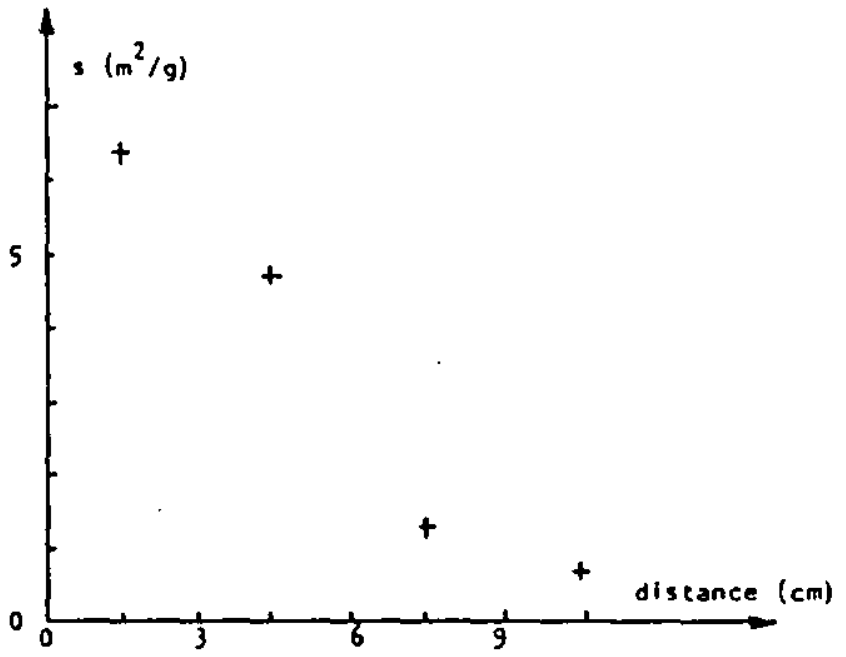

FIG.9.1. Surface developed by air oxidation as a function of the distance from the outer surface. 


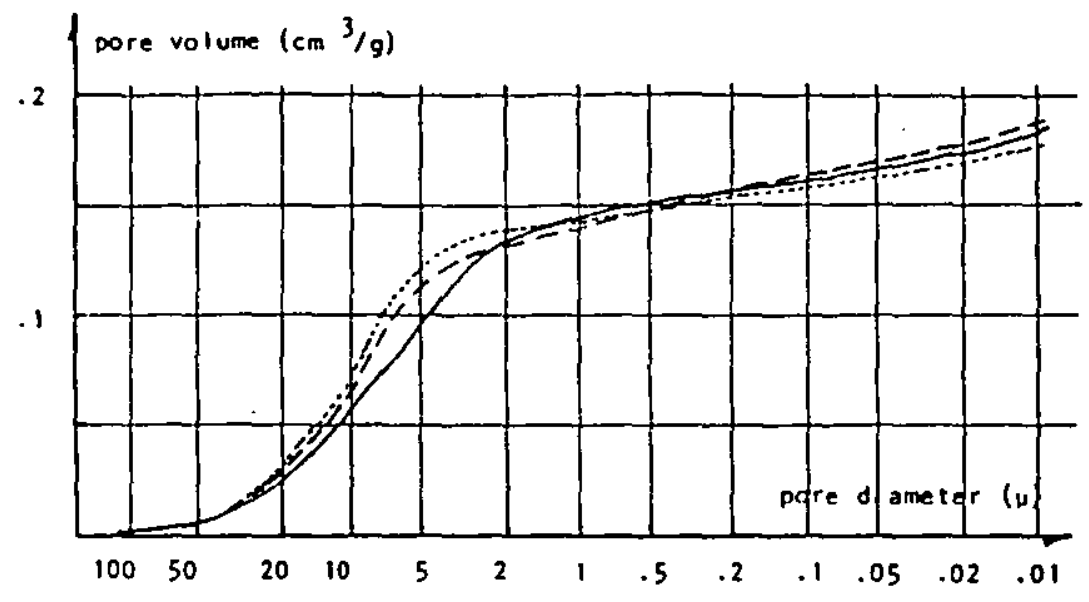

FIG.9.2. Typical porosimeter curves of anodes.

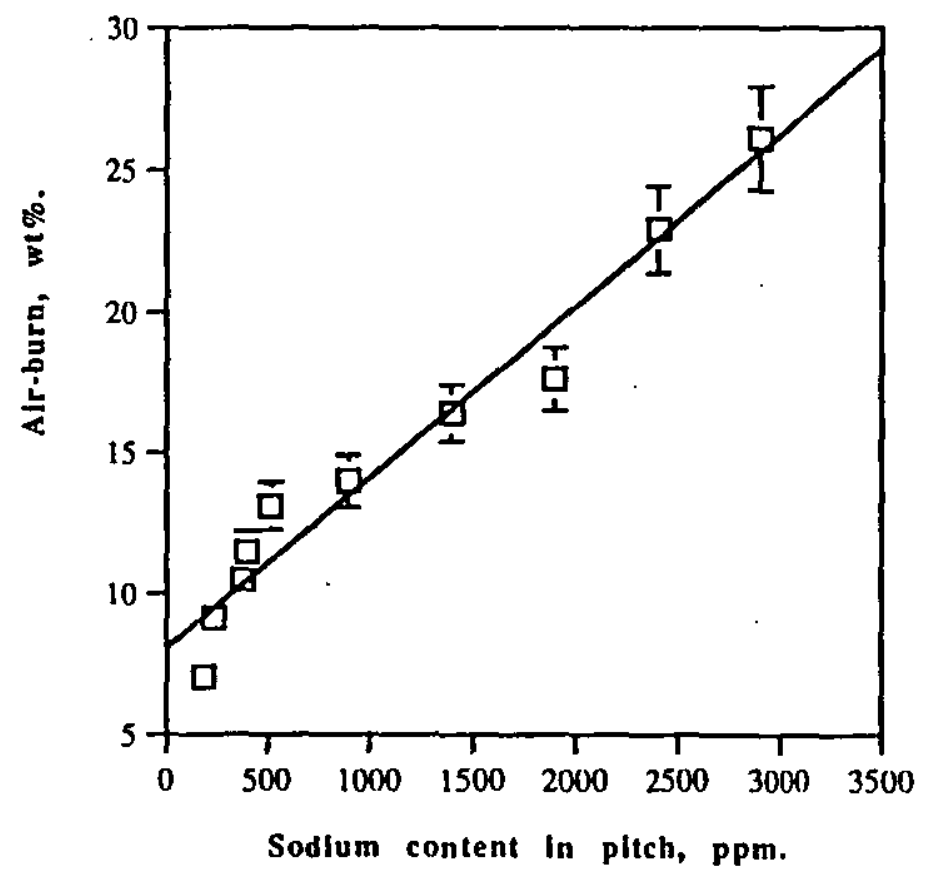

FIG.9.3. Variation of airburn with the sodium content for all the pitches. 


\section{CONCLUSIONS}

Although there is no readily available panacea to the problems of excess carbon consumption of anodes in aluminium production, the important influence on anode consumption, and aluminium extraction costs, of anode carbon gasification in air and carbon dioxide at elevated temperatures is now readily apparent.

Anode carbons which are one of the basic ingredients of the aluminium smelting process, are also one of the most difficult to control. The raw materials and process used in producing anodes can dramatically influence the rate of consumption of anodes and the efficiency of smelting pots, leading to potentially large fluctuations in aluminium quality and smelter profitability. Moreover, with existing plant configurations, there is little that can be done to minimise contact between the anode carbon and the reactant gases. Hence attention was focussed on the anode carbon itself and, in particular, on the effect of raw materials on its gasification behaviour. It was this aspect of the problem which was addressed by this study, and which tried to answer all or some of the questions outlined in Chapter 6 . From this research the following conclusions were reached.'

1. The suitability of the correlations obtained between the series of test anodes made using sodium-doped pitch and oxidation, dusting and cumulative debris losses were indicated in each case by the correlation coefficients of simple and multivariable linear regression analysis. Regression analysis gave a better interpretation of the influence of sodium content on oxidation, dusting and cumulative debris loss.

2. In accord with the often-reported efficiency of sodium as a catalyst of carbon oxidation, the mean air oxidation rate significantly increases with the pitch sodium content, giving an almost linear relationship between these two variables. Dusting rate during the oxidation test also showed a general increase with sodium content of the binder pitch used but the trend was less regular, a consequence probably brought about by differences in care of handling the oxidised carbon lumps whose surfaces were very friable, thus leading to differences in the amount of carbon dislodged from the surface. Nevertheless, a linear relationship was obtained between dusting loss and pitch sodium content. 
3. It appears from the results that a doubling in oxidation rate causes approximately a four fold increase in dusting rate, as the sodium content is increased from that as-received to additions of upto 2000ppm. Thus, it is likely that sodium induces even more dusting than would occur in the undoped condition. Furthermore, the variation of this dusting rate with increased oxidation rate followed a linear relationship.

4. An increase in pitch sodium content from that as-received to additions of upto 500ppm gave a doubling in the specific surface disintegration, ie. the ratio of loose particles (dust loss) to the burning loss. This indicates an increase in the selective $\mathrm{O}_{2}$ burn of the binder matrix. The variation of the cumulative debris loss, ie. dusting plus friability test loss (abrasion loss), with the number of revolutions in the friability test for the six test anodes, showed that in each case there was a tendency for the loss to decrease slightly with increasing number of revolutions. It was concluded that the degree of oxidative damage to the specimen decreased with distance from the surface. It was considered that it was the friability of the outer layers of an oxidised anode carbon which are important in the dusting which occurs during aluminium extraction and that this was best represented in the tests by the cumulative debris loss after the first forty revolutions in the friability test.

5. The cumulative debris loss increased with the sodium content, the rate of increase slowing as the sodium content increases beyond $2000 \mathrm{ppm}$. This supports the above proposition that the total structural damage caused by oxidation decreases with distance from the surface. The cumulative debris loss for the six anodes increased linearly with the oxidation loss. The increase in debris loss on increasing the pitch sodium content was about twice that for the oxidation loss. The conclusion reached at this stage was that the higher sodium content in the binder pitch enhances preferential oxidation of the pitch coke leaving loosely bound grist particles in the outer layers of the carbon. Thus, it was clearly evident from the obtained correlations that the sodium content has a strong influence on air reactivity and subsequently on dusting.

6. For the series of test anodes made using pitches varying in QI content, the air oxidation rate increased with the pitch QI content. The rate of increase decreasing with increasing QI content. Dusting losses, during the oxidation test showed a linear increase with both the pitch QI content and the oxidation loss. 
7. The ratio of dusting loss to oxidation loss, which indicates selective airburn of the binder matrix, increased with the pitch QI content. It appeared from the established correlation that an increase in pitch QI content from 3.7 to 11.5 $w t \%$, causes the oxidation loss to approximately double and with a threefold increase in dust loss.

8. From the surface friability test, the variation of the cumulative debris loss with the number of revolutions for the four test anodes, showed that in each case there was a tendency for the loss to decrease with increasing number of revolutions. Thus, implying that the degree of oxidative damage to the specimen decreased with distance from the surface. The variation of this cumulative debris loss, to 40 revs, increased with pitch Ql content, the rate of increase appearing to accelerate as the $\mathrm{Q}$ content increases. The debris loss also increased with the oxidation loss, the increase accelerating as the oxidation loss increased.

9. It was conciuded from these preliminary findings that the pitch QI content influenced the oxidation behaviour of the anode carbon produced using it. However, closer compositional examination of the pitches containing the different QI contents, revealed that these pitches had significantly different sodium amounts, as was evident from atomic absorption spectroscopy. This suggested that it was more likely for the sodium content and not the QI content to significantly affect the anode carbon gasification, since sodium is a known catalyst of oxidation reactions. Nevertheless, it is established that primary QI causes a reduction in the size of the optical texture of the resultant pitch coke. Also its presence can be detrimental to the production of carbon artefacts by decreasing the efficiency of wetting of filler by binder pitch. This consequently leads to a carbon with poor interfacial bonding between binder coke and filler coke and which is more susceptible or prone to dusting after oxidation. Thus, it can be concluded that primary $\mathrm{Q}$ also influences anode carbon reactivity but to a lesser degree than sodium. This presumably explains the trends obtained for the different QI pitches differ from those observed for the sodium doped pitches.

10. Moreover, the catalytic activity of the sodium is influenced by the parent pitch and in particular its primary QI content. Because primary QI increases coke yield so presenting more active carbon sites at which the sodium particles can catalyse the carbon-oxygen reaction, it is proposed that the $Q$ I influence 
operates in conjunction with the sodium influence, whereby it enhances the catalytic activity during anode oxidation. Evidence for this can be found in the comparison of the carbon loss with distance from the external surface, this loss being enhanced by the presence of $Q$ l. Consequently increased outer layer friability and dusting ensues.

11. The friability test developed and used in this study amply demonstrated the enhanced friability of the outer surface, but did not identify the mechanism of particle loosening. The SEM studies of etched surfaces of oxidised and unoxidised carbons attempted to investigate this mechanism of the increased oxidation and dusting loss, by trying to identify the sites of oxidative attack. Thus, it showed clearly that the structure consists of filler particles bound together by a binder mixture of pitch coke and small filler particles; areas of pitch coke could not be separately identified with certainty. After oxidation, near the exterior of the specimen there was so little binder phase present that it was difficult to see how the material held together. Nearer the centre of the specimen, small filler particles could be identified in the interstices between filler particles and this points to the pitch coke as the position where preferential attack on the anode carbon structure originally occurred.

12. It is suggested that since primary QI material agglomerate within the granular texture of the binder phase, clearly observed as circular cup-shaped features, this opens up the structure of the isotropic areas increasing the accessibility for oxidising gases and therefore increasing the reactivity of the isotropic areas which are preferentially gasified. Consequently, as previously mentioned, sodium within the coke structure is thought to be associated with primary QI material in the pitch which is preferentially gasified. Catalysts act at the point of contact with the carbon surface so the sodium situated at the site of preferential gasification will be available to catalyse the gasification reaction.

13. Two surface analysis techniques were applied to unoxidised and oxidised anode carbon specimens in order to locate whether the sodium was in the pitch coke or distributed throughout the anode structure. Both techniques proved unsuccessful in establishing with certainty where the sodium was located. However, PLM and SEM analysis of dust collected after each oxidation test run consisted predominantly of filler coke particles, similar in appearance to the oxidised large filler particles. This substantiated the above findings which 
suggests that most of the burning must have taken place within the binder coke phase or at the binder coke/filler coke interface. Moreover, because the dusting tendency increased with sodium content, this implies that the sodium was distributed largely within the binder coke. This situation is much more severe than if the sodium catalyst is located mainly within the petroleum coke, because it will greatly exaggerate any existing tendency towards dusting.

14. Image analysis was used to assess the variation of porosity, with distance from the external surface, of carbons made using pitches varying in sodium and QI contents, after air oxidation. The two series of carbons were also studied after exposure to carbon dioxide at elevated temperatures. Using the variation in the volume porosity across the surface of an undoped, unoxidised anode as a base, it was observed that the porosity-distance curves obtained for the two series of carbons, showed higher porosity, due to higher gasification rate, at the edge than at the centre of the specimen, the difference between edge and centre increasing with the overall gasification rate as determined from weight changes. Also, as the overall gasification rate increased with sodium and/or QI content of the pitch, the porosity measured by image analysis increased both at the edge and at the centre of the specimen, and was predominantly open or interconnected. These results are in accord with data given earlier regarding the friability of specimen surfaces after gasification in air.

15. Apparent densities for all the anodes indicated that the presence of sodium did not affect the volume, and hence the structural porosity, of the anode carbons after carbonisation, but it did affect the anode porosity on gasification with air or carbon dioxide.

16. The porosity-distance curves obtained agree with the concentration profile for gaseous reactant near and within a porous char particle operating under the Zone If reaction scheme, ie. they conform with the surface reaction and pore diffusion control of gasification by both gaseous air and carbon dioxide under the conditions used. One consequence of the operation of a diffusion control mechanism was that, as the temperature rose, the slope of the Arrhenius plot departed from linearity and an apparent decrease in activation energy ensued. This was confirmed by thermogravitmetric studies of the effect of temperature on the variation of gasification rates in air of the two series of carbons. The studies also established the change-over temperature for the rate-controlling mechanism to change from chemical to diffusion control. Thus, it was observed 
that for oxidation in air, when the reaction temperature was raised into the diffusion control temperature zone, the activation energy fell to one half its value in the chemical control zone. This low activation energy region was reached at a temperature near $500^{\circ} \mathrm{C}$ thus all the carbons exposed to air at $550^{\circ} \mathrm{C}$ were oxidised under conditions where the reaction was occurring preferentially near the outer layers of the test pieces. These are the conditions under which oxidation and dusting occurs when anode carbons are used in an extraction cell, as discussed above.

17. Linear correlations were obtained for the variation of airburn and activation energies against the sodium content for all the pitches studied. These implied that all the data could be attributed to the sodium effect rather than any influence by pitch QI content. But as mentioned above, the quinoline insolubles influence can not be discounted since the results obtained for the two series of carbons were not identical. It therefore appears justifiable to conclude from all the foregoing deductions that the dusting of carbon anodes, seen in aluminium extraction, is associated with the preferential attack on the pitch coke within the binder phase in the outer layers of the carbon structure. Factors which influence the oxidation rate of the pitch coke appear from this work to have a crucial bearing on the friability of the outer layers of oxidised anode carbon and, by inference, dusting. The sodium and to a lesser degree quinoline insolubles content of the pitch are two such factors.

Due to the wide variety of raw materials used in anode carbon manufacture, it is recognised that the findings of the present work may not be applicable in every industrial situation. That was not the intention. The aim of the work was to establish the role of the coke from the pitch binder which had not hitherto been given much consideration. It has now been demonstrated that the pitch quality, in particular its sodium and QI contents, does influence those processes (airburn, $\mathrm{CO}_{2}$ reactivity and dusting) which contribute to excess carbon consumption. Thus, the work has made a contribution to the understanding of the oxidation behaviour, in air and $\mathrm{CO}_{2}$, of baked pitch-bonded anode carbons relevant to the problem of excess anode consumption, and also to the use of coal tar pitch as binders for anode production. 


\section{REFERENCES}

1. World Mineral Statistics, 1983-87

2. 'European Marketing Data and Statistics 1990', 25th Edition, Euromonitor Publications Ltd., London, 1990

3. Crockett, R.N. \& Richard, N., "Bauxite, Alumina and Aluminium", HMSO 1978, Mineral Dossier No.20

4. Grjotheim, K. \& Welch, B.J., Aluminium Smelter Tech., Al-Verlag, Dusseldorf, 1980

5. Barat, P.J. \& Brault, T. Light Metals 1974, p19, AIME

6. Adair, R.R., Freeman, E.M. \& Boult, E.H. Carbon 1971, 9, 763

7. Heuchamps, N. BI. Soc. Chim. France, 1965, p2955

8. Barillon, E. "Mechanism of Carbon Dust Formation in Aluminium Electrolysis", Milan, Italy, 1971.

9. Boero, J.F.R. Light Metals 1981, 110th AIME An. Meeting, 1981, p44

10. Barrillon, M.E. AIME, New York, March 1971

11. Roundtable Forum: "Discussing the Issues in Carbon Anode Technology". J. Metals $1990,42,52-5$

12. Marsh, H., Taylor, D.A. \& Lander, J.R. Carbon 1981, 19, 375-381

13. Marsh, $H$. Proceedings of a Conversazione on "The Production of Liquid Aluminium", 25th An. Conf. of Metallurgists 1986, Series 25-7, No. 2, 1986

14. Ragan, S. \& Marsh, H. Carbon 1983, 21, 157-165 
15. Jones, S.S., Hildebrandt, R.D. \& Hedlund, M.C. Paper A77-97, 106th AIME An. Meeting, 1977

16. Jones, S.S., Hildebrandt, R.D. \& Hedlund, M.C. Light Metals 1979, p553, AIME

17. Brown, J.A. \& Rhedey, P.J. Light Metals 1975, p253, AIME

18. Turkdogain, E.T., Oleson, R.G. \& Vinters, J.V. Carbon 1970, 8, 545

19. Jones, S.S. \& Hildebrandt, R.D. Light Metals 1974, p901, AIME

20. McNeil, D. 'Coal Carbonisation Products', Published by British Carbonisation Research Association 1975

21. Gemmeke, W., Colin, G. \& Zander, M. Light Metals 1978, 1, 355

22. Standard Methods for Testing Tar and Its Products, S.T.P.T.C new methods to be published by The British Carbonisation Research Association.

23. Franklin, R.E. Proc. Roy. Soc. 1951, London, A 209, 196

24. Jones, S.S. \& Hildebrandt, R.D Light Metals 1975, p291, AIME

25. Rhedey, P.J. \& DuTremblay, D. Light Metals 1977, p301, AIME

26. Jahnig, C.E., "Kirk-Othmer Enc. of Chemical Technology", 3rd Ed., 1982, 17,183

27. Scott, C.B. \& Folkins, H.O. Light Metals 1972, Sym. on Anode Raw Metals, AIME 1972

28. Kemnitzer, W.J. \& Edgerton, Jr., C.D. Bureau of Mines, Info. Cir. 8259, 1965

29. Stadelhofer, J.W., Marrett, R. \& Gemmeke, W. Fuel 1987, 60, 877

30. Jones, S.S. \& Hilderbrandt, R.D. Light Metals 1981, p423, AIME 
31. Farago, F.J. \& Stood, R.R. Light Metals 1976, p351, AlME

32. Li, K.W. \& Friday, J.R. Carbon 1974, 12, 225

33. Vogi, M.F., Jones, G.R. \& Tyler, G.A. Light Metals 1984, p1697, AIME

34. Rhedey, R. Trans. Met. Soc. 1967, 239, 1084, AIME

35. Wallouch, R.W. \& Fair, F.V. Carbon 1980, 18, 147

36. Whittaker, M.P. \& Miller, F.C. Ind. Eng. Chem. Pdt. R\&D, 1970, 9, 187

37. Goodnow, W. Panel Remarks, Carb. Mtis. in Al. Ind., 111th AlME An. Mtg., 1982

38. Belitskus, D. Light Metals 1982, p673, AIME

39. Belitskus, D. Light Metals 1978, p341, AIME

40. Rhedey, P. Light Metals 1971, p385, AIME

41. Peterson, R.W. Light Metals 1982, p691, AIME

42. Rolf, A., Rausch, B. \& Wilderforster, R. Light Metals 1989, p495, AlME

43. Jones, S.S., Hildebrandt, R.D \& Hedlund, M.C. Extd. Abs., 14th Bien. Carbon Conf.81, 1979

44. Asher, R.C. J. Inorg. Nucl. Chem. 1959, 10, 238

45. Dewing, E.W. Trans. TMS-AIME, 1963, 227, 1328

46. Frank, W.B. \& Foster, L.M. J. Phys. Chem. 1960, 64, 95

47. Dewing, E.W. Paper presented at the AIME An. Meeting, Feb. 1974

48. Amelinckx, S., Delavignette, P. \& Heerschap, M. Chem. \& Phys. of Carbon 1965, Ed. Walker Jr, P.L., Marcel Dekker, New York, 1, 1 
49. Baker, R.T.K. J. Catalysis $1982,78,473$

50. Marsh, H. \& Walker Jr, P.L. Chem. \& Phys. of Carbon 1979, Ed. Walker Jr, P.L., Marcel Dekker, New York, 15, 229

51. Marsh, H. \& Griffiths, J. Ext. Abs. Int. Sym. on Carbon, Toyohashi, Japan, p 81

52. Moore, H. Chem. \& Phys. of Carbon 1981, Ed. Walker Jr, P.L. \& Thrower, P.A., Marcel Dekker, New York, 17, 233

53. Black, L.C.F., Mathews, J.F. \& Ubbelohde, A.R. Proc. Roy. Soc. 1960, London, 339, 49

54. Berger, D., Carton, B. \& Herold, A. Chem. \& Phys. of Carbon 1979, Ed. Walker Jr, P.L., Marcel Dekker, New York, 12, 1-37

55. Brooks, J.D. \& Taylor, G.H. Chem. \& Phys. of Carbon 1968, 4, 243

56. Marsh, H. Proc. of 4th Conf. on Industrial Carbon and Graphites, 1976 , S.C.I. London, p2-38

57. Dubois, J., Agache, C. \& White, J.L. Metallography 1970, 3, 337

58. White, J.L. American Chem. Soc. Sym., Series 21, 'Petroleum Derived Carbons', 1976, p282

59. Honda, H., Kimura, H. \& Sanada, Y. Carbon 1971, 9, 695

60. Sanada, Y., Furuta, T. \& Honda, H. Carbon 1972, 10, 644

61. Hallimond, A.F. 'The Polarizing Microscope', 3rd Edition, Vickers Ltd., 1970

62. Marsh, H. \& Crawford, D. Carbon 1984, 22, 413

63. Gonzales, R.C. \& Wintz, P. Digital Image Processing, Addison-Wesley, London, 1977 
64. Taylor, G.H. Fuel 1961, 40, 465

65. White, J.L. Progress in Solid State Chemistry 1974, 9, 59

66. Marsh, H. \& Walker Jr, P.L. Chem. \& Phys. of Carbon 1979, 15, p237

67. Patrick, J.W., Reynolds, M.J. and Shaw, F.H.. Optical anisotropy of carbonized coking and caking coals. Fuel 1979, 58, 69

68. Patrick, J.W., Shaw, F.H. and Willmers, R.R. Microscopic examination of polished coke surfaces etched by ionic bombardment. Fuel 1977, 56, 81

69. Patrick, J.W., Sims, M.J. and Stacey, A.E. Quantitative characterization of the texture of coke. Journal Microscopy 1977, 109, 137

70. Hoover, D.S., Davies, A., Perrotta, A.J. \& Spackman, A. Ext. Abs., 14th Bien. Conf. on Carbon. American Soc., 1979, p393

71. Rand, B., "The Pitch-Mesophase Transformation as Studied by Thermal Analytical and Rheological Techniques", p45-61

72. Smith, G.W., White, J.L. \& Buechler, M. Carbon 1985, 23, 117-121

73. Brooks, J.D. \& Taylor, G.H. Nature 1965, 206, 697

74. Marsh, H., Latham, C.S. \& Gray, E.M. Carbon 1985, 23, 555-570

75. Kremer, H.A. Chemistry \& Industry, Sept. 1982, p702-713

76. Stadelhofer, J.W. Fuel 1980, 59, 360-361

77. Walker Jr, P.L., "Carbon and Coal Gasification".

78. Marsh, H., "Oxygen in the Metal and Gaseous Fuel Industries", Special Pub. No.32, Chemical Society, London, 133, 1978

79. Lander, J.R. \& Marsh, H, Carbon '82, Ext. Abs. 6th London Int. Carbon \& Graphite Conf., SCI, London, 112, 1982 
80. Gregg, S.J. \& Tyson, R.F.S. Carbon 1965,3, 39

81. McEnaney, B. \& Dovaston, N.G., Thermal Analysis, Proc. 3rd ICTA, Davos 1971, Birkhauser, 3, 309

82. McEnaney, B. \& Willis, M. Carbon 1976, Baden-Baden 1976, 105

83. French, M. \& Marsh, H. Fuel 1981, 60, 418

84. Marsh, H., Rand, B. \& Robson, D. Carbon 1970, 8, 503

85. Figueiredo, J.L. \& Ferro-Garcia, M.A. Carbon 1987, 25, 703

86. Tong, S.B., Pareja, P. \& Back, M.H. Carbon 1982, 20, 191

87. Radovic, L.R. \& Lizzio, A.A., Ext. Abs. 18th Bien. Conf. on Carbon, Amer. Carbon Society, Mass, USA, 1987, 454

88. Causion, P. \& McEnaney, B. Fuel 1985, 64, 1447

89. Laine, N.R; Walker Jr, P.L. \& Vastola, F.J., J. Phys. Chem. 1963, 67, 2030

90. Rao, M.B., Vastola, F.J. \& Walker Jr., P.L. Carbon 1983, 21, 401

91. Stein, S.E. \& Brown, R.L. Carbon 1985, 23, 105

92. Walker Jr., P.L., Chemistry and Industry, 1982, 9, 683

93. Feates, F.S., Harris, P.S. \& Reuben, B.G., J. Faraday I, 1974, 70, 2011

94. Cremer, E., Advances in Catalysis, $1955,7,75$

95. Gladstone, S. \& Eyring, H., "The Theory of Rate Processes", Ed. L.P. Hammet, McGraw-Hill, 1941

96. Walker, P.L. \& Rusinko, F., Advances in Catalysis, 1959, 11, 133 
97. Jenkins, R.G. \& Piotrowski, A., 194th National Meeting ACS, Louisiana, USA, $1978,4,147$

98. Smith, I.W. Fuel 1978, 57, 409

99. Laurendeau, N.M., Prog. Energy Comb. Sci., 1979, 4 , 221

100. Atkins, P.W., Phy. Chem., Oxford Uni. Press, 1978

101. Boudouard, M.O., Annales de Chimie et de Physique, 1901, 27, 24

102. Ergun, S., J.Phys. Chem., 1956, 60, 480

103. Gadsby, J., Long, F.J. \& Sleightom, P., Proc. Roy. Soc.A193, 1948, 357

104. Strange, J.F. \& Walker Jr., P.L. Carbon 1976, 14, 345

105. Rao, Y.K. \& Jalan, B.P., Metallurgical Trans., 1972, 3, 2465

106. Ahmed, S. \& Back, M.H. Carbon 1985, 23, 513

107. Vastola, F.J., Hart, P.J. \& Walker Jr., P.L. Carbon 1964, 2, 65

108. Foord, A.D., PhD. Thesis, Uni. of Newcastle upon Tyne, 1972

109. McKee, D.W., Chemistry and Physics of Carbons, NY, 1981, 16, 1

110. Sato, H. \& Akamatu, H. Fuel $1954,33,195$

111. Harker, H., Proceedings of the 4th Conf. on Carbon, 1960, Pergamon Press, 125

112. Fox, D.A. \& White, A.H., Ind. Engng. Chem., 1931,23, 259

113. Neumann, B. \& Kroger, C., Chem., 1931, 197, 321

114. Long, F.J. \& Sykes, K.W., J. Chem. Phys., 1950, 47, 361 
115. Amarigilio, H. \& Duval, X. Carbon 1966, 4, 323

116. Kapteijn, F. \& Abbel, G. Fuel 1984, 63, 1036

117. Moulijn, J.A. \& Kapteijn, F., "Carbon and Coal Gasification", Proc. NATO Adv. Sci. Inst., Portugal, 1986, 181

118. Cerfontain, M.B., Meijer, R., Kapteijn, F. \& Moulijn, J.A., J. Catal., $1987,107,173$

119. Cerfontain, M.B., Agalianos, D. \& Moulijn, J.A. Carbon 1987, 25, 351

120. Inul,T. \& Otowa, T. Carbon 1982, 20, 213

121. Freund, H. Fuel $1986,65,63$

122. Cerfontain, M.B. \& Moulijn, J.A. Fuel 1986, 65, 1349

123. Cerfontain, M.B. \& Moulijn, J.A. Carbon 1988, 26,41

124. McKee, D.W. \& Chatterji, D. Carbon 1975, 13, 381

125. Adjorlolo, A.A. \& Rao, Y.K. Carbon 1984, 22, 173

126. Fox, D.A. \& White, H.H., Ind. Eng. Chem., 1931, 23, 259

127. Tromp, P.J.J. \& Cordfunke, E.H.P., Thermochim. Acta, 1984, 77, 49

128. Patrick, J.W. \& Shaw, F.H. Fuel 1972, 51, 69

129. Dunks, G.B., Stelman, D. \& Yosin, S.J. Carbon 1980, 18, 365

130. McKee, D.W. Carbon $1970,8,131$

131. Walker Jr., P.L., Shelef, M. \& Anderson, R.A., "Chemistry and Physics of Carbon", NY, 1968, 4, 287

132. Thomas, J.M. \& Walker Jr., P.L., 1st Sym. on Carbon, Tokyo, 1964 
133. Hennig, G.R., " Chemistry and Physics of Carbon", NY, 1960, 2, 1

134. Marsh, H., O'Hair, T.E., Reed, R., Trans. Faraday Soc., 1965, 61, 285

135. Baker, R.T.K., "Carbon and Coal Gasification", Proc. NATO Adv. Sci. Int., Portugal, 1986, p231

136. Baker, R.T.K. and Chludzinski Jr., J.J. Carbon 1981,19, 75

137. Rodriguez, N.M., Marsh, H., Sherwood, R.D. \& Baker, R.T.K. Carbon 1987, 5, 629

138. Baker, R.T.K. Carbon 1986, 24, 715

139. Gray, C.F. \& Metrailer, W.J. I \& EC Prod. Res. Dev., 1963, 2(2), p152

140. Onder, H., Jungblut, G. \& Bernhauser, E. Met. Soc. AIME, TMS Paper Selection, A81-31, 1981

141. Marsh, H., Dachille, F., lley, M. \& Walker Jr, P.L. Fuel 1973, 52, 253

142. Tillmanns, H., Pietzka, G. \& Pauls, H. Fuel 1978, 57,171

143. Forrest, M. \& Marsh, H. Fuel 1983, 62, 612

144. Bradford, D.J., Senior, A. \& Bailey, P.A. Proc. 3rd Conf. Ind. Carbon Graphite, SCI, London, 1971, p520

145. Markovic, V., Lander, J.R. \& Marsh, H. Ext. Abs. 15th Bien. Conf. on Carbon, American Carbon Soc. \& Pennsylvania Uni., Philadelphia, 1981, p415

146. Walker Jr, P.L., Rusinko, F. and Austin, L.G. Adv. Catal. 1959, 11, 133

147. Wheeler, A. Advances in Catalysis $1951,3,249-327$

148. Lewis, J.B. 'Thermal Gas Reactions of Graphite', in Modern Aspects of Graphite Technology, Ed. L.C.F. Blackman, London, 1970 
149. Sattersfield, N.Ch. "Mass Transfer in Heterogeneous Catalysis", M.I.T. Press, Cambridge, 1970

150. Paulin, A. "Structure of Anodes and Gas Flow through Anodes in Aluminium Electrowinning", III Yugoslav Sym. on Al., 1978, Vol. 1, p166

151. Boero, J.F.R. Light Metals 1981, Procs. of Sessions, 110th AlME An. Meeting, Chicago, Illinois, p441

152. Barillon, E. "Factors Affecting Carbon Anode Consumption in the Electrolytic Production of Aluminium", 3rd International ICSOBA Congress, Nice, 1973

153. Hewitt, G.F. Chem. \& Phys. of Carbon 1961, Ed. Walker, P.L., Marcel Dekker, New York, Vol. 1 


$$
\text { • }
$$


